\title{
Mechanisms associated with success and failure of the anadromous migration of Atlantic salmon
}

\author{
by
}

Robert J. Lennox

A thesis submitted to the Faculty of Graduate and Postdoctoral Affairs in partial fulfillment of the requirements for the degree of

Doctor of Philosophy

in

Biology

Carleton University

Ottawa, Ontario

(C) 2018

Robert J. Lennox 


\section{Abstract}

Nearly every animal accomplishes life history tasks that enable growth and fecundity, factors that determine the ultimate fitness of an individual's life, by moving. Migration allows individuals to maximize their potential fitness by exploiting temporal differences in productivity of discrete habitats. Migratory species have high cultural and ecological importance as vectors linking and fertilizing separate ecosystems; however, their reliance on multiple habitats and long-distance movements exposes them to stressors. I applied electronic tagging to observe the behaviour of wild Atlantic salmon, a migratory fish threatened by climate change, habitat destruction, disease, and overexploitation. Observations were applied to evaluate how stressors affected migration success. Atlantic salmon were generally tolerant to stressors as they migrated upriver to spawning grounds. Resumption of migration was delayed for stressed salmon relative to a control group (Chapter 2) and captured salmon selected spawning grounds significantly lower in the river than expected based on the distribution of uncaught fish (Chapter 3). Salmon also exhibited movement away from holding sites when captured late in the season (Chapter 4) but the extent of movement was not significantly different from expected based on observations in Chapter 3. Ultimately, most salmon survived stressors and many were recaptured by recreational anglers (Chapter 5); mortality was best predicted by water temperature at capture (Chapter 6). Selection against some migratory behaviours such as early run timing is ongoing, but stabilizing selection for large body size is predicted to preserve migration phenotypes in Atlantic salmon. Oncoming changes to climate, however, were predicted to delay the freshwater entry of salmon (Chapter 7) and may result in multiple stressors during 
migration. Further research is needed into the cumulative effects of multiple stressors and how they may operate on imperiled salmon populations. Long-term consequences may manifest through carryover effects that reduce the probability of overwinter survival and iteroparity, insidious consequences that should be further investigated. This thesis provides a framework for addressing questions about the survival, delay, and extent of movement of animals encountering anthropogenic stressors during migration. Future work may follow this model to investigate migration and evaluate the impact of stressors on migration success. 


\section{Acknowledgments}

Steve contacted me at the end of 2012 to describe a project in Norway collaborating with NINA on the recreational Atlantic salmon fishery and the need for a student to lead the project with the final line "are you that student?"; I think back often to that email and how it completely changed my entire life forever. Steve gave me the opportunities to achieve whatever I could dream of, from researching salmon in Arctic Norway to bonefish in distant tropics of French Polynesia and both the confidence and support to take on challenging projects on anything that interested me, from why fish get caught to whether predator removal is successful. Because of Steve I have been able to accomplish goals that I never knew I would be able to. The time, dedication, and care that Steve has shown me truly embodies the meaning of teamwork and mentorship. Thank you so much, Steve. My only hope to repay you for the wonderful life that you have helped me realize is to pay it forward to others that I may someday have the opportunity to mentor myself.

I had many mentors throughout this experience. Ingebrigt, Eva, and Fred gave me opportunities and responsibilities with my research in Norway and took so much extra time to guide me through the challenges of learning to become a competent and confident scientist and I am extremely grateful everyday for their confidence in me. Andy sent me to the far reaches of the world to carry out visions of unifying fisheries science with international development, opportunities that I am so thankful for that have greatly enriched my life. Jake and Graham took a lot of extra personal time during their own theses mentoring me as a young student and providing additional feedback and insight 
into my work that really helped me develop as a scientist. Kim and Colin supported me extensively through the challenges I confronted in statistical analyses and coding that I wanted very badly to overcome. Thanks also to the many anonymous helpers on stackexchange and stackoverflow, which have been such incredible learning resources.

I was very lucky to find such a perfect fit with Steve at Carleton in Ottawa, my hometown. Spending extra time with my family these years has been invaluable and I have tried to cherish it. As I move into another phase of my life I reflect on how lucky I have been to get to spend so much time with those that I love. Miranda supported me through myriad challenges for many years and gave me much of her time and love as I strived to develop as a fish scientist. Andrea has helped me so much in maintaining an important balance with my work and has greatly enriched my life. Colin, Ellis, Eric, Matt, Oliver, Sam, and Sly were always there for me and I am eternally grateful for their friendship and camaraderie. Bec, Danni, Jess, Katie, and Kayla were invaluable team members during the many years at Dalhousie in which I struggled to see a bright future but persisted in working towards it with their help. Thank you all so much for being great friends and making these years so incredibly enjoyable.

This thesis greatly benefited from a Canada Graduate Scholarship from the Natural Sciences and Engineering Research Council of Canada. I also received support from Carleton University and the Fisheries Society of the British Isles during my thesis research for living and travel expenses that helped me live out many of my dreams. 


\section{Thesis Format and Co-authorship}

This thesis is comprised of six chapters that are in various stages of publication in peerreviewed journals. Repetition among chapters reflects the format in which they were submitted to those journals in establishing context and implications of findings. Throughout the process of completing my $\mathrm{PhD}$ studies I have taken pride in the great network that I have been able to establish with encouragement and faith from my many mentors. The work presented in this thesis benefitted greatly from the input and guidance from co-authors that are thanked and acknowledged below for their considerable contributions to each of the chapters in this thesis.

\section{Chapter 2 Experimental evaluation of the locomotor activity patterns of Atlantic salmon in the early phase of the spawning migration following exposure to a fisheries stressor}

Lennox, R. J., Chapman, J. M., Twardek, W., Broell, F., Bøe, K., Whoriskey, F. G., Fleming, I., Robertson, M., and Cooke, S. J. (In Prep). Experimental evaluation of the locomotor activity patterns of Atlantic salmon in the early phase of the spawning migration following exposure to a fisheries stressor.

Cooke, Whoriskey, and I conceived a study using physiological telemetry to study Atlantic salmon migration in an experimental setting during a meeting in January 2016. I designed the study concept myself with assistance from Chapman, Twardek, and Bøe in 
implementing the study at the Campbellton River in Newfoundland and Labrador. Broell provided data processing assistance by calculating jerk activity from the accelerometers. Analytical decisions were my own, I coded and implemented the analysis for the gls model and the simulation myself. Robertson provided data on untagged salmon from the counting fence for the simulation. I wrote the manuscript myself with input from Cooke and other coauthors after completion of a first draft. The research will be submitted to the special biologging issue of the Journal of Animal Ecology.

\section{Chapter 3 Use of simulation approaches to evaluate the consequences of catch-and- release angling on the migration behaviour of adult Atlantic salmon (Salmo salar)}

Lennox, R. J., Cooke, S. J., Diserud, O. H., Havn, T. B., Johansen, M. R., Thorstad, E. B., Whoriskey, F. G. and Uglem, I. (2016). Use of simulation approaches to evaluate the consequences of catch-and-release angling on the migration behaviour of adult Atlantic salmon (Salmo salar). Ecological Modelling, 333, 4350.

Uglem, Thorstad, Whoriskey, and I designed the basic concept for the study at a meeting in Trondheim in 2014 with input from Egil Liberg on feasibility. Data for this study were collected in summer 2014 in Lakselva, Norway under the supervision of Uglem and Thorstad and with field assistance and implementation consultation from Johansen and Havn. The idea to use distributional data from the spawning counts and implement a simulation to test the hypothesis was my own, implemented with statistical counsel from 
Diserud. I wrote the manuscript with input from all co-authors. This research was published in the journal Ecological Modelling in 2016.

\section{Chapter 4 Behaviour and survival of wild Atlantic salmon (Salmo salar) captured and released while surveillance angling for escaped farmed salmon}

Lennox, R. J., Havn, T. B., Thorstad, E. B., Liberg, E., Cooke, S. J., and Uglem, I. (2017). Behaviour and survival of wild Atlantic salmon Salmo salar captured and released while surveillance angling for escaped farmed salmon. Aquaculture Environment Interactions, 9, 311-319.

In 2015, Thorstad and Uglem suggested investigating the surveillance fisheries in Norway as a follow up on our previous research on catch-and-release. Thorstad, Uglem, Havn, and I designed the study. Havn, Liberg, and I collected data in Laksleva in 2016. The ideas and implementation of the data analysis were my own. I wrote the manuscript with input from all authors after completion of a draft. This research was published in the journal Aquaculture Environment Interactions in 2017.

\section{Chapter 5 Influence of gear switching on recapture of Atlantic salmon (Salmo salar) in catch-and-release fisheries}

Lennox, R. J., Diserud, O. H., Cooke, S. J., Thorstad, E. B., Whoriskey, F. G., Solem, Ø., Havn, T. B., and Uglem, I. (2016). Influence of gear switching on recapture of 
Atlantic salmon (Salmo salar) in catch-and-release fisheries. Ecology of Freshwater Fish, 25(3), 422-428.

In 2013, Uglem and I discussed the potential for historical tagging data from Norwegian rivers to be applied to investigate gear switching. Solem, Havn, and I collected field data along with citizen scientists that reported catches. I collected baseline data from the online database following input from Uglem. Diserud and I analyzed the data and I prepared the manuscript with input from coauthors listed above. This research was accepted by the journal Ecology of Freshwater Fish in 2015 and published in 2016.

\section{Chapter 6 Pan-Holarctic assessment of post-release mortality of angled Atlantic salmon Salmo salar}

Lennox, R. J., Cooke, S. J., Davis, C. R., Gargan, P., Hawkins, L. A., Havn, T. B., Johansen, M. R., Kennedy, R., Svenning, M-A., Uglem, I., Webb, J., Whoriskey, F. G., and Thorstad, E. B. (2017). Pan-Holarctic assessment of post-release mortality of angled Atlantic salmon Salmo salar. Biological Conservation, 209, $150-158$.

I approached Thorstad with this idea in January 2015 and we contacted biologists that we believed would have relevant data. Davis provided input on data analysis but ultimately, I selected and implemented the data analysis on my own. I wrote the manuscript with input 
from all co-authors following completion of a draft. This research was published in the journal Biological Conservation in 2017.

\section{Chapter 7 River warming portends bioenergetic failure of adult Atlantic salmon Salmo salar during the spawning migration}

Lennox, R. J., Eliason, E. J., Havn, T. B., Johansen, M. R., Thorstad, E. B., Cooke, S. J., Diserud, O. H., Whoriskey, F. G., Farrell, A. P., and Uglem, I. (In Press). River warming portends bioenergetic failure of adult Atlantic salmon Salmo salar during the spawning migration. Freshwater Biology, 00, 00-00.

The original concept for this chapter was developed by myself with Whoriskey, Thorstad, and Uglem at a meeting in Trondheim in April 2014. Our intention was to recapture salmon tagged with temperature loggers and use radio telemetry data to investigate their migration within the large lake Nedrevatn that forms part of the Lakselva system. I, Havn, and Johansen collected data in Lakselva in the summer of 2014 to investigate. None of the salmon entered the lakes but Diserud and I worked to model the relationship between fish habitat and river temperatures. Whoriskey suggested using the data to apply a bioenergetics model and I worked with Eliason and Farrell to develop such a model based on unpublished data of Atlantic salmon metabolism. I developed a gls regression model to estimate the relationship between water temperature and fish habitat temperature with input from Diserud and under the guidance of Eliason I applied the bioenergetics model to estimate 
energy depletion. I wrote the manuscript and received input from coauthors after completion of a draft. The paper will be published in the journal Freshwater Biology. 


\section{Table of Contents}

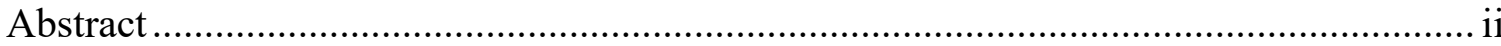

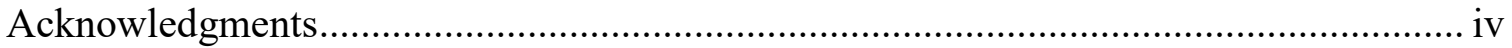

Thesis Format and Co-authorship ...................................................................... vi

Chapter 2 Experimental evaluation of the locomotor activity patterns of Atlantic salmon in the early phase of the spawning migration following

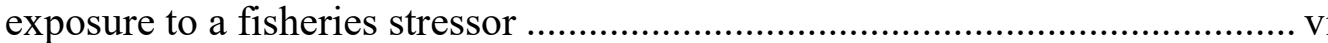

Chapter 3 Use of simulation approaches to evaluate the consequences of catchand-release angling on the migration behaviour of adult Atlantic salmon (Salmo salar) vii

Chapter 4 Behaviour and survival of wild Atlantic salmon (Salmo salar) captured and released while surveillance angling for escaped farmed salmon viii Chapter 5 Influence of gear switching on recapture of Atlantic salmon (Salmo salar) in catch-and-release fisheries viii

Chapter 6 Pan-Holarctic assessment of post-release mortality of angled Atlantic salmon Salmo salar ................................................................................. ix

Chapter 7 River warming portends bioenergetic failure of adult Atlantic salmon Salmo salar during the spawning migration ..............................................

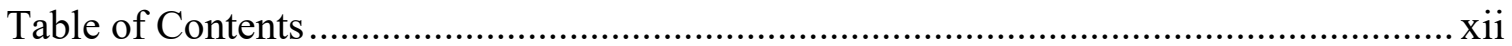

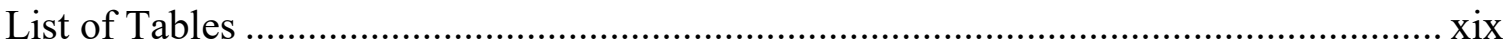




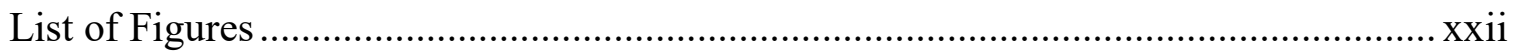

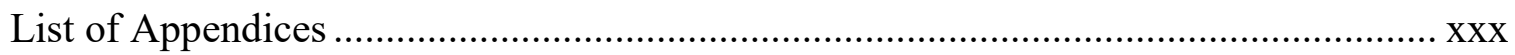

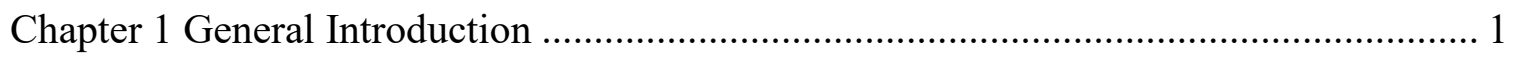

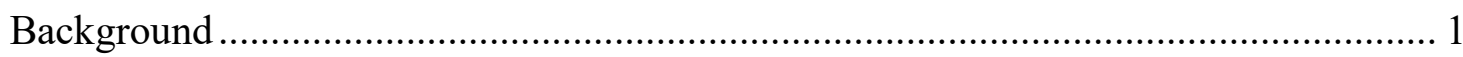

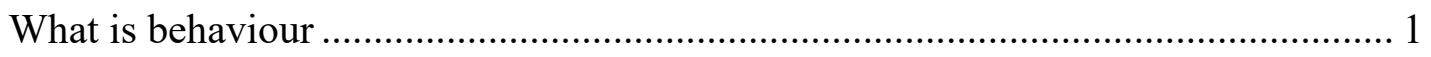

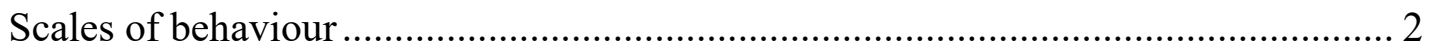

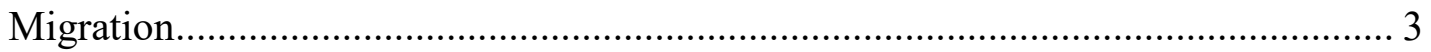

The unifying concept of conservation behaviour............................................... 5

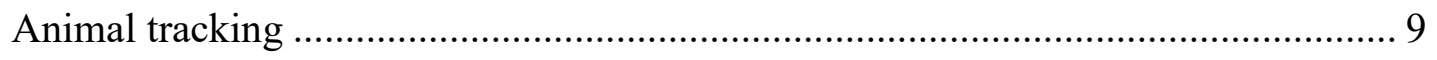

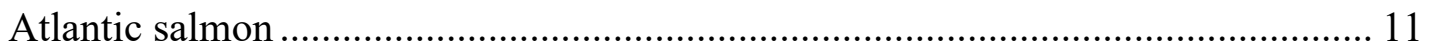

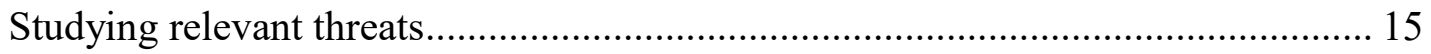

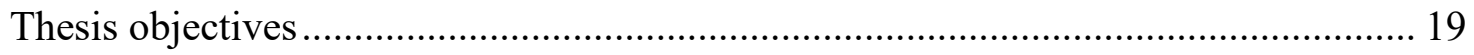

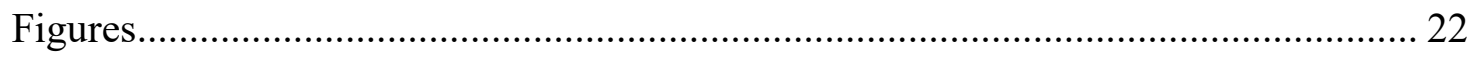

Chapter 2 Biologging and biotelemetry tools reveal two scales of Atlantic salmon

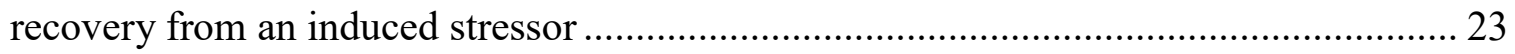

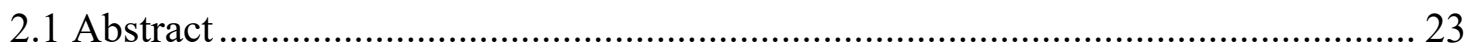

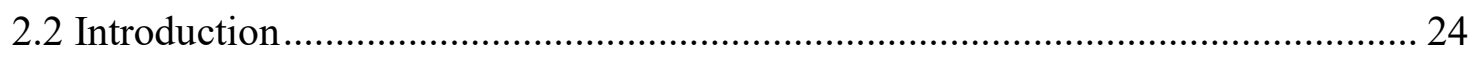

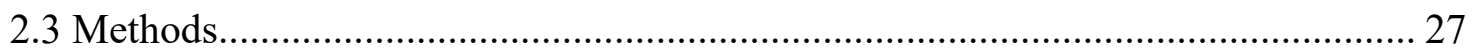

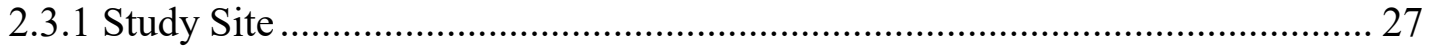

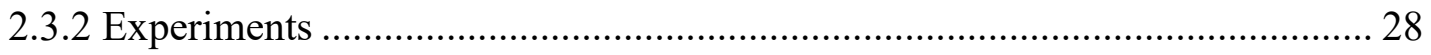




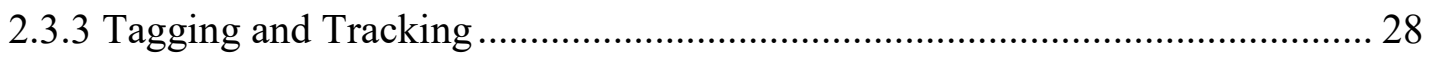

2.3.4 Data Analysis ........................................................................................... 29

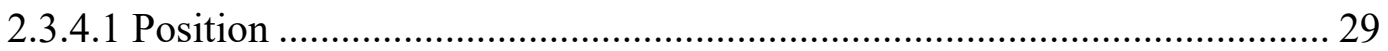

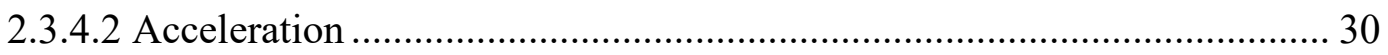

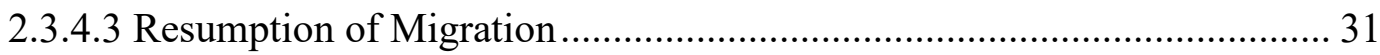

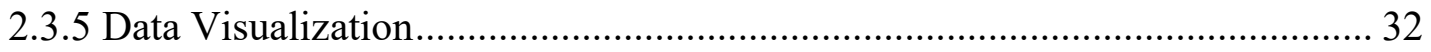

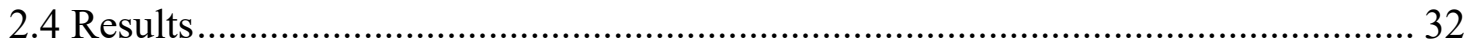

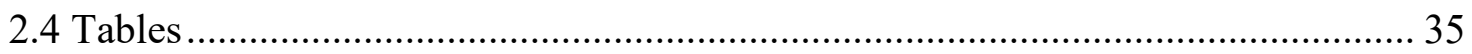

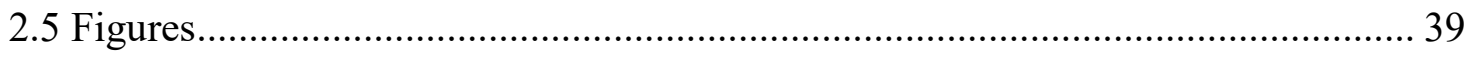

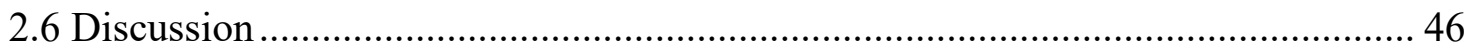

Chapter 3 Use of simulation approaches to evaluate the consequences of catch-andrelease angling on the migration behaviour of adult Atlantic salmon (Salmo salar) ....... 53

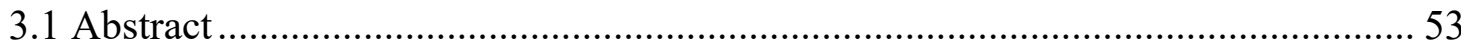

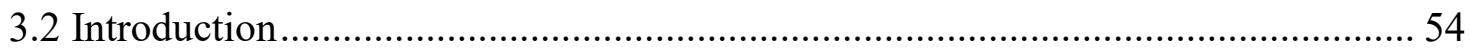

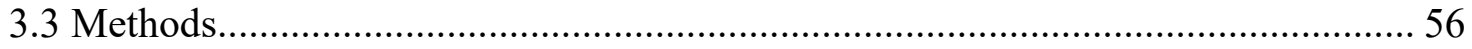

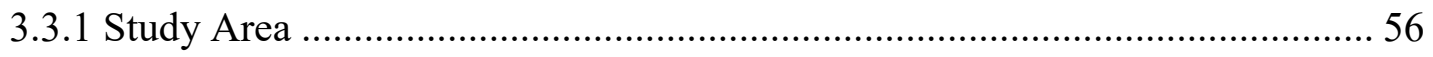

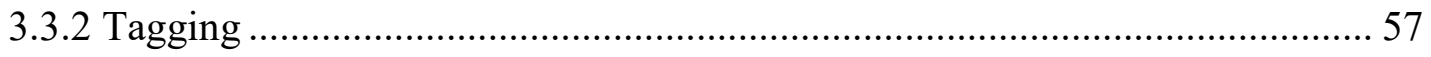

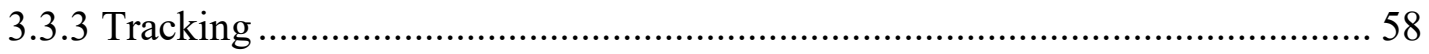

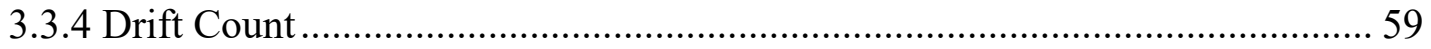

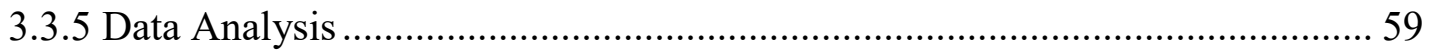


3.3.5.1 Free distribution

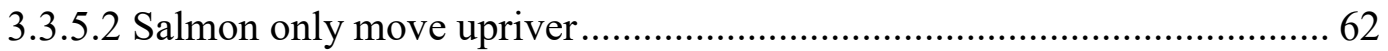

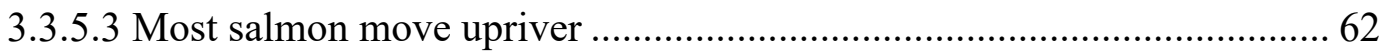

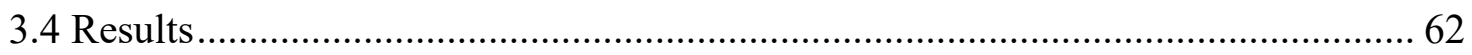

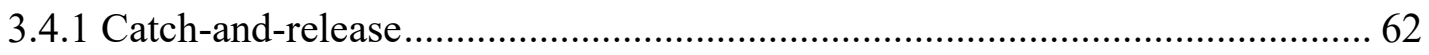

3.4.2 Spawning distribution of catch-and-release salmon ................................ 63

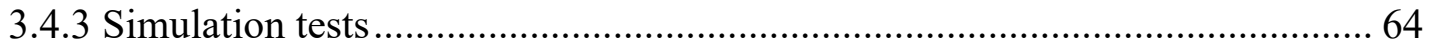

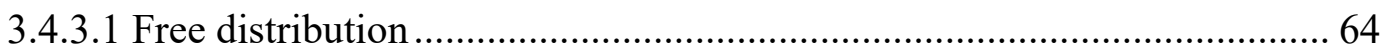

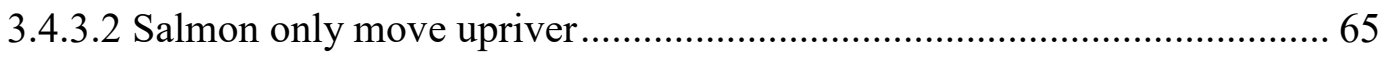

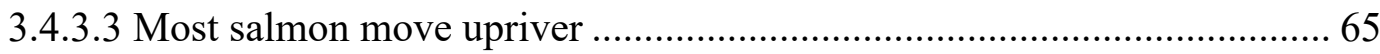

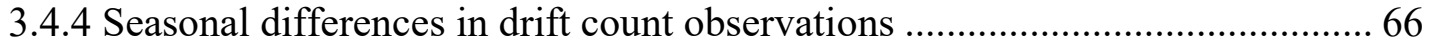

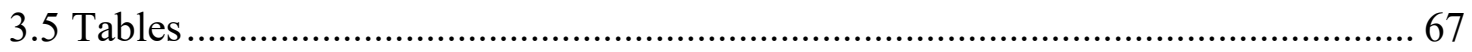

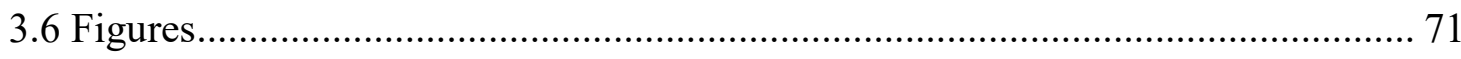

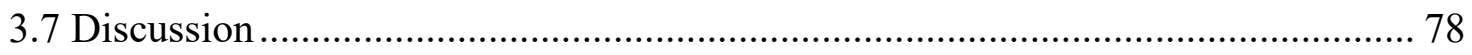

Chapter 4 Behaviour and survival of wild Atlantic salmon (Salmo salar) captured and released while surveillance angling for escaped farmed salmon ................................ 84

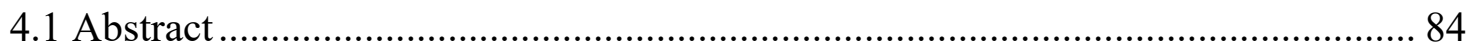

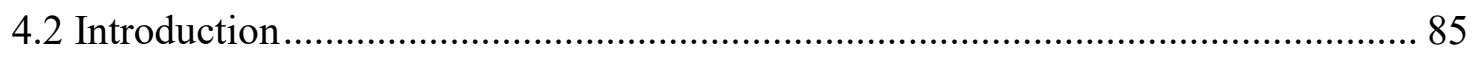

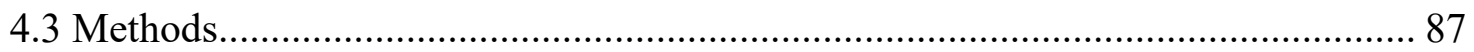

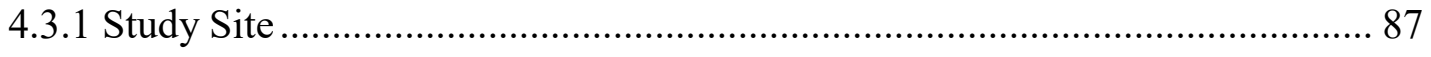


4.3.3 Data Analysis .............................................................................................. 90

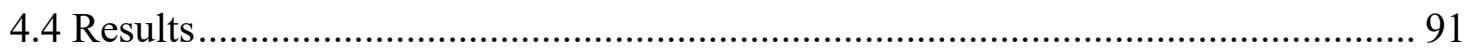

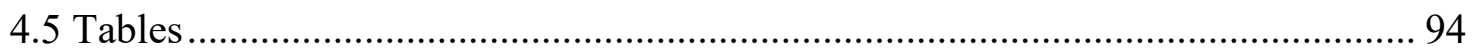

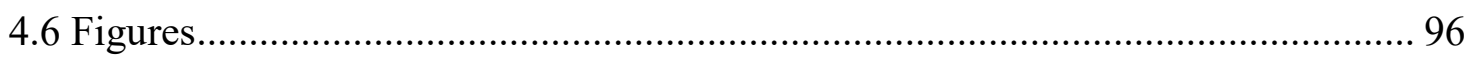

Chapter 5 Influence of gear switching on recapture of Atlantic salmon (Salmo salar) in

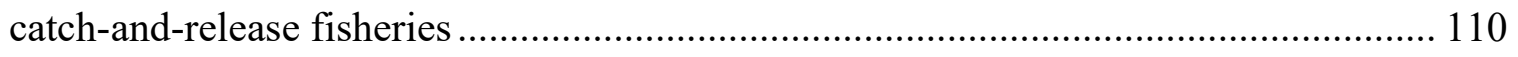

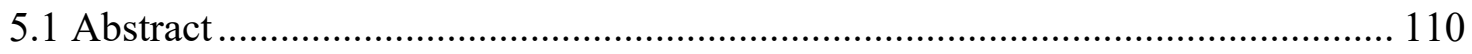

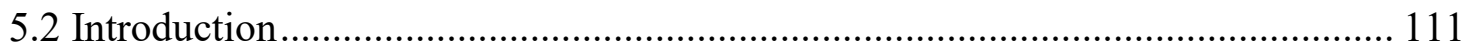

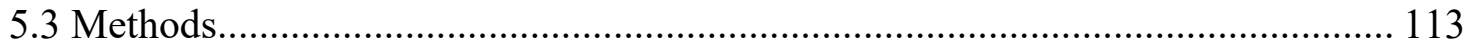

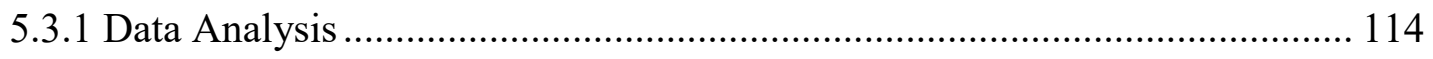

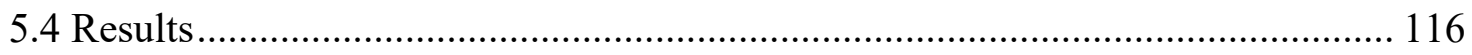

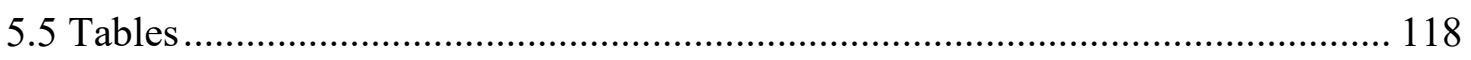

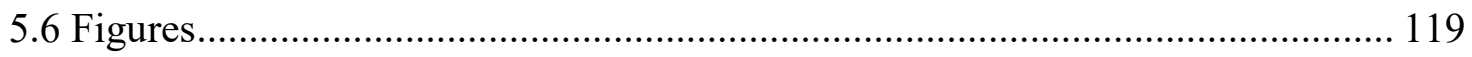

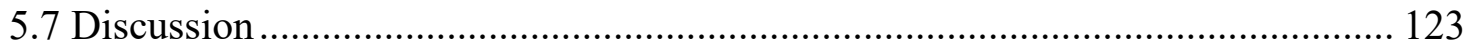

Chapter 6 Pan-Holarctic assessment of post-release mortality of angled Atlantic salmon

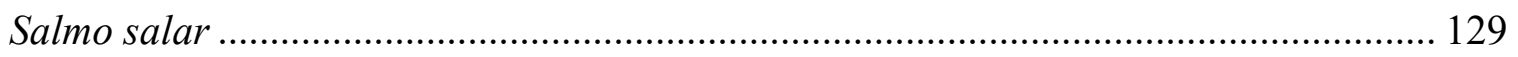

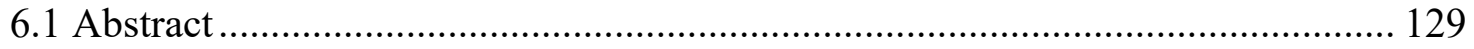

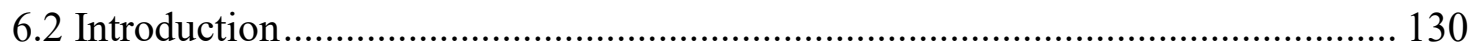

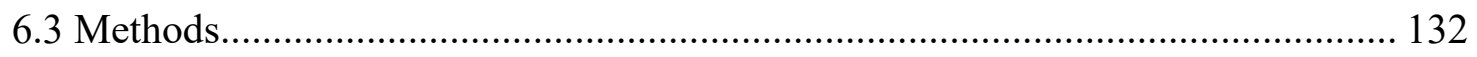


6.3.1 Data Collection

6.3.2 Data Analysis.

6.4 Results 136

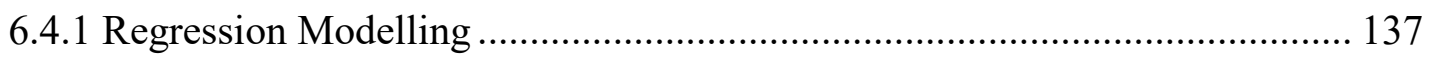

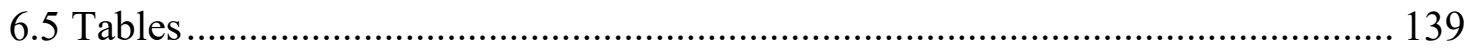

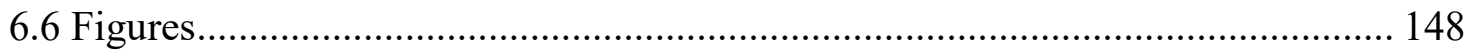

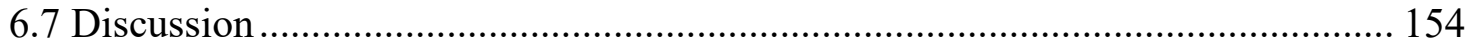

Chapter 7 River warming portends bioenergetic failure of adult Atlantic salmon Salmo

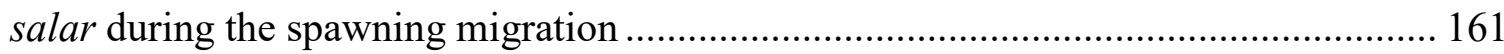

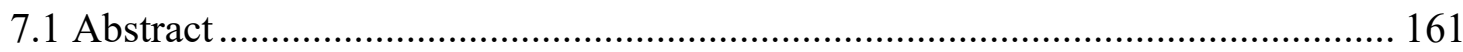

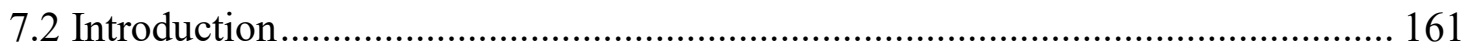

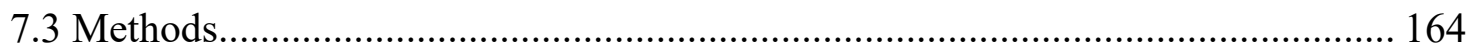

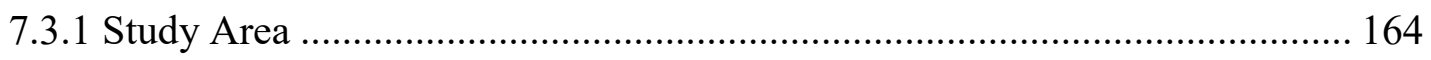

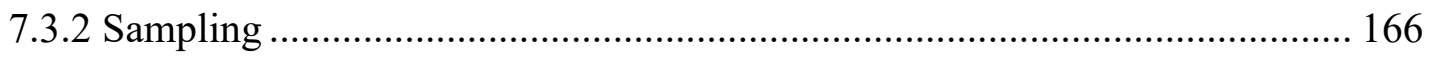

7.3.3 Archival Temperature Logger Validation............................................... 167

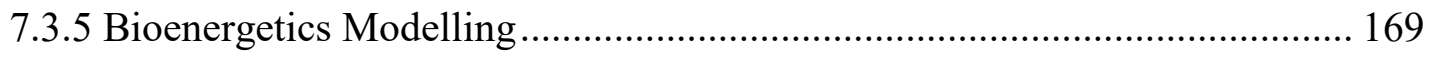

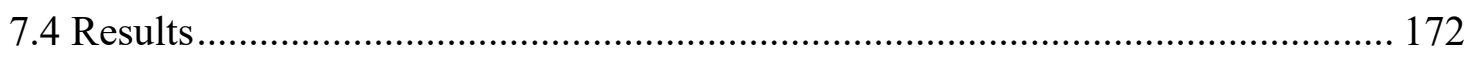

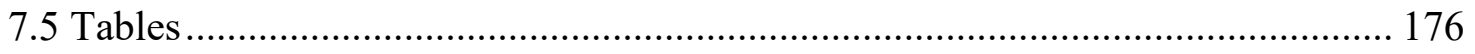

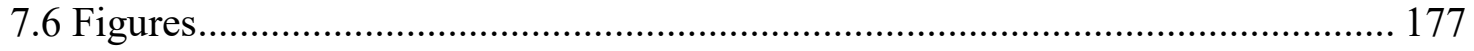

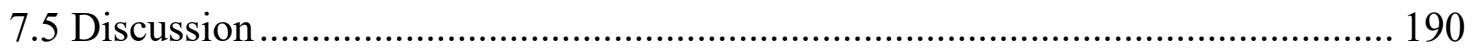


7.5.1 Limitations

Chapter 8 Synthesis and Future Research Directions

The behaviour-physiology interface

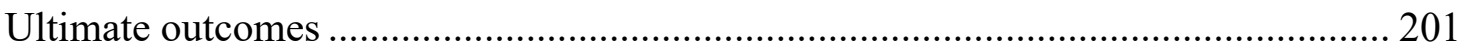

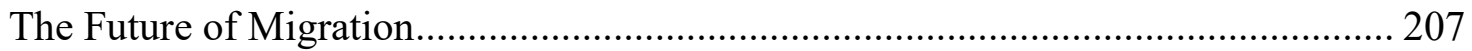

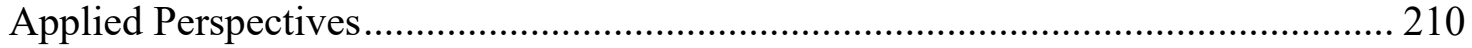

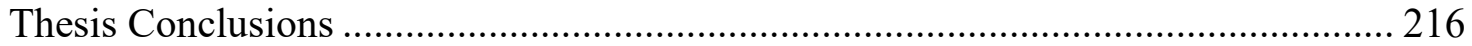

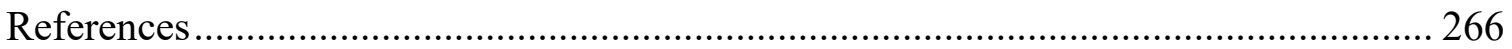




\section{List of Tables}

Table 2.1 Summary of 39 tagged Atlantic salmon (Salmo salar) in the Campbellton River, Newfoundland and Labrador. Salmon were double tagged with external accelerometer tags and radio transmitters implanted in the stomach and released on July 9 or 10, 2016. The fate of salmon was either dead (died soon after release), returned to the counting fence, or unknown (tracked moving after release but never recaptured at the counting fence) 35

Table 2.2 Generalized least squares regression (gls) modelling jerk, a metric summarizing the dynamic movement of the body across three axes. The gls incorporated time nested within individual in an exponential correlation structure to account for temporal autocorrelation in the model residuals.

Table 3.1 Individual data on the radio tagged salmon in the Lakselva River, Norway. Thirty-nine salmon were captured between July 13 and August 28, 2014, eight of which were recaptured later in the migration, one of which disappeared, and one of which died. One of the recaptured salmon was re-released and remained in the river for spawning. The spawning pool was determined by radio tracking in the fall during the spawning season and the net movement is the number of pools.

Table 4.1 Summary of distance (river $\mathrm{km}$ ) moved by Atlantic salmon (Salmo salar) released by surveillance fishing. Each fish was tracked 1 h, $1 \mathrm{~d}, 2 \mathrm{~d}$, and $3 \mathrm{~d}$ after release, Mean, median, standard deviation (SD), and range of relative distances and absolute distances from the release site are presented. Number of fish tracked in each sample is 
also included because some positions were not available due to tracking error. For the final positions, one fish that exited the river is excluded from the total.

Table 4.2 Generalized least squares regression of log-transformed movement within $3 \mathrm{~d}$ by Atlantic salmon (Salmo salar) released by surveillance anglers during the autumn fishing season. P-values are relative to the reference levels of categorical variables (reference levels for each factor: Gear $=$ Fly, Sex $=$ Female, Colour $=$ Brown, Bleeding $=$ Negative)

Table 5.1 Total salmon catches in the Norwegian study rivers in 2012 and 2013. Salmon catches were downloaded from the publicly available catch databases. Salmon tagging data encompasses radio and anchor tags. For the total salmon catch, percentages of fish captured on different gears are given. The percentage of captured fish released in these two years in these rivers is also given. Recapture rates are calculated from the number of tags returned by anglers from salmon tagged during the same angling season. 118 Table 6.1 Summary of data collected and shared for this project including the number of salmon tagged, average length ( $\pm 1 \mathrm{SD})$, location and average water temperature ( $\pm 1 \mathrm{SD})$ of fish capture. Studies that did not have the associated data are marked by NA. See Figure 6.1 for a map of the study sites. Mean water temperature is "Mean Temp $\left({ }^{\circ} \mathrm{C}\right)$ " and number of dead fish is the column "Mort". 139

Table 6.2 Regression coefficients, p-values, and odds ratios for logistic regression model fit to Atlantic salmon survival data from 11 studies. Odds ratios indicate odds of survival and are for a one-unit (day for Date, $\mathrm{cm}$ for Total Length, $\mathrm{s}$ for Play Time, ${ }^{\circ} \mathrm{C}$ for Water Temperature) increase of continuous predictors and for a change in odds between levels 
of categorical predictors. The reference level for hook location is deep hooked and for Gear the reference level is bait. Odds ratios less than 1 indicate a decrease in odds. .... 147 Table 7.1 Summary of fish from which iButton archival temperature loggers were recovered. The table details the size of the salmon as well as the number of days the tags

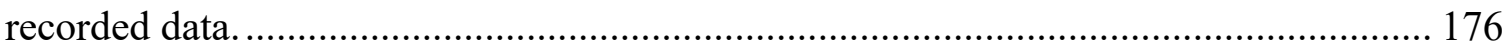




\section{List of Figures}

Figure 1.1 Adult Atlantic salmon (Salmo salar) captured during the upstream migration in Lakselva, Norway in August 2014 (left) and September 2016 (right). On the left, the individual was double tagged with a radio transmitter and a temperature logger and on the right the fish was only tagged with a radio transmitter. Electronic tagging was applied in this thesis to investigate the behaviour and survival of fish during the spawning migration to investigate mechanisms of success and failure of the migration. 22

Figure 2.1 Map of the experimental area used to investigate migrations of Atlantic salmon (Salmo salar) in the Campbellton River, Newfoundland. Salmon were captured in the counting fence trap on July 8 and 9, experimented, tagged, and released below the trap on July 9 and 10, and monitored within the arena by radio telemetry for one week

and at counting fence trap until September 6, 2016. 39

Figure 2.2 Radio tracking positions of Atlantic salmon (Salmo salar) tagged and released (yellow point) in the Campbellton River, Newfoundland. Density contours indicate the relative distribution of Atlantic salmon based on radio positions for control and treatment group salmon with higher density indicated by red rings. Note that most detections were recorded in the pool directly above the counting fence above the island. Most other detections were recorded at the confluence of the two branches of the river on either side of the island below the highway bridge. 40 Figure 2.3 Summary plots describing activity of Atlantic salmon tagged and released in an experimental migration arena in the Campbellton River, Newfoundland, Canada. Jerk is a composite metric summarizing activity based on axes of tri-axial accelerometer 
loggers. The pre-specified model tested whether ambient light (left panel), temperature (central panel), time, treatment group, and the interaction between treatment group and time (right panel) affected the activity of salmon in units of jerk. The final model incorporating an exponential correlation structure by time nested within individual $(\mathrm{N}=$ 13) suggested no effect of ambient light but a weak effect of treatment $(\mathrm{P}=0.08)$, treatment $\times$ time interaction $(\mathrm{P}=0.08)$, and a significant effect of temperature $(\mathrm{P}=0.001)$ on salmon activity. Dashed horizontal lines indicate the mean value of jerk throughout the study (1.51).

Figure 2.4 Density plot displaying the most probable mean time to return after release (black) for 34 Atlantic salmon (Salmo salar) tagged and released from experimentation in the Campbellton River, Newfoundland. The simulated distribution of most probable number of days to return was generated by assigning daily probabilities of tagged salmon to return on a given day equal to the proportion of untagged salmon trapped at the fish counting fence on that day. The area under the white curve indicates the observed distribution of days elapsed before returning for control salmon $(\mathrm{P}=0.24)$ and the area under the grey curve represents treatment $(\mathrm{P}<0.01)$ salmon.

Figure 3.1 Lakselva in Porsanger, Finnmark, Norway. The river incorporates two major lakes, Øvrevatnet and Nedrevatnet. Atlantic salmon return to the river from the ocean through the Porsangerfjord throughout the summer and migrate upriver to spawning grounds. For this study, salmon released by anglers were tagged at various points in the river. Note that the river flows south to north 71

Figure 3.2 Relationship between the release location and spawning position of 30 salmon released by anglers. Discrete spawning pools are assigned based on locations where 
spawning counts occurred in September 2014. The dashed line indicates a 1:1

relationship between release pool and spawning pool (i.e. no upriver movement). Points

are jittered to reduce overlap. $\mathrm{R}^{2}=0.74$.

Figure 3.3 Simulated test statistic distributions for the mean number of pools moved for Atlantic salmon under alternative null hypothesis of no effect of catch-and-release on post release movements and final choice of spawning pool. The black circles indicate the observed mean number of pools moved from the release location to the spawning location among the tagged salmon. The left panel gives the simulated distribution for the free distribution of salmon, the centre panel shows the distribution for the upriver movement only simulation, and right-hand panel the distribution for the upriver movement simulation that excludes all salmon that spawned at or below the release site. Observed movement (black circle) in the first two panels are based on 30 salmon whereas the right panel includes 15 salmon after removing individuals that spawned downriver of the release site (see Table 3.1 for list of salmon with negative movement that were excluded) 74

Figure 3.4 Violin plots of annual drift counts in Lakselva. The width of violins indicate the spawning densities at corresponding pools of the river based on observations by drift counters. Note that across years there was some inconsistency in visibility, excluding some pools from the count; for example, the lower pools in the 2011 count. Only data from the 2014 count were used for the simulation models 76

Figure 4.1 Changes in position of individual Atlantic salmon caught by surveillance fishing in Lakselva. Positions were recorded by manual tracking one hour, one day, two 
days, and three days after release. Distances are presented relative to the river mouth $(\mathrm{rkm})$.

Figure 4.2 Proportion of Atlantic salmon (Salmo salar) positioned below, within, or above the release location in Lakselva by $100 \mathrm{~m}$ after $1 \mathrm{~h}, 1 \mathrm{~d}, 2 \mathrm{~d}, 3 \mathrm{~d}$, and at the end of

the study

Figure 4.3 Plot of the relative distances traveled by Atlantic salmon (Salmo salar) captured in a surveillance fishery. The colour scale indicates the temporal change in position of fish in the river based on fixed interval tracking and logging station data in days after tagging. The asterisk demarcates the fish that exited the river prior to spawning. Date is the day after release.

Figure 4.4 Violin plots of positions of Atlantic salmon (Salmo salar) released from a summer recreational fishery $\left(\mathrm{N}_{2014}=21\right)$ and surveillance fishery $\left(\mathrm{N}_{2016}=35\right.$ having excluded one fish that exited prior to spawning). Positions for the 2014 fish are taken on October 24, 2014 and are relative to positions taken on September 15, 2014. Positions for 2016 are the final positions in the river taken on 22-24 October relative to the release site.

Figure 5.1 Number of recaptured salmon $\left(\mathrm{N}_{\text {total }}=46\right)$ initially captured by flies, lures, and worms. The shaded area indicates the number of salmon that were recaptured by a different gear than they were first captured by (i.e. exhibited gear switch).

Figure 5.2 Simulated probability distribution of the percentage of salmon that would exhibit gear switch in the absence of gear avoidance. The distribution represents the outcomes of 10,000 simulations, which multinomially assigned a recapture gear to 46 salmon based on gear catch probability. Among 46 salmon recaptured in Rivers Gaula, 
Lakselva, Orkla, and Otra in 2012 and 2013, 32 (70\%) exhibited gear switch, represented by the black diamond.

Figure 6.1 Geographic distribution in North America and Europe of 12 salmon rivers with catch-and-release data included in this study. Red points indicate the location of the river where fish were sampled and electronically tagged. 148

Figure 6.2 Model predicted probability of survival for Atlantic salmon released from recreational fisheries as a function of total length. Predictions are based on a logistic regression model with continuous predictors adjusted to the mean value and categorical predictors adjusted to the most frequent value. Shaded area corresponds to the $95 \%$ confidence interval.

Figure 6.3 Model predicted probability of survival for Atlantic salmon released from recreational fisheries as a function of the time played by anglers. Predictions are based on a logistic regression model with continuous predictors adjusted to the mean value and categorical predictors adjusted to the most frequent value. Shaded area corresponds to the $95 \%$ confidence interval.

Figure 6.4 Model predicted probability of survival for Atlantic salmon released from recreational fisheries as a function of water temperature at capture. Predictions are based on a logistic regression model with continuous predictors adjusted to the mean value and categorical predictors adjusted to the most frequent value. Shaded area corresponds to the $95 \%$ confidence interval.

Figure 6.5 Model predicted probability of survival for Atlantic salmon released from recreational fisheries as a function of gear type used for capture. Predictions are based on a logistic regression model with continuous predictors adjusted to the mean value and 
categorical predictors adjusted to the most frequent value. Error bars indicate the $95 \%$ confidence interval.

Figure 6.6 Model predicted probability of survival for Atlantic salmon released from recreational fisheries as a function of hooking location. Predictions are based on a logistic regression model with continuous predictors adjusted to the mean value and categorical predictors adjusted to the most frequent value. Error bars indicate the $95 \%$ confidence interval.

Figure 7.1 Lakselva in Porsanger, Finnmark, Norway. The watershed incorporates two major lakes, Øvrevatnet and Nedrevatnet. Atlantic salmon return to Lakselva from the ocean via Porsangerfjord throughout the summer and migrate upriver to spawning grounds. The location of the river temperature logger is located on the map. For this study, all tagged salmon remained in Lakselva below the lakes throughout their migration.

Figure 7.2 Double-tagging Atlantic salmon (Salmo salar) with coded radio transmitting tags (bottom) and archival temperature loggers (top). Salmon were maintained submerged in water in a PVC tube during tagging and externally tagged prior to release.

Figure 7.3 Fish thermal experience logged in Lakselva by salmon 142.123-75, whose logger remained active until December 16, 2014 (note that the values have been adjusted based on the regression analysis; see Supplementary Material). 179

Figure 7.4 The relationship between fish temperature and the river temperature in Lakselva. Each grey line represents values from a temperature logger of an individual salmon in the river. The solid black line is the line of identity at $y=x$. Linear mixed 
effects modelling supported a linear relationship between river temperature and habitat temperature of salmon during this period and the line of prediction is illustrated by the broken black line (note that the value is adjusted based on the regression analysis; see Supplementary Material).

Figure 7.5 Predicted somatic energy density of Atlantic salmon (Salmo salar) based on equations derived by Jonsson et al. (1997) in the River Drammen, Norway. Both curves follow polynomial equations and represent measurements made in July $\left(E_{\text {initial }}=\right.$ $\exp \left(0.044 \times \mathrm{L}_{\text {TOTAL }}+6.99\right)$ and November, following spawning $\left(\mathrm{E}_{\text {post-spawn }}=\exp (0.035 \times\right.$ $\left.\mathrm{L}_{\text {TOTAL }}+6.51\right)$. Broken vertical lines represent the lengths I selected for the bioenergetics modelling in this study, showing the energetic scope during the freshwater migration. 182 Figure 7.6 Atlantic salmon oxygen metabolism between 7 and $22{ }^{\circ} \mathrm{C}$ at four swimming speeds. Values for the resting fish were mass-corrected for three sizes using a scaling exponent of 0.80 (see Clarke and Johnston 1999). Curves are presented for three body lengths, near the minimum, mean, and maximum values encountered in Lakselva. Values for resting and $1.0 \mathrm{bl} \mathrm{s}^{-1}$ were derived from swim tunnel respirometry (see Table 2). Values for 0.5 and $0.7 \mathrm{bl} \mathrm{s}^{-1}$ were interpolated from these data by averaging the oxygen uptake values. Regression curves were fit to the plots using a polynomial (second order) equation fit to the $1.0 \mathrm{bl} \mathrm{s}^{-1}$ data and exponential curves fit at other swimming speeds. Dashed portions of the curves are extrapolations made by the regression equations beyond the temperature ranges at which oxygen uptake were measured (i.e. $0-7^{\circ} \mathrm{C}$ ). 184 Figure 7.7 Predicted cumulative energetic expenditure (kCal) of Atlantic salmon measuring either $63.5,89.0$, or $119.0 \mathrm{~cm}$, either resting or swimming at $0.5,0.7$, and 1.0 bl s${ }^{-1}$ from July 13 - December 16 . Monthly ticks are the first day of the noted month. 
Daily temperatures experienced were converted from measured river values with the regression equation: $\mathrm{t}_{\mathrm{FISH}}=3.24+\left(0.76 \times \mathrm{t}_{\mathrm{RIVER}}\right)$ at present river temperatures or given increases of 1,2 , or $4{ }^{\circ} \mathrm{C}$. The horizontal line indicates the scope for depletion (i.e. initial energy minus post-spawn energy) for each size class based on regression equations in Jonsson et al. (1997). The shaded area signifies the approximate spawning period in Lakselva, October 10-31. Energy depletion increased at higher temperatures, faster rates of movement, and larger body size. 186 Figure 7.8 Predicted proportion of energy remaining to Atlantic salmon measuring either $63.5,89.0$, or $119.0 \mathrm{~cm}$, either resting or swimming at $0.5,0.7$, and $1.0 \mathrm{bl} \mathrm{s}^{-1}$ from July 13 - December 16. Monthly ticks are the first day of the noted month. Fish habitat temperatures were calculated from the regression equation: $\mathrm{t}_{\mathrm{FISH}}=1.62+0.88\left(\mathrm{t}_{\mathrm{RIVER}}\right)$ at present river temperatures or given increases of 1,2 , or $4{ }^{\circ} \mathrm{C}$. The horizontal line represents the expected proportion of energy remaining in a post-spawn salmon of each size based on a regression equation in Jonsson et al. (1997). The shaded area signifies the approximate spawning period in Lakselva, October 10-31. Relative energetic depletion increased at higher temperatures and for faster rates of movement but decreased with body size. 


\section{List of Appendices}

Appendix A. Atlantic Salmon Journal Article on Atlantic salmon catch-and-release

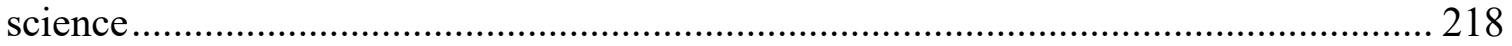

Appendix B. Abstracts of relevant Atlantic salmon publications................................... 226

Appendix C. Abstracts of non-thesis publications from graduate courses ..................... 230

Appendix D. Abstracts of non-thesis publications …………..................................... 235 


\section{Chapter 1 General Introduction}

\section{$\underline{\text { Background }}$}

What is behaviour

Mobile animals acquire information, integrate it through sensory mechanisms, and use it to make decisions with the ostensible objective of maximizing fitness (McNamara and Houston 1986; Real 1992; Dall et al. 2005). Any behavioural decision made by an animal must be supported by an underlying physiological framework to execute it, particularly relying on structural (skeletal and muscular) and cardiorespiratory systems to deliver oxygen to tissues, metabolize energy substrates, and execute movements (Dickinson et al. 2000; Brown et al. 2004). The emergence of behaviour therefore must be coevolved with physiological and cognitive systems to support it (Lorenz 1958; Tinbergen 1963). The potential for animals to behave in response to stimuli permits individuals to adjust energy processing by balancing energy acquisition and expenditure (i.e. optimal foraging), making habitat selections, and optimizing growth and fecundity (Charnov 1976; Pyke et al. 1977; Werner and Anholt 1993).

Behaviour is distinct from other movements insofar as it represents a conscious or decided response to a stimulus (Tinbergen 1963). Reflexes, spasms, actions of the autonomic nervous system (e.g. tail beating, opercular pumping), and fixed action patterns are involuntary and therefore do not suit the definition of behaviour (Tinbergen 1963; Lorenz 1981). However, behaviour can be interpreted or analyzed from multiple 
perspectives, as demonstrated by Tinbergen (1963), who defined animal behaviour in four questions that are mutually consistent, in that behaviour simultaneously has functional, phylogenetic, causative, and developmental explanations.

\section{Scales of behaviour}

Although animal behaviour may be brief in temporal scale, many behaviours are prolonged and may even overlap with other behaviours (e.g. foraging during ranging). Foraging, sheltering, aggression (i.e. physical or nonphysical interactions with conspecifics), and reproducing are fundamental behaviours to animal fitness as they exploit their environment to maximize growth, fecundity, and probability of survival (Tinbergen 1963; Dall et al. 2005; Davies et al. 2012). To accomplish these tasks, most animals (excluding some sessile animals such as tunicates and crinoids) must move (Nathan et al. 2008; Schick et al. 2008). Movement behaviour may be realized throughout the individual's life and across scales (Morales and Ellner 2002; Papastamatiou et al. 2009; Owen-Smith et al. 2010). Most behaviours require a decision about movement, predominantly within the individual's home range, which overlaps with suitable habitat (Railsback et al. 1999; Dingle and Drake 2007). Foraging movements within the home range are characterized by resource acquisition on daily schedules that may be described as station keeping, in which the individual emerges from relative inactivity within a shelter (i.e. roost, nest, den) and accesses different areas within the home range (Kennedy 1985; Dingle and Drake 2007). These movements are characterized by directed, tortuous movements that include frequent turning to find resources (Turchin 1991; Jonsen et al. 
2005; Whoriskey et al. 2017). Scheduling of these movements depends on endogenous rhythms and high degrees of inter-individual variation may exist within populations in the expression of these movements (Kadri et al. 1997; Papastamatiou et al. 2009; Harrison et al. 2014). Animals may dissolve their home range and move beyond it in a movement behaviour termed ranging (Dingle and Drake 2007), in which a new home range is established e.g. to improve resource acquisition. Individuals may also abandon their home range during migration, a specialized behaviour allowing individuals to exploit productivity in distant habitats (Dingle 1980; Kennedy 1985; Dingle and Drake 2007).

\section{Migration}

Migration is a predictable, synchronized movement of animals between reproductive and conditioning (i.e. foraging, maintenance) habitats (Dingle 1980; Dingle and Drake 2007). Unlike ranging or other movements, animals that are migrating will not cease in their pursuit of their destination even when encountering suitable habitat, often because migrants undergo atrophy of alimentary organs to conserve energy and avoid distraction (Kennedy 1985; Dingle and Drake 2007). Migration behaviour is available (although not necessarily expressed) in many taxa because of the advantages conferred to individuals departing breeding habitat (Berthold 1999; Alerstam et al. 2003; Altizer et al. 2011); expression of migration may depend on individual physiological (Brodersen et al. 2008) or ecological (Hulthén et al. 2015) thresholds. Orientation mechanisms are essential for migration (Able 1980; McDowall 2001) but the mechanisms for orientation are not necessarily conserved across species. A magnetic sensory system likely guides 
many long-distance migrants along with visual and olfactory cues at short distances (Lennox et al. 2016a [Appendix C]). Although many migrations are philopatric and involve individuals returning to natal territory (Greenwood 1980; McDowall 2001; Hendry et al. 2004), some species such as sea lamprey (Petromyzon marinus) have no fidelity for their rearing grounds and migrate into unfamiliar habitat for breeding following conspecific cues (Bjerselius et al. 2000).

Migration is highly visible and manifests in most animal taxa from insects to large mammals as they exploit spatiotemporal dynamics in habitat phenology stimulated by seasonal climatic changes that generate peaks or valleys in the energy landscape (Alerstam et al. 2003; Dingle and Drake 2007). The seasonal disappearance and reappearance of migratory animals from habitats generates spatial nutrient pulses along a landscape; influx of migratory animals imports nutrients and therefore migratory animals represent essential vectors for ecosystem fertilization. This so-called nutrient subsidization (Gende et al. 2002; Childress et al. 2014) has broad implications for ecosystem productivity and changes to migratory dynamics can alter ecologically important processes within ecosystems (Moore and Schindler 2008; Satterfield et al. 2015). Migratory species are also culturally important; humans have relied on the periodical reappearance of migratory animals for millennia, including caribou herds (Stewart et al. 2004), duck flocks (Byers and Dickson 2001), and salmon runs (Hindar et al. 2007) as components of subsistence. Migration is therefore a highly visible and valuable ecological phenomenon. The long-distance movements and reliance on multiple habitats renders migratory species especially vulnerable to disturbance, notably habitat degradation/destruction, loss of connectivity, overexploitation, and climate change 
(Wilcove and Wikelski 2008; Robinson et al. 2009; Bowlin et al. 2012; Lennox et al. 2016a [Appendix C]).

Accuracy is essential to successful migration (Able 1980; McDowall 2001). Individuals must accurately synchronize the timing of their departures and arrivals to coincide with favourable environmental conditions. Accurate timing conserves energy (Lennox et al. 2016a [Appendix C]). Migrants also benefit from accurately navigating to ensure that their movement is energetically efficient, synchronized, and follows the best path (Chapman et al. 2011; Hewson et al. 2016). Individuals that become lost or distracted during migration will be delayed and encounter depleted or suboptimal conditions upon arrival if they survive (Bradshaw and Holzapfel 2008; Jones and Cresswell 2010). Early arrival at breeding sites allows individuals to secure high-quality territory and prior residence has been demonstrated to increase individual fitness but there is a trade off in energy conservation (Dickerson et al. 2005; Tentelier et al. 2016). There is therefore intense selection for navigational mechanisms in migrants and for correct behaviour (Nosil et al. 2005).

\section{The unifying concept of conservation behaviour}

The behaviour of animals is a fundamentally interesting and important topic of scientific investigation (i.e. ethology; Tinbergen 1963; Lorenz 1981) because it aids in interpreting ecological processes including species composition, species interactions, and nutrient cycling (Davies et al. 2012). Behaviour directly contributes to individual fitness potential and is therefore a relevant metric to apply to conservation and management 
plans (Sutherland 1998; Buchholz 2007). Conservation emerged as an interdisciplinary science incorporating biological and social sciences into a unified applied field of inquiry with the objective of preserving biodiversity (Soulé 1985). Conservation biology has expanded and evolved to incorporate modern tools and techniques for identifying, monitoring, predicting, and mitigating conservation priorities (Sutherland et al. 2004; Wikelski and Cooke 2006; Bottrill et al. 2008). Conservation and resource management are now challenged to understand the responses of individuals and populations to putative stressors and implement mitigations that assist in preserving biodiversity (Cooke et al. 2013a).

Stressors disrupt the homeostasis of an individual animal and the underlying mechanisms of many animal behaviours are related to the restoration of homeostasis following exposure (Romero 2004). Studying behaviour therefore requires an understanding of animal physiology to determine how behaviour is used to cope with stressors (Cooke et al. 2013a). Stressors are external stimuli and are distinguished from life history challenges that require energy investment (e.g. foraging, reproduction, sheltering, movement) in that they are unpredictable to the individual and therefore it is unanticipated (Romero 2004; Wingfield 2013). However, animals are nonetheless prepared to cope with stressors and restore homeostasis by responding to physiological cascades elicited by stressors (Barton 2002; Wingfield 2013), termed the allostatic load (McEwen and Wingfield 2003). In fish, stressors are perceived by the sensory system, interpreted in the cortex, and integrated by the stress axis to circulate catecholamines and glucocorticoids, which mediate changes to cardiophysiology, muscular performance, and, ultimately, behaviour as an effort to correct hormone imbalances instigated by stress 
(Romero 2004; Flik et al. 2006). Catecholamines (epinephrine and norepinephrine) are released by the chromaffin cells in the head kidney, which increase oxygen uptake at the gills and transport in the blood that are required for behaviours to be executed (Wendelaar Bonga 1997; Barton 2002). Interpretation of a stressor by the hypothalamus stimulates release of transmitters that communicate with the pituitary gland and the release of adrenocorticotropic hormone (ACTH) and $\alpha$-melanophore-stimulating hormone to the bloodstream, communicating with the interrenal gland from which cortisol is ejected into the blood (Wendelaar Bonga 1997; Barton 2002; Flik et al. 2006; Wingfield 2013). The action of cortisol has varied impacts on energy processing in fish with a focus on the liver where glycogenolysis and gluconeogenesis increase circulating glucose concentrations in the blood to fuel behaviour and restore homeostasis (van der Boon et al. 1991).

Acute stressors generally do not have enduring impacts on individuals following the encounter as the stress hormones are metabolized (Pickering et al. 1987), although complete recovery may be prolonged (Pickering et al. 1982). Chronic stress occurs when individuals are exposed to protracted changes to their environment or prolonged exposure to a stressful stimulus such that cortisol is consistently elevated, fast-energy is continuously available, and the scope for responsiveness to the stressor is diminished (Sapolsky et al. 2000; King et al. 2016). The consequences of chronic stress on fish may include inability to respond appropriately to stressors, reduced growth, delayed maturity, impoverished fecundity, and reduced capacity to fulfill potential fitness (Pickering et al. 1987; Barton and Iwama 1991; Santos et al. 2010), although some species (classically the semelparous salmonids) are highly resistant to stress incurred during reproduction 
(Wingfield and Sapolsky 2003). The adaptive nature of chronic stress is an emerging topic and the experience of chronic stress may depend on its adaptiveness to the population; where a potential fitness advantage is enjoyed by the individuals that redirect energy to the stress response or condition offspring to live in a stressful environment (Boonstra 2013). Although chronic stress in response to natural predators may be adaptive (Boonstra 2013), human activities should avoid imposing chronic stress upon wild animals.

Baseline animal behaviour can be measured in free-living animals in their natural environment (Hussey et al. 2015; Kays et al. 2015). However, stressors can yield prolonged or permanent changes to animal behaviour that can be measured to evaluate impacts and test potential mitigations (Lennox et al. In Press, a [Appendix D]). Downstream impacts of stressors on the physiology and cognition of individuals can alter performance or affect decision-making (Lima 1983; Kassahn et al. 2009). Behaviour responding to stress is an evolved mechanism to cope with change; however, there is increasing mismatch between behaviour and fitness outcomes for animals (McLean 1997; Tuomainen and Candolin 2011).

Stressors can alter animal behaviour in ways that could be either adaptive or maladaptive, depending on the long-term consequences of the behaviour elicited (Boonstra 2013). Maladaptive behaviour will yield perverse outcomes for populations as individuals fail to respond to stressors when the individual had a better alternative that it did not express. Research is ongoing to understand how individuals respond to stressors and whether behavioural disorders, in which the individual expresses an incorrect or maladaptive behaviour, emerge. Such disorders could include migration behaviours that 
yield negative consequences for fitness potential by reducing the probability of ascending to the appropriate spawning territory at the correct time. Among partially migratory species, the expression of migration may change (e.g. Brodersen et al. 2008; Martin et al. 2018); in most species, the timing of migration may shift to track climate change (Sims et al. 2004; Otero et al. 2014; Dempson et al. 2018).

Behavioural biology now provides information to managers that is essential to conservation, particularly because the ecology of individuals provides relevant information about the species (Clemmons and Buchholz 1997; Sutherland 1998; Buchholz 2007). Behavioural data provide resolution on the timing, periodicity, and extent of animal activity and habitat requirements throughout the animal's life that can be incorporated into management and conservation plans (Allen and Singh 2016; Lennox et al. In Press, a [Appendix D]). For example, marine reserves should be designed to protect local species (e.g. Filous et al. 2017). Fishing regulations should also depend on knowledge of where animals are and how they are behaving; using fishery catch data to model the distribution of migrating salmon around Vancouver Island, British Columbia, Putman et al. (2014) provided details about the potential for fishing area closures and quotas as managers strive to maintain sustainable harvest of the wild fish. Evidently, there is considerable value in collecting behavioural data and applying it to conservation, particularly as human activities are likely to influence behavioural patterns exhibited by animals.

Animal tracking 
Direct observation of behaviour is possible using visual identification techniques but these methods are very limiting because they can lack a reliable mechanism to consistently identify individuals (e.g. Gubili et al. 2009). Capturing and marking individuals therefore provides an effective tool for investigation but requires recapture of the marked individual to estimate behaviour. Early efforts to delineate site fidelity and home range of fish relied on visual observations (Lewis and Flickinger 1967). Markrecapture methods have been used to investigate the fidelity of Atlantic salmon to natal rivers for centuries (Walton 1653) and the natural history of salmon was studied in the River Tay, Scotland by tracking the return of fin-clipped smolts to the river (Brown 1862). Mark-recapture techniques using dart or anchor tags have remained an important method for large-scale tracking of fish (Le Cren 1965; Fonteneau and Hallier 2015).

Modern methods to investigate animal movement often involve the application of electronic tags (Adams 1965). Electronic tags communicate with receivers either passively (e.g. passive integrated transponders) or actively (e.g. acoustic or radio transmitters, satellite tags), or else log data onboard (e.g. light-based geolocators; see Cooke et al. 2004; Hussey et al. 2015; Lennox et al. 2017a [Appendix D]). These tools are especially useful for investigating aquatic animals that cannot be directly observed in their environment (Hussey et al. 2015). Environmental and physiological data can also be collected using electronic tags attached to fish that either transmit or log information (Payne et al. 2014; Wilson et al. 2015; Cooke et al. 2017). Standard biologging tools include accelerometers that measure fine-scale positions of the tag in three axes to reconstruct movement, temperature loggers that measure the ambient temperature experienced. Together, these tools provide unparalleled insight into the daily lives of 
animals that can be applied to make fundamental discoveries about individual or population distributions or test hypotheses relevant to natural resource management.

Transmitting tags provide effective technology for tracking animal movement without the need to recover the tag. Radio transmitters can be applied on land and in freshwater but cannot generally be used in the marine environment where signals rapidly attenuate in saltwater (but see Thiem et al. 2013); for marine applications, acoustic transmitters (Trefethen 1956) are often preferred so long as the instrumented animals are expected to remain within the range of the receivers (Heupel et al. 2006). Radio telemetry relies on communication between the tag and a compatible receiver tuned to the specific frequency at which the tag is transmitting and has the advantage of using the receiver outside of water (Slater 1963). Multiple tags may transmit on the same frequency if they are coded with unique transmission patterns that can be decoded by the receiver to identify distinct individuals. Mobile tracking of tags may be conducted to locate tags manually; alternatively, gates may be established with automatic listening stations continuously searching for tags passing a checkpoint in a river or forest corridor (Heupel et al. 2006). As needed, positions of tags can be calculated by triangulation of the tag position when multiple simultaneous tracking points are available for the same individual (Adams 1965).

Atlantic salmon

Atlantic salmon (Salmo salar) is one of the world's most recognizable fishes. In fact, Atlantic salmon may be the most numerically abundant fish in the world owing to its 
popularity in global aquaculture (Gross 1998). Atlantic salmon is an iteroparous anadromous species native to rivers flowing into the North Atlantic Ocean in continental Europe, the northeast of Russia, Iceland, Canada, and the northeastern United States (MacCrimmon and Gots 1979; Klemetsen et al. 2003). The distribution of Atlantic salmon, however, is contracting, with imperilled populations largely extirpated at the southern boundary of their historic range (i.e. United States, Spain, Portugal, France, Germany); over 300 populations of Atlantic salmon have disappeared (WWF 2001). Threats to the persistence of wild Atlantic salmon include habitat destruction, climate change, disease, competition with escaped farmed fish and other invasive species, and overexploitation (Parrish et al. 1998; Forseth et al. 2017; Nicola et al. 2018).

Juvenile Atlantic salmon spend multiple years in their natal rivers as parr before maturing (a small proportion of mostly males; Hutchings and Myers 1994) or undergoing smoltification, a physiological transition inducing physical changes, osmoregulatory remodelling, and negative rheotaxis as they emigrate natal rivers to the ocean where they will feed and grow (Folmar and Dickhoff 1980; McCormick et al. 1998). Marine feeding grounds are predominantly coastal areas such as those around the Faroe Islands and Greenland although there are probably many other less important areas and salmon seem to be broadly distributed within the ocean (Hansen and Quinn 1998; Strøm et al. 2018). According to Thorpe et al. (1998), the onset of maturation and return migration is cued by individual condition and thereby determines the number of winters spent at sea prior to spawning. One-sea winter salmon (i.e. grilse) dominate in years in which the ocean is warm (Jonsson and Jonsson 2004). Maturing Atlantic salmon return from marine feeding areas throughout the year in anticipation of spawning from October-January in natal 
streams and may mill near the entrance of the river for weeks or months prior to initiating the freshwater migration (Ulvan et al. 2017; Mahlum et al. In Press). Salmon have high fidelity to their natal streams but 5-10\% will stray to non-natal areas (Jonsson et al. 2003; Ulvan et al. 2017). Salmon stocks may be genetically structured in large rivers with philopatry to specific tributaries (Verspoor et al. 2005; Vähä et al. 2007). Re-entry into freshwater coincides with atrophy of the alimentary organs and the onset of reproductive maturation (Kadri et al. 1995; Persson et al. 1998). Salmon migrate up rivers in three phases: active movement in which the individual ascends the stream towards spawning territory, holding near the eventual spawning site, or searching (characterized by up- and down-stream movements; Økland et al. 2001). In smaller rivers, salmon may hold in large pools during the summertime where water temperatures and levels are more stable prior to initiating the final phase of migration in the autumn (Richard et al. 2014).

Although ideal distribution theory posits that competitors should spread out across a landscape (Fretwell and Lucas 1969), many species congregate at high quality sites (Reed and Dobson 1993). Correspondingly, male and female salmon at high quality spawning habitat are more successful (Tentelier et al. 2016). Juvenile salmon growth is density dependent (Einum et al. 2006; Teichert et al. 2010); therefore, the distribution of spawners influences offspring survival (Teichert et al. 2010). Spawning occurs on small beds of gravel often near the tail out of pools (Fleming 1996; Bardonnet and Baglinière 2000; Armstrong et al. 2003). Redds are excavated in the gravel by females, which cut into the gravel with the tail to form a depression where the eggs will be deposited (Lucas et al. 1993). Females will remain near the redds and court males, which compete for access to the females (Järvi 1990; Weir et al. 2004). Salmon may mature as parr, 
predominantly males, and precautious male parr adopt a sneaker phenotype to infiltrate anadromous male spawning attempts (Hutchings and Myers 1988), which increases effective population size (Perrier et al. 2014). During the spawning season, salmon may travel several hundred metres between sites and engage in multiple breeding efforts (Taggart et al. 2001). The number of mating events is strongly predictive of reproductive success and does not necessarily correlate with individual size (Garant et al. 2001).

Unlike semelparous Pacific salmon, migration and spawning are not lethal to the iteroparous Atlantic salmon (Fleming 1998). After spawning, Atlantic salmon will move into deep pools to overwinter in the river (Bardonnet and Baglinière 2000). Salmon experience near-zero temperatures during the winter, suggesting a slow metabolism and limited energy requirements (Halttunen et al. 2013). Individuals in poor condition following spawning may exit the river immediately afterwards (Halttunen et al. 2013). Delaying outmigration until the springtime is likely advantageous to match the timing of outmigration with the timing of peak ocean productivity. These post-spawned kelts will recondition in the ocean or estuary for one (consecutive repeat spawning) or multiple (alternate repeat spawning) years before re-initiating migration into their natal river (Strøm et al. 2017). Repeat spawners are important components of the spawning population and provide protection against poor year classes (Niemelä et al. 2006a). Atlantic salmon may spawn up to six times (Ducharme 1969) but most will only spawn once. Females have shorter spawning intervals that ostensibly conserve energy (Hendry and Beall 2004). Consequently, females, as well as small salmon, are more likely to survive spawning and return to sea successfully (Jonsson et al. 1991a). 


\section{Studying relevant threats}

Because of their reliance on multiple habitats to complete their life history and owing to their long, inter-jurisdictional movements, salmon are vulnerable to human disturbance (Parrish et al. 1998). Salmon depend on connectivity within rivers and between the river and ocean, which can be interrupted by barriers or can be imperiled by the installation of aquaculture operations or deployment of fisheries (Nicola et al. 2018). Dams separate reaches of river habitat and challenge both the downstream migration of smolts to the ocean and the upriver migration of maturing salmon to spawning grounds (Croze 2008; Havn et al. 2018). Aquaculture operations in coastal zones aggregate parasitic sea lice that burden and may kill migrating salmon (Halttunen et al. 2018). Farmed fish escaping from aquaculture also have negative interactions with salmon as they will migrate into native spawning rivers and compete with wild fish, resulting in damaging genetic introgression that reduces the fitness of the native stock (Gross 1998; Moe et al. 2016; Svenning et al. 2017). Atlantic salmon fisheries were historically exploitative as the annual return of Atlantic salmon represented an important food source for coastal peoples (Hindar et al. 2007). Development of large-scale marine fleets led to offshore fisheries for salmon in their conditioning habitat, particularly in coastal Greenland. These mixed-stock fisheries resulted in substantial damage to Atlantic salmon populations. Closure of the marine fisheries was positive for salmon conservation and there was subsequently an increase in the proportion of repeat spawning salmon (Dempson et al. 2004). Recreational fishing for salmon probably has a long history but became established in the 1800s and shifted from Europe into the North American fisheries (Nettle 1857). Now, recreational salmon fisheries are economically important 
throughout their range (Olaussen and Skonhoft 2008; Stensland and Baardsen 2012;

Grilli et al. In Press) but may represent a relevant stressor upon imperilled salmon populations (Thorstad et al. 2003) because many are captured during their migration to spawning grounds (Gudjonsson et al. 1996; Erkinaro et al. 1999; Downton et al. 2001). Recreational fisheries are valuable components of resource-based economies (Stensland 2013; Tufts et al. 2015; Barnett et al. 2016). Fish and fisheries can have substantial economic benefits but there is also a realization that fisheries must be sustainable to be beneficial (Cooke and Cowx 2004; Brownscombe et al. 2017a). Recreational fisheries are exploitative and rely on the capture of wild or stocked fish but in general the extent of exploitation is less than in commercial or subsistence fisheries because recreational fisheries predominantly use hook and line, a relatively inefficient capture tool compared to nets or traps that can have high catch-per-unit-effort. Fishing with bait, lures, or flies (i.e. gear) provides a sensory stimulus to a fish that it can accept or decline; fish that accept the gear may be hooked and then captured. Anglers exert some influence over their individual catch rates through gear selection and movement (Lennox et al. 2017a [Appendix D]).

The probability of an individual fish being captured by recreational angling is termed vulnerability and is an integrated phenotype incorporating physiology and behaviour of individuals (Lennox et al. 2017a [Appendix D]). Vulnerability is difficult to empirically define because it is unobservable without a capture event. At the population scale, catchability defines the stock's propensity to be captured by anglers and may vary by sex, age, experience, population, or other variables (Arreguín-Sánchez 1996). Fish that are captured in recreational fisheries may die instantly or soon after capture because of 
injury or physiological disturbance resulting from the hooking and fighting (Wood et al. 1983; Wedemeyer and Wydoski 2008; Cooke et al. 2013b). Immediate mortality is highly visible, but most fish are landed alive and the angler may harvest or release the catch (Cooke and Cowx 2004; Arlinghaus et al. 2007; Ferter et al. 2013). The extent of harvest in recreational fisheries varies greatly by fishery with large interindividual heterogeneity (Arlinghaus et al. 2007; Ferter et al. 2013; Brownscombe et al. 2014). The decision to release fish is not exclusively voluntary (Sutton and Ditton 2001; Policansky 2002; Millard et al. 2003) but may be influenced by regulations imposed on fisheries (Millard et al. 2003; Bartholomew and Bohnsack 2005) that in turn affect angler behaviour and effort (Veinott et al. 2018a). Many fish captured in recreational fisheries survive capture and are released; delayed mortality is insidious in these fisheries because it is unobservable and therefore challenging to quantify and incorporate into management models (Muoneke and Childress 1994). Delayed mortality may arise because of the inability to recover, increased vulnerability to predation, or infection on wound sites (Davis 2010; Raby et al. 2014). Released fish are intended to survive and return to the common population without fitness costs (Wydoski 1977; Arlinghaus et al. 2007; Cooke and Schramm 2007). Ultimately, many fish may be captured multiple times (Meka 2004).

Fisheries challenge fish with unpredictable demands on the physiological system to respond to a stressor. Fisheries simulate predatory encounters as fish recruit anaerobic flight responses to power an escape. Most fish will fight hard to exhaustion before being landed by an angler, depleting glycogen, phosphocreatine, and ATP in the white muscle and accumulating metabolic by-products such as lactate, which dissociates, leaks from the white muscle into the blood, and results in acute metabolic acidosis (Wood et al. 
1983). Recovery of oxygen debt following exposure to a stressor requires additional energy along with re-synthesis of anaerobic substrates (Milligan 1996).

Fisheries are relevant venues through which to study stress and behaviour in wild fish. For some fish populations, interaction with fisheries is highly probable as fisheries can capture a high proportion of the total population (e.g. Twardek et al. 2018). For Atlantic salmon, estimates of exploitation suggest that up to $80 \%$ of spawners can be captured by anglers during the upriver migration, not including some that will be hooked and not landed (Erkinaro et al. 1999 and references therein). Not only is recreational capture a prominent stressor for fish, but it also elicits an acute generalized stress response that provides information with which to interpret the individual- and populationscale consequences of stressors. Fish must also be captured for study and using the capture event as the proximate stressor for investigation is sensible to avoid multiple stressors.

Recreational fisheries are operating in a changing world (Elmer et al. 2017) where species encounter many different stressors. Recreational fishing itself can impose multiple stresses upon the animal when they are captured multiple times. For migrants, recreational fishing impacts could therefore be additive or multiplicative, particularly if recapture occurs before complete recovery from the initial impact. As freshwater becomes impacted by human activities including habitat destruction and climate change, operation of recreational fisheries requires an understanding of how these threats impact migrating fish and research is needed to define an operating space for recreational fishing in the context of the other stressors that fish encounter (Rockström et al. 2009; Elmer et al. 2017). 
Beyond the fundamental interest in evaluating the responses of fish to stressors, there are broad applications to evaluating the impacts of fisheries on individual fish and on fish populations. Managers benefit from fisheries data to estimate the impacts of fishing on the population such that they can establish evidence-based regulations to manage the fishery (Radomski et al. 2001). Fisheries data can subsequently be communicated to users, including anglers, to implement best practices in the fisheries that maximize sustainability (Conway and Opossomer 2007; Nguyen et al. 2012;

Brownscombe et al. 2017a). Best practices may be fishing practices, including the gear selected, handling practices, as in the strategies used by anglers to hold or photograph fish (e.g. air exposure), or release practices (e.g. handheld recovery, recovery bags) and should ideally be developed in concert with other stressors fish encounter in each system.

\section{$\underline{\text { Thesis objectives }}$}

The human population is increasing (Cohen 2003) along with concomitant increases in industrial pollution, infrastructure development, and agri/aquaculture allotment to support the continually accelerating resource demands (Foley et al. 2005; Kiers et al. 2008; Casillas and Kammen 2010; Larsen et al. 2016; Newbold et al. 2016). Despite these demands, maintenance of global biodiversity must remain a priority given the myriad services that intact ecosystems and biodiversity provide to humans (Costanza et al. 1997; Holmlund and Hammer 1999). Humans are responsible for fragmenting ecosystems and filling them with stressors that have the potential to alter individuals, scaling to populations and whole ecosystem function. This thesis investigates the fate of a 
migrating animal exposed to stressors to evaluate mechanisms of success and failure in its migration. As described above, migration is an ecologically important but imperiled phenotype and it is necessary to study how stressors may alter the expression of migration behaviour in animals to better understand the behaviour and to develop conservation plans that preserve these important species. My research focused on the upriver phase of salmon migration and used electronic tagging and tracking to observe it (Figure 1.1). Interference of the salmon migration was predicted to affect the timing, location, and energy available to spawning.

In Chapters 2 and 3, I assessed changes in the temporal and spatial elements of migration using simulation. Chapter 2 investigated delays in the resumption of upriver migration by salmon following an experimental stressor and Chapter 3 tested for changes in the spatial distribution of migrants on spawning grounds following interaction with a stressor. In Chapter 4, I evaluated the movement and positioning of salmon in the holding phase of their migration after applying a stressor proximate to their known place and time of spawning. In Chapter 5, I focused on repeated stressors by studying the incidence of recapture in recreational fisheries and testing for avoidance behaviour by investigating gear switching by salmon. Next, I used a data sharing collaboration to determine the extent to which Atlantic salmon survive catch-and-release (Chapter 6), a question that is important to answer to determine the potential for fisheries-induced evolution associated with delayed mortality and the possible selection against certain behavioural phenotypes, particularly run timing. Finally, I applied a bioenergetics model to calculate the energy depletion of salmon associated with increased water temperature in freshwater, an oncoming threat to salmon persistence that could influence the expression of migration 
(Chapter 7). In combination, these approaches will reveal how a migrating animal responds to stressors and assist in understanding mechanisms by which migration success can be altered by common challenges that they encounter. 
$\underline{\text { Figures }}$

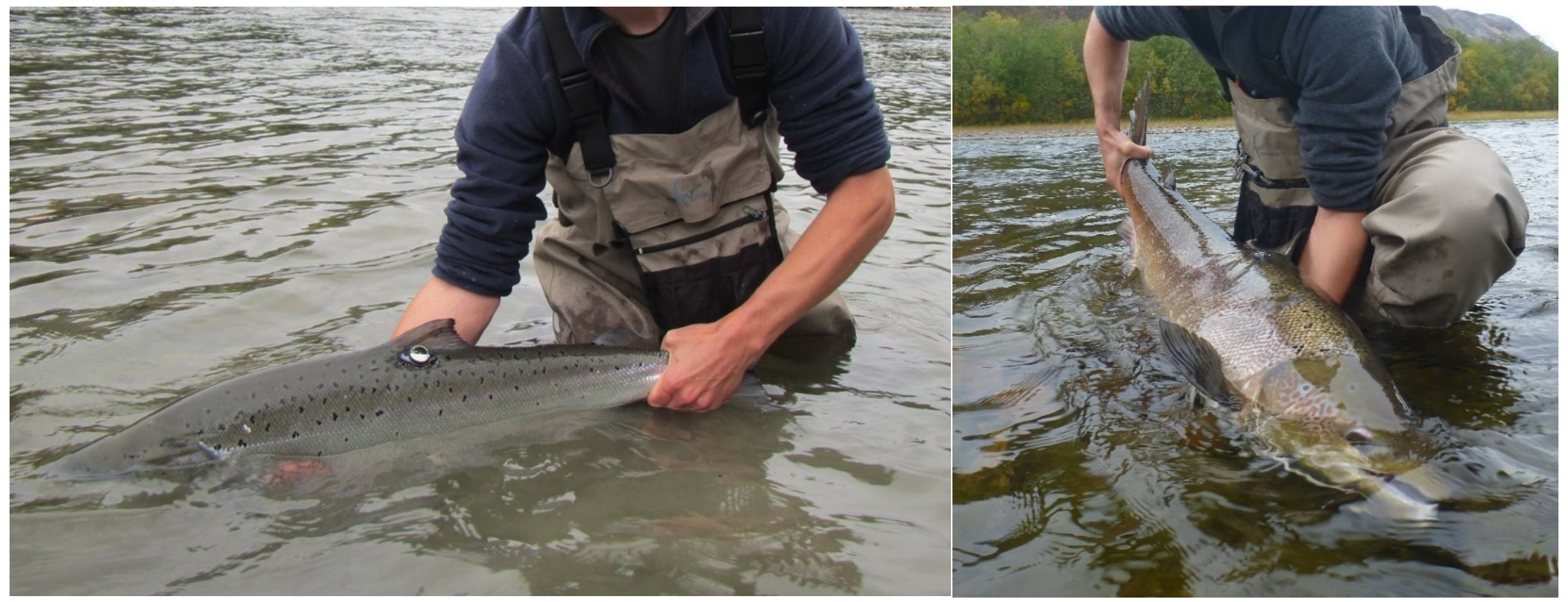

Figure 1.1 Adult Atlantic salmon (Salmo salar) captured during the upriver migration in Lakselva, Norway in August 2014 (left) and

September 2016 (right). On the left, the individual was double tagged with a radio transmitter and a temperature logger and on the right the fish was only tagged with a radio transmitter. Electronic tagging was applied in this thesis to investigate the behaviour and survival of fish during the spawning migration to investigate mechanisms of success and failure of the migration. 


\section{Chapter 2 Biologging and biotelemetry tools reveal two scales of Atlantic salmon recovery from an induced stressor}

\subsection{Abstract}

For migratory animals, movement is essential to fitness; they must move at appropriate times and to appropriate places or suffer survival or reproductive costs. Human activities such as live-release fisheries intercept fish during migration, altering an individual's physiology and behaviour. I investigated the locomotor activity of wild Atlantic salmon (n =39) at two scales: on fine scales using accelerometer data loggers and on broad scales by tracking fish with radio telemetry and monitoring returns to a counting fence trap in the Campbellton River, Newfoundland. Half the sample population was exposed to experimental exercise and air exposure (treatment) characteristic of live release fishing in water of moderate temperature $\left(18.8 \pm 1.3{ }^{\circ} \mathrm{C}\right)$. Treatment and control animals were then released $3 \mathrm{~m}$ downstream of the original counting fence capture site. Three salmon died within $1 \mathrm{~d}$ of release, one control and two treatment fish. The remaining 36 salmon were tracked in different locations below the counting fence including the estuary and several were inferred to have re-entered the ocean; all but two of the surviving fish (both in the treatment group) returned to the counting fence to resume the 2016 spawning migration (survival $=86-91 \%)$. There were no differences in post-release activity, measured by an index of total body action (jerk), between control and treatment salmon $(\mathrm{P}=0.81)$ but locomotor activity was significantly and negatively related to water temperature measured at the counting fence $(\mathrm{P}<0.01)$. Comparison of mean time to return against a null model 
generated by simulation, however, revealed that treatment salmon were significantly delayed in returning to the counting fence $(\mathrm{P}<0.01)$ whereas control fish were not $(\mathrm{P}=$ 0.24). I observed different responses between control and treatment salmon and ultimately observed individuals that were tolerant to the simulated stressors. However, the results suggest that there may be other costs associated with fisheries that should be accounted for and mitigated to ensure sustainability.

\subsection{Introduction}

Movement allows animals to meet needs and accomplish diverse life history objectives (Nathan et al. 2008). However, animals move at various spatial and temporal scales, complicating interpretations of how movement directly contributes to lifetime fitness. Migration is a large-scale (relative to the size of a given animal), synchronized movement of animals across a landscape between habitats that allows them to optimize lifetime reproductive potential by exploiting multiple habitats throughout the ontogeny (Dingle and Drake 2007). Physiological changes undergone by migratory animals can cause them to ignore stimuli such as food, implying that migratory movement is directly linked to reproductive potential and therefore fitness (Dingle 1980). Migratory animals may undergo extensive physiological remodelling to prepare for migration and then confront further disturbances that disrupt navigation, delay progress and arrival time, and/or deplete energy (Lennox et al. 2016a [Appendix C]). Migrants may be vulnerable or tolerant to stressors and there is variation in this response among and within species 
and populations (Wilcove and Wikelski 2008; Robinson et al. 2009; Lennox et al. 2016a [Appendix C]).

Challenges encountered during the migration can affect the success of individual migration. Although human activities can potentially interfere with all migratory taxa, literature has predominantly focused on investigating the progress and success of fish migrations, particularly salmonids, which are exposed to myriad stressors during the upriver phase of their spawning migration. Studies of migratory salmonids have linked anthropogenic stressors to the fallback distance away from the release location (Mäkinen et al. 2000; Havn et al. 2015), total migration distance (Lennox et al. 2015 [Appendix B]), or spawning position (Chapter 3). Fitness costs following exposure to stressors may be observed/inferred when an impacted individual's capacity to reach spawning territory at the appropriate time is inhibited, or when excessive energetic costs are imposed on an individual recovering from a stressor. Experimental approaches aiming to determine the extent to which migrants are affected and to evaluate costs of hypothesized disturbances benefit from fine-scale observations of individuals exposed to stressors, which may be acute but transient.

Tracking individual position with biotelemetry provides relevant information about the movement of individuals and progress along the migration route, however, it does not capture the inter-individual variation in response to short-term, acute physiological and behavioural disturbance. Combining biotelemetry with biologging tags equipped to measure the individual's environment, physiology, or fine-scale behaviour provides in-depth understanding of the broader-scale movements observed with biotelemetry. Tri-axial accelerometer biologgers record the position of a tagged aquatic 
animal in three-dimensional space at high frequency (Brown et al. 2013). Attached to a fish, accelerometers recording at $<1 \mathrm{~Hz}$ can be used to measure the individual movement throughout a study period to identify periods of activity and inactivity. Accelerometer traces (e.g. rapid or slow) can be applied to relate fine-scale behaviour to individual or environmental metrics (Brownscombe et al. 2013; Whitney et al. 2016; Lennox et al. In Press, $\mathrm{b}[$ Appendix D]). In combination, biotelemetry and biologging offer the potential to quantify physiology and behaviour of animals at multiple scales and can assist with interpreting the status and changes over time of free ranging animals exposed to stressors during the migration (Cooke et al. 2016).

Our study applied both biotelemetry and biologging tools to investigate Atlantic salmon migration in the context of an experimentally applied stressor to fish freely migrating upriver. Atlantic salmon is an anadromous migrant that normally makes rapid progress upriver towards the spawning destination and will hold for weeks or months before reproduction (Økland et al. 2001; Klemetsen et al. 2003; Richard et al. 2014). Migrants are exposed to myriad stressors such as drought or warm water temperatures (Alabaster 1990; Baisez et al. 2011) or by human interventions such as pollution (Thorstad et al. 2005), obstructions (Gowans et al. 1999; Croze 2008), or fisheries (Mäkinen et al. 2000; Thorstad et al. 2003). A river in Newfoundland, Canada with an impermeable fish counting fence provided a site within which to observe experimental animals and monitor the migration. Specifically, I examined whether exercise and air exposure simulating a fishing encounter altered the locomotor activity of salmon and migratory progress to upriver spawning sites relative to control fish that were only 
tagged. I predicted short-term reductions to activity and delayed upriver progress of salmon exposed to stressors during their migration.

\section{$\underline{2.3 \text { Methods }}$}

\subsubsection{Study Site}

I collected Atlantic salmon from the Campbellton River, Newfoundland, Canada. The Campbellton River drains about $296 \mathrm{~km}^{2}$ approximately $40 \mathrm{~km}$ into Indian Arm in Notre Dame Bay near the community of Campbellton, Newfoundland and Labrador. The Campbellton River is one of the most popular fishing rivers among Atlantic salmon anglers in Newfoundland (Downton et al. 2001). The wild stock returning to the Campbellton River has been enumerated annually by a Fisheries and Oceans Canada (DFO) counting fence about $345 \mathrm{~m}$ from the river mouth (49.276681, -54.922011; Figure 2.1; Downton et al. 2001; Veinott et al. 2018b). The fence prevents fish from passing upriver until all salmon ascending the river are manually counted in the facility's trap and then passed upriver. Counts of adult salmon from 2014-2016 were 4055, 4016, and 2748 individuals of predominantly one sea winter (Veinott et al. 2018b). During the study period, the trap operated from June 8 to September 6 continuously during the day and was monitored for the presence of experimental fish by closed circuit video camera (7h00 $-18 \mathrm{~h} 00)$. Members of the science team could then ensure they were present during fence operations to retrieve tags (see below). Water temperature during the experiment averaged $18.9 \pm 1.3^{\circ} \mathrm{C}$. 


\subsubsection{Experiments}

Salmon were collected from the trap the day before experimentation (July 8 or 9 , 2016) and held overnight in an in-river flow-through holding pen. On July 9 or 10 , salmon were dip netted from the holding pen and transported in a water-filled container approximately $20 \mathrm{~m}$ to a circular experimental arena filled with ambient water at the start of each trial. Fish were assigned to one of two groups, either a treatment group that simulated a generalized stressor $(\mathrm{N}=21$; mean fish length $54.2 \pm 2.6 \mathrm{~cm} \mathrm{FL})$ or a control group ( $\mathrm{N}=18 ; 54.1 \pm 2.6 \mathrm{~cm})$. The generalized stressor involved a chase to exhaustion ( $74 \pm 29 \mathrm{~s}$ ) followed by an air exposure of $10 \mathrm{~s}$. Animals were then tagged with an accelerometer and a radio tag following the stressor and released. Control fish were transferred to the experimental arena but were not exposed to exhaustive exercise prior to inserting the gastric radio tag and attaching the accelerometer (see below). Exhaustion of treatment-group animals was characterized as cessation of burst swimming in response to chasing. Exhaustion times were shorter than the exhaustion times normally recorded for salmon in this size range being captured by anglers (Chapter 6). Salmon in the control group were only tagged and were not chased or air exposed. All fish were released into the river approximately $3 \mathrm{~m}$ below the fish trap into a holding pool.

\subsubsection{Tagging and Tracking}


All salmon in both the control and treatment groups were externally tagged with an accelerometer data logger $\left(50 \mathrm{~Hz}, 10\right.$-bit resolution, $\pm 8 \mathrm{~g}_{0}$, Maritime bioLoggers, Halifax, NS) waterproofed with a plastic rubber coating (Performix Brand Plasti-Dip, Blaine, Minnesota, USA). Accelerometers were affixed with steel wire by passing two hypodermic needles through the dorsal musculature behind the dorsal fin. To confirm the fates of released fish, radio transmitting tags (Sigma 8, Newmarket, ON, Canada) were inserted into the stomach to track the position of fish in the river following release and to recover accelerometer tags from any mortalities in the river.

The fish's return migration to the counting fence was manually tracked using a handheld radio receiver (SRX 600, Lotek Wireless, Newmarket, ON) and a six-element Yagi antenna (AF Antronics, Urbana, IL). Daily surveys for the tagged salmon were conducted beginning at the counting fence and descending by foot along the riverbank to the highway bridge along both sides of an island (Figure 2.1). Surveys continued beyond the estuary to the peninsula to find salmon that were not found in the river. The small width and relatively shallow depth of the river indicated that it was highly improbable that a salmon in the river would go undetected. Visual surveys by snorkel were also conducted in the river and estuary to identify and recover dead fish.

\subsubsection{Data Analysis}

\subsubsection{Position}


To investigate differences in the distribution of animals from the two treatment groups following release, positions derived from radio transmissions were used to calculate $95 \%$ kernel utilization distributions using the kernelUD function in the R package adehabitatHR with grid size of 100 (Calenge 2006). To account for absence of animals that were not detected, a position in the ocean was assumed given that the radio coverage would have detected any fish in the estuary or river. Distributional area was calculated for the two groups using the kernel.area function and the difference was established by dividing the area of each distributional polygon.

\subsubsection{Acceleration}

Acceleration data were downloaded from accelerometer loggers recovered from treatment $(\mathrm{N}=6)$ and control $(\mathrm{N}=7)$ survivors as well as three individuals that died soon after release. Acceleration-derived activity was calculated using a moving variance window applied to the jerk time series $\left(\mathrm{m} \mathrm{s}^{-3}\right)$, described below. First, high-frequency noise was removed (IIR Butterworth filter with a $10 \mathrm{~Hz}$ cut-off) from the acceleration series, then jerk (change in acceleration, $\mathrm{m} \mathrm{s}^{-3}$ ) was computed as the differential of the acceleration for each axis. The total jerk was taken as the norm of the tri-axial jerk (i.e. the square-root of the sum of the squared value in each axis) at each time instant (termed RMS jerk in this MS; see, e.g. Simon et al. 2012) and represents the specific contribution of animal movement to vectoral acceleration. I then calculated hourly estimates of activity as the root-mean-square of Jerk based on a 60 min moving window for each fish. 
All acceleration processing was performed using MATLAB (The MathWorks Inc., USA).

To test if this measure of activity of salmon was significantly related to the treatment variable as well as other potentially relevant variables: the time since release (h), water temperature measured hourly at the counting fence, and diel effects of ambient light were considered as predictor variables. Ambient light was considered as a binary variable, light or dark, by checking whether a sample fell within or beyond values of nautical dawn and dusk based on values extracted with the getSunlightTimes function in the suncalc package for R (Agafonkin and Thieurmel 2015). I also considered the interaction between treatment group and time to check whether there was a difference in the activity across time for treatment compared to control salmon (i.e. a recovery profile). I selected a generalized least squares model implemented with the gls function in the nlme R package (Pinheiro et al. 2017). Nested effects by individual and temporal autocorrelation were incorporated using a correlation structure, and comparison of common correlation structures by AIC value (Zuur et al. 2009). The data structure suggested an exponential structure in the form $\operatorname{corExp}($ form = time $\mid I D))$ in which the time variable was the sample date time and ID was the individual fish. No model reduction was attempted and all fixed effects were retained for the final model.

\subsubsection{Resumption of Migration}

Dates of upriver ascent were recorded when fish were recovered in the counting fence trap. To test the hypothesis that the fisheries stressor delayed the upriver migration 
of salmon, I generated a probability distribution of the mean date of ascent to the fish trap for the surviving fish. To generate the distribution, I assigned a probability of ascent equal to the proportion of untagged salmon ascending to the fish trap on each day of the season (following the start of the experiment) as enumerated at the counting fence and then used the sample function in R to select an ascent date for each fish, weighted by the assigned daily probabilities, with 10,000 iterations (Chapter 3, 5). A p-value testing the null hypothesis that mean timing of ascent was not different from the null model was then computed by calculating the proportion of simulated values smaller than the mean observed arrival dates for tagged and untagged salmon.

\subsubsection{Data Visualization}

Figures were plotted using ggplot2 (Wickham 2008) with the packages ggridges (Wilke 2017) and gridExtra (Auguie 2017) in R (R Core Team 2017).

\section{$\underline{2.4 \text { Results }}$}

Three salmon were confirmed to have died within $1 \mathrm{~d}$ of the experiment (Table 2.1). Accelerometer tags were recovered. Two of the three mortalities were in the treatment group and one was in the control group. This small sample size precluded formal analysis of factors influencing mortality. Two additional treatment group animals never returned to the counting fence; however, they were both tracked multiple times to different positions in the estuary within one week of release and hence survived 
treatment/tagging. These two fish may have gone back to sea and subsequently re-entered the river after the counting fence was removed (6 September 2016), or alternatively suffered delayed mortality. Overall minimum survival was therefore $87-92 \%$ (control $94 \%$, treatment $81-90 \%$ ) and a mortality rate of $4-13 \%$ was attributed to the treatment effect; owing to small sample size, however, it was not possible to determine whether this was a significant difference with mortality occurring in the control group.

Most radio telemetry detections occurred in the pool directly below the counting fence where salmon were also visually observed holding alongside untagged fish. Fish were also detected below the outflow of two branches of the river on the estuary side of the highway bridge and in the estuary (Figure 2.1). Salmon that were not detected were inferred to have entered saltwater where the tags' transmissions were blocked from detection. Kernel density estimation of the distribution of control $\left(0.08 \mathrm{~km}^{2}\right)$ animals equated to $78 \%$ of the distribution calculated for treatment $\left(0.10 \mathrm{~km}^{2}\right)$ animals (Figure 2.2).

Accelerometers were recovered from fish that returned to the fence as well as those that came off prematurely onto the riverbed. Inspection of the accelerometer traces allowed us to determine when the tag was no longer attached to the fish and filter the data set. Generalized least squares regression revealed a significant effect of water temperature on jerk-derived hourly activity index with a negative slope (Table 2.2), suggesting that salmon activity decreased as temperatures increased from 13.5 to $23.4{ }^{\circ} \mathrm{C}$. Treatment salmon (1.52 $\pm 0.53 \mathrm{~m} \mathrm{~s}^{-3}$ average hourly rate of movement) were observed to have similar activity across the study period compared to control salmon $(1.48 \pm 0.48 \mathrm{~m}$ $\mathrm{s}^{-3}$ ), and both treatment group and the time $\times$ treatment interaction had small but not 
significant test statistics (Table 2.2). Activity was similar during daylight $(1.53 \pm 0.52 \mathrm{~m}$ $\left.\mathrm{s}^{-3}\right)$ and dark (1.45 $\pm 0.50 \mathrm{~m} \mathrm{~s}^{-3}$; Table 2.2). Date time was also not a significant term, having a slope of 0 (Table 2.2; Figure 2.3).

After releasing the tagged salmon and commencing monitoring for the study, 1504 salmon entered the trap at the counting fence after July 10 (first release group) and 1447 after July 11 (second release group). The average date of capture at the fence after both dates was August 8 (day 221) with a maximum of 57 salmon returning on July 11 (for the second release group the maximum was 52 on July 14) and a minimum of zero occurring on nine days. The null distribution of days to return following tagging suggested a mean of 23 days for 34 salmon to return given the null hypothesis that timing of return was independent of treatment; however, tagged control salmon returned on average 26 days after release $(p=0.24)$ and tagged treatment salmon returned on average $32 \mathrm{~d}$ after release $(\mathrm{p}<0.01$; Figure 2.4$)$; therefore, the null hypothesis that resumption of migration was independent of treatment was rejected. 


\subsection{Tables}

Table 2.1 Summary of 39 tagged Atlantic salmon (Salmo salar) in the Campbellton River, Newfoundland and Labrador. Salmon were double tagged with external accelerometer tags and radio transmitters implanted in the stomach and released on July 9 or 10, 2016. The fate of salmon was either dead (died soon after release), returned to the counting fence, or unknown (tracked moving after release but never recaptured at the counting fence).

\begin{tabular}{|c|c|c|c|c|}
\hline Group & Date Released & Length & Fate & Date Fate Determined \\
\hline \multirow[t]{14}{*}{ Control } & July 9 & 535 & Returned & July 14 \\
\hline & & 546 & Returned & August 1 \\
\hline & & 509 & Returned & July 26 \\
\hline & & 520 & Returned & July 27 \\
\hline & & 542 & Returned & August 1 \\
\hline & & 515 & Dead & July 10 \\
\hline & & 512 & Returned & July 27 \\
\hline & & 550 & Returned & July 25 \\
\hline & July 10 & 545 & Returned & August 30 \\
\hline & & 566 & Returned & August 30 \\
\hline & & 507 & Returned & August 8 \\
\hline & & 563 & Returned & August 27 \\
\hline & & 538 & Returned & July 12 \\
\hline & & 518 & Returned & July 27 \\
\hline
\end{tabular}




\begin{tabular}{|c|c|c|c|c|}
\hline & & 525 & Returned & August 23 \\
\hline & & 625 & Returned & July 26 \\
\hline & & 580 & Returned & August 9 \\
\hline & & 554 & Returned & August 1 \\
\hline Treatment & July 9 & 570 & Returned & August 7 \\
\hline & & 560 & Returned & July 26 \\
\hline & & 588 & Returned & July 29 \\
\hline & & 547 & Returned & July 26 \\
\hline & & 518 & Unknown & \\
\hline & & 574 & Returned & August 27 \\
\hline & & 520 & Returned & August 27 \\
\hline & & 536 & Dead & July 10 \\
\hline & & 515 & Returned & July 25 \\
\hline & & 540 & Returned & August 17 \\
\hline & July 10 & 540 & Returned & August 30 \\
\hline & & 560 & Returned & August 27 \\
\hline & & 542 & Unknown & \\
\hline & & 535 & Returned & August 1 \\
\hline & & 504 & Returned & August 1 \\
\hline & & 558 & Returned & August 27 \\
\hline & & 522 & Returned & August 23 \\
\hline & & 524 & Dead & July 11 \\
\hline & & 505 & Returned & August 11 \\
\hline
\end{tabular}


564 Returned

545 Returned
August 1

August 17 
Table 2.2 Generalized least squares regression (gls) modelling jerk, a metric summarizing the dynamic movement of the body across three axes. The gls incorporated time nested within individual in an exponential correlation structure to account for temporal autocorrelation in the model residuals.

\begin{tabular}{llll}
\hline Fixed Effect & Coefficient $\pm \mathrm{SE}$ & $\mathrm{t}$-value & $\mathrm{p}$-value \\
\hline (Intercept) & $193.26 \pm 201.79$ & 0.96 & 0.34 \\
Ambient Light (Light) & $0.05 \pm 0.03$ & 1.60 & 0.11 \\
Group (Treatment) & $-454.90 \pm 307.79$ & -1.77 & 0.08 \\
Time & $0.00 \pm 0.00$ & -0.95 & 0.34 \\
Temperature & $-0.05 \pm 0.02$ & -4.01 & $<0.01$ \\
Group (Treatment) $\times$ Time & $0.00 \pm 0.00$ & 1.77 & 0.08 \\
\hline
\end{tabular}




\subsection{Figures}

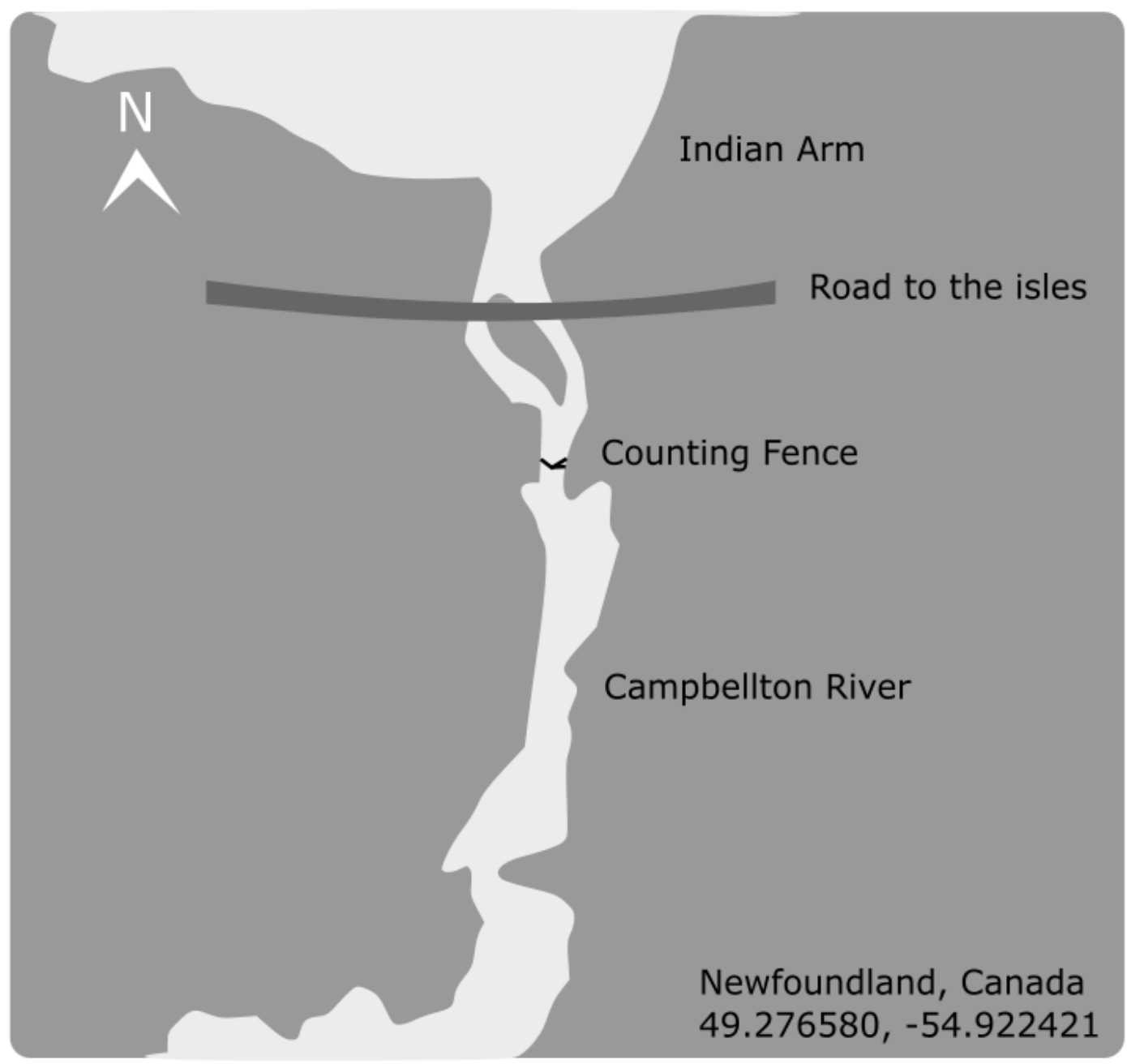

Figure 2.1 Map of the experimental area used to investigate migrations of Atlantic salmon (Salmo salar) in the Campbellton River, Newfoundland. Salmon were captured in the counting fence trap on July 8 and 9, experimented, tagged, and released below the trap on July 9 and 10, and monitored within the arena by radio telemetry for one week and at counting fence trap until September 6, 2016. 


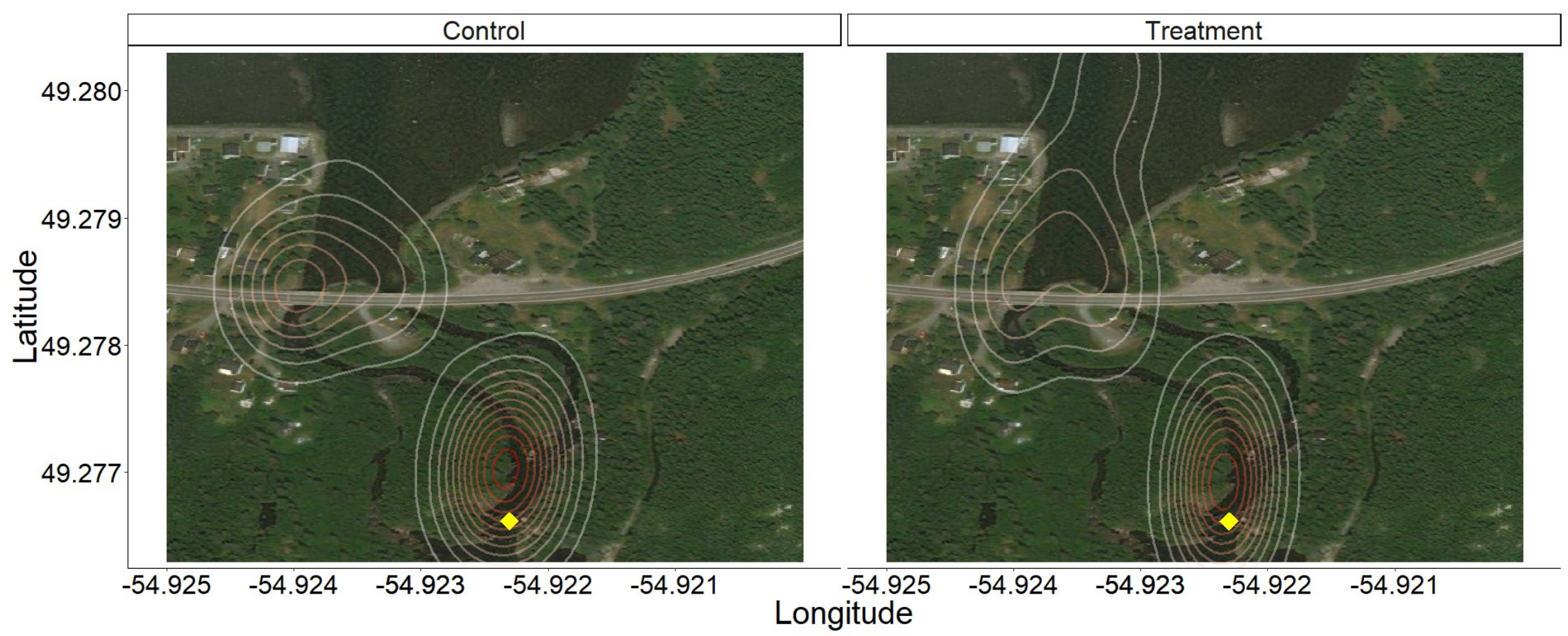

Figure 2.2 Radio tracking positions of Atlantic salmon (Salmo salar) tagged and released (yellow point) in the Campbellton River, Newfoundland. Density contours indicate the relative distribution of Atlantic salmon based on radio positions for control and treatment group salmon with higher density indicated by red rings. Note that most detections were recorded in the pool directly above the counting 
fence above the island. Most other detections were recorded at the confluence of the two branches of the river on either side of the island below the highway bridge. 

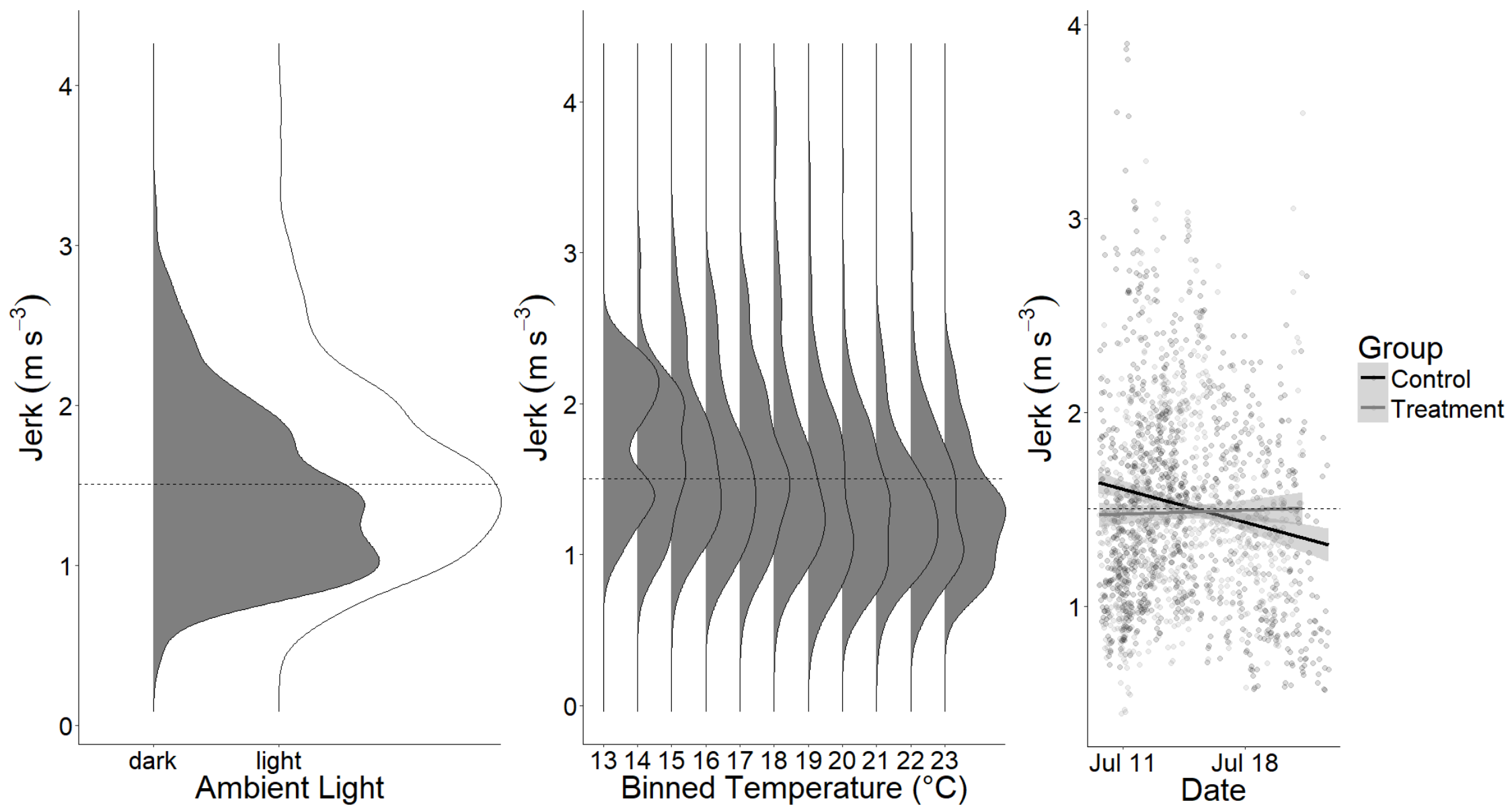

Figure 2.3 Summary plots describing activity of Atlantic salmon tagged and released in the Campbellton River, Newfoundland, Canada. Jerk is a composite metric summarizing activity based on axes of tri-axial accelerometer loggers. The pre-specified model tested whether ambient light (left panel), temperature (central panel), time, treatment group, and the interaction between treatment group and time (right 
panel) affected the activity of salmon in units of jerk. The final model incorporating an exponential correlation structure by time nested within individual $(\mathrm{N}=13)$ suggested no effect of ambient light but a weak effect of treatment $(\mathrm{P}=0.08)$, treatment $\times$ time interaction $(\mathrm{P}=0.08)$, and a significant effect of temperature $(\mathrm{P}=0.001)$ on salmon activity. Dashed horizontal lines indicate the mean value of jerk throughout the study (1.51). 


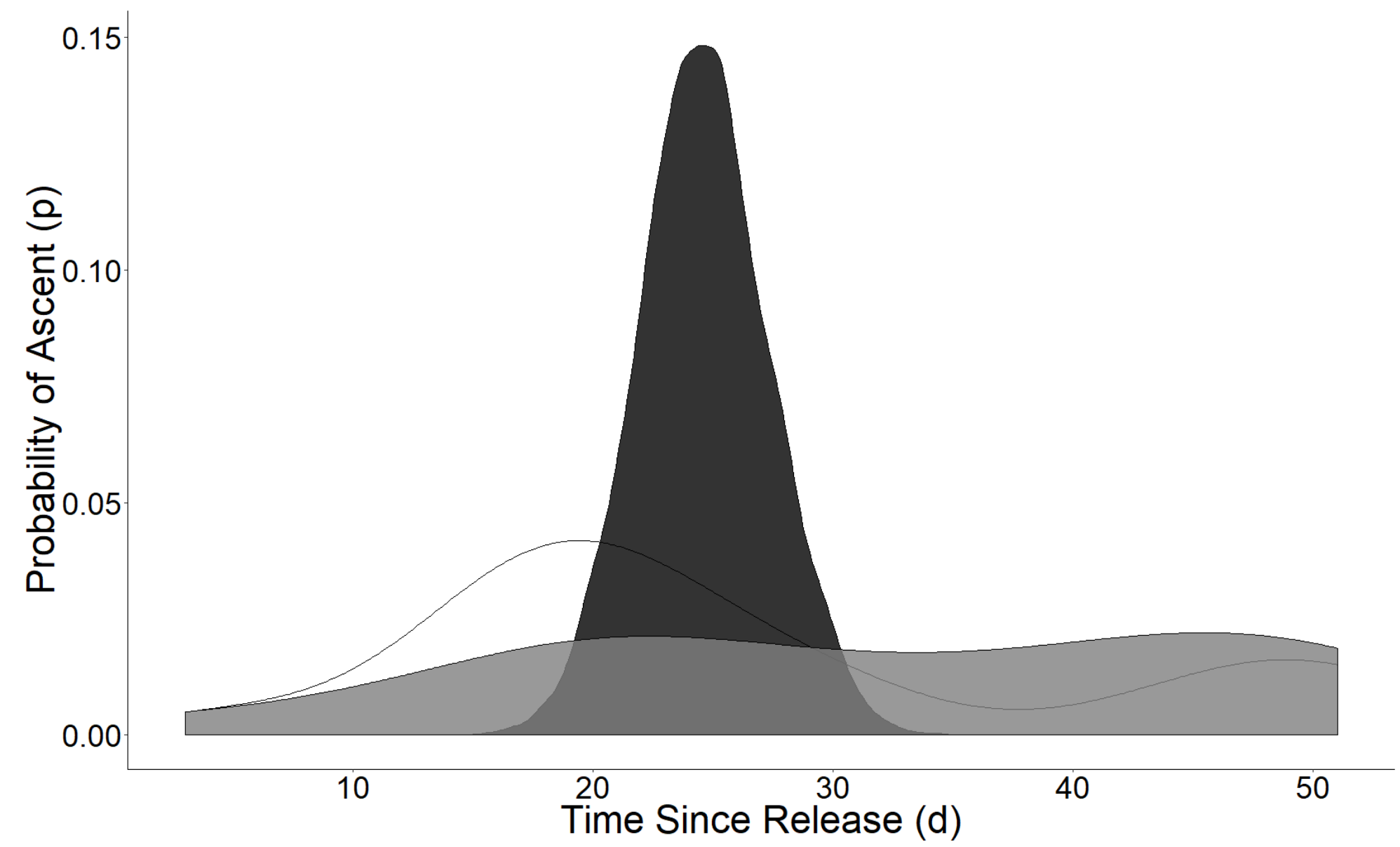

Group

Control

Simulated

Treatment

Figure 2.4 Density plot displaying the most probable mean time to return after release (black) for 34 Atlantic salmon (Salmo salar) tagged and released from experimentation in the Campbellton River, Newfoundland. The simulated distribution of the most probable number of days to return to the fence was generated by assigning daily probabilities of tagged salmon to return on a given day equal to 
the proportion of untagged salmon trapped at the fish counting fence on that day. The area under the white curve indicates the observed distribution of days elapsed before returning for control salmon $(\mathrm{P}=0.24)$ and the area under the grey curve represents treatment $(\mathrm{P}<$ 0.01) salmon. 


\section{$\underline{\text { 2.6 Discussion }}$}

The combined approach of biologging (accelerometers) and biotelemetry (radio transmitters) provided a unique opportunity to track the progress of an animal along its migration in an experimental setting, investigating responses to a stressor using a finescale investigation of activity and coarse-scale observations of progress. I used this opportunity to test the impacts of a generalized stressor that mimicked an encounter with a fishery, which I used to interpret the effects of exercise and exhaustion on migration. The findings suggest that this species is relatively tolerant to the stressor. Mortality of individuals exposed to the treatment was low (4-13\%) and appeared similar for the treatment and control group fish. Fine scale activity (jerk) for both control and treatment animals in the days following release was similar and stable and did not change significantly over time; however, there was a significant effect of temperature on hourly activity rates for both treatment and control fish. Although there was no difference in fine-scale activity between treatment and control groups, run timing of treated salmon was significantly delayed compared to predicted dates such that the broad-scale effects to migration were not reflected in jerk activity, suggesting that findings manifested at the coarse-scale were not reflected by fine-scale changes to activity levels after release.

Temperature is an established driver of physiology and behaviour (Brett 1971; Fry 1971). The influence of temperature has been extensively studied for fish and particularly for Atlantic salmon, revealing that temperature can delay upriver migration (Baisez et al. 2011), influence post-release mortality in fisheries (Dempson et al. 2002; Gale et al. 2013; Chapter 6), influence the ascent of fishways (Booth et al. 1997; Gowans 
et al. 1999), and vary the timing of spawning (Heggberget 1988). Here, I found that temperature was the only significant predictor of jerk-derived activity index in Atlantic salmon, which was otherwise independent of time, treatment group, and ambient light. Frechette et al. (In Press) showed that this species uses behavioural thermoregulation to buffer exposure to potentially stressful temperatures during the migration. Furthermore, Chapter 7 establishes an exponential relationship between the rate of oxygen consumption and water temperature for Atlantic salmon at slow swimming speeds in the Norwegian river Lakselva; a reduction in activity at higher temperatures is therefore a logical behavioural response to reduce energy expenditure at high temperatures. Elsewhere, studies suggest that Atlantic salmon upriver migration is negatively related to temperature (Erkinaro et al. 1999; Karppinen et al. 2004). Climate change effects that increase freshwater temperatures could be expected to prolong Atlantic salmon migration owing to delays associated with high temperature (Baisez et al. 2011).

Other factors considered in the model, specifically treatment, time post-release, and diel period, were not significant. I predicted that activity may increase at night given that several studies have shown that migration activity is predominantly nocturnal (reviewed in Thorstad et al. 2008). Although patterns in the data were suggestive of diel effects, I found no effect of darkness on activity. Instead, activity was significantly related to water temperature, which peaks during the day but cools at night, yielding the patterns in the data I observed. There was weak evidence for a treatment effect and a treatment $\times$ time interaction. A significant interaction would have been interpreted as evidence that treatment affected the rate of change of activity, or recovery from the treatment. The relatively brief bout of exercise that treatment animals were exposed to 
may have not been extreme enough to calculate the time to recovery from the salmon acceleration data. This is a limitation of the method used because I chased the fish in experimental tanks until they were unwilling to continue. In fisheries, fish may not fight continuously and may make use of currents to cause resistance against the angler and the flow may also facilitate reoxygenation of tissues during the fight, allowing longer times to exhaustion. Compared to swim tunnels, manual chasing allows the fish to stop intermittently when it becomes acclimated to the chase. I also used a relatively brief air exposure interval that would approximate best practices for handling exhausted salmon (Cooke et al. 2015). Longer intervals would have increased impairment and mortality and may have provided a more pronounced signal of recovery. Even without evidence of impairment in fine-scale activity from the accelerometers, the coarse-scale investigation revealed that the treated salmon were delayed in resuming upriver migration through the experimental area based on timing of return to the fence.

Radio tracking revealed that the salmon that I released exhibited fallback. Even though I released salmon directly below the counting fence, many salmon were tracked below the island at the river mouth and several ostensibly re-entered the ocean because I could no longer detect them with radio telemetry. Salmon early in the migration can probably transition relatively easily between salt and freshwater and Thorstad et al. (2005) observed salmon moving more than $14 \mathrm{~km}$ downriver to enter the sea during a pollution event in the river Numedalslågen. Temperatures experienced by the salmon that returned to marine waters would have been lower than in the river, which could prolong recovery. Wilkie et al. (1997), examined re-synthesis of the primary anaerobic substrate glycogen, clearance of the anaerobic by-product lactate, and correction of muscular $\mathrm{pH}$ in 
exercised Atlantic salmon and found it was slower at $12^{\circ} \mathrm{C}$ than $18^{\circ} \mathrm{C}$. Cooler temperatures experienced by salmon that returned to sea would mean an overestimation of the temperature experienced in the regression model that was based on river temperature. Fallback from the release point as observed in this study is a commonly reported consequence of disturbances encountered by upriver migrants (Frank et al. 2009) and has been observed following various fisheries stressors for Atlantic salmon (Mäkinen et al. 2000; Havn et al. 2015). Mäkinen et al. (2000) suggested that more extreme stressors (gill netting compared to recreational angling) can increase the extent of Atlantic salmon fallback. Fallback may be either a mechanism driving delays or truncations in migration that have been observed for angled salmon (see Tufts 2000; Lennox et al. 2015 [Appendix B], Chapter 3) and perhaps a symptom of the underlying physiological disturbance leading to those observations.

Behaviour is a relevant metric to explore animal responses to stressors but the scale of investigation must ideally be matched to the expected response (Schreck 1990; Schreck et al. 1997; Sopinka et al. 2016). Accelerometers provide information about instrumented animals that is fine in temporal and spatial scales and can be effectively applied to observe small changes in individual movement or activity. Within 4-5 mins of release, Brownscombe et al. (2013) observed bonefish (Albula vulpes) swimming slowly $\left(<2\right.$ tailbeats $\left.\mathrm{s}^{-1}\right)$ or resting but swimming faster $\left(>3\right.$ tailbeats $\left.\mathrm{s}^{-1}\right)$ after release if placed in a recovery bag for $15 \mathrm{~min}$. Whitney et al. (2016) used accelerometer data to calculate a $10.5 \mathrm{~h}$ (mean) recovery period for angled blacktip sharks (Carcharhinus limbatus). After 2-5 h, Broell et al. (2016) observed a cessation of resting in shortnose sturgeon (Acipenser brevirostrum). In freshwater turtles (Sternotherus odoratus, Chrysemys picta), 
Gutowsky et al. (2017) found it took $2 \mathrm{~h}$ to recover from $4 \mathrm{~h}$ confinement in a commercial fishing net from depth, temperature, and acceleration data on biologgers. This example used jerk, which has previously been applied for investigating animal behaviours (e.g. Simon et al. 2012; Ydesen et al. 2014) and provides a simple summary of tri-axial movement of instrumented animals. The modelling may have suffered from survivor bias, insofar as I was unable to recover all the accelerometer tags owing to unforeseen issues with tag retention. Although external tagging of migratory salmon is common (e.g. Thorstad et al. 2000), the accelerometer tag package was somewhat less streamlined than tags used in recent studies (reviewed in Jepsen et al. 2015) such that there was presumably moderate drag which put pressure on the tag package when they were exposed to high flows. External tags are not intended for long-term tracking given the expectation that they will eventually fall off (Jepsen et al. 2015) but that occurred at an accelerated pace in this study (days not months). Although nearly all the salmon returned to the fence, the inability to recover some tags may have meant that the subsample was biased in some way, for example by only being able to consider fish that remained close to the counting fence after release. Nonetheless I provide some of the best short-term and fine-scale evidence for impacts of stressors on fish swimming in rivers. Further research combining physiological methods of assessing recovery with these behavioural metrics will provide robust insight into recovery from stressors.

Interpretation of the ultimate costs associated with the treatment and the fate of salmon following delayed migration is somewhat difficult. Total survival was high (87$96 \%$ ) and aligns with $93 \%$ post-release survival predicted in Chapter 6 in a composite analysis of Atlantic salmon recreational fishing studies, including Havn et al. (2015) in 
which water temperatures were similarly high $\left(86 \%\right.$ survival at $\left.18-21^{\circ} \mathrm{C}\right)$. Radio tracking allowed us to determine that mortality occured relatively soon after release (similar to the results of Havn et al. 2015), although the final fate of two of the salmon was never determined. Both salmon that disappeared before the end of the study period were tracked on multiple days in multiple locations including upriver movements after release, therefore they would not have been considered mortalities based on the criteria typically used in catch-and-release studies, in which upriver movement after release was interpreted as evidence of survival (Thorstad et al. 2003; Havn et al. 2015; Lennox et al. 2015 [Appendix B]). Reproductive success of this age class of fish, one sea winter (i.e. grilse), in the Escoumins River, Quebec, Canada was found to be highly dependent on run timing, with early arrival at spawning grounds contributing to higher realized reproductive output (Richard et al. 2013), meaning that delays in migration as observed in this study may affect fitness. It is uncertain whether early arrival affects salmon reproductive success (Tentelier et al. 2016), but if prior residence is important for Atlantic salmon to access high quality substrate, then delays caused by fisheries could impose a substantial cost by offsetting the benefits of abandoning feeding opportunities at sea for early river entry. Although delays caused by stressors could result in directional selection, potential fisheries-induced evolution away from early run timing phenotypes is most likely to be relevant for populations with substantial harvests where early return fish tend to be both larger and more sought after (Consuegra et al. 2005; Pérez et al. 2005).

Evidently, salmon can recover from non-lethal disturbance and continue their migration. In this study, the effect of experimental exhaustive swimming stress only manifested itself in delayed migration and not in finer scale measures of activity (see also 
Lennox et al. In Press, b [Appendix D]). Increasingly, Atlantic salmon can probably be viewed as a species that is tolerant to a suite of stressors during their upriver migration, but that are highly sensitive to temperature. I found that salmon activity was significantly related to water temperature on a fine-scale, which assists in understanding broad-scale observations of salmon migration behaviour in other studies that have identified an effect of temperature on movement rates, migration speed, and fish passage (Alabaster 1990; Erkinaro et al. 1999; Gowans et al. 1999; Karppinen et al. 2004). Increasing temperatures consequently have broad effects on salmon migration that require further investigation (Chapter 7). Ultimately, exposure to acute stressors such as catch-and-release fisheries does not appear to impose substantial fitness costs to migrating salmon, and management tools such as live release can be viewed as viable options to balance the value of fisheries sectors with the conservation of species. 


\section{Chapter 3 Use of simulation approaches to evaluate the consequences of catch-and- release angling on the migration behaviour of adult Atlantic salmon (Salmo salar)}

\section{$\underline{3.1 \text { Abstract }}$}

Many maturing anadromous Atlantic salmon encounter recreational anglers upon returning to freshwater. Economically and culturally important salmon fisheries include catch-andrelease as a management tool to maintain spawning escapement given that most salmon released by anglers survive ( $97 \%$ in this study). However, sublethal alterations to behaviour with associated costs to individual fitness potential are recognized as an important consideration when releasing fish alive. For this study, 39 salmon were captured by recreational anglers, externally tagged with radio transmitters, and released. Seven of the salmon were recaptured and harvested, one died after catch-and-release, and one exited the river. Data from the annual visual drift count of spawning salmon were used to calculate the probability of untagged spawning in each pool of the river and input into simulation models to predict most likely upriver movement of the tagged salmon following release. Ten thousand simulation steps selected a spawning pool for the tagged salmon, permitting a calculation of the average expected movement by salmon for comparison to the average movement observed by radio tracking. The average observed movement by the released salmon was significantly less than the average expected movement generated by all three

models, indicating that live release had shortened the migration distance of the Atlantic salmon. Given that recreational anglers can capture a large percentage of migrating 
salmonids, management may aim to ensure sufficient escapement of uncaptured fish to ensure an even distribution of Atlantic salmon in their spawning rivers.

\subsection{Introduction}

Atlantic salmon migration in freshwater incorporates multiple phases of activity including active upriver movement, holding, and searching with upstream and downstream movements before staging near the eventual spawning destination, weeks or months in advance of spawning (Økland et al. 2001). Atlantic salmon are philopatric with most individuals able to locate their natal rivers (Fleming 1996) and even specific tributaries within a system (Heggberget et al. 1986; Verspoor et al. 1991). The timing and speed of migration by Atlantic salmon through freshwater depends on a variety of factors, including sex (Lucas et al. 1993), size (Kristinsson et al. 2015), and experience (Niemelä et al. 2006a, b). However, anthropogenic challenges including pollution (Thorstad et al. 2005), artificial barriers (Croze 2008), and climate change (Baisez et al. 2011) alter migratory patterns exhibited by salmon. In addition, recreational fishery practices such as catch-and-release have the potential to influence the migratory behaviour of salmon in rivers.

Recreational fisheries are popular worldwide and can be important components of the economy for many communities (Arlinghaus and Cooke 2009). The sustainability of recreational fisheries, however, depends on the ability of the targeted fish population to persist despite harvest and non-harvest mortality imposed by angling activities (Coggins et al. 2007; Cooke and Schramm 2007). Traditionally, many recreational anglers 
harvested their catch; however, catch-and-release is now increasing in many fisheries. From a regulatory perspective, catch-and-release focuses on maintaining the socioeconomic benefits of fisheries while sustaining fish populations that are being exploited. As a result, catch-and-release practices assume that fish released by anglers survive with limited sublethal consequences to their lifetime reproductive success (Arlinghaus et al. 2007; Wilson et al. 2014). Catch-and-release is increasingly practiced in recreational salmon fisheries but scientific evaluations of catch-and-release for salmon have focused on demonstrating that mortality for caught and released fish is infrequent $(<0.10$; Thorstad et al. 2003; Richard et al. 2013, 2014; Gargan et al. 2015). However, mortality studies alone probably underestimate the impacts of catch-and-release because they do not consider sublethal effects (Cooke et al. 2002). Sublethal effects occur because of aerobic debt (Kieffer 2000; Lee et al. 2003a, b), metabolic disturbance (Wood et al. 1983), physiological stress (Pankhurst 2011), and exhaustion induced by angling. Prolonged recovery can result in behavioural impairment, causing significant indirect and direct impairments to potential fitness, such as reduced growth or fecundity (Cooke et al. 2002; Wilson et al. 2014). Sublethal effects of fisheries interactions can be difficult to measure because equating a capture event to fitness is challenging. However, migrating salmonids provide a useful model for identifying sublethal effects of angling because the upriver migration towards spawning grounds might reflect fitness (Dingle 1980).

There is correlative evidence that angling alters migration patterns of Atlantic salmon. Two documented alterations to migratory patterns that have been observed for Atlantic salmon released by anglers are downriver movement from the release site (Mäkinen et al. 2000; Thorstad et al. 2003; Havn et al. 2015) and shortened migration 
distance (Tufts et al. 2000; Lennox et al. 2015 [Appendix B]). However, the extent to which catch-and-release causes significant changes to an individual's migration is not quantified. Determining whether migration is negatively affected by angling requires an estimate of where salmon would spawn if they were not captured by anglers. Yet, it is difficult to know where salmon are destined to spawn in the river prior to the spawning period itself, necessitating the development of a novel tool using a simulation of the spawning distribution of non-angled fish within the river as a proxy for the ultimate distribution of released fish at spawning time. This information provides a natural baseline against which hypotheses regarding the impacts of catch-and-release can be tested. To do so, I compared the observed movement of salmon against null modelpredicted movement.

\section{$\underline{3.3 \text { Methods }}$}

\subsubsection{Study Area}

River Lakselva is a $45 \mathrm{~km}$ long river that drains into the Porsangerfjord in Porsanger, Finnmark, Norway. The confluence of Lakselva with the fjord is at 70.078757 $\mathrm{N}, 24.926302 \mathrm{E}$. Lakselva is a large, unregulated river with one major tributary (Vuolajohka) and two large lakes (Figure 3.1). Atlantic salmon enter Lakselva during the spring and summer and spawn in Lakselva and Vuolajohka in October. The recreational fishery is regulated by the Lakselva Landowner's Association, which limits access to most of the fishery via a licensing system. There are also reaches of river where angling 
is regulated by single landowners or local businesses. The annual salmon fishing season in Lakselva begins June 1 and continues through August 31 followed by surveillance angling to enumerate fish of wild or farmed origin in September and October.

\subsubsection{Tagging}

Historical catch records indicate that few salmon enter this river in June; therefore, I focused the tagging efforts between July 13 and August 28, 2014. Salmon selected for tagging $(\mathrm{N}=39)$ were those that were typical of caught-and-released fish (i.e. not moribund see Lennox et al. 2015 [Appendix B]). After being landed by an angler, salmon were transferred to a water-filled tube where they were placed in a prone position. The individual was measured and a radio transmitter in the frequency range $142.114-$ 142.213 (Advanced Telemetry Systems [ATS], Minnesota, USA) was attached externally below the dorsal fin. The tagging methods followed Lennox et al. (2015 [Appendix B]), using sterile hypodermic needles and stainless-steel wire to secure the radio tag through the dorsal musculature. Anglers that captured salmon handled them naturally and I did not attempt to interfere with their fish handling (e.g. by telling them to use a net, not to air expose the fish too long, etc.). However, I declined to tag two angled salmon; one salmon was critically injured (hooked in gills) and the other was too small to support the tag comfortably. In total, 39 Atlantic salmon $(89 \pm 16 \mathrm{~cm}$ TL, range: $62-121 \mathrm{~cm})$ captured by anglers were radio tagged and released. Many $(\mathrm{N}=18)$ of the salmon were caught and released in pools relatively close to the head of the tide and most $(\mathrm{N}=26)$ were fresh fish based on their silver colour and/ or the presence of salmon lice. Mean 
water temperature at capture was $14 \pm 1^{\circ} \mathrm{C}$. All handling and tagging were conducted according to Norwegian regulations for treatment and welfare of animals.

\subsubsection{Tracking}

To ensure complete coverage of the watershed, four stationary data logging stations were installed at key points in the river to monitor passage of salmon. Data logging receivers (Advanced Telemetry Systems [ATS], Minnesota, USA; R4520CD Coded Receiver-Datalogger) were established with paired Lotek (Newmarket, Canada; 6 element Yagi tuned to $142 \mathrm{MHz}$ ) antennas (one pointing upriver and one pointing downriver) to establish directionality of movement by salmon past the receiver. The stations were installed above and below each of the lakes and near the mouth of the tributary Vuolajohka (Figure 3.1). The listening stations were checked biweekly and were active throughout the summer and into the autumn. In addition to the stationary logging stations, mobile tracking was conducted along the river using a vehicle mounted receiver and a magnetic whip antenna (Magnetic Roof-Mount Dipole, Laird Technologies, Missouri, USA). Salmon positions were determined on alternating days starting on July 14 and continuing through the end of the angling season on August 31, 2014. During the autumn, positioning occurred on September 2, September 15, September 24, and October 24. I used the salmon's position on September 24 as an estimate of the spawning position in the river. On September 24-25, a snorkel survey was conducted in conjunction with radio tracking to visually confirm survival of some salmon with nominal movement after release. 


\subsubsection{Drift Count}

The Landowner's Association conducts an annual visual count of the Atlantic salmon population to estimate the total number of fish in the river. The count is conducted by two experienced persons who drift passively downriver while snorkeling. For each section of the river (typically delineated by pools), the number of spawning salmon is estimated based on these visual observations. Although drift counts are considered underestimates of the total number of salmon, Orell and Erkinaro (2007) found that they provided accurate indices of spawning biomass during the salmon spawning season. In 2015, the drift count in Lakselva was conducted on September 1314, and spawning was observed to have commenced (E. Liberg, personal communication). Staff were aware, and noted the presence of, tagged salmon based on visual identification of the external radio tags. I collected drift count data from Lakselva for 2011, 2013, 2014, and 2015.

\subsubsection{Data Analysis}

Each pool in the drift count was assigned a number with the pool closest to the fjord being Pool 1 and the pool farthest upriver being number 57 (Figure 3.1). Pools that could not have salmon counted by divers due to poor visibility were assigned zero salmon for the purposes of analysis. The release and spawning pools (the latter being inferred from the position of the salmon in the river on September 24) were compared to assess 
the movement of salmon released by anglers. The analyses could be conducted on 30 of the 39 tagged salmon because one died, one exited the river, and seven were recaptured and killed by anglers prior to spawning season. I calculated the correlation coefficient of the relationship between the salmon's release and spawning pools. To test whether catchand-release affected the movement of salmon within the river, a series of simulations was conducted to create a distribution of the most probable average movement of salmon from the release site under the null hypothesis of no effect of catch-and-release.

The simulation tests were implemented as follows: each pool was assigned a probability that a salmon would spawn there based on the proportion of salmon observed spawning there by the drift count. These pool probabilities were calculated and applied to each of the 30 radio-tagged salmon with the apply function in R (R Core Team 2014). A single simulation step was implemented using the sample function in $\mathrm{R}$, which selected a spawning pool for each salmon based on the assigned probabilities, permitting a calculation of expected movement by subtracting the number of the release pool from the number of the simulated spawning pool. For example, a fish captured and released in Pool 1 could be assigned Pool 10 as a spawning pool in a simulation step, equating to an expected movement of nine pools. Averaging the expected movement among the 30 salmon and repeating the simulation 10,000 times, a probability distribution was generated that described the average expected movement of salmon from the site of their release to spawn. The average expected movement was then compared to the average observed movement of the 30 radio-tracked salmon. The p-value of the test described the probability that the average observed movement differed from the average expected movement. I conducted three simulations each using different assumptions (described 
below) and generating different null models. All null models assumed that there was no impact of being caught and released on a salmon's movement.

Finally, I present data from the drift count in Lakselva for 2011, 2013, 2014, and 2015 to assess temporal stability in the distribution of spawning salmon within the river. I used violin plots as implemented by ggplot2 (Wickham 2009), which illustrate the density of spawners along the length axis of the river. To test for differences in the average spawning position across years I used a Kruskal-Wallis non-parametric analysis of variance.

\subsubsection{Free distribution}

In the first simulation, radio-tagged salmon were assumed in the null model to distribute anywhere in the river to spawn, independently of where they were caught and released. The probability of choosing a given spawning pool was estimated as the proportion of the total number of spawners in the river observed in this pool during the drift count. This corresponds to an assumption that salmon freely distribute in a river and concentrate in some areas, presumably of high quality or quantity spawning substrate. Although it is known that salmon are positively rheotactic and migrate primarily upriver to spawning sites, this simulation assumed that no matter where salmon were captured, they could in theory move up or down independent of the release location by maintaining equal spawning pool probabilities for all salmon. 


\subsubsection{Salmon only move upriver}

In the second simulation, spawning pool probabilities were adjusted based on the release pool for each radio-tagged salmon such that any pools downriver of the release pool had zero probability of salmon spawning there and upriver pool spawning probabilities were adjusted accordingly for each fish.

\subsubsection{Most salmon move upriver}

The third simulation was identical to the second, with the exception that it excluded salmon that spawned at or below the release site. This restricted the simulation to 15 salmon that spawned at least one pool upriver from the release location. Fifteen salmon that spawned at or below the release pool were excluded under the assumption that these fish were captured after completing their migration whereas the other 15 were ostensibly captured during their upriver migration.

\section{$\underline{3.4 \text { Results }}$}

\subsubsection{Catch-and-release}

Only one of the 39 tagged salmon is known to have died. This occurred soon after release and its drifting carcass was observed by an angler downriver of the release site hours later (E. Liberg, pers. comm.). Therefore, survival from catch-and-release was high 
( $97 \%$ of released fish). Total mortality $(\mathrm{N}=2)$ from catch-and-release angling was $95 \%$ (total $\mathrm{N}=40$ ) after including one moribund salmon that was not released because of bleeding. One tagged salmon exited from the river in August and did not return; the individual was a grilse (i.e. one-sea-winter salmon) that had exhibited unexpected up- and down-stream behaviour after release, first moving upriver within hours of release and eventually moving downriver two kilometres below the initial release site prior to exiting in August, several weeks before the spawning period. Given the movement trajectory of that salmon, it was inferred that it had survived catch-and-release and exited the river voluntarily, possibly to spawn in a different river. Nine salmon (23\%) were reported as having been recaptured by anglers later in the angling season, with seven of them being harvested and two re-released. One of the seven harvested salmon was recaptured twice before being killed. Two tagged salmon that were captured multiple times remained in the river through the spawning season. One of the recaptured salmon was angled as a kelt the year after tagging on June 20, 2015.

\subsubsection{Spawning distribution of catch-and-release salmon}

There was a strong positive correlation between the catch-and-release location and the final spawning position $\left(\mathrm{R}^{2}=0.74\right.$ Figure 3.2$)$. During the spawning period, all the salmon that were present in the river were in regions of the river known to be spawning locations. In addition, 20 (71\%) of the tagged salmon were visually identified in spawning aggregations during the drift count. The Lakselva Landowners' Association counted 1341 salmon spawning in the main stem of Lakselva during the autumn 
spawning count in 2014. The drift count was conducted in 72 pools in the river, which I summarized into 57 pools for analysis based on the locations of pools in the river and counts from previous seasons for the purposes of continuity. According to the drift count, most of salmon spawned below the lakes, with only ten salmon counted above Øvrevatnet. However, there were some areas in the river that were too murky for the counting staff to conduct the count in, making some areas of the river appear depauperate in the count. Most notably, sections of the river between Øvrevatnet and Nedrevatnet were not counted due to poor visibility, nor was the tributary Vuolajohka. Given that these regions were upstream of where all the tagged salmon spawned, I suggest that this would not affect the results.

\subsubsection{Simulation tests}

\subsubsection{Free distribution}

When the simulation permitted salmon to distribute themselves anywhere within the river to spawn, salmon were predicted to move on average seven pools upriver from the catch-and-release site (Figure 3.3). A theoretical 30 salmon released in the given pools (Table 3.1) would therefore move on average seven pools per individual toward spawning grounds if they were assumed to freely distribute themselves as the untagged fish in the river did. This was mostly because most of radio-tagged fish were captured in lower reaches of the river and would therefore be most likely to move upriver where most of the salmon were counted during the drift count. Based on fish positions from tracking 
data from September, the tagged salmon moved on average only two pools upriver from the release site, significantly less than expected based on the free distribution hypothesis $(\mathrm{P}=0.03)$

\subsubsection{Salmon only move upriver}

When salmon in this null model were restricted from backtracking to downriver spawning grounds, the simulation indicated that salmon should move on average 20 pools upriver following release. Many fish were captured in the lower parts of the river and would therefore be highly likely to migrate to middle or upper reaches for spawning where the large numbers of untagged fish were found during the visual counts. However, as noted above, the radio-tracked fish showed limited movement. In this simulation, where downstream movements were discounted and assigned 0 values, the average movement was two pools per individual, again a highly significant difference from the model's prediction $(\mathrm{P}=0.00$; Figure 3.3).

\subsubsection{Most salmon move upriver}

When the second simulation was repeated excluding all salmon that showed any downriver movements, the simulation reduced the predicted movement per fish to only 10 pools upriver per individual. Observed movement was six pools per individual, still a highly significant difference compared to the model's expected movement $(p=0.01$;

Figure 3.3). 


\subsubsection{Seasonal differences in drift count observations}

The average spawning pools in Lakselva were $30(2011 ; \mathrm{N}=849), 25(2013 ; \mathrm{N}=$ 1254), $21(2014 ; \mathrm{N}=1337)$, and $26(2015 ; \mathrm{N}=832)$. I observed some temporal inconsistency in the distribution of spawning salmon within Lakselva (Figure 3.4). Indeed, there was a significant difference in the distribution of spawners across years $\left(\chi^{2}\right.$ $=250.22, \mathrm{df}=3, \mathrm{P}<0.01)$. However, visual analysis (Figure 3.4) revealed consistent shapes in the distribution of spawning salmon and indicated that most of spawning salmon are consistently below Pool 49, which was the last pool prior to the first lake, Nedrevatnet (Figure 3.1). Moreover, most salmon in the river spawned in pools in the middle of the anadromous stretch of the river. 


\subsection{Tables}

Table 3.1 Individual data on the radio tagged salmon in the Lakselva River, Norway. Thirty-nine salmon were captured between July 13 and August 28, 2014, eight of which were recaptured later in the migration, one of which disappeared, and one of which died. One of the recaptured salmon was re-released and remained in the river for spawning. The spawning pool was determined by radio tracking in the fall during the spawning season and the net movement is the number of pools.

\begin{tabular}{|c|c|c|c|c|c|}
\hline Capture Date & Total Length (cm) & Fate & Release Pool & Spawning Pool & $\begin{array}{l}\text { Net Movement } \\
\text { (\# of pools) }\end{array}$ \\
\hline July 13 & 73 & Survived to Spawn & 7 & 18 & 11 \\
\hline July 14 & 97 & Recaptured & & & \\
\hline July 15 & 98 & Recaptured & & & \\
\hline July 16 & 91 & Recaptured & & & \\
\hline July 16 & 90 & Survived to Spawn & 21 & 27 & 6 \\
\hline July 17 & 95 & Survived to Spawn & 1 & 1 & 0 \\
\hline July 17 & 80 & Recaptured & & & \\
\hline
\end{tabular}




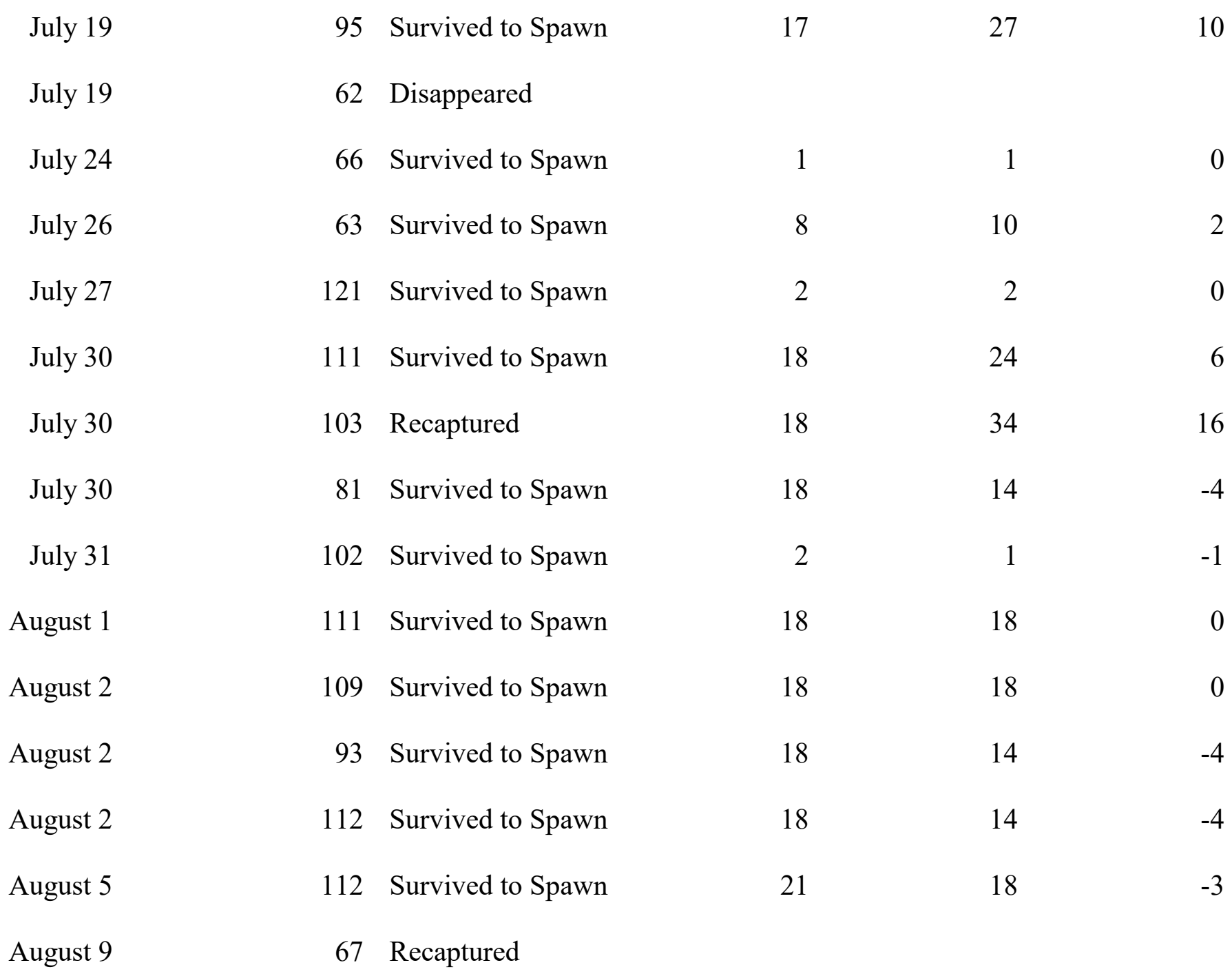




\begin{tabular}{|c|c|c|c|c|c|}
\hline August 9 & 90 & Died & & & \\
\hline August 10 & 64 & Survived to Spawn & 1 & 3 & 2 \\
\hline August 10 & 94 & Survived to Spawn & 1 & 2 & 1 \\
\hline August 12 & 94 & Survived to Spawn & 2 & 3 & 1 \\
\hline August 13 & 99 & Survived to Spawn & 2 & 10 & 8 \\
\hline August 13 & 69 & Survived to Spawn & 14 & 20 & 6 \\
\hline August 14 & 69 & Survived to Spawn & 1 & 2 & 1 \\
\hline August 14 & 84 & Recaptured & 1 & 13 & 12 \\
\hline August 14 & 91 & Survived to Spawn & 27 & 21 & -6 \\
\hline August 15 & 76 & Recaptured & & & \\
\hline August 15 & 89 & Survived to Spawn & 27 & 27 & 0 \\
\hline August 16 & 101 & Survived to Spawn & 21 & 24 & 3 \\
\hline August 17 & 102 & Recaptured & & & \\
\hline August 17 & 112 & Survived to Spawn & 2 & 2 & 0 \\
\hline August 20 & 83 & Survived to Spawn & 21 & 27 & 6 \\
\hline
\end{tabular}


August 24

August 28
77 Survived to Spawn

21

66 Survived to Spawn 


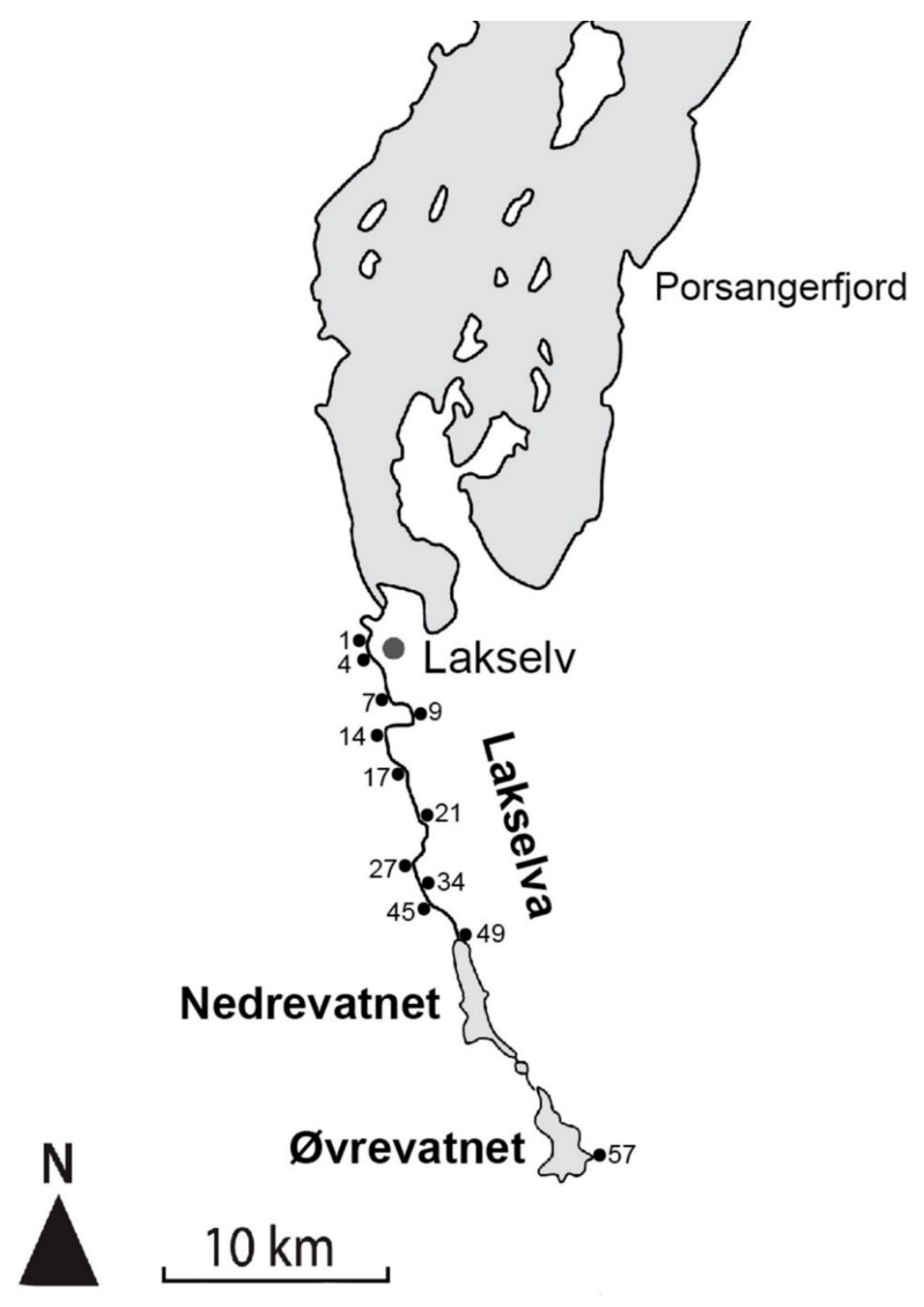

Figure 3.1 Lakselva in Porsanger, Finnmark, Norway. The river incorporates two major lakes, Øvrevatnet and Nedrevatnet. Atlantic salmon return to the river from the ocean through the Porsangerfjord throughout the summer and migrate upriver to spawning grounds. For this study, salmon released by anglers were tagged at various points in the river. Note that the river flows south to north. 


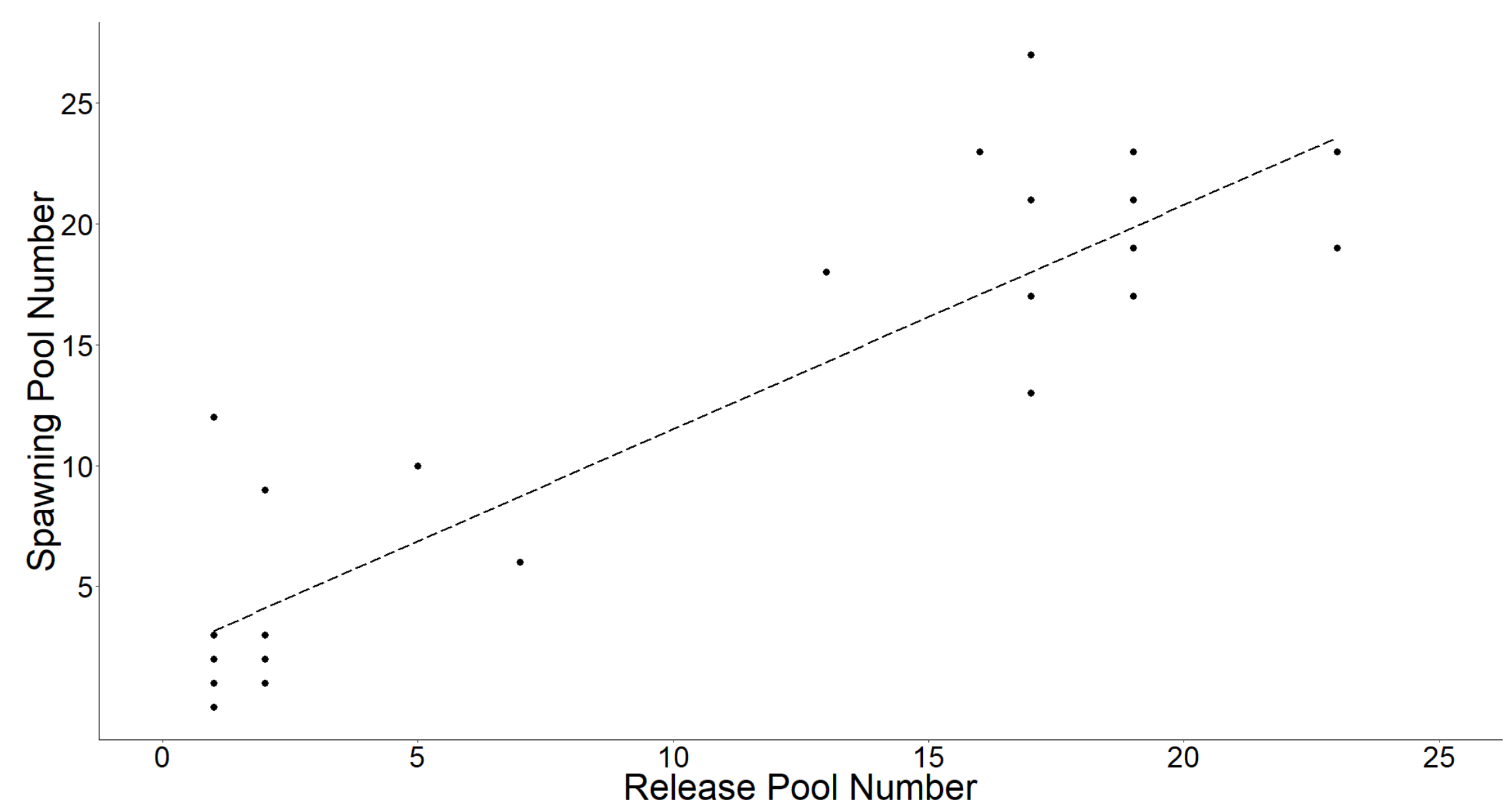

Figure 3.2 Relationship between the release location and spawning position of 30 salmon released by anglers. Discrete spawning pools 
are assigned based on locations where spawning counts occurred in September 2014. The dashed line indicates a 1:1 relationship between release pool and spawning pool (i.e. no upriver movement). Points are jittered to reduce overlap. $\mathrm{R}^{2}=0.74$. 

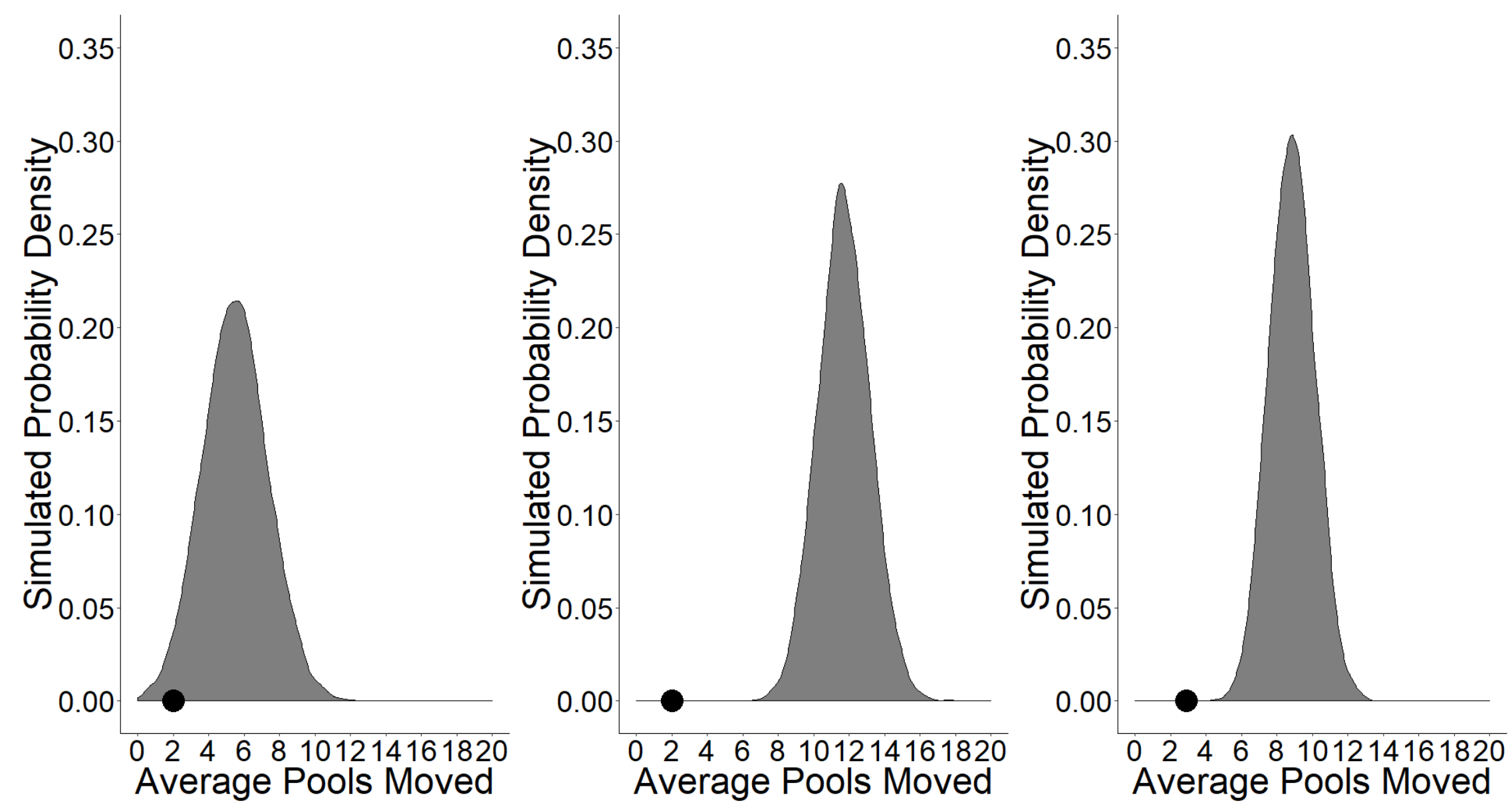

Figure 3.3 Simulated test statistic distributions for the mean number of pools moved for Atlantic salmon under alternative null hypothesis of no effect of catch-and-release on post release movements and final choice of spawning pool. The black circles indicate the observed mean number of pools moved from the release location to the spawning location among the tagged salmon and the grey distributions 
are the results of the simulations. The left panel provides the simulated distribution for the free distribution of salmon, the centre panel shows the distribution for the upriver movement only simulation, and right-hand panel the distribution for the upriver movement simulation that excludes all salmon that spawned at or below the release site. Observed movement (black circle) in the first two panels are based on 30 salmon whereas the right panel includes 15 salmon after removing individuals that spawned downriver of the release site (see Table 3.1 for list of salmon with negative movement that were excluded). 


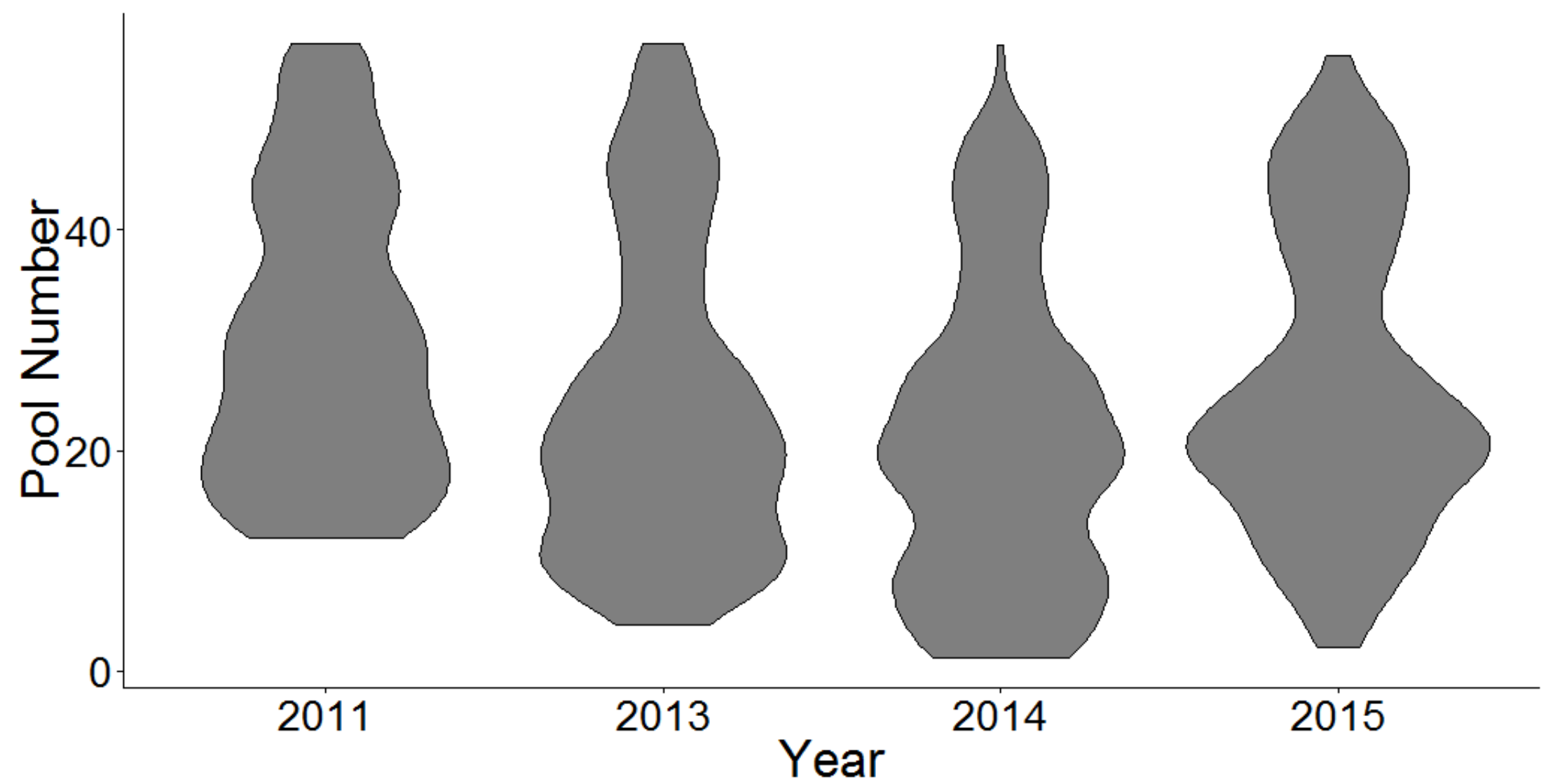

Figure 3.4 Violin plots of annual drift counts in Lakselva. The width of violins indicates the spawning densities at corresponding pools of the river based on observations by drift counters. Note that across years there was some inconsistency in visibility, excluding some 
pools from the count; for example, the lower pools in the 2011 count. Only data from the 2014 count were used for the simulation models. 


\section{$\underline{\text { 3.7 Discussion }}$}

Similar to other studies on the effects of catch-and-release angling on Atlantic salmon, I identified high survival of the fish released by anglers. One mortality among 39 salmon represents a high probability of survival for salmon given good angling practices. Interestingly, I calculated an exceptionally high recapture rate of salmon in Lakselva. Generally, instances of recapture are infrequent in salmon fisheries and in Chapter 5, a recapture rate of $18 \%$ was calculated from data in multiple Norwegian rivers (including Lakselva) in 2012-2013. Here, 23\% salmon were recaptured including one individual that was recaptured twice (but counted in the percentage only once) and excluding one individual that was recaptured as a kelt the following summer. This high frequency of recapture is interesting because there have been no studies of the effects of multiple capture on salmon during their spawning migration, possibly because it is viewed as an infrequent occurrence. Some individuals tend to have higher vulnerability to angling than others (Cox and Walters 2002; Tsuboi and Morita 2004), but the mechanisms are unclear, particularly for Atlantic salmon (Chapter 5). That a relatively high proportion of salmon released by anglers goes on to be recaptured generates questions about how effective catch-and-release can be in some fisheries with high exploitation rates (e.g. Gudjonsson et al. 1996; Downton et al. 2001). High recapture of salmon suggests that further research is necessary to evaluate the physiological and behavioural effects of recapture for salmon during a sensitive life stage. Indeed, encounters with recreational anglers are stressful for fish in the short-term. Burst exercise during angling increases the concentration of circulating stress hormones and results in osmoregulatory disruptions (Kieffer 2000; 
Wood 1991; Barton 2002). After release, there is an energetic burden associated with repayment of oxygen debt (Scarabello et al. 1991) and restoration of intramuscular fuels (Kieffer 2000).

Our simulation models indicated that the salmon released in Lakselva had shorter migrations than expected from model inputs. Two other studies have identified reduced migratory distances traveled by salmon as a sublethal consequence of catch-and-release (Lennox et al. 2015 [Appendix B]; Tufts et al. 2000). However, these studies used a reference group of radiotagged fish that had been captured using means other than angling (traps or nets), and these capture methods could also have stressed the fish potentially confounding their utility as controls. The novel approach presented here used untagged fish from a passive count rather than a control group that had potentially been subjected to stress as a method to generate a more robust estimate of expected movement by released salmon.

A sublethal effect of angling on Atlantic salmon was observed, yet it is not clear what the impacts of movement reductions would have on individual fitness and salmon population dynamics. For Atlantic salmon released by anglers, reduced upriver migration resulting from catch-and-release has the potential to decrease fitness via densitydependent egg or fry mortality (Einum and Nislow 2005) or via outbreeding effects when salmon do not successfully reach their natal spawning destination (Heggberget et al. 1986). However, the extent of substructuring by Atlantic salmon within rivers is probably insufficient to harm the population if some individual spawn slightly downriver (Garant et al. 2000) particularly within smaller rivers such as Lakselva without major tributaries (Jordan et al. 1992; Vähä et al. 2011). It could be suggested that short migrations are 
symptomatic of larger disturbances associated with stress or exhaustion given that breeding success is influenced by physiological condition on spawning grounds (de Gaudemar and Beall 2004; Hendry and Beall 2004). However, other studies of released salmon have found that parr densities increased in years following catch-and-release (Whoriskey et al. 2000; Thorstad et al. 2003), that late season catch-and-release does not affect gamete or fry quality (Booth et al. 1995; Davidson et al. 1994), and that wild salmon released by anglers are able to successfully reproduce (Richard et al. 2013). Nonetheless, if reduced migration following catch-and-release corresponds to reduced activity overall, there could be fewer reproductive encounters by released salmon corresponding with decreased fitness. Even though salmon in this study did not travel as far as was expected based on the simulation, every salmon (except the one that exited the river prematurely and the one that died) was tracked at suitable spawning territory and many were also visually observed in aggregations of spawning conspecifics during drift counting.

An alternative explanation for the findings is that the salmon captured by anglers never intended to continue migrating because they were in the holding phase of migration (Økland et al. 2001). This implies that salmon are more likely to be captured by anglers at the end of migration than during the upriver migration phase. Vulnerability to recreational angling is a complex function of the biotic and abiotic environment (Stoner 2004), individual-level characteristics (Cooke et al. 2007), and the fisheries environment (i.e. gear types used; Chapter 5). However, changing vulnerability to angling at different stages of fish migration has not previously been explored. Migratory salmon behaviour does change at different stages of the migration, which has the potential to influence 
angling vulnerability. For example, dominant males become aggressive on spawning grounds (Hendry and Beall 2004), a behavioural change that could influence vulnerability to angling. Therefore, behavioural vulnerability could increase when salmon arrive at spawning grounds and indeed many fish remain in holding pools near spawning grounds for long periods of time prior to spawning (Økland et al. 2001) meaning that salmon spend most of their time in freshwater at or near their spawning sites. This suggests that angling vulnerability and capture probability should both be greater on spawning grounds than during the migration and that the shortened migration that I observed was a function of this change in capture probability.

Combining a visual survey with the radio telemetry in this study proved important for estimating survival of salmon after catch-and-release. I had several salmon exhibit limited post-release movement, including some that would have been categorized as dead using established protocols for the interpretation of electronic tagging data (Lennox et al. 2015 [Appendix B]) based on their lack of movement, which were confirmed to be alive via visual observation. Indeed, telemetry studies can also underestimate the movement of animals (Ovidio et al. 2000), particularly without fine-scale positioning systems (Hanson et al. 2007). Although I am confident that the periodic tracking allowed us to accurately identify the movements of salmon at a coarse scale (i.e. among pools), it is possible for salmon to make forays up or downriver in short periods of time that could have been missed (i.e. searching behaviour; Økland et al. 2001). For example, one salmon tagged in Pool 2 was tracked once in Pool 5; however, it returned to Pool 2 before the next tracking and remained there until spawning. These brief forays can only be detected by chance if tracking is only periodic. Moreover, Taggart et al. (2001) noted that salmon may move up 
to $5 \mathrm{~km}$ between redds during the spawning season. Although I accept that the methods may not have captured all movements caught and released salmon made, the overall trend observed among salmon was striking because upriver movement was largely restricted throughout the remainder of the summer and into the spawning season.

Using simulation methods to test hypotheses about salmon movement was determined to be a useful approach to testing the hypothesis. Salmon are dynamic animals and although well studied, their behaviour remains somewhat cryptic. Simulation provided an analytical tool for exploring different but equally rational hypotheses to develop models of expected movement by the released salmon. Although I found that there was some inconsistency in the spawning distribution of salmon in Lakselva across years, it was interesting and important to the study to note that general trends were similar. Ultimately, the results of all three simulations were concordant allowing us to make inferences about the population that I studied. Annual visual spawning counts of fish similar to those that I used to generate spawning pool probabilities are available for many rivers making this method a valuable tool for work over and beyond stock assessment in the future.

Survival of salmon released by anglers in Lakselva is promising for salmon conservation efforts and demonstrates the utility of catch-and-release for management of the salmon fishery. However, the model predicted longer migrations after catch-andrelease than I observed, suggesting that the upriver migration could have been hindered by angling, which could be a relevant sublethal effect of catch-and-release. Future research into the behavioural vulnerability of salmon at different stages of migration are necessary to develop a mechanistic understanding of these observations to know whether 
the catch-and-release sample is biased towards fish that have completed migrating. Moreover, studies that monitor the fitness-related endpoints of released salmon could provide important information about the effects of catch-and-release on reproduction including gamete development prior to spawning and intraspecific competition for mating opportunities or fertilization success. The fact that one of the tagged fish was recaptured as a kelt confirms that these fish survive longer than I monitored and research efforts must therefore extend to monitor the outmigration and return migration of salmon. Knowledge that many salmon can be affected by recreational fisheries (Erkinaro et al. 1999) may lead managers to ensure sufficient escapement of uncaptured fish to ensure that recreational angling does not affect spawning in upriver reaches. 


\section{Chapter 4 Behaviour and survival of wild Atlantic salmon (Salmo salar) captured and released while surveillance angling for escaped farmed salmon}

\section{$\underline{4.1 \text { Abstract }}$}

Many Norwegian rivers survey the spawning stock for escaped farmed salmon with surveillance fishing by rod and reel after the recreational angling season. However, the benefits of surveillance fishing depend on the ability for wild salmon to reintegrate the spawning stock soon after release. To evaluate the impacts of surveillance fishing, I captured, radio-tagged, and released wild Atlantic salmon in River Lakselva, Norway, in a surveillance fishery occurring just prior to the spawning period. Among 39 salmon captured, three were not released; one bleeding from the gills, one farmed, and one farmed and bleeding. Thirty-six wild fish were tagged and released. Salmon survived surveillance angling (95\% total survival, 100\% catch-and-release survival). Tagged fish were tracked on average $1.2 \pm 2.8(\mathrm{SD}) \mathrm{km}$ from the release site at the end of the experiment during the spawning season, not significantly different from the distanced moved by salmon radio tagged throughout the summer during a similar interval in Chapter 3 (15 September - 24 October 2014). Total movement within three days of release was inferred to average $1.9 \pm$ 2.1 (SD) $\mathrm{km}$, excluding one individual that exited the river. Tracking data revealed an immediate behavioural reaction of salmon to surveillance catch-and-release, the long-term consequences of which are uncertain. Surveillance fishing may be problematic in rivers with small and vulnerable wild stocks in which a high proportion of the spawning 
populations is sampled. Surveillance fishing completed with ample time before spawning would be a precautious approach to minimize potential effects during spawning.

\subsection{Introduction}

Atlantic salmon populations have declined throughout their range and many have been extirpated (Parrish et al. 1998). Yet, Atlantic salmon is one of the most abundant fishes on earth because its high economic value resulted in intense cultivation and the global proliferation of salmon aquaculture (Gross 1998). These farmed Atlantic salmon have been subjected to artificial selection that has increased the growth rate, fat content, and age at maturity, and reduced stamina, egg size, and genetic diversity (Gross 1998; Ferguson et al. 2007). Farmed salmon have been developed by commercial breeding programs since the early 1970s, and as a result, now exhibit a wide array of genetic differences compared to wild conspecifics (Ferguson et al. 2007; Karlsson et al. 2011; Glover et al. 2017). Nevertheless, farmed salmon may still interbreed with wild salmon, potentially causing significant outbreeding effects (McGinnity et al. 1997, 2003; Fleming et al. 2000; Skaala et al. 2012). Salmon that escape aquaculture facilities enter the ocean and may aggregate with conspecifics at marine feeding areas prior to maturing and migrating into freshwater (Hansen and Jacobsen 2003). The proportion of escaped farmed salmon in samples of Atlantic salmon from Norwegian rivers varied between average 9$18 \%$ close to the spawning period during 2006-2015 (Anon. 2016a). The occurrence of escaped farmed salmon in Norwegian rivers over many years has resulted in a significant genetic introgression from farmed salmon in many wild populations (Glover et al. 2012, 
2013; Skaala et al. 2012; Karlsson et al. 2016). In the most recent of these studies, Karlsson et al. (2016) reported that significant genetic introgression was observed in 77 of 147 Norwegian rivers analysed. Introgression of escapees has also been observed beyond Norway and is considered a challenge throughout the native range of Atlantic salmon (Crozier 1993; Clifford et al. 1997). A recent study observed that gene flow from escaped farmed salmon has altered age and size at maturation in wild Atlantic salmon in many Norwegian rivers (Bolstad et al. 2017).

Intrusion of non-native salmon threaten the genetic integrity and viability of wild salmon (Fleming et al. 2000, McGinnity et al. 2003; Skaala et al. 2012). Anglers may be able to recognize, and subsequently remove, escaped farmed salmon by identifying morphological differences, but genetic analyses or scale reading is necessary for accurate determination in many instances (Lund and Hansen 1991; Fiske et al. 2005). Scale sampling programs from recreational fisheries can provide evidence about the extent of farmed salmon intrusion in wild salmon rivers. However, farmed Atlantic salmon are known to enter rivers later in the season than wild fish (e.g. Moe et al. 2016; Svenning et al. 2017), and often after the recreational fishery has closed. Therefore, scale samples obtained during the summer underestimate the extent of farmed salmon in the population. To address this, many rivers have specialized surveys of the spawning stock for escaped farmed fish using rod and reel in the autumn, a period when the highest number of fish have entered the river, to collect scales from a representative sample of the spawning population in the river. Inevitably, many wild Atlantic salmon are captured by these surveillance fisheries, which are intended to be released unharmed so that they can return to pre-spawning and spawning activities. 
Survival of Atlantic salmon released by rod and reel is consistently high (Chapter 6) but there is evidence that recreational angling can alter the behaviour of wild Atlantic salmon during upriver migration (Mäkinen et al. 2000; Thorstad et al. 2003; Havn et al. 2015). Many Atlantic salmon captured in summer fisheries are captured during the upriver movement phase of migration, which begins after river entry. Fish captured in surveillance fisheries are likely to have completed upriver movement and be in the holding phase of the migration, at or near the spawning destination (Økland et al. 2001). Capture, handling (including scale removal for analysis), and release of wild Atlantic salmon in autumn surveillance fisheries may result in mortality of released fish or elicit similar behavioural responses such as long movements away from the holding sites. Success of surveillance fisheries is contingent on balancing the benefits of enumerating the intrusion of farmed salmon against the potential impacts that could be imparted on wild salmon caught and released close to the time of spawning, which remains poorly understood. To determine whether wild Atlantic salmon captured by autumn surveillance fishing with rod and reel are negatively impacted by catch-and-release, I tagged salmon with radio transmitters after capture and scale sampling and monitored in-river movements until the spawning season.

\section{$\underline{4.3 \text { Methods }}$}

\subsubsection{Study Site}


The study was conducted in the River Lakselva, Finnmark, Norway. Lakselva discharges into the Porsanger Fjord and has $45 \mathrm{~km}$ available to wild Atlantic salmon. Most of the salmon spawn in river reaches below two lakes (Chapter 3). The recreational fishing season for Atlantic salmon concludes on 31 August and fishing for sea trout (Salmo trutta) concludes on 15 September. Surveillance fishing is then conducted until approximately two weeks prior to peak spawning. For this study, surveillance fishing was conducted between 19 September and 2 October, 2016. During this period, water temperatures were $9.6 \pm 0.6^{\circ} \mathrm{C}\left(\right.$ range $=8.4-10.7^{\circ} \mathrm{C}$ ) as measured by a water temperature logger (HOBO Pendant Temperature/ Light Data Logger 64K-UA-002-64, Onset, Massachusetts, USA) deployed in a shaded area of the river at $9 \mathrm{rkm}$ (river kilometres; i.e. kilometres from the river mouth) at a depth of $2 \mathrm{~m}$ from the surface.

\subsubsection{Experiments}

All tagged salmon were captured by three anglers. Sex was visually determined by secondary sexual traits such as development of kype and colouration. Research was conducted with 19 female $($ mean $=98 \pm 20 \mathrm{~cm} \mathrm{SD} \mathrm{TL}$; range $=58-116 \mathrm{~cm}$ TL $)$ and 20 male $(77 \pm 21 \mathrm{~cm}$ TL; range $=55-113 \mathrm{~cm})$ Atlantic salmon captured by surveillance fishing. Five individuals ( $65 \pm 8 \mathrm{~cm}$ TL; 4 males, 1 female) were considered to be freshly entered into the river based on their silver colouration, one of which had sea lice attached with egg strings, which indicates that it had very recently entered freshwater. Salmon were captured by artificial flies $(\mathrm{N}=19)$ and lures (i.e. metal spoons; $\mathrm{N}=20)$. After fighting for an average of $321 \pm 270 \mathrm{~s}$, salmon were landed in a knotless mesh landing net 
$(\mathrm{N}=37)$ or tailed $(\mathrm{N}=2)$ and were rapidly transferred into a water-filled PVC tube by placing the fish into a plastic sling designed to hold fish with enough water to respire. The fish's eyes were covered by a damp towel in the tube to keep it calm. Each fish was measured ( $\mathrm{cm} \mathrm{TL}$ ), sexed if possible, assessed for colour (silver, intermediate, or brown), and tagged. Tags were rectangular $(21 \times 52 \times 11 \mathrm{~mm}$, mass in air $=15 \mathrm{~g})$ coded radio transmitters (Advanced Telemetry Systems, Isanti, Minnesota, USA) in the frequency range $142.144-142.484 \mathrm{MHz}$. The tags were attached by passing steel wire $(0.8 \mathrm{~mm})$ through hypodermic needles inserted between the pterygiophore bones. A white plastic back plate was placed on the opposite side from the tag (Chapter 3). After tagging, 5-8 scales were removed from the fish's right side, posterior to the dorsal fin near the midline using needle nose pliers, which were used to determine the origin of the fish as wild or escaped farmed. Total exposure to air from landing the fish to release was $2 \pm 2 \mathrm{~s}$ (range $=0-7 \mathrm{~s}$ ). Fish were held in water for $62 \pm 82 \mathrm{~s}$ (range $=0-6 \mathrm{~min}$ ) before they swam away volitionally.

The position of each fish in the river was determined at $1 \mathrm{~h}, 1 \mathrm{~d}, 2 \mathrm{~d}$, and $3 \mathrm{~d}$ after capture as well as once weekly until 24 October. Positions were determined using a vehicle-mounted ATS R4500CD coded receiver datalogger attached to either a dipole antenna (Magnetic Roof-Mount Dipole, Laird Technologies, Earth City, Missouri, USA) and a 4-element Yagi antenna for precise determination. To ensure adequate coverage of the river and to note any fish that moved out of the tracking area, directional stationary logging stations mounted with two 6-element Yagi antennas each were also established near the confluence of the river with the fjord at $4 \mathrm{rkm}$ and at $20 \mathrm{rkm}$, beyond which access by road is limited. Fine-scale positioning permitted the identification of upstream 
movement of fish, confirming survival and also to calculate movement from the capture site after sampling. Observation by snorkeling or sudden position movements provoked by snorkeling were used to confirm survival (on 6 and 23 October 2016) for fish that were not recorded to move upstream between tracking surveys.

\subsubsection{Data Analysis}

Catch-and-release mortality was calculated as the percentage of fish determined to have died based on the tracking after release. Fish that moved up river immediately after release required an additional upriver movement occurring more than $2 \mathrm{~d}$ after release to be considered a survivor. Snorkel surveys were conducted to verify survival of any salmon for which there was doubt about survival. Total mortality was calculated by adding delayed mortality and immediate mortality (i.e. the sample fish that were killed due to extensive bleeding).

Tracking data were imported into ArcGIS software (ESRI 2011) to calculate the distance from the river mouth of each position in rkm. Positions for each fish were then used to determine the extent of downriver movement immediately after release and the final position in the river relative to the release location. Because fish were tracked at fixed intervals in the first $3 \mathrm{~d}$, I could infer the minimum movement in this period by summing the absolute values of the changes in position of fish in the river from each tracking point. Final positions of fish compared to the release site were calculated and compared to the change in position of fish tagged in the summer recreational fishery in 2014 (Chapter 3). The 2014 data comprised 21 fish that were tracked on 24 October and 
15 September, which is a comparable period to that in 2016. However, fish in 2014 were tagged during the summer (13 July -29 August) and I therefore interpreted movement of those fish as expected movement of fish during this period. I excluded one fish from 2016 that exited the river and compared the relative movement of fish in the SeptemberOctober period for salmon tagged in the two experiments with a Welch two-sample t-test implemented with the t.test function in R (R Core Team 2016).

To determine which factors influenced movement of salmon from the release site within the $3 \mathrm{~d}$ fixed interval tracking period, generalized least squares regression was implemented with the gls function in the R package nlme (Pinheiro et al. 2014). The model is based on 32 salmon given that four individuals had incomplete tracking records within $3 \mathrm{~d}$. The full models are presented as the final models. Generalized least squares regression was used ( $g l s$ function in nlme package) instead of multiple linear regression because it can incorporate variance structures that account for heteroscedasticity in model residuals (Pinheiro et al. 2014). The dependent variable, inferred distance moved within 3 $\mathrm{d}$, was $\log$ transformed to account for non-normality of residuals and a varIdent variance structure was incorporated in the model to account for heteroscedasticity of the bleeding predictor variable, which was coded as a factor (Pinheiro et al. 2014).

\subsection{Results}

Among the 39 Atlantic salmon captured, there were two individuals that incurred injury to the gills and were not released (one of farmed origin, one wild). One additional individual was determined to be of farmed origin based on external traits and was also 
not released (farmed origin of this individual was later confirmed by expert scale analysis); all other individuals were confirmed by scale analysis to be of wild origin. Therefore, the sample of tagged fish consisted of 36 wild Atlantic salmon $(87 \pm 20 \mathrm{~cm}$ $\mathrm{TL}$; range $=55-116 \mathrm{~cm})$. Every salmon that was released was confirmed to have survived the surveillance fishing based on in-river movements made after release, observation by snorkeling, and/or by sudden changes in radio-derived position provoked by snorkeling. Catch-and-release survival was therefore $100 \%$. Total survival of the fish captured during the monitoring was $95 \%$, considering that two individuals were killed due to injuries. One individual (1 SW $62 \mathrm{~cm}$ male, brown coloured at release) was recorded passing by the stationary logger near the river mouth $13 \mathrm{rkm}$ downriver from the release location before it disappeared from the river, and most likely did not spawn in Lakselva. Movements by this fish were determined to be volitional, and not the passive drifting of a fish carcass, based on the periodic up- and down-river movements recorded by the stationary logger.

Three of the fish that were released were bleeding slightly, two of which were captured by lures and one by a fly. One of the bleeding fish shook the hook out while in the net, indicating that it was not likely lodged in a critical location, one was hooked in both the upper and lower jaws simultaneously, and one was hooked in the corner of the jaw.

Within one hour of release, salmon were on average $0.04 \pm 0.12 \mathrm{rkm}$ downriver from the release site $($ range $=-0.52-0.17 \mathrm{rkm}$; Table 4.1), although $17(47 \%)$ were approximately in the same position $( \pm 20 \mathrm{~m}$ ) as where they were released and $75 \%$ were within $\pm 100 \mathrm{~m}$ (Figure 4.1). One day after release, $33 \%$ were within $\pm 100 \mathrm{~m}$ of the 
release location; one moved upriver $2.5 \mathrm{rkm}$ and another moved down $2.5 \mathrm{rkm}$ (Figure 4.2). After two days, only $15 \%$ were within $\pm 100 \mathrm{~m}$ and after day three, $19 \%$ were within $\pm 100 \mathrm{~m}$. The final position of salmon, taken at the end of October, was on average upriver of the release location by $1.23 \pm 2.80 \mathrm{rkm}(\mathrm{range}=-2.98-11.11 \mathrm{rkm})$ and only one individual (3\%) was within $100 \mathrm{~m}$ of release (Figure 4.3). More fish moved upriver more than downriver from the release site, suggesting that movements were volitional rather than the result of being swept down current. The net change in position was not significantly different for the 2016 fish captured by surveillance fishing compared to fish captured in the summer recreational fishery in $2014(\mathrm{t}=-0.89, \mathrm{df}=36.84, \mathrm{P}=0.38$;

Figure 4.4). The farthest point recorded from the release site was on average $2.19 \pm 2.87$ rkm although the median was $0.96 \mathrm{rkm}$.

The inferred distance moved within $3 \mathrm{~d}$ of release was on average $1.93 \pm 2.11 \mathrm{~km}$. Silver coloured fish moved more than brown coloured fish, but the difference was weakly significant (Table 4.2). No other predictors were significant in the model (Table 4.2). 


\section{$\underline{4.5 \text { Tables }}$}

Table 4.1 Summary of distance (river $\mathrm{km}$ ) moved by Atlantic salmon (Salmo salar) released by surveillance fishing. Each fish was tracked 1 h, $1 \mathrm{~d}, 2 \mathrm{~d}$, and $3 \mathrm{~d}$ after release, Mean, median, standard deviation (SD), and range of relative distances and absolute distances from the release site are presented. Number of fish tracked in each sample is also included because some positions were not available due to tracking error. For the final positions, one fish that exited the river is excluded from the total.

\begin{tabular}{|c|c|c|c|c|c|c|}
\hline & Timepoint & $\mathrm{N}$ & Mean $(\mathrm{km})$ & SD & Median $(\mathrm{km})$ & Range $(\mathrm{km})$ \\
\hline \multirow{5}{*}{ Relative } & $1 \mathrm{hr}$ & 36 & -0.04 & 0.12 & 0.00 & $-0.52-0.17$ \\
\hline & $1 \mathrm{~d}$ & 36 & 0.15 & 0.92 & 0.00 & $-2.50-2.50$ \\
\hline & $2 d$ & 34 & 0.33 & 1.86 & 0.12 & $-4.74-5.23$ \\
\hline & $3 d$ & 32 & 0.23 & 1.86 & 0.12 & $-6.38-3.47$ \\
\hline & Final & 35 & 1.23 & 2.79 & 0.29 & $-2.98-11.11$ \\
\hline \multirow{5}{*}{ Absolute } & $1 \mathrm{hr}$ & 36 & 0.07 & 0.11 & 0.00 & $0.00-0.52$ \\
\hline & $1 \mathrm{~d}$ & 36 & 0.58 & 0.71 & 0.27 & $0.00-2.50$ \\
\hline & $2 \mathrm{~d}$ & 34 & 1.20 & 1.44 & 0.58 & $0.00-5.23$ \\
\hline & $3 d$ & 32 & 1.13 & 1.48 & 0.50 & $0.00-6.38$ \\
\hline & Final & 35 & 1.82 & 2.44 & 0.76 & $0.02-11.11$ \\
\hline
\end{tabular}


Table 4.2 Generalized least squares regression of log-transformed movement within $3 \mathrm{~d}$ by Atlantic salmon (Salmo salar) released by surveillance anglers during the autumn fishing season. P-values are relative to the reference levels of categorical variables (reference levels for each factor: Gear $=$ Fly, Sex $=$ Female, Colour $=$ Brown, Bleeding $=$ Negative $)$.

\begin{tabular}{llrr}
\hline Fixed Effect & Estimate $\pm \mathrm{SE}$ & $\mathrm{t}$-value & $\mathrm{p}$-value \\
\hline (Intercept) & $-11.83 \pm 16.35$ & -0.72 & 0.48 \\
Length & $0.01 \pm 0.02$ & 0.54 & 0.60 \\
Fight Time & $0.00 \pm 0.00$ & 0.14 & 0.89 \\
Recovery Time & $0.00 \pm 0.00$ & -0.71 & 0.49 \\
Release Date & $0.04 \pm 0.06$ & 0.60 & 0.55 \\
Gear (Lure) & $0.25 \pm 0.47$ & 0.53 & 0.60 \\
Sex (Male) & $1.30 \pm 0.70$ & 1.86 & 0.08 \\
Colour (Intermediate) & $-0.55 \pm 0.86$ & -0.64 & 0.53 \\
Colour (Silver) & $1.37 \pm 0.70$ & 1.97 & 0.06 \\
Bleeding (Positive) & $1.41 \pm 0.88$ & 1.59 & 0.13 \\
\hline
\end{tabular}


$\underline{4.6 \text { Figures }}$

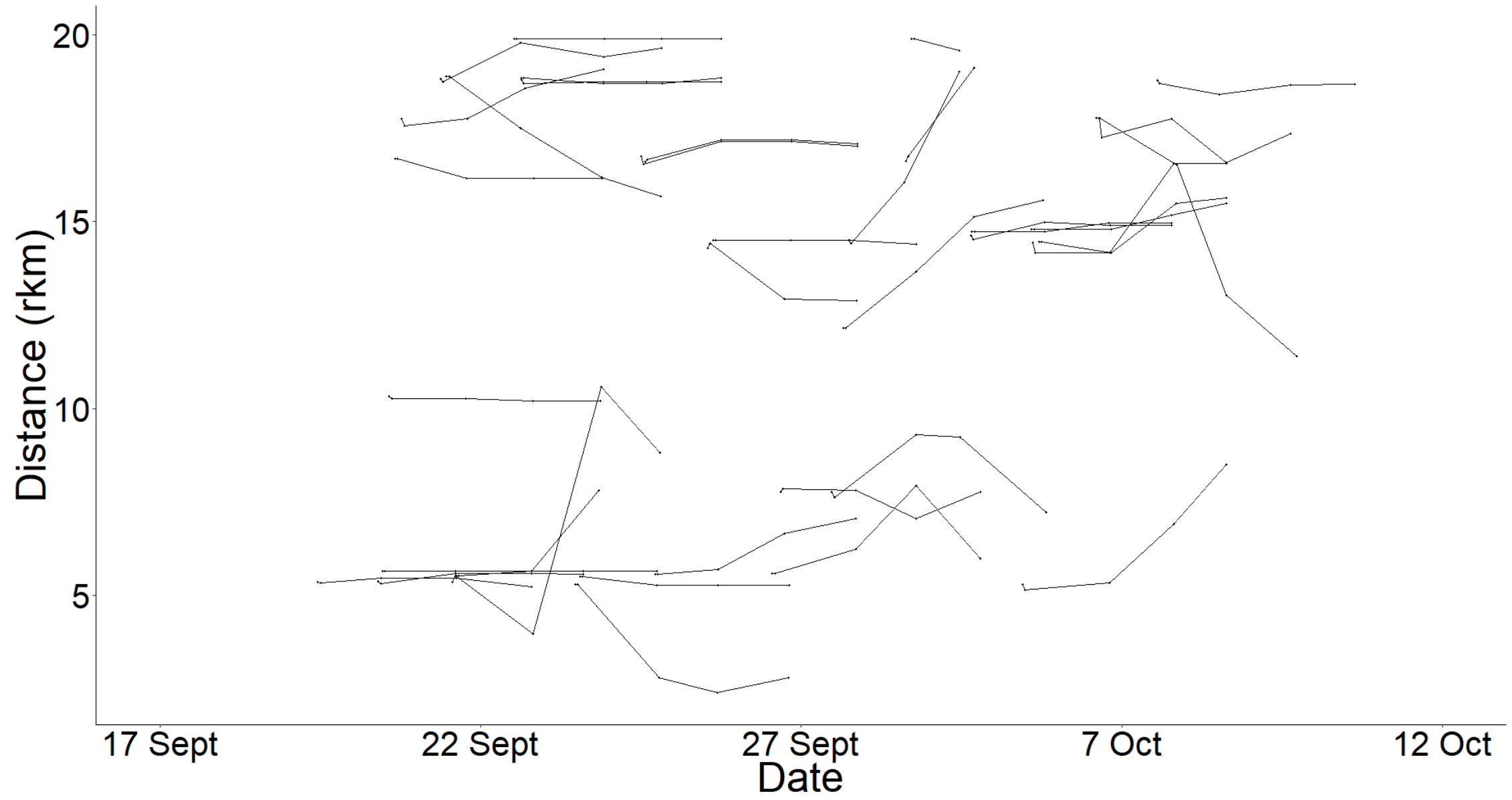


Figure 4.1 Changes in position of individual Atlantic salmon caught by surveillance fishing in Lakselva. Positions were recorded by manual tracking one hour, one day, two days, and three days after release. Distances are presented relative to the river mouth (rkm). 


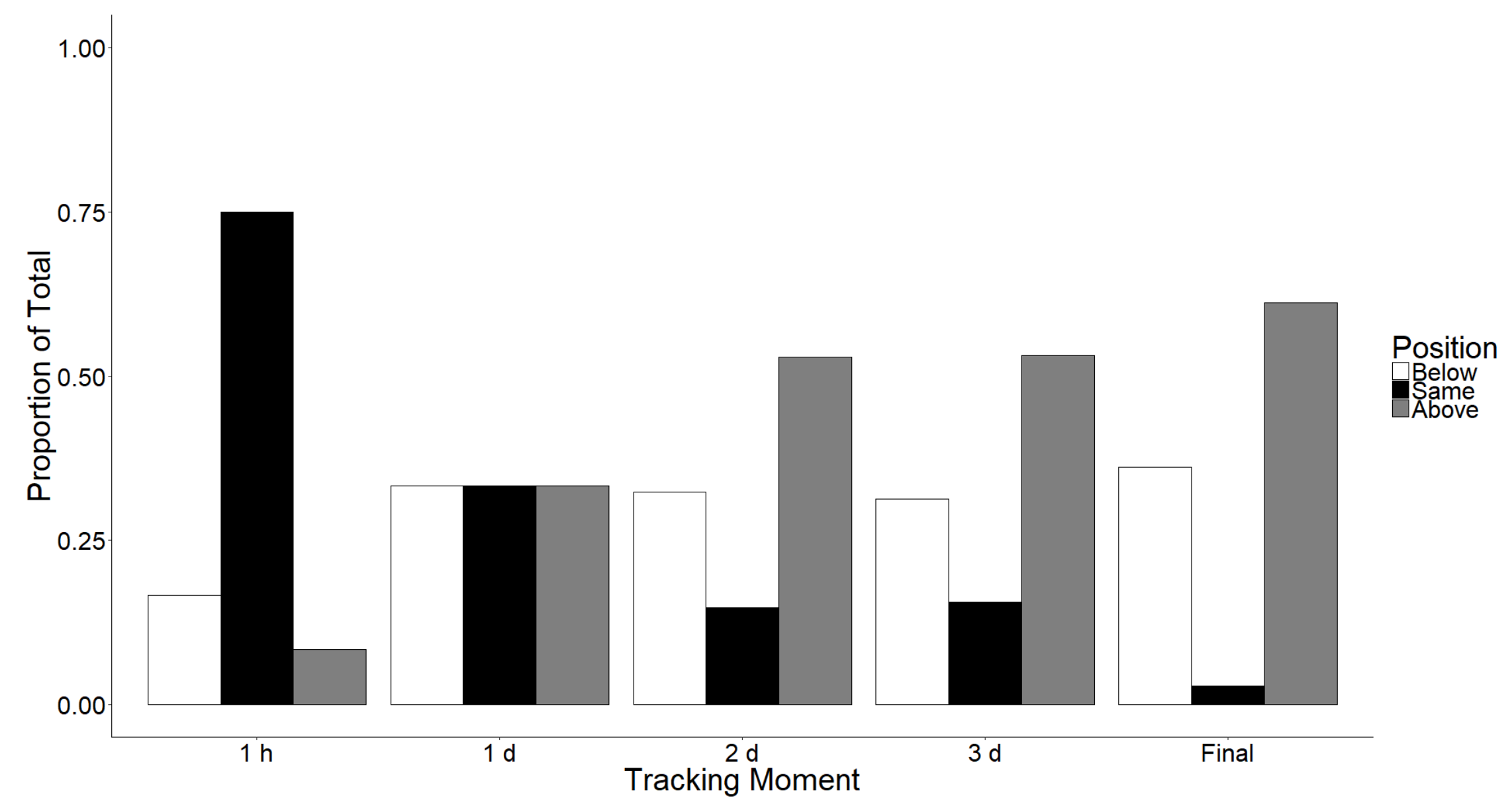


Figure 4.2 Proportion of Atlantic salmon (Salmo salar) positioned below, within, or above the release location in Lakselva by $100 \mathrm{~m}$ after $1 \mathrm{~h}, 1 \mathrm{~d}, 2 \mathrm{~d}, 3 \mathrm{~d}$, and at the end of the study. 


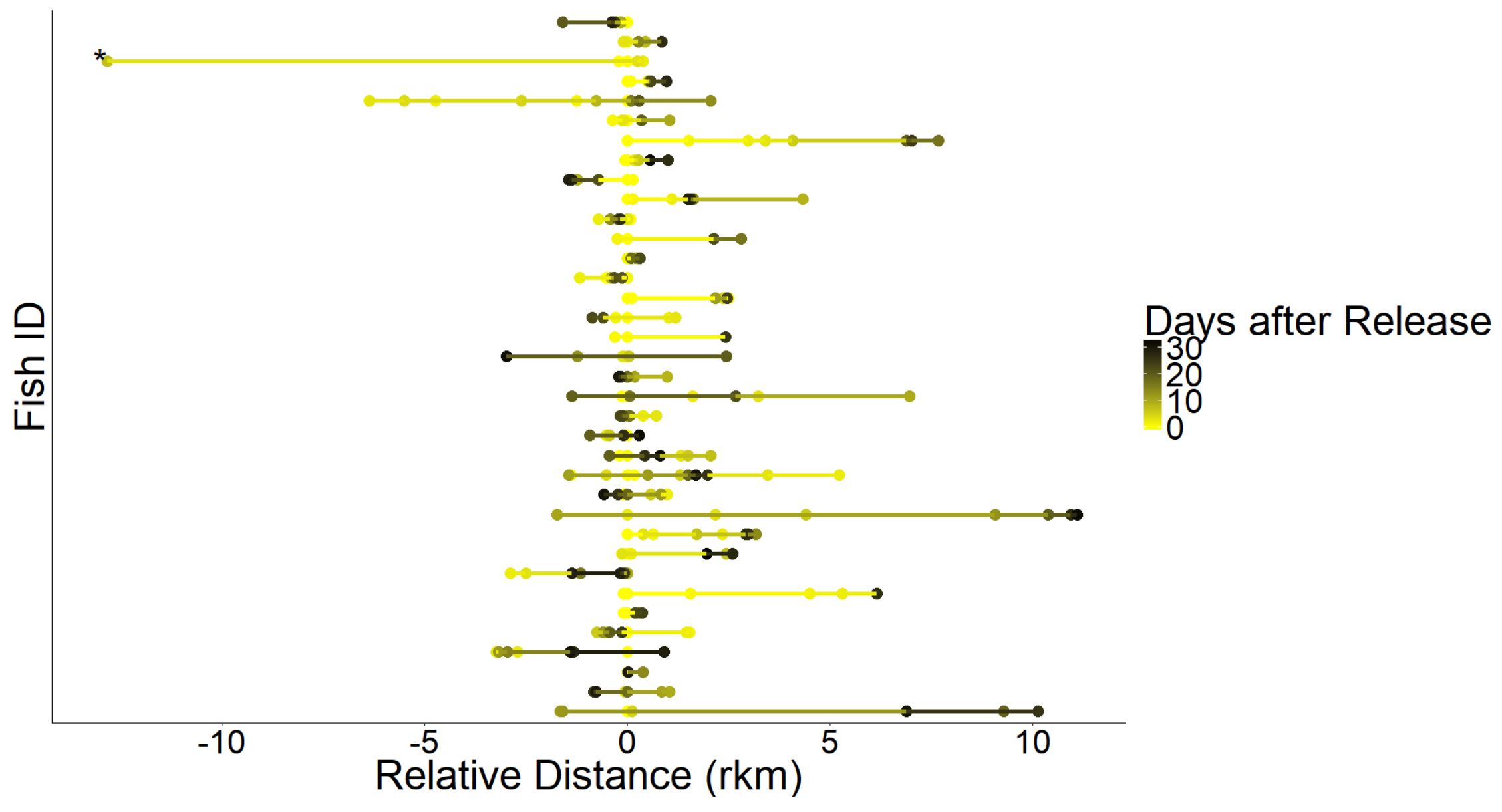


Figure 4.3 Plot of the relative distances traveled by Atlantic salmon (Salmo salar) captured in a surveillance fishery. The colour scale indicates the temporal change in position of fish in the river based on fixed interval tracking and logging station data in days after tagging. The asterisk demarcates the fish that exited the river prior to spawning. Date is the day after release. 


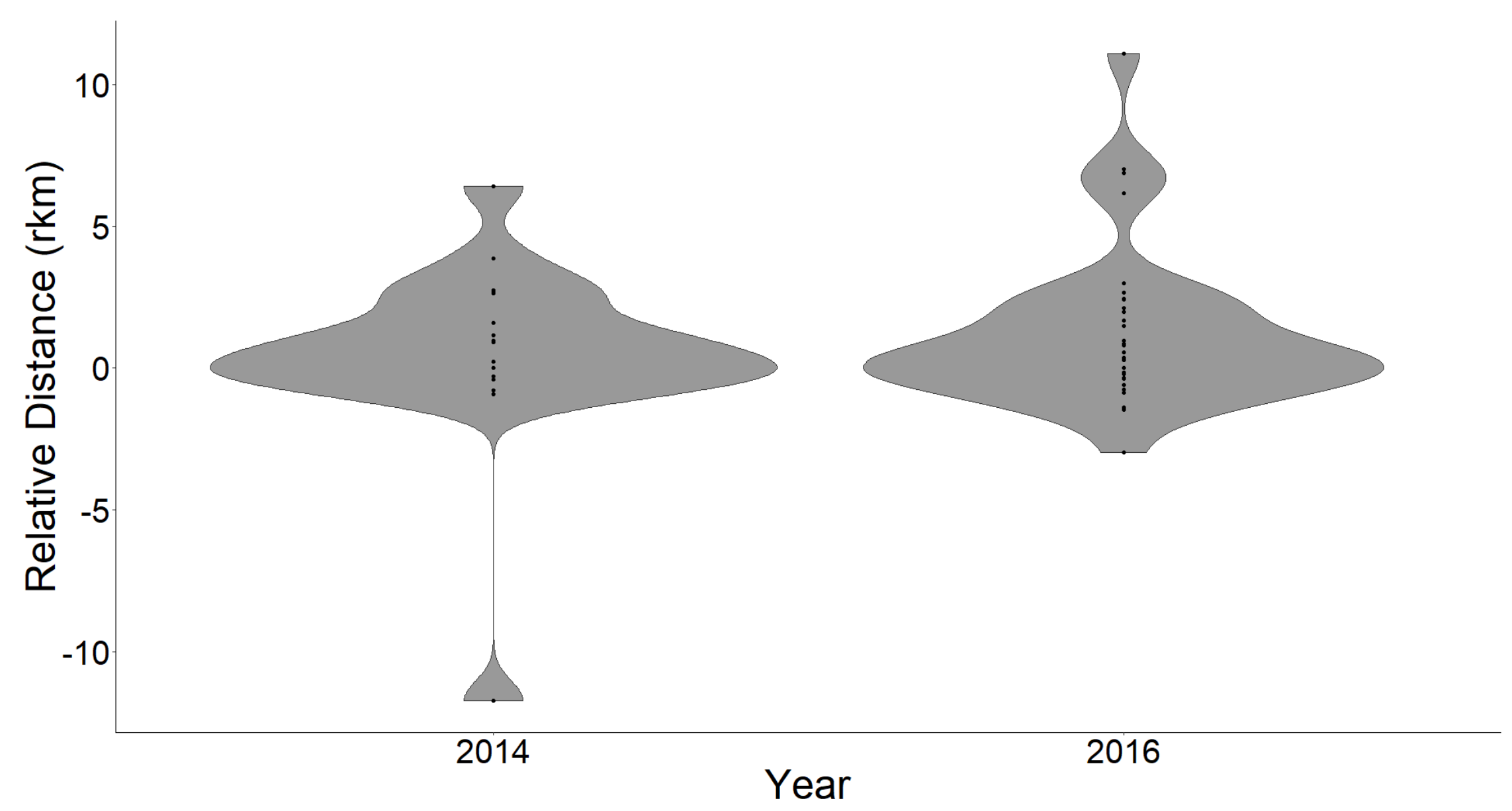

Figure 4.4 Violin plots of positions of Atlantic salmon (Salmo salar) released from a summer recreational fishery $\left(\mathrm{N}_{2014}=21\right)$ and surveillance fishery $\left(\mathrm{N}_{2016}=35\right.$ having excluded one fish that exited prior to spawning). Positions for the 2014 fish are taken on October 
24, 2014 and are relative to positions taken on September 15, 2014. Positions for 2016 are the final positions in the river taken on 22 24 October relative to the release site. 


\subsection{Discussion}

Physical and physiological impacts of capture and handling result in some mortality of fish captured in fisheries (Arlinghaus et al. 2007; Chapter 6). It is therefore expected that the surveillance fishery would result in the mortality of some wild fish, and, similar to other studies of Atlantic salmon, that this mortality would be infrequent. Immediate mortality of salmon in the surveillance fishery, resulting from damage caused by the hook, was similar to that in other studies (3-10\%; Havn et al. 2015; Lennox et al. 2015 [Appendix B], 2016 [Chapter 3]). Delayed mortality of salmon in the surveillance fishery was null, which is consistent with other assessments using telemetry that have generally identified infrequent post-release mortality, with high water temperature being the most consistent predictor of post-release mortality (Chapter 6). Water temperatures in September and October are cooler than during the summer and therefore warm water temperature is not likely to be a risk factor for surveillance fishing mortality. This does not preclude the occasional immediate mortality event such as I observed here but in general, mortality in fall surveillance fisheries would appear to be negligible.

Capture and handling are known to cause biochemical disturbances in fish (see Thorstad et al. 2003 for data on Atlantic salmon blood analyses in response to angling), which can manifest as behavioural anomalies or impairment (Mäkinen et al. 2000; Thorstad et al. 2003; Havn et al. 2015). Even though all released salmon survived the surveillance fishery, most of them were beyond $0.10 \mathrm{rkm}$ from where they were holding in preparation of spawning. This is suggestive of an acute disturbance caused by capture and handling, which is similar to the behavioural responses of salmon to catch-and- 
release in the summer recreational fisheries. Radio tracking of salmon released from an experimentally extended recreational fishery in the Dee River also identified high survival of fish captured later in the season and with similar up- and downriver movement away from the release site (Dee River Trust 2010). Radio tagged salmon caught in bag nets in the fjord and released in July moved $0.36 \mathrm{rkm}$ (males) or $0.80 \mathrm{rkm}$ (females) between 11October and 1 November in the River Alta, which is close to Lakselva, (Økland et al. 1995). Although these surveys were performed later in Alta than the study in Lakselva, the total distances were inferred from more frequent tracking surveys. Salmon that are holding position prior to spawning are likely maintaining a position near their eventual spawning site and not necessarily on it (Økland et al. 2001; Richard et al. 2014). Movement away from holding pools therefore does not necessarily suggest a loss of territory, especially given that individuals move among pools during the spawning season anyways (Taggart et al. 2001) and a comparison to the movement exhibited by salmon in 2014 indicated no major differences in displacement during a similar period.

It is notable that five salmon captured in the surveillance fishery were silver in colour, suggesting that they had recently entered the river. Most salmon enter rivers weeks or months before spawning to stage near spawning grounds (Økland et al. 2001; Quinn et al. 2015). Silver salmon moved more than brown salmon, which is sensible given that these fish would be more likely to be in the active migration phase, on the way to spawning grounds, than holding near spawning territories (Økland et al. 2001). However, the movements made by the silver salmon were not unidirectional towards upriver territory and included downstream running. Downstream running (i.e. fallback) 
and erratic movement are believed to be symptoms of a stress response by salmon (Mäkinen et al. 2000; Havn et al. 2015). Although Thorstad et al. (2007) identified no differences in behavioural responses or survival after catch-and-release of silver and brown salmon, salmon might have differences in the stress responsiveness at different stages of reproductive maturity. For example, Raby et al. (2013) described an attenuated stress response of Pacific salmons (Oncorhynchus gorbuscha, O. keta) on spawning grounds, suggesting a change in physiological pathways later in migration as fish prepare for spawning.

Escaped farmed Atlantic salmon represent an immediate and growing threat to the conservation of wild salmon populations (Karlsson et al. 2016; Forseth et al. 2017; Glover et al. 2017). Scale sampling revealed that $5 \%$ of the salmon captured during surveillance fishing were of farmed origin, which is concerning given that there are no farms in the immediate vicinity. The genetic integrity of the Lakselva population was recently characterized as being of moderate quality due to genetic introgression of farmed salmon in the wild population (Anon. 2016b; Karlsson et al. 2016). Maintaining records of farmed salmon in rivers can assist with long-term tracking of trends in wild salmon conservation, particularly in prioritizing conservation efforts towards rivers where intrusion by farmed salmon is most frequent.

Given that the objective of any monitoring activity should be to minimize impacts on wild fish, other methods could be compared to sampling with rod and reel. However, surveillance fishing appears to be a relatively low-impact method of surveying the spawning stock for farmed fish. Although I observed 100\% survival of fish that were released, there was some immediate mortality of fish captured in the surveillance fishery 
and I observed acute disturbances to the behaviour, specifically movement away from the release location that is probably beyond the normal activity that salmon engage in during this period. In addition, one fish exited the river and was probably lost from the spawning population. Ultimately, the net change to position from September to spawning in the end of October was not different from expected movement based on fish tagged in the early season in 2014, suggesting that most salmon released by surveillance fisheries can return to the spawning population. Future research should make a more direct comparison with a control group to determine what the expected movement of fish is during the autumn and establish to what extent they move within the river. Research should also shift to a more direct quantification of fitness by assessing the spawning success of fish released from the surveillance fishery. Chronic stressors have repeatedly been linked to reproductive suppression or failure in salmonids (Weiner 1986; Pickering et al. 1987; Campbell et al. 1992). Recreational angling, however, is an acute stressor and there is evidence to suggest that fish exposed to acute stressors, even proximate to spawning, can restore homeostasis relatively quickly, which would attenuate any longer-term effects. Pickering et al. (1987) measured decreasing androgenic hormones in the blood of brown trout (Salmo trutta), which recovered within $24 \mathrm{~h}$ in captivity. Correspondingly, Davidson et al. (1994) and Booth et al. (1995) calculated high hatching success of eggs laid and fertilized by Atlantic salmon subjected to simulated late-season angling. Although this is the best available evidence as to whether salmon captured in surveillance fisheries would likely contribute viable progeny, impacts of long-term survival are unknown and deserve further consideration given that hatching success is not an ultimate measure of offspring fitness (e.g. for birds; Berntsen and Bech 2016). 
In the absence of direct measurements of fitness impairments caused by surveillance fishing, an appropriate precaution would be to maintain a buffer period between the end of surveillance fishing and the initiation of spawning to provide salmon with time to recover. Future studies incorporating a control group will assist with defining an appropriate buffer period, including physiological (e.g. Raby et al. 2015) and behavioural assessments (e.g. Whitney et al. 2016) of the recovery time of salmon after exercise. In general, longer buffer periods will be best but this must be considered against the run timing of farmed fish to ensure a representative sample (Moe et al. 2016; Svenning et al. 2017). Farmed salmon also tend to have different distribution within the river than wild fish and have been observed migrating farther upriver than wild fish (Moe et al. 2016), therefore efforts to refine surveillance fishing methods may be necessary to further ensure representative sampling.

Despite the behavioural disturbance observed among the salmon in Lakselva, capture and release of a small population sample for surveillance fishing is unlikely to affect the spawning in rivers with large stocks. Indeed, any negative impacts may be offset by benefits provided by collecting important information about escaped farmed salmon intrusion that allows for remediation or restoration and contributes to good fisheries management and long-term sustainability. Where rivers are considered to have vulnerable stocks (e.g. small spawning biomass), surveillance fishing could be more damaging to the population, because it is required to sample a relatively large proportion of the spawning populations in such rivers to obtain a statistically justifiable sample size compared to rivers with large wild stocks. Caution should be exercised when implementing surveillance fisheries with river-specific conservation needs and objectives 
of foremost consideration, particularly in balancing the expected gains in terms of information about the intrusion of escaped farmed salmon in rivers. 


\section{Chapter 5 Influence of gear switching on recapture of Atlantic salmon (Salmo salar) in catch-and-release fisheries}

\subsection{Abstract}

Anglers that release Atlantic salmon in recreational fisheries do so with the intention that the fish will survive and contribute to subsequent generations. In some instances, salmon that are released may be recaptured, but mechanisms associated with recapture are unclear. To test whether gear avoidance influences recapture rates, I analyzed data from tagging programs in major Norwegian Atlantic salmon fishing rivers to determine how frequently salmon were recaptured by different gear than that which they were initially captured (i.e. gear switch). Among 339 salmon captured, externally tagged, and released in 2012 and 2013, 46 (14\%) were recaptured; 70\% of these recaptured salmon exhibited gear switch. To test whether this gear switch percentage could be expected in the absence of gear avoidance, a simulation was conducted, which accounted for variation in catch probability among rivers and across time with different gear types based on comprehensive catch data. Each simulation step provided a simulated rate of gear switch under the null hypothesis of no gear avoidance. A distribution was generated, which described the probability that I would observe $70 \%$ gear switch. The simulated results indicated that this rate of gear switch was highly unlikely $(\mathrm{P}=0.003)$ if recapture gear is assumed to be independent of initial capture gear, suggesting that salmon avoided familiar gear types. Changes to behaviour after release, including learned hook avoidance, may explain the observation of gear avoidance by recaptured salmon. 


\section{$\underline{5.2 \text { Introduction }}$}

Recreational angling is a popular activity and may represent a considerable component of many regional economies (Arlinghaus and Cooke 2009; Cowx et al. 2010). Fishing can exert substantial pressure on fish stocks and persistent effort from anglers may result in a large proportion of fish from a stock or population being captured (e.g. Gudjonsson et al. 1996; Downton et al. 2001). Individual differences in catchability occur within fish populations, meaning that certain individuals have traits that predispose them to being captured by anglers (Cox and Walters 2002). In some instances, behavioural or physiological traits that increase catchability have a genetic basis (Consuegra et al. 2005; Philipp et al. 2009; Klefoth et al. 2013). It follows that individuals that are predisposed to capture by recreational fishers may be captured and released multiple times (Tsuboi and Morita 2004), potentially reducing the positive effects conferred by catch-and-release to some extent (Bartholomew and Bohnsack 2005). However, prior investigations into fish recapture by anglers have indicated that some species or individuals become difficult to recapture over time (Askey et al. 2006; Beukema and de Vos 1974; Kuparinen et al. 2010).

Recreational Atlantic salmon angling is an economically and culturally important activity throughout coastal regions along the North Atlantic coast (Aas et al. 2011; Verspoor et al. 2008). Depending on local regulations, anglers are permitted to fish for salmon using a variety of terminal tackle, which may include artificial flies, lures, or live bait. To compensate for declining stock sizes in many rivers (Parrish et al. 1998), salmon 
fisheries are increasingly using catch-and-release as a management tool (Lennox et al. 2016b [Appendix B]). In rivers that permit harvest, some anglers may nonetheless practice voluntary catch-and-release as a result of conservation ethic (Stensland et al. 2013; Gargan et al. 2015). Theoretically, catch-and-release maintains a higher number of fish available to anglers to catch so long as fish survive and return to the population of vulnerable fish.

Efforts to understand factors that influence mortality of salmon in catch-andrelease fisheries have confirmed that the released fish do survive and therefore become available to anglers to catch again (Chapter 6). Many of these fish also proceed to be recaptured, with rates reported in the literature varying between $4 \%$ and $11 \%$ (Webb 1998; Gowans et al. 1999; Whoriskey et al. 2000; Thorstad et al. 2003; Richard et al. 2013). Salmon evidently re-enter the vulnerable population but there appear to be mechanisms influencing the propensity with which fish are recaptured (Lennox et al. 2017b [Appendix D]). Gear avoidance or selectivity has been demonstrated to affect catch rates in recreational fisheries (e.g. Beukema, 1970; Beukema and de Vos 1974), and it is possible that recapture rates in some salmon fisheries are likewise affected by gear avoidance. If that were the case, it would be expected that salmon would be unlikely to be recaptured by the same fishing gear multiple times, a phenomenon termed gear switching. For instance, salmon caught by flies would be more likely to be recaptured by lures or worms rather than flies, or vice versa. In this study, I analyzed recapture trends of tagged salmon in Norwegian recreational fisheries by testing whether the gear that a salmon was captured by a second time was independent of the gear that it was captured by initially. 


\section{$\underline{5.3 \text { Methods }}$}

During the angling seasons (June 1 - September 15 in most rivers) of 2012 and 2013, adult Atlantic salmon returning to Norwegian rivers Gaula, Lakselva, Orkla, and Otra from the ocean were captured by recreational anglers and externally tagged with either radio transmitters or t-bar anchor tags. Radio tagged salmon were typically landed in knotless landing nets and transferred to a water-filled PVC tube (to ensure adequate gill ventilation) for tagging (Chapter 3). External radio tagging methods followed those of Økland et al. (2001), in which rectangular radio transmitters (dimensions $=21 \times 52 \times$ $11 \mathrm{~mm}$, model F2120 from Advanced Telemetry Systems, Minnesota, USA) were attached by steel wire through the dorsal musculature beneath the dorsal fin. For all other tagged fish, anchor tags (Floy Manufacturing, Washington, USA) were inserted into the dorsal musculature in pairs (to limit the effects of tag loss) with a cartridge-fed applicator (Dell 1968). Participating anglers were instructed on how to properly apply anchor tags to salmon including appropriate placement points for the tags, and best practices for salmon handling, such as the need to limit air exposure in order to maximize post-release survival. Details about the capture location and time, size and sex of the fish, release methods, and capture gear were recorded as available. If a fish that had been tagged was later recaptured during the same fishing season, the individual was identified from its tag number. A relatively high reward (500 NOK) was offered to anglers in order to increase the probability of reporting recaptured salmon (Pollock et al. 2001). To ensure ease of reporting, a cellular phone and email address were printed on tags. The phone number 
and email address were dedicated exclusively to monitoring for reports of recaptures. Anglers that reported recaptured fish provided details about the date, time, and location of capture, as well as the gear that they had used to capture the fish. All handling and tagging was conducted according to the Norwegian regulations for treatment and welfare of animals and approved by the Norwegian Animal Research Authority.

\subsubsection{Data Analysis}

To test for gear avoidance using recapture data, it was necessary to compare the observed frequency of gear switch to the expected frequency of gear switch given no gear avoidance. If gear catch probabilities (i.e. probability that a fish would be captured by a fly, lure, or worm) were equal across space (rivers) and time (month of a given year) in this study, the expected probability of gear switch would be $2 / 3$ (because three different gear types were used). However, the probability that salmon would be captured by a given gear type varies in different rivers and over time because of different effort expended by anglers with each gear type (i.e. most anglers use flies) and due to changing river conditions (i.e. clarity, temperature, flow) during the season that may affect the efficiency of each gear type.

To account for the large variation in gear catch probability, I developed a simulation in which each tagged and recaptured salmon, according to the null hypothesis of no gear avoidance, was assigned gear catch probabilities based on the river, year, and month in which it was recaptured. Gear catch probability was estimated by the proportion of the total angling catch landed by each gear type in the space (i.e. river) and time (i.e. 
month) of interest, which were calculated from publicly available catch logs registered in each river. For example, two tagged salmon were recaptured in River Gaula in August 2012. In this river in August 2012, 68\% of salmon were captured by flies, $17 \%$ by lures, and $15 \%$ by worms; for the simulation these values were assigned as gear catch probabilities for each of the two recaptured salmon.

Once gear catch probabilities were assigned to each recaptured salmon, the simulation was conducted. In each simulation step, every recaptured salmon was multinomially assigned a gear type using the respective gear catch probabilities. At the end of the simulation step, the percentage of fish for which simulated recapture gear type differed from tagging capture gear type (i.e. a gear switch had occurred) was calculated. To obtain the distribution of gear switching frequency under the null hypothesis of no gear avoidance, the simulation was repeated 10,000 times. By comparing the observed percentage of gear switches to this simulated null distribution, it was possible to calculate the $P$-value of the hypothesis test; the P-value being the probability of observing an equal or greater number of gear switches than I did.

To test whether initial capture gear affected distance or time between capture and recapture, an analysis of variance (ANOVA) was conducted. To determine whether gear switching was associated with time to be recaptured or distance traveled between the capture and recapture site, two-tailed Student's t-tests were conducted comparing mean time elapsed and mean distance traveled between gear switching salmon and non-gearswitching salmon. Descriptive statistics of time and distance between capture and recapture are presented as means \pm one standard deviation. Statistics and figures were generated using the open-source statistical computing software R (R Core Team 2014). 


\section{$\underline{5.4 \text { Results }}$}

In 2012 and 2013, external tags were affixed to 339 Atlantic salmon (Table 5.1). Among the tagged salmon, most were initially caught on flies (67\%), followed by worms $(18 \%)$, and lures $(15 \%)$. Later in the season, $46(14 \%)$ of the tagged salmon were recaptured and reported by anglers (Table 5.1). Among these 46 salmon recaptured in Gaula, Lakselva, Otra, and Orkla, 32 (70\%) exhibited gear switch (Figure 5.1). The simulated null distribution of the percentage of gear switches for the 46 recaptured salmon (Figure 5.2) had a mean percentage of gear switches of 52\% (24 of 46). Given that I observed $70 \%$ of salmon exhibiting gear switch, gear switch occurred significantly more frequently than expected if salmon did not have any gear preference $(\mathrm{P}=0.003$; Figure 5.2).

There were no differences among initial capture gear types in terms of distance or time elapsed between capture and recapture (distance: $F_{2,42}=0.46, P=0.63$; time: $F_{2,43}=$ $0.62, \mathrm{P}=0.54)$. On average, salmon were recaptured $22 \pm 17$ days after initial capture (range $=0-78$ days). There was no difference in distance from location of initial release to recapture $(\mathrm{t}=0.36, \mathrm{df}=23.50 \mathrm{P}=0.72)$ nor in the time elapsed from initial release to recapture $(\mathrm{t}=1.19, \mathrm{df}=34.33, \mathrm{P}=0.24)$ between gear switching salmon and those that did not switch gear. Salmon were recaptured $10 \pm 16 \mathrm{~km}$ upriver of the initial release location (range $=-10-50 \mathrm{~km}$ ), however, 11 of the 46 salmon were recaptured below the initial release site and 18 were recaptured within one km upriver or downriver of the 
initial release site. One salmon was recaptured in a different river than the release river and was excluded from the distance comparison. 
Table 5.1 Total salmon catches in the Norwegian study rivers in 2012 and 2013. Salmon catches were downloaded from the publicly available catch databases. Salmon tagging data encompasses radio and anchor tags. For the total salmon catch, percentages of fish captured on different gears are given. The percentage of captured fish released in these two years in these rivers is also given. Recapture rates are calculated from the number of tags returned by anglers from salmon tagged during the same angling season.

\begin{tabular}{lrrrrrrr}
\hline River & \multicolumn{3}{c}{$2012 / 2013$ Catch Data } & & \multicolumn{2}{c}{ Tagging Data } \\
\hline & Total Catch & Fly & Lure & Worm & Released & Total tagged & Recaptured \\
\hline Gaula & 7422 & $50 \%$ & $21 \%$ & $29 \%$ & $30 \%$ & 99 & $25 \%$ \\
Lakselva & 3520 & $93 \%$ & $6 \%$ & $1 \%$ & $36 \%$ & 77 & $8 \%$ \\
Orkla & 5423 & $56 \%$ & $19 \%$ & $25 \%$ & $50 \%$ & 67 & $10 \%$ \\
Otra & 3270 & $41 \%$ & $38 \%$ & $21 \%$ & $13 \%$ & 96 & $8 \%$ \\
\hline Total & 19635 & $58 \%$ & $21 \%$ & $22 \%$ & $38 \%$ & 339 & $14 \%$ \\
\hline
\end{tabular}




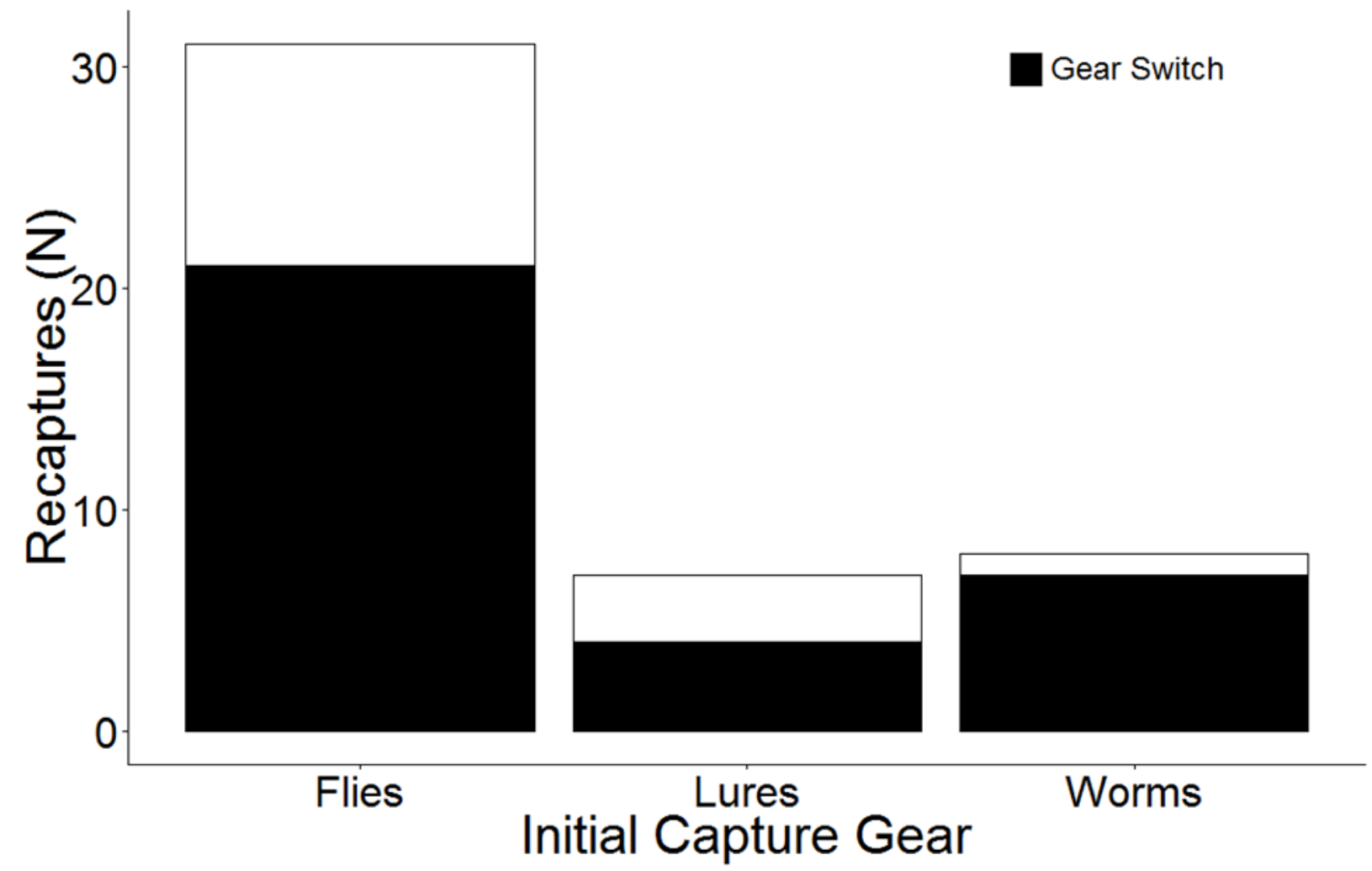


Figure 5.1 Number of recaptured salmon $\left(\mathrm{N}_{\text {total }}=46\right)$ initially captured by flies, lures, and worms. The shaded area indicates the number of salmon that were recaptured by a different gear than they were first captured by (i.e. exhibited gear switch). 


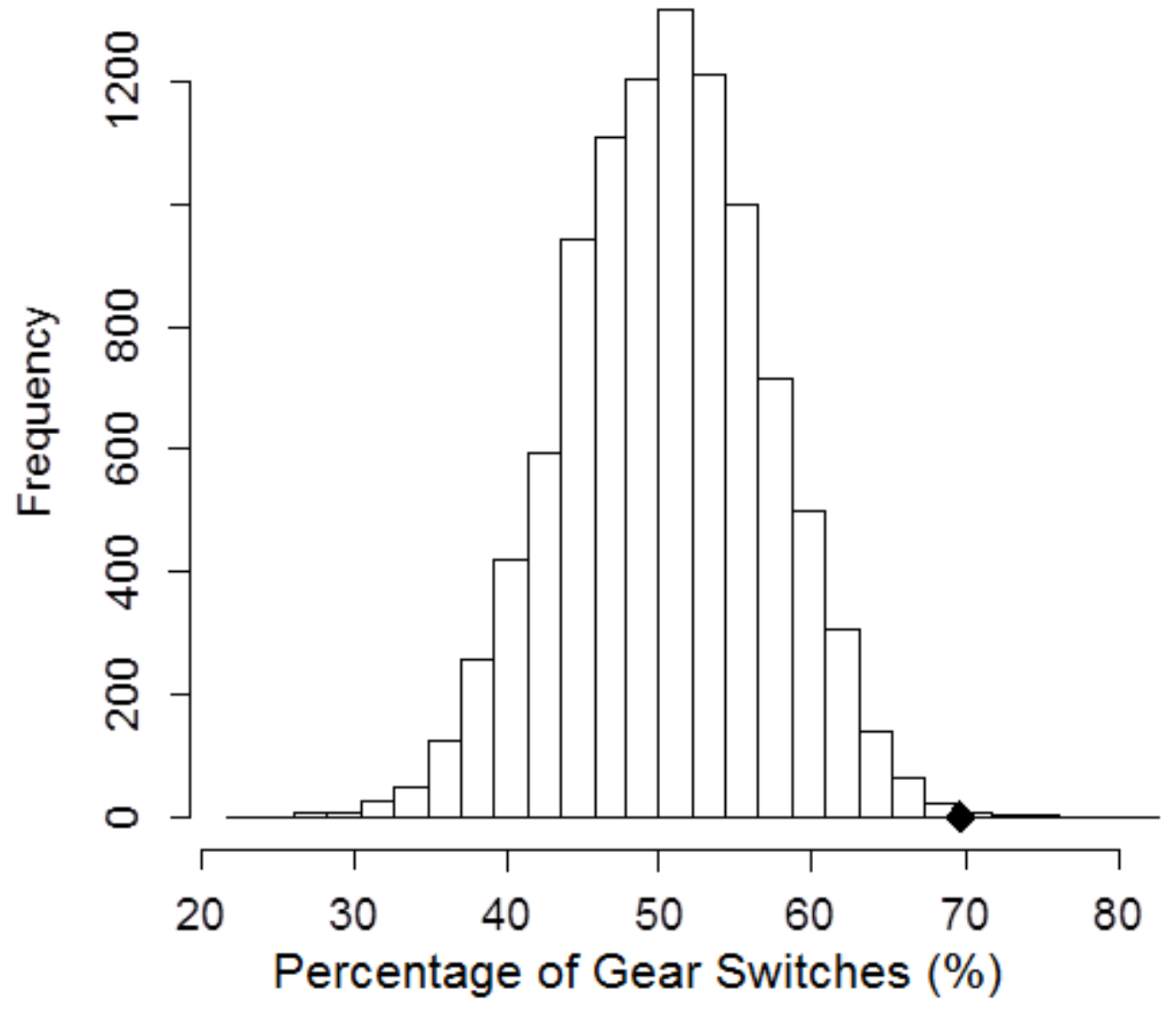


Figure 5.2 Simulated probability distribution of the percentage of salmon that would exhibit gear switch in the absence of gear avoidance. The distribution represents the outcomes of 10,000 simulations, which multinomially assigned a recapture gear to 46 salmon based on gear catch probability. Among 46 salmon recaptured in Rivers Gaula, Lakselva, Orkla, and Otra in 2012 and 2013 , 32 (70\%) exhibited gear switch, represented by the black diamond. 


\section{$\underline{5.7 \text { Discussion }}$}

The recapture rates of caught-and-released salmon observed in this study are among the highest reported for Atlantic salmon recreational fisheries. It is apparent from the simulation of gear switch that recapture events were driven at least in part by salmon that were naïve to gear types that they had not previously been captured by. I therefore demonstrated that salmon appear to avoid recapture by the same gear as they had previously been captured by. This reveals that although salmon released by anglers do reenter the vulnerable population, the extent to which they provide successive opportunities to anglers to catch them depends on the variation of effort with gear types within the river.

Factors that affect the vulnerability of fish are typically attributed to either intraspecific variation in physiological or behavioural traits (i.e. "heterogeneity"; Marten 1970) or to changes to behaviour after release that affect the availability of fish in the river to be caught (i.e. “contagion”; Marten 1970). Learning could be considered contagion when salmon avoid familiar gear. Learned avoidance by released salmon may explain the observation that salmon were unlikely to be captured by the same gear type multiple times in this study. Fish are capable of learning or changing patterns in behaviour because of past experiences (Dill et al. 1983). Moreover, it is increasingly evident that learning is important to behavioural development of fish (Brown et al. 2011) and that learning to recognize future dangerous situations is adaptive (Lima and Dill 1990). Salmonids learn, and it likely plays an important role in migratory behaviour (Dodson 1988). Raat (1985) identified declining catch per unit effort of common carp 
(Cyprinus carpio) in association with hooking and observed that the avoidance behaviour was lost after a one-year absence of fishing effort. Salmonids have also been demonstrated capable of discriminating against angling gear, and Askey et al. (2006) suggested that declining catch rates of rainbow trout (Oncorhynchus mykiss) after several days of angling resulted from released fish learning hook avoidance.

In the study, gear avoidance by salmon is consistent with observations from other studies that describe learned hook avoidance, however, an alternative explanation for the observed rate of gear switch is that salmon are not necessarily consciously discriminating among gear types, but implicitly doing so by changing their migratory behaviour or habitat selection. Huntingford and Wright (1989) described changes to habitat selection by stickleback (Gasterosteus aculeatus) in response to predator burden. Behavioural changes often result from catch-and-release of salmon, particularly departure from normal migratory patterns immediately after release (i.e. fallback; Mäkinen et al. 2000; Thorstad et al. 2007). Cox and Walters (2002) described such changes in behaviour or habitat selection resulting from catch-and-release angling as changes to spatial vulnerability. Similarly, recaptured salmon may have switched gear because they were in different areas of the river after catch-and-release than before, for instance by moving to deeper water. If released salmon seek out different areas of the river in which to recover, gears that have better access to such areas would have disproportionate success. For instance, if released salmon are more likely to be found in deeper habitat, they would be more likely to be recaptured by worms or spoons, which have better access to deep water than flies. 
Gear switching salmon were not necessarily recaptured later after initial capture than non-gear switching salmon. The suggestion that salmon learn implies that they must eventually also forget (e.g. Raat 1985), in which circumstance it may be expected that gear switching salmon would be recaptured soon after catch-and-release and non-gearswitching salmon would be captured significantly longer after catch-and-release. Correspondingly, Thorley et al. (2007) found that salmon captured early in the angling season are most likely to be recaptured, implying some role of forgetting supporting recapture in salmon fisheries. However, I did not identify a relationship between gear switching and time elapsed between capture and recapture. In Thorley et al. (2007), early run fish captured in February were most likely to be recaptured, whereas the angling season in Norway does not begin until June. The briefer period during which salmon could be captured may explain the differences in temporal recapture trends.

Salmon were often recaptured at or near the initial capture site, even after a long period of time elapsing between initial capture and recapture. This may occur because the salmon were captured the first time at spawning grounds and were therefore not likely to continue migrating. Alternatively, catch-and-release may reduce the capacity or motivation for salmon to continue migrating after catch-and-release. Several salmon were recaptured below the initial capture location. Fallback, downriver movement made by salmon after catch-and-release (Mäkinen et al. 2000; Thorstad et al. 2003) is often attributed to stress or exhaustion from angling. Mäkinen et al. (2000) suggested that the magnitude of fallback may be related to the degree of stress experienced based on a comparison between gill net and rod caught salmon. However, the fitness consequences of fallback are not well understood, particularly in terms of whether salmon that fall back 
are less likely to reach their ultimate spawning destination, reproduce successfully, or survive over the winter.

Various factors influence the propensity of various gear types to capture fish. Gear types may select for fish with different behavioural types and may result in different magnitude of hooking injury and mortality (e.g. Gargan et al. 2015), which could affect recapture rates with different gear types. Salmon may not necessarily categorize different gears the way that I did in this study (i.e. as flies, lures, or worms), and colour, size, shape, or depth fished may all be proximate factors that are avoided and could be further investigated in a future study. Interestingly, olfactory cues may be an important factor that salmon learn to avoid after capture, particularly that of earthworms, which trigger the sense of smell whereas flies or lures do not. Garrett (2002) stated that fish may not be able to discriminate well against live baits and Beukema (1970) found that northern pike (Esox lucius) had difficulty learning to avoid worms relative to avoiding lures. However, I did not identify such a trend and salmon may have less difficulty learning to avoid worms given that they are not actively feeding during migration and therefore not necessarily attracted to food the same way that a pike would be (Kadri et al. 1995; but see Johansen [2001], who found that Atlantic salmon may feed opportunistically on invertebrates during the migration).

Salmon recapture in this study was associated with gear switching, suggesting that recapture would be most frequent in fisheries that permit the use of multiple gear types. However, gear usage is different depending on the river or region. Depending on local conventions, many different gears are used for catching salmon, for instance in Ireland, Gargan et al. (2015) report that anglers target migrating salmon using live prawns, which 
are not used in Norway. In some fisheries, management strategies may limit the use of live baits, control the use of weighted lines or flies, or otherwise restrict fishing gear in an effort to reduce the efficiency with which anglers capture fish. Based on the findings, it could be expected that fisheries where anglers are restricted from using many different types of gear there would be fewer instances of recapture relative to mixed-gear fisheries where gear switch may increase recapture rates. However, I could not identify any empirical support for this, particularly because most rivers are open to multiple gear types. The exception is Richard et al. (2013), which identified 5\% recapture of tagged salmon in the Escoumins River, Canada where angling is restricted to fly fishing. Although this is a relatively low rate of recapture, Thorstad et al. (2003) calculated a similarly low rate of recapture (4\%) in River Alta, Norway, which is a mixed gear fishery. More data would be necessary for accurately determining the effect of gear restrictions on salmon recapture.

Capturing migrating salmon is an economically and culturally important activity that is also relatively mysterious: neither scientists nor anglers truly understand why salmon that do not feed while migrating are catchable. Many salmon may be captured during the upriver migration (Gudjonsson et al. 1996), and individuals that are released may be captured multiple times. In this study, I have demonstrated that released salmon that are recaptured exhibited gear avoidance and were more frequently recaptured by different gear than they were first captured by. Improved understanding about mechanisms that underlie spatial and behavioural vulnerability of fish to angling provides some insight into salmon behaviour during the migration and has the potential to inform 
fisheries managers about factors that influence catches in recreational fisheries (Arlinghaus et al. 2013). 


\section{Chapter 6 Pan-Holarctic assessment of post-release mortality of angled Atlantic salmon Salmo salar}

\subsection{Abstract}

Recreational Atlantic salmon fisheries are culturally and economically important, but confronted with global population declines, catch-and-release has frequently replaced harvest in these fisheries. Many studies have evaluated the effects of catch-and-release angling on Atlantic salmon; however, studies typically focused on a single system and had small sample sizes. Combining data from Atlantic salmon catch-and-release studies conducted in 12 rivers throughout the pan-Holarctic range of wild Atlantic salmon, I modeled delayed mortality data using logistic regression. The model was based on 512 salmon $(75 \pm 15 \mathrm{~cm}$ SD TL) captured and released with electronic tags (i.e. radio or acoustic transmitters), which permitted the determination of fish fate after release (delayed mortality). The percentage of salmon categorized as survivors after release was high (93\%). Salmon with longer body length tended to be played for longer durations $\left(\mathrm{R}^{2}=0.60\right)$ but there was no significant effect of fish length or playing time on mortality. Water temperature at capture emerged as a significant predictor of delayed mortality of salmon. Individuals captured by flies had significantly higher survival $(96 \%)$ compared to lure $(86 \%)$ and natural bait $(85 \%)$ caught salmon. Data from throughout the range of Atlantic salmon confirm that fish captured by anglers adhering to best practices have high probability of surviving catch-and-release angling. 


\section{$\underline{6.2 \text { Introduction }}$}

Fisheries can have substantial and diverse impacts on ecosystems and on the environment (Dayton et al. 1995; Chuenpagdee et al. 2003; Large et al. 2015). For some fish that escape fisheries (Chopin and Arimoto 1995) or are released (Arlinghaus et al. 2007), interactions with fishing gear can cause physical damage, physiological stress, or cognitive impairment that contribute to decreased fitness (Raby et al. 2014; Wilson et al. 2014). Encounters can be also be lethal. Some fish die upon capture but more may experience delayed mortality after release arising from physical injuries or prolonged physiological responses (Muoneke and Childress 1994; Bartholomew and Bohnsack 2005; Arlinghaus et al. 2007). For these reasons, increased adoption of catch-and-release in recreational fisheries has been confronted by concerns arising from doubts that the practice provides the anticipated population conservation benefits (Barnhart 1989; Spitler 1998). Therefore, substantial efforts have been made to document the effects of recreational angling on individual fish as well as fish populations to determine the sustainability of recreational catch-and-release fisheries and to manage their risk against the conservation, economic, and cultural benefits (Muoneke and Childress 1994; Cooke and Suski 2005; Arlinghaus et al. 2007).

The Atlantic salmon has a pan-Holarctic distribution and has been targeted by fisheries for millennia (Hindar et al. 2007, 2010; Turrero et al. 2014a), with recreational fisheries increasing in popularity during the 1800 s and spreading from the British Isles to other nations by the end of that century (Verspoor et al. 2008). Conservation concerns resulted in catch-and-release being advocated as early as the mid-1800s (Nettle 1857). 
During the $20^{\text {th }}$ century, declining salmon stocks resulted in the closure of many commercial fisheries (Dempson et al. 2004) as well as implementation of catch-andrelease as a regulatory strategy for recreational Atlantic salmon fisheries (Barnhart 1989), which was believed to maximize the socioeconomic value society derived from each salmon while concurrently minimizing fishery impacts on populations (Policansky 2002). However, Atlantic salmon catch-and-release has received specific criticism from stakeholders (e.g. Wydoski 1976; Barnhart 1989) arising from concerns that released fish may frequently experience delayed mortality post-release because of the capture event.

Several investigators have examined the effects of recreational angling on individual Atlantic salmon behaviour, wounding, or survival. These include studies of captive fish on the impacts of various hook types (Warner and Johnson 1978; Warner 1979), the short and long-term physiological effects of angling (Tufts et al. 1991; Wilkie et al. 1996, 1997), and short-term survival in cages or pens (Booth et al. 1995; Dempson et al. 2002). Most recently, there has been an interest in documenting the fate of fish after release (i.e. delayed mortality) by integrating electronic tagging of fish (Donaldson et al. 2008). Electronic tagging and tracking have permitted intensive remote monitoring of behaviour and survival of released wild salmon (Gargan et al. 2015; Havn et al. 2015; Lennox et al. 2015 [Appendix B]; Richard et al. 2013; Thorstad et al. 2003; Webb 1998). Most of these studies have reported that survival of salmon after release can be relatively high (>90\%). However, individual studies have suffered from an inability to collect and tag sufficient numbers of salmon to meet a key study objective: identify factors that can be used to explain mortality of salmon released by anglers and potentially predict the outcome of salmon catch-and-release events. 
By compiling the data available from a variety of published and unpublished studies on Atlantic salmon released from recreational angling gear, I overcame the small sample size problem to explain causes of delayed mortality in sport fisheries throughout the Atlantic salmon's geographic range. Data sharing is an important part of contemporary science and integral to broad analyses (Parr and Cummings 2005; Kowalczyk and Shankar 2011; Tenopir et al. 2011). I focused on data from telemetry studies in which the post-release fate of free-swimming fish could be quantified over the long-term from detection data. The data used were collated from studies conducted throughout the distribution of wild Atlantic salmon, generally with the common goal of calculating the post-release delayed mortality of adult salmon prior to spawning to identify the factors contributing to mortality.

\section{$\underline{6.3 \text { Methods }}$}

\subsubsection{Data Collection}

Data from telemetry studies in which wild Atlantic salmon were tagged after being captured on recreational angling gear were shared among the authors. Data were collected from rivers throughout the range of Atlantic salmon (Figure 6.1; graphics created with the maptools package in R [Bivand and Lewin-Koh 2015] and ggplot2 [Wickham 2009]). All available metadata about salmon that were tagged, including fish size, the year and location of the study, the date and water temperature when the fish were captured, were collated (Table 6.1). 
Most data came from studies where a biologist worked alongside recreational anglers capturing fish from riverbanks, with biologists tagging the salmon prior to release. In the Escoumins River, fish released by anglers were marked by adipose fin punch, verified by genetic analysis, and were then recaptured in an upstream fish ladder and tagged then (see Richard et al. 2014). Although the anglers had a range of experience, they were generally described as being experienced in salmon fishing and handling. Both radio and acoustic tags were used to monitor the movement and survival of salmon after release. In studies on Norwegian salmon, individuals that were assessed as having life-threatening wounds were not tagged, therefore the information necessary for modelling was not available. Fish were anaesthetized with clove oil in the Escoumins River and in tricaine methanesulfonate in Rivers Dee and Bann. No anaesthetic was used for tagging in the other studies. For the analysis, fishing gear types were reduced to three categories: fly (e.g. dry fly, wet fly, tube fly, bead head nymph, fly suspended under a float indicator), natural bait (e.g. worms, shrimp), and lures (e.g. spoons, spinners, wobblers). Reported fork lengths of salmon were converted to total length by multiplying fork length by 1.046; fish weight in Webb (1998) was converted to length from a standard length-weight conversion chart developed for the River Dee (Hawkins, unpublished data). Hooking locations were classified in two categories: superficial (e.g. jaw/ mouth/ foul) and deep (e.g. gills, eyes, throat/ esophagus, roof of mouth, tongue). When a multi-pronged hook was lodged in both a superficial and a deep location, the fish was deep hooked.

Because studies were conducted independently, not all datasets were fully complete and I encountered an analytical problem with missing data. Instead of deleting 
entries with missing data, I opted to impute missing values. Completing data sets with imputation is useful for preserving relationships between predictor and outcome variables without biasing regression coefficients (Harrell 2015a). The dataset was therefore completed using multiple imputation implemented by the aregImpute function in the $\mathrm{R}$ (R Core Team 2016) package Hmisc (Harrell 2014), which uses simple bootstrapping and predictive mean matching to replace missing values based on observations from the nonmissing target variables (Harrell 2014). The aregImpute function generates values by fitting a flexible additive model based on all non-missing observations available for that variable. The number of knots used for continuous variables by the aregImpute function was specified to be 0 and the number of imputations was set to 5 as recommended by the package documentation (Harrell 2014). To provide additional information to the imputation algorithm to predict missing water temperature values, the latitude of the study river was included as well as an estimated mean air temperature at the closest weather station on the date of capture.

Detections of tagged fish were used to establish the fate of Atlantic salmon that were released using both radio and acoustic telemetry receivers (Table 6.1). Given that the data were collected in various contexts with different study designs and limitations, there were some differences among studies in how the endpoint of mortality of the fish was determined (Table 6.1). Generally, observations that the tag had ceased movement without up- or down-river movement during or after spawning was interpreted as mortality. Fish that were recaptured by anglers were considered survivors. 


\subsubsection{Data Analysis}

To avoid biasing parameter estimates and to increase predictive power, a single set of candidate predictors was established for the full model, without reduction (Harrell 2015a). Gear type, date of year (i.e. Julian day), hook location, play time, water temperature, and total length were considered as potentially relevant fixed effects as well as the interaction between water temperature and play time. Air exposure was not included because data for air exposure were not consistently reported as a continuous variable. Information on the extent of bleeding was also excluded because it was not collected in a consistent manner and there was likely to be significant observer bias among studies; instead, hook location was used as an index of injury. Sex was excluded because external sex determination can be difficult for immature adult salmon (Kadri et al. 1997) and incorrect assignment would add uncertainty to the model.

Survival was modeled by logistic regression. Each study was conducted independently in various rivers using slightly different tagging techniques and methods of determining survival (Table 6.1), so the study ID was initially incorporated as a random intercept in the model in consideration of possible lack of independence. Mixed effects logistic regression was implemented by the glmer function in the R package lme4 (Bates et al. 2015). Continuous predictors were scaled because the original model failed to converge due to large eigenvalue ratios. Model fit was assessed with the hoslem_gof function in the sjstats package (Lüdecke 2016). Factors with few levels that are used as random effects can result in small or null intercept values of random effects. Although comparison of models fitted with random effects is possible with linear models by using 
information criteria, it is trivial for generalized linear models. The variance estimate of the random effect was zero, indicating that the variation among studies was nominal. I therefore opted for a fixed effects logistic regression implemented by $l \mathrm{rm}$ in the rms package (Harrell 2015b). Logistic regression fitted without random effects is more flexible for testing model fit and modeling predicted probabilities (calculated using the Predict function in rms with continuous variables set to the mean and categorical predictors set to the most frequent value). Index adjusted (Steyerberg et al. 2010) Brier's Score and Harrell's c (equivalent to area under the curve; Harrell 2015a) were used to evaluate predictive performance of the logistic regression model. Odds ratios are presented to highlight the importance of predictor variables on mortality by exponentiating regression coefficients. Model fit of the logistic regression was assessed with the native test in the rms package, which is the le Cessie - van Houwelingen - Copas - Hosmer unweighted sum of squares test for global goodness of fit (Hosmer et al. 1997) at $\alpha=0.05$.

\section{$\underline{6.4 \text { Results }}$}

I collated salmon telemetry data from 12 rivers between the $48^{\text {th }}$ and $70^{\text {th }}$ northern parallel latitudes in Canada, Ireland, Scotland, Northern Ireland, and Norway (Figure 6.1). Survival data were available from 512 individuals (mean fork length $75 \pm 15 \mathrm{~cm}$ TL; range: $44-122 \mathrm{~cm}$ TL). The studies generating the data were conducted between 1996 and 2014 and all fish were captured between March 2 and October 15 (median date of capture $=$ August 9). Salmon were captured at water temperatures ranging from $7.5-$ 
$22{ }^{\circ} \mathrm{C}$ (mean $=14 \pm 3{ }^{\circ} \mathrm{C} ; 176$ missing values). On average, salmon were played for $9 \pm$ 7 min (range: $2-70$ min; 199 missing values). There was a positive correlation between salmon size and playing time $\left(\mathrm{R}^{2}=0.60\right)$. Most salmon were captured by artificial flies $(\mathrm{N}=279)$ with others captured on natural bait $(\mathrm{N}=11)$ or lures $(\mathrm{N}=56 ; 166$ missing values). Most $(\mathrm{N}=288)$ salmon were hooked superficially in the jaw or mouthparts but some were deep hooked $(\mathrm{N}=20)$. Others were foul hooked $(\mathrm{N}=9)$ and there were 195 missing values. Among the 512 salmon caught and released in these studies, 478 were categorized as catch-and-release survivors (93\%).

\subsubsection{Regression Modelling}

Total length of fish $(\mathrm{z}=0.69, \mathrm{P}=0.49$; Table 6.2; Figure 6.2) and playing time ( $\mathrm{z}$ $=-1.27, \mathrm{P}=0.20$; Table 6.1; Figure 6.3) exerted no significant effect on salmon survival. Delayed mortality, however, was significantly influenced by water temperature at the time of capture $(\mathrm{z}=-3.08, \mathrm{P}<0.01$; Table 6.2$)$. Odds of mortality increased by 1.38 for each ${ }^{\circ} \mathrm{C}$ unit increase in water temperature. Model-predicted probability of mortality for salmon captured at the mean temperature of $14{ }^{\circ} \mathrm{C}$ is $4 \%$, and $16 \%$ at the max temperature of $22{ }^{\circ} \mathrm{C}$ (Figure 6.4). Salmon captured by flies had higher survival (95\%) than salmon captured by lures $(85 \%)$ or bait $(86 \%)$. Delayed mortality of salmon caught by flies was also significantly more frequent $(\mathrm{z}=2.12, \mathrm{P}=0.03)$ relative to mortality of salmon captured fishing with bait (Table 6.2). Odds of survival increased by 5.55 for flycaught fish relative to those captured by bait $(\mathrm{z}=2.12, \mathrm{P}=0.03)$, and by 1.75 for lurecaught fish relative to bait-caught fish $(\mathrm{z}=0.66, \mathrm{P}=0.51$; Table 6.2; Figure 6.5). Flies 
more frequently deep hooked fish (8\%) compared to bait $(0 \%)$ and lures $(3 \%)$. Survival was high for fish hooked in deep (96\%) and superficial (93\%) anatomical locations and was not a significant predictor of mortality $(\mathrm{z}=0.42, \mathrm{P}=0.72$; Table 6.2; Figure 6.6). The model fit the data $(\mathrm{z}=1.05, \mathrm{P}=0.29)$ and had moderate predictive performance (Brier's Score $=0.06$; Harrell's $c=0.73$ ). 


\section{$\underline{6.5 \text { Tables }}$}

Table 6.1 Summary of data collected and shared for this project including the number of salmon tagged, average length $( \pm 1$ SD), location and average water temperature $( \pm 1 \mathrm{SD})$ of fish capture. Studies that did not have the associated data are marked by NA. See Figure 6.1 for a map of the study sites. Mean water temperature is "Mean Temp $\left({ }^{\circ} \mathrm{C}\right)$ " and number of dead fish is the column "Mort".

\begin{tabular}{|c|c|c|c|c|c|c|c|c|c|c|}
\hline \multirow[b]{3}{*}{ Study } & \multirow[b]{2}{*}{ Mean } & \multirow[b]{3}{*}{ Year } & \multirow[b]{3}{*}{ River } & \multirow[b]{3}{*}{ Nation } & \multirow{3}{*}{$\begin{array}{l}\text { Tag } \\
\text { Type }\end{array}$} & \multirow{3}{*}{$\begin{array}{l}\text { Total } \\
\mathrm{N}\end{array}$} & \multirow[b]{3}{*}{ Mort } & \multirow{3}{*}{$\begin{array}{c}\text { Mean Length } \\
\text { (cm) }\end{array}$} & \multirow{3}{*}{$\begin{array}{l}\text { Mean } \\
\text { Temp } \\
\left({ }^{\circ} \mathrm{C}\right)\end{array}$} & \multirow[t]{3}{*}{ Fate } \\
\hline & & & & & & & & & & \\
\hline & Tagging Date & & & & & & & & & \\
\hline & & & & & Gastric & & & & & Cessation of \\
\hline & & & & & Radio & & & & & movement \\
\hline & & & & & & & & & & and \\
\hline Dee River & & & & & & & & & & observation \\
\hline Report & 8 October & 2008 & Dee & Scotland & & 20 & 0 & $76 \pm 9$ & NA & of carcass \\
\hline
\end{tabular}


Gastric

Radio

Dee River

\section{Report}

Scotland
Gastric

Radio

Dee River

Report

1 October

2010 Dee

Scotland

External

Radio

Gargan et al.

Ireland

60

$376 \pm 10$

60

$0 \quad 73 \pm 8$

21
Cessation of

movement

and

observation

NA of carcass

Cessation of

movement

and

observation

NA of carcass

No upstream

movement

of tagged

$13 \pm 1$ fish. 
External

Radio

Gargan et al.

2015

17 September 2007 Owenmore Ireland

Gargan et al.

2015

28 September 2006 Feale

Ireland

External

Radio

Gargan et al.

2015

26 August

2007 Mulkear

Ireland

External

Radio
25 July

2012 Otra
External

Radio

Havn et al.

2015
No upstream

movement

of tagged

$31 \quad 1 \quad 58 \pm 6$

$13 \pm 1$ fish

No upstream

movement

of tagged

$15 \quad 1 \quad 60 \pm 6$

$14 \pm 1$ fish

No upstream

movement

of tagged

$9 \quad 4 \quad 56 \pm 6$

$11 \pm 1$ fish.

Transmitter

recorded in

$\begin{array}{lll}52 & 9 & 68 \pm 9\end{array}$

$17 \pm 1 \quad$ same 
location

through

study with

no upstream

movement.

External

Radio

Havn et al.

2015

2 August

2013 Otra

Norway

Johansen et al.

unpublished

18 July

Orkla

Norway
23

$4 \quad 65 \pm 10$

$6 \quad 0 \quad 76 \pm 15$
Transmitter

recorded in

same

location

through

study with

no upstream

$20 \pm 1$ movement.

Transmitter

$12 \pm 1$ recorded in 


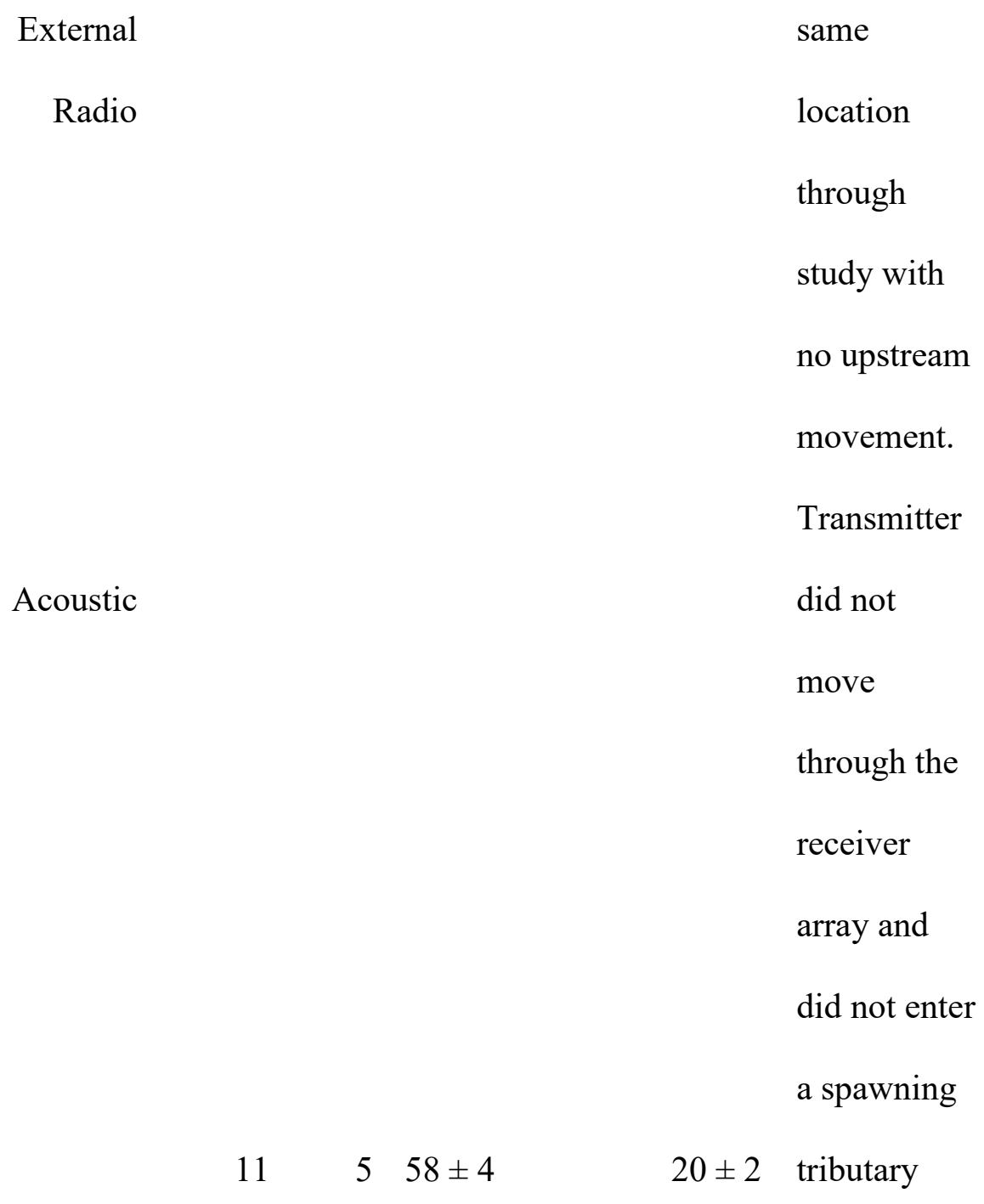




\section{External}

Radio

Lennox et al.

2015

[Appendix B] 1 July

2013 Gaula

Norway

External

Radio

Chapter 3

3 August

2014 Lakselva

Norway
Visual

confirmation

of survival

during

spawning.

One fish that

disappeared

considered a

$\begin{array}{lll}27 & 3 & 89 \pm 10\end{array}$

$14 \pm 3$ survivor.

Visual

confirmation

of survival

during

spawning.

$39 \quad 1 \quad 90 \pm 16$

$14 \pm 1$ One fish that 
disappeared

considered a

survivor.

Gastric

Radio

Richard et al.

2014

23 June

2011 Escoumins

Svenning et

al.

unpublished

9 July

Thorstad et al.

2003
1 August 1999 Alta
Canada

20

$0 \quad 77 \pm 5$

Radio

Norway

External

Norway
Radio
31
Motion

sensor in

tag. One fish

that

regurgitated

tag

$15 \pm 1 \quad$ excluded

Stationary

transmitter

$0 \quad 83 \pm 14$

$11 \pm 1$

\section{Stationary}

$11 \pm 1 \quad$ transmitter 
Thorstad et al.

2003

25 July

2000 Alta

Thorstad et al.

2003

22 July

2001 Alta

Thorstad et al.

2003

5 July

2003 Alta

Gastric

Radio
Radio

18

$1 \quad 96 \pm 12$

Stationary

Norway

Norway

Norway

.

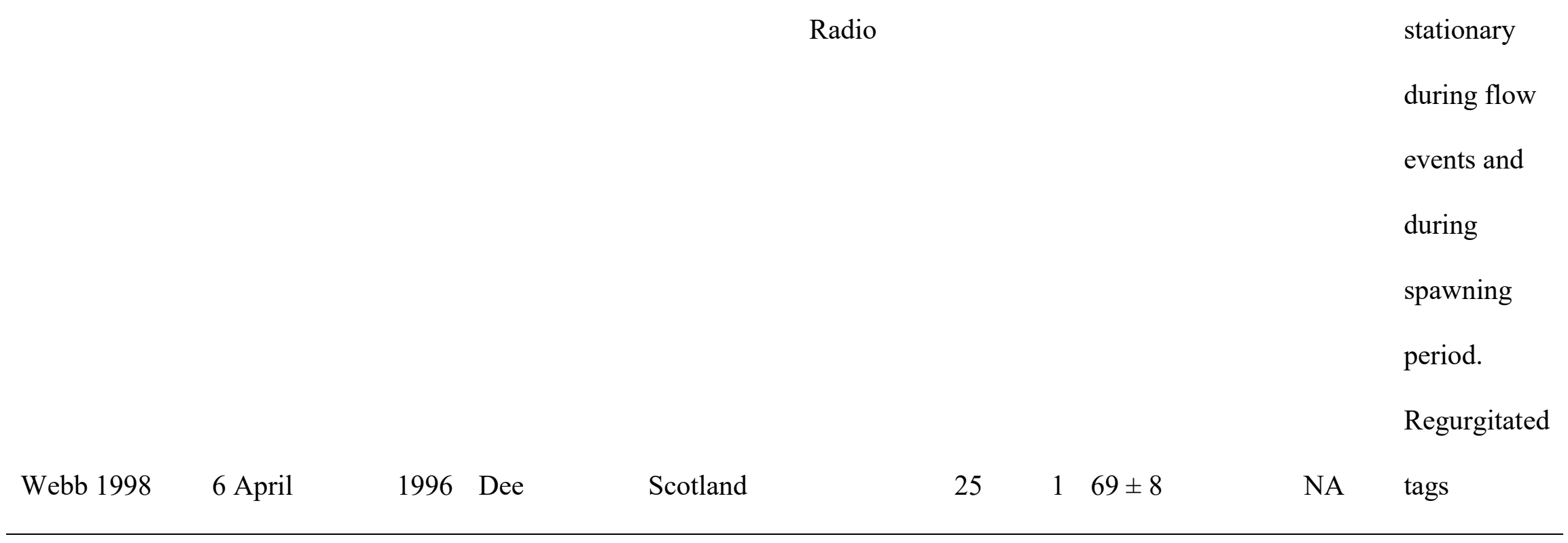


Table 6.2 Regression coefficients, p-values, and odds ratios for logistic regression model fit to Atlantic salmon survival data from 11 studies. Odds ratios indicate odds of survival and are for a one-unit (day for Date, $\mathrm{cm}$ for Total Length, $\mathrm{s}$ for Play Time, ${ }^{\circ} \mathrm{C}$ for Water Temperature) increase of continuous predictors and for a change in odds between levels of categorical predictors. The reference level for hook location is deep hooked and for Gear the reference level is bait. Odds ratios less than 1 indicate a decrease in odds.

\begin{tabular}{lcccr}
\hline & Estimate $\pm \mathrm{SE}$ & z-value & P-value & Odds Ratio \\
\hline Intercept & $4.53 \pm 2.87$ & 1.58 & 0.11 & \\
Date & $0.00 \pm 0.01$ & 0.42 & 0.68 & 1.00 \\
Total Length & $0.01 \pm 0.02$ & 0.69 & 0.49 & 1.10 \\
Play Time & $-0.21 \pm 0.16$ & -1.27 & 0.20 & 0.81 \\
Water Temperature & $-0.33 \pm 0.11$ & -3.08 & $<0.01$ & 0.72 \\
Hook Location (Superficial) & $0.33 \pm 0.78$ & 0.42 & 0.68 & 1.39 \\
Gear (Fly) & $1.74 \pm 0.82$ & 2.12 & 0.03 & 5.71 \\
Gear (Lure) & $0.56 \pm 0.85$ & 0.66 & 0.51 & 1.75 \\
Water Temperature $\times$ Play Time & $0.01 \pm 0.01$ & 1.06 & 0.29 & 1.01 \\
\hline
\end{tabular}




\subsection{Figures}

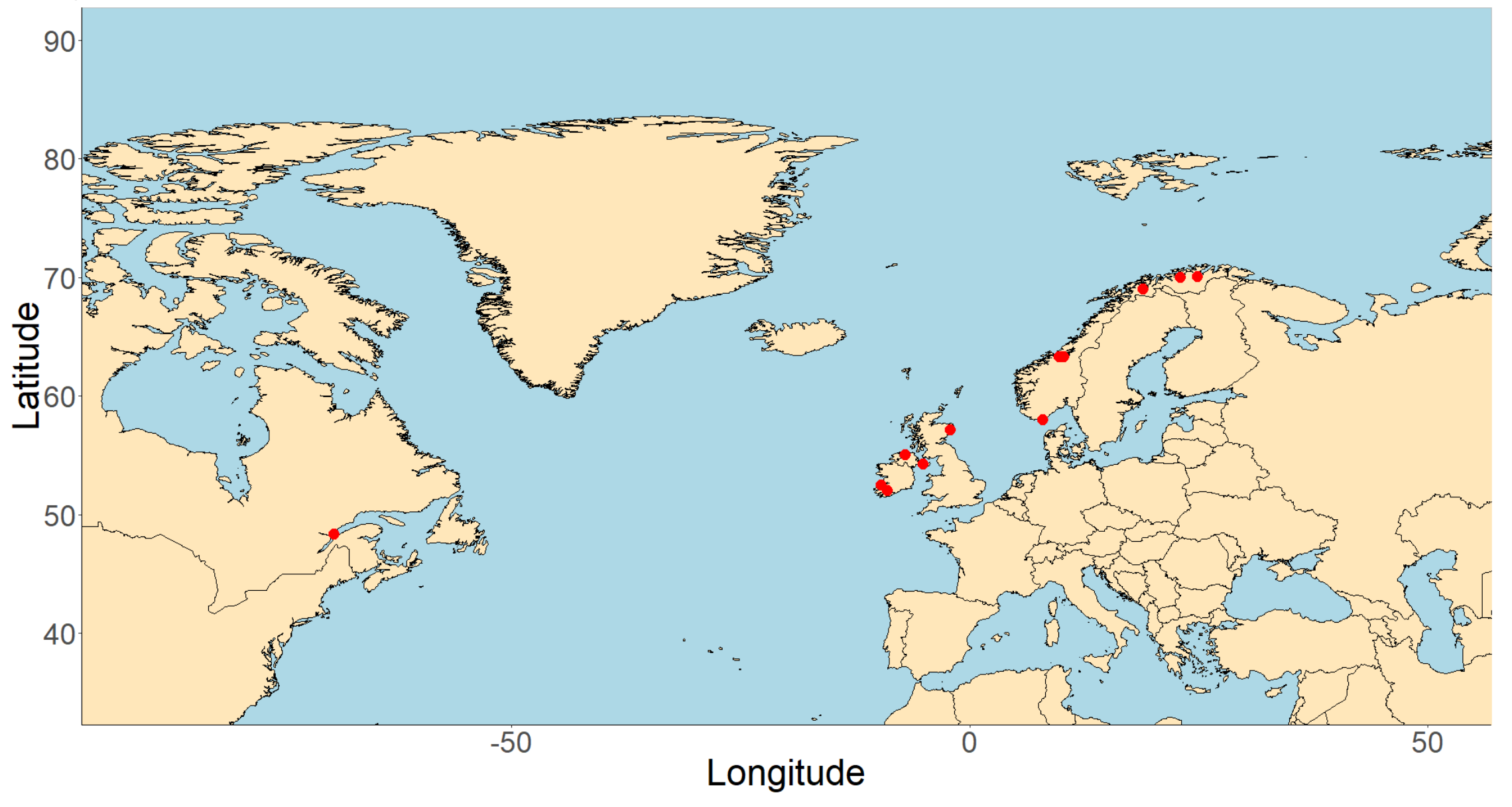

Figure 6.1 Geographic distribution in North America and Europe of 12 salmon rivers with catch-and-release data included in this study. Red points indicate the location of the river where fish were sampled and electronically tagged. 


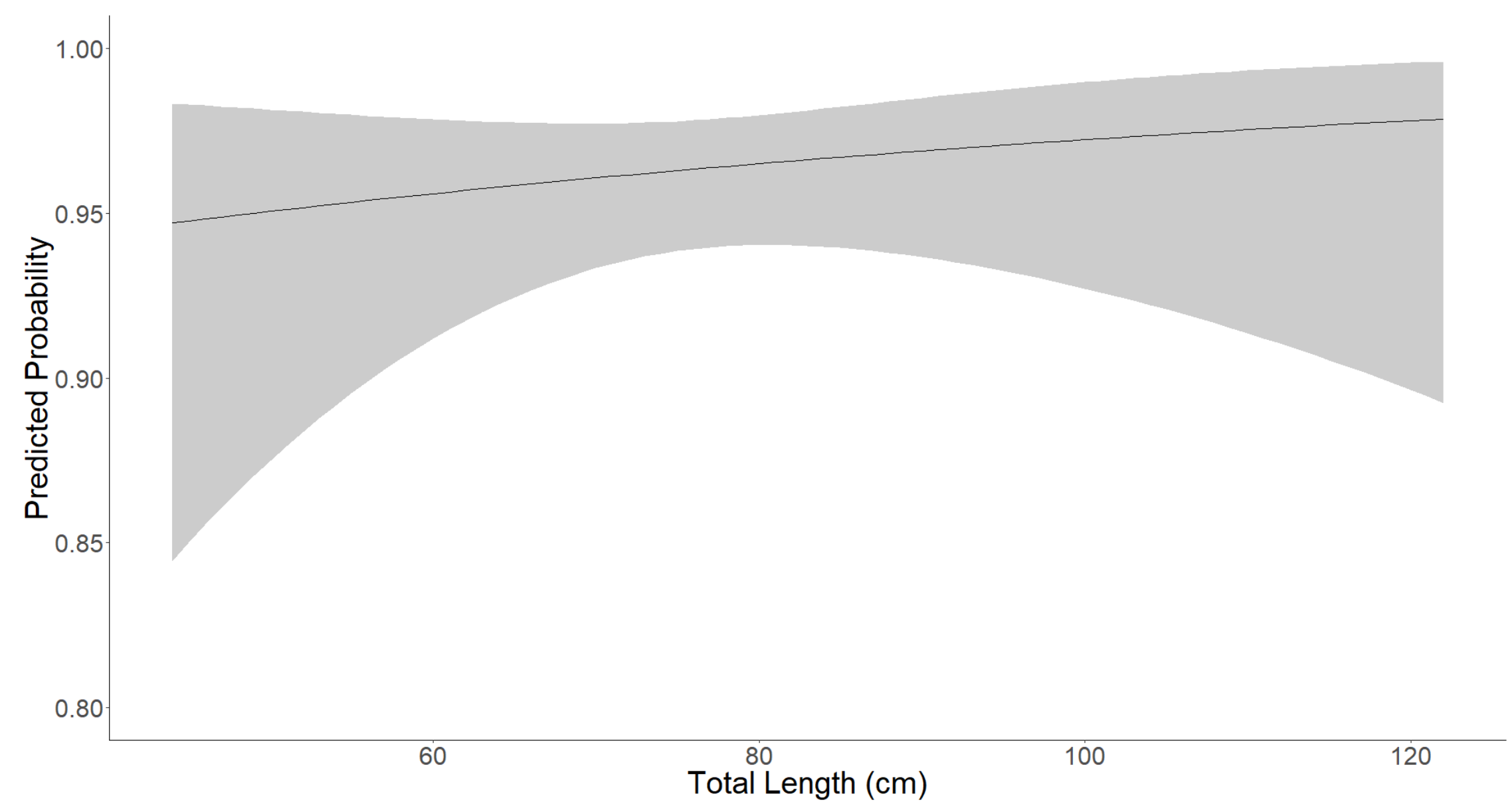

Figure 6.2 Model predicted probability of survival for Atlantic salmon released from recreational fisheries as a function of total length. Predictions are based on a logistic regression model with continuous predictors adjusted to the mean value and categorical predictors adjusted to the most frequent value. Shaded area corresponds to the $95 \%$ confidence interval. 


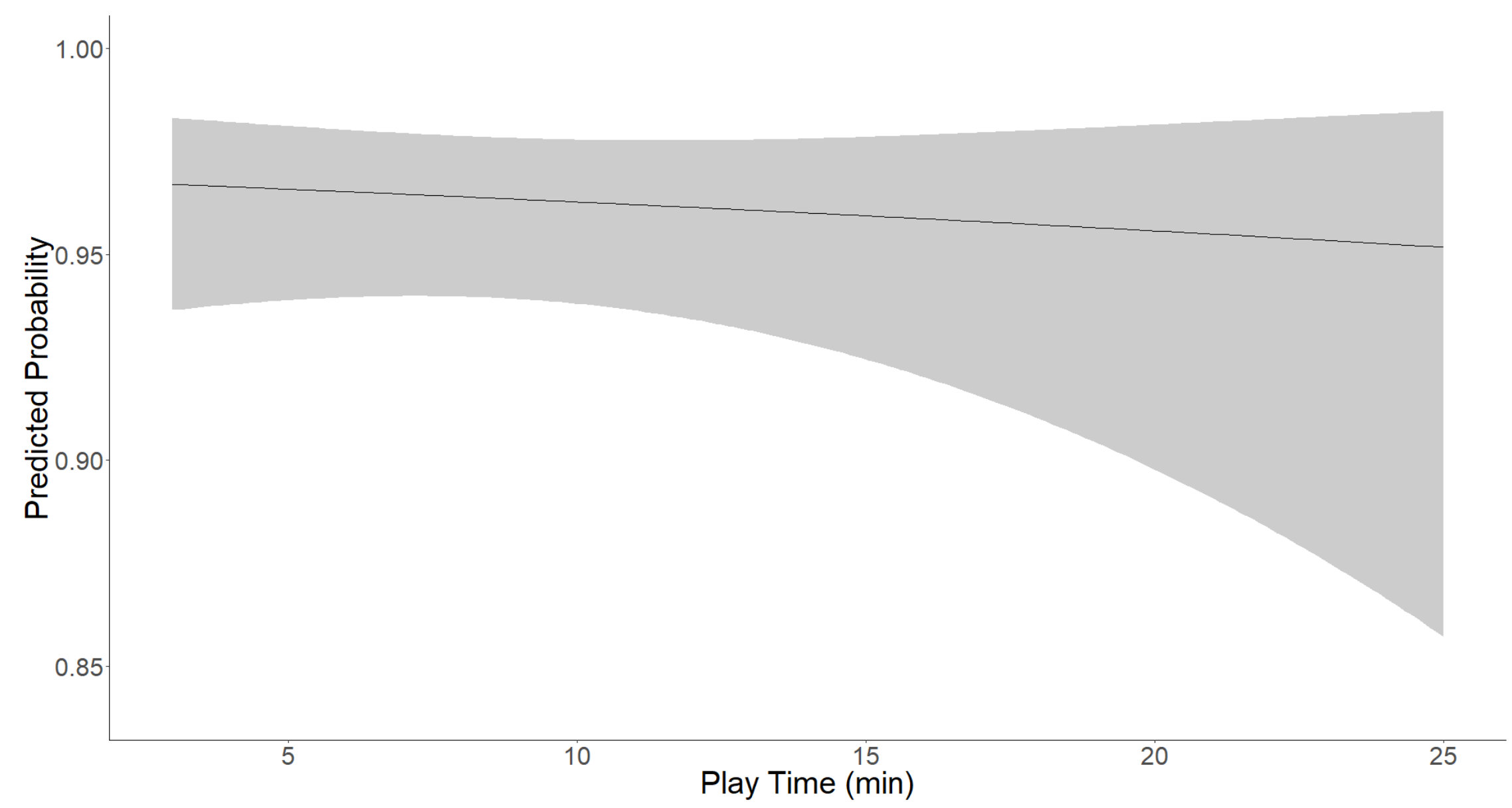

Figure 6.3 Model predicted probability of survival for Atlantic salmon released from recreational fisheries as a function of the time played by anglers. Predictions are based on a logistic regression model with continuous predictors adjusted to the mean value and categorical predictors adjusted to the most frequent value. Shaded area corresponds to the $95 \%$ confidence interval. 


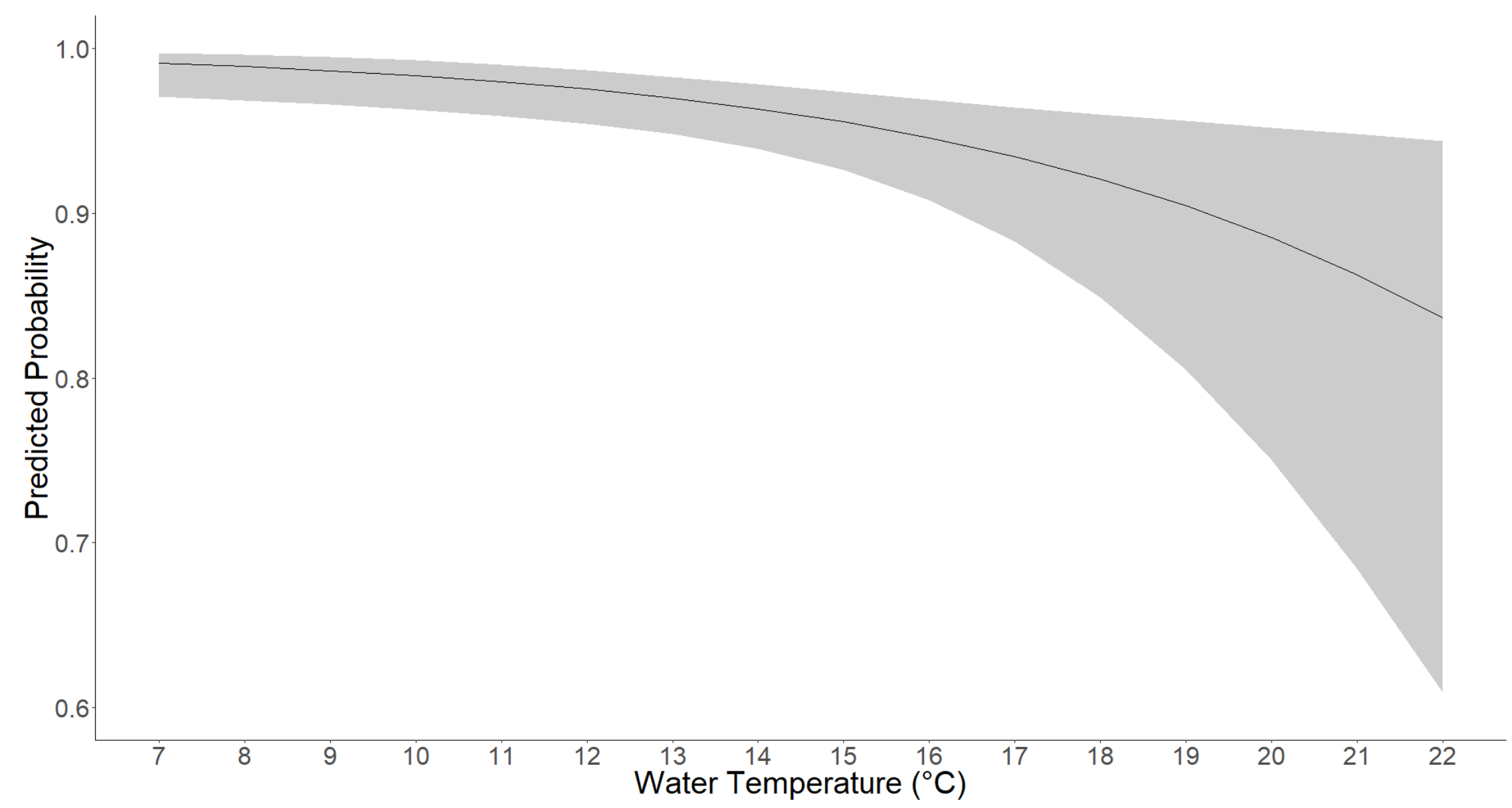

Figure 6.4 Model predicted probability of survival for Atlantic salmon released from recreational fisheries as a function of water temperature at capture. Predictions are based on a logistic regression model with continuous predictors adjusted to the mean value and categorical predictors adjusted to the most frequent value. Shaded area corresponds to the $95 \%$ confidence interval. 


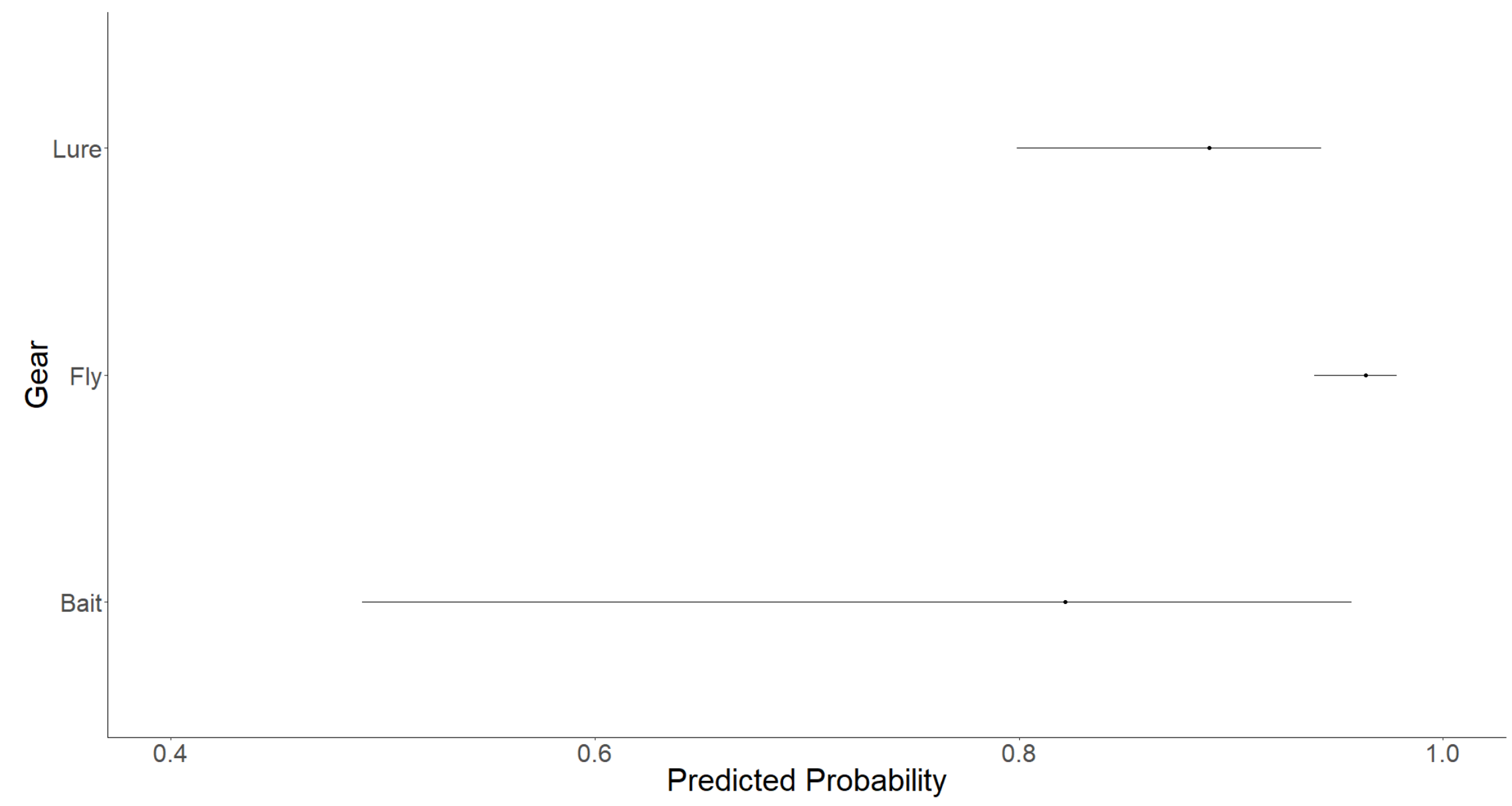

Figure 6.5 Model predicted probability of survival for Atlantic salmon released from recreational fisheries as a function of gear type used for capture. Predictions are based on a logistic regression model with continuous predictors adjusted to the mean value and categorical predictors adjusted to the most frequent value. Error bars indicate the $95 \%$ confidence interval. 


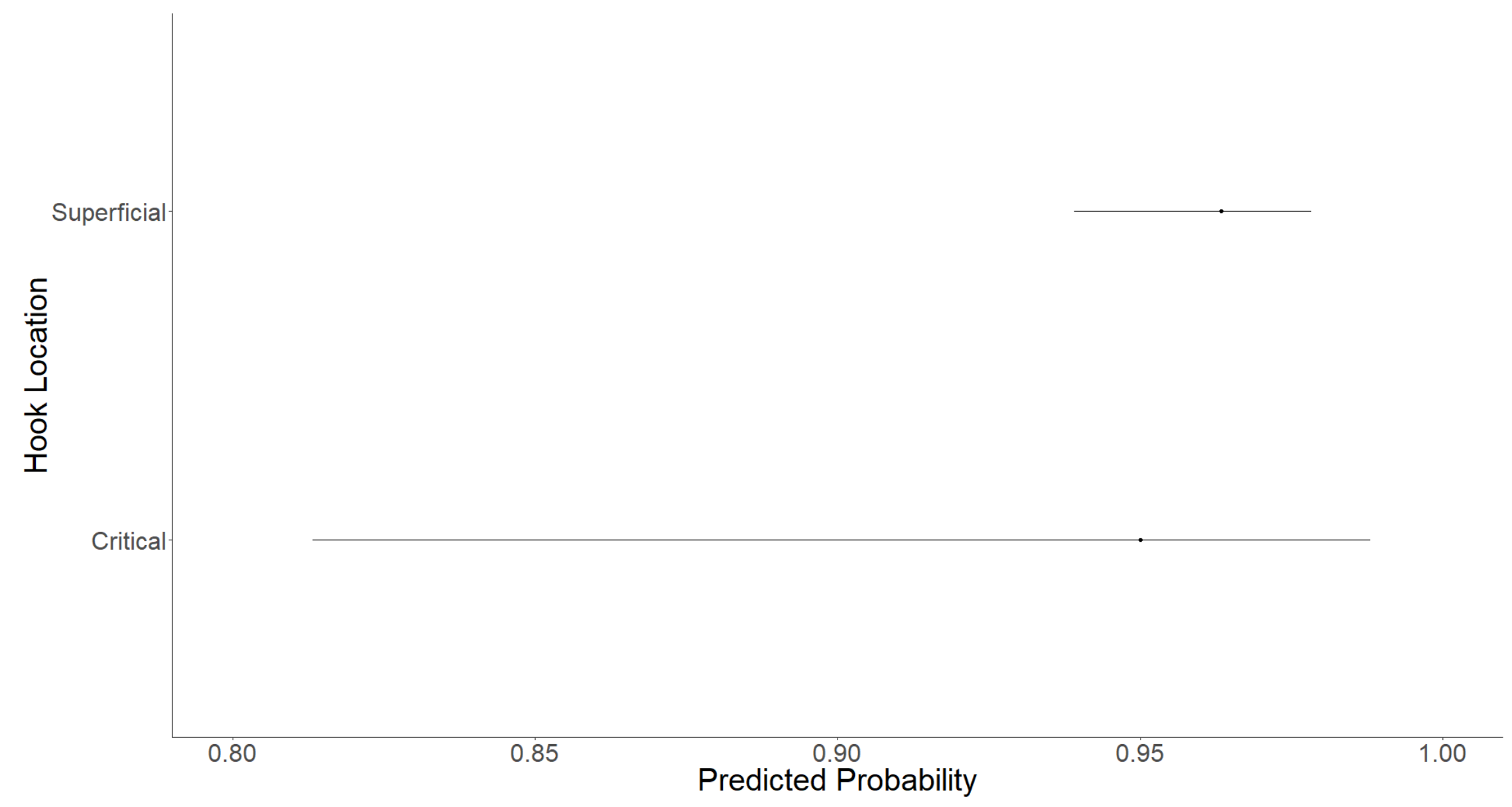

Figure 6.6 Model predicted probability of survival for Atlantic salmon released from recreational fisheries as a function of hooking location. Predictions are based on a logistic regression model with continuous predictors adjusted to the mean value and categorical predictors adjusted to the most frequent value. Error bars indicate the $95 \%$ confidence interval. 


\section{$\underline{6.7 \text { Discussion }}$}

Recreational Atlantic salmon fisheries in spawning rivers can be highly exploitative and capture a large percentage of the total adult population during their upriver migration (Gudjonsson et al. 1996; Erkinaro et al. 1999; Downton et al. 2001). Therefore, mortality due to catch-and-release fishing could exert significant populationscale effects on this species, particularly given that Atlantic salmon fishing is selective for behavioural, physiological, and life history phenotypes (e.g. large fish, repeat spawners that tend to be females, the bolder fish; Consuegra et al. 2005; Pérez et al. 2005; Hard et al. 2008). Whereas most catch-and-release mortality studies have observed infrequent delayed mortality of released salmon ascending to spawning grounds, small sample sizes have mostly precluded an accurate assessment of risk factors contributing to delayed mortality. The approach has reaffirmed that survival of released salmon is frequent in catch-and-release fisheries (93\%), supporting the implementation of catchand-release as a tool for managing these fisheries. However, I also identified significant risk factors that were important predictors of mortality. This knowledge can help guide management of recreational salmon fisheries.

The most salient finding from the analysis was that Atlantic salmon mortality increased when water temperature at capture increased. Water temperature had previously been recognized as a significant risk factor in catch-and-release salmon fisheries (Dempson et al. 2002; Wilkie et al. 1996, 1997; Havn et al. 2015). At high water temperatures, exhausted fish have impaired ability to replenish intramuscular glycogen and cannot restore intramuscular $\mathrm{pH}$ associated with high levels of lactate (Wood et al. 
1983). Wilkie et al. (1996) found that angling at temperatures above $20{ }^{\circ} \mathrm{C}$ resulted in complete exhaustion of anaerobic muscular fuels. Havn et al. (2015) identified fallback and long delays before recovering upriver migration for salmon caught and released at high water temperature (data included in this study). In the analysis, water temperature was a significant predictor of delayed mortality. Some fisheries have adopted seasonal or threshold-based closures as management practices to reduce fishing effort during physiologically sensitive warm-water periods for Atlantic salmon (Dempson et al. 2001). It is always controversial to close rivers for extended periods during angling seasons because of the economic consequences (Bielak 1996) but it is relevant to have data that can contribute to estimates of survival for fish captured during these periods where fisheries experience high temperatures.

Physical injury caused by hooking is the most important predictor of post-release fisheries mortality (Muoneke and Childress 1994). Hooks that penetrate vital organs or tissues can cause critical damage or result in exsanguination (Muoneke and Childress 1994; Bartholomew and Bohnsack 2005). In the data, there were no differences in odds of survival for deep hooked fish compared to those that were superficially hooked. However, I emphasize that by focusing on delayed mortality this might underestimate the impacts of deep hooking because those fish are not often released by anglers (see Methods). There was only one mortality among 20 released salmon that had been deep hooked, perhaps because fish were captured and handled by experienced anglers with the necessary tools to remove hooks without damage. Anglers that carefully remove the hooks may therefore release salmon that are deep hooked and expect them to survive. In other fisheries, cutting the line rather than attempting to remove the hook has been 
demonstrated to be effective for mitigating delayed mortality of deeply hooked fish (Fobert et al. 2009); however, similar research is lacking for Atlantic salmon and cutting the line was not included in the analysis.

The fishing gear used by anglers can influence the hooking damage and condition of fish captured by anglers. When allowed by local regulations, salmon anglers use a variety of methods when targeting salmon, which I simplified to flies, lures, and bait. Warner and Johnson (1978) demonstrated higher survival of fly-caught juvenile landlocked salmon relative to worm-caught (bait) salmon. This was suggested to be one of the most needed catch-and-release research priorities for Atlantic salmon by Hühn and Arlinghaus (2011). Fly-caught fish had significantly higher post-release survival than those captured by lures or bait. This is probably because flies tend to be fished with smaller hooks than lures or bait, and future research should focus more specifically on the effects of hook size to determine whether smaller hooks paired with lures would improve post-release survival. Higher post-release survival of fish captured by flies is not necessarily an indictment of fishing with other methods but can be a consideration when estimating the extent of post-release mortality of salmon expected in a given fishery. Adult Atlantic salmon body size can vary greatly depending on the number of years an individual fish has spent feeding at sea. The analysis included data from various rivers that hold salmon with different life history traits, including rivers Alta and Lakselva where the fish tend to spend more time at sea than occurs for other populations and consequently have larger body size at maturity (Thorstad et al. 2003; Chapter 3). Larger fish tend to be more exhausted by angling due to longer playing and handling times (Meka and McCormick 2005) and correspondingly have greater extents of 
physiological disturbance to muscular tissue (Ferguson et al. 1993; but see Booth et al. 1995) as well as greater impairment of their reproductive success (Richard et al. 2013). I expected to see some effect of body size on catch-and-release mortality but found no evidence that body size influenced post-release survival. Moreover, I did not find an effect of playing time. This suggests that playing times are not of serious concern to salmon mortality in recreational fisheries, but anglers and managers should be aware that extended playing times arising from using incorrect methods or inexperience with landing and handling fish may nonetheless be detrimental (Richard et al. 2013). The effect of playing time and handling probably increase when water temperatures rise (Gingerich et al. 2007). Although not a significant factor in the data, the interaction of factors (particularly between water temperature and others) is an area that requires further research for fisheries in general.

The data were collected with various methods for tagging, tracking, and determining mortality. This can introduce variation that violates the assumption of independence in regression models, which is why I considered modelling the data using the mixed effects regression with study as a random intercept. However, the variance estimate of the random effects in the mixed effects model was zero, indicating nominal influence of the random component on the model. It could be that the variation among studies was captured by the fixed effects. Although there were methodological differences among studies, the studies varied mostly by the size distribution of the fish captured, gear used in the study rivers, and water temperature in the rivers, which were tested as fixed effects. Mixed effects modelling may differ more from logistic regression in instances where systematic variation in vulnerability to fishing-induced mortality 
existed among populations, such as differences in thermal sensitivity. Anttila et al. (2014) found only minor differences in thermal plasticity of Atlantic salmon between individuals from northern and southern populations, suggesting that the species probably does not have highly site-specific variation that would affect delayed mortality.

The fate of fish released by anglers is difficult to quantify but telemetry offers an opportunity to study free-living fishes for this purpose (Donaldson et al. 2008). However, proper design of telemetry studies to evaluate post-release mortality is important and there was variation among studies in the review that imposed some statistical limitations. Studies did not use identical criteria for assigning fates to fish that were released, based on the implementation of different tag technology (i.e. radio or acoustic transmitters), tracking (i.e. fixed array or active tracking), or other approaches. Moreover, transmitter loss/ malfunction can be difficult to separate from mortality. It is important to consider that transmitter loss has been shown to be higher for gastric radio tagging methods than external attachment or implantation (Smith et al. 1998; Thorstad et al. 2013), which might bias the estimation of mortality; albeit given the small number of total mortalities it is unlikely to have introduced systematic error. Visual surveys may be necessary to accurately classify survival (Chapter 3) or activity sensors in the tags that can be used to infer mortality more accurately (e.g. Richard et al. 2014). In some cases, post-release predation can contribute to fisheries mortality (Raby et al. 2014); in this study, some mortalities registered in River Bann may have been due to seal (Phoca vitulina) predation. Given that risk factors (i.e. water temperature, injury) that govern vulnerability to post-release predation are not well understood (Raby et al. 2014), I opted to include these fish in the analysis under the rationale that post-release predation is a component of 
overall catch-and-release mortality. Nonetheless, I recognize how such challenges could influence interpretations of models. I also acknowledge that the delayed mortality rate presented in this study probably represents a maximum estimate given the methods used to quantify mortality were mostly inferential rather than direct.

Logistic regression is effective for generating predictions but has lower power than survival analysis for detecting important predictors (Murray 2006). Survival analysis is properly suited to handling telemetry data because it allows for disappearance of some individuals (i.e. right censoring), delayed entry (i.e. left censoring), and has more power to detect significant predictors of survival (Murray 2006; Harrell 2015a). Survival analysis was not possible in the study based on the nature of the sampling designs, but small changes to the sampling design could enable future studies to implement such an analysis by relocating fish at fixed intervals. Data-driven approaches to managing fisheries can assist with management and facilitate emergency closures or other restrictions to meet conservation targets. In salmon fisheries, the model suggests that delayed mortality is sufficiently rare that it is difficult to systematically predict which individuals are likely to die after release. Nonetheless, the identification of significant factors is relevant for understanding how delayed mortality operates across the range of Atlantic salmon.

Although mortality is catastrophic for individual fitness potential, catch-andrelease can also impart sublethal effects on fish that could significantly impair lifetime fitness potential that may be underrepresented when mortality is the only metric used to assess fishery sustainability. There is evidence for sublethal effects of catch-and-release on Atlantic salmon migration (Chapter 2,3) and reproductive success (Richard et al. 
2013), albeit equivocal evidence of reduced reproductive output (Booth et al. 1995; Richard et al. 2013). This study sought to analyze delayed mortality of Atlantic salmon and confirmed that it is a relatively rare occurrence that is difficult to predict. Future research must address questions related to the spawning activity and energetics of salmon released by anglers and determine whether post-spawning behaviour and survival are negatively affected.

Catch-and-release can be an effective conservation measure for recreational fisheries. Yet, some fish die after catch-and-release; understanding why this occurs can provide important insight for managing recreational fisheries. Although Atlantic salmon are a well-studied species in the context of catch-and-release fisheries (Cooke and Suski 2005; Hühn and Arlinghaus 2011), it was clear from the available literature that the relative importance of many potentially influential factors was not well understood because of small sample size from individual studies. The collaborative approach therefore provides improved insight into the effects of angler practices, extrinsic conditions, and inter-individualistic differences that can be used to predict salmon mortality in fisheries. The intention is that the predictor variables considered in this paper will facilitate a better understanding of delayed mortality of salmon and recognition that salmon handled using best practices are likely to survive to spawning, which will lead to a more sustainable approach to Atlantic salmon recreational fishing. 


\section{Chapter 7 River warming portends bioenergetic failure of adult Atlantic salmon Salmo salar during the spawning migration}

\subsection{Abstract}

Climate change poses a challenge to wild fishes, yet little is known about the behavioural use and metabolic consequences of thermally heterogeneous water encountered by wild salmon during their energetically stressful upstream spawning migration. Archival temperature loggers revealed the thermal habitat of adult migrating Atlantic salmon, which was used to apply bioenergetics models that estimated temperature-driven metabolic expenditures as part of the costs of the migration. Between July 16 and August 19, the mean water temperature experienced by salmon $\left(t_{\mathrm{FISH}}\right)$ ranged from $11.5-18.0{ }^{\circ} \mathrm{C}(14.5 \pm$ 1.2 SD $\left.{ }^{\circ} \mathrm{C}\right)$ and closely followed the ambient surface water temperature $\left(t_{\mathrm{RIVER}}\right)$ of the river $\left(11.5^{\circ}-18.5^{\circ} \mathrm{C} ; 14.8 \pm 1.4^{\circ} \mathrm{C}\right)$ such that the regression equation $t_{\mathrm{FISH}}=1.62+0.88\left(t_{\mathrm{RIVER}}\right)$ provided an accurate index $(\mathrm{t}=260.83, \mathrm{P}<0.01)$ of fish thermal experience. Temperature increases project to elevate energetic costs, albeit more drastically for small $(63.5 \mathrm{~cm}$ TL) salmon $(51 \%$ to $65 \%)$ than large $(119.0 \mathrm{~cm}$ TL) salmon $(20 \%$ to $26 \%)$. I conclude that warming could drive the evolution of different life history phenotypes in the system, e.g. delayed river entry or reduced probability of iteroparity, with more dire consequences for smaller individuals.

\subsection{Introduction}


Temperature constrains the distribution of species (Pörtner 2002) and influences the timing and expression of many life history events (Walther et al. 2002) such as breeding, aestivation/hibernation, and migration. For ectotherms such as most fishes, temperature directly influences and can ultimately limit the rates of enzymatic, metabolic, and cardiac processes (Fry 1971; Behrisch 1979; Farrell et al. 2009). At temperatures beyond optimum, the tissue demands for oxygen continue to increase (Pörtner and Knust 2007) but the capacity to deliver that oxygen decreases (i.e. decline in aerobic scope; Priede 1977) until glycolytic ATP production replaces aerobic respiration (i.e. anaerobiosis; Pörtner 2002). Warm water temperature can be energetically taxing (Rand et al. 2006; Katinic et al. 2015), accelerate maturation (Morbey et al. 2005), and promote pathogen infection and development (Harvell et al. 2002).

In many rivers, water temperature is increasing due to climate change (Webb, 1996; Mote et al. 2003; Caissie 2006). This is a concern in the Arctic where water temperatures are projected to increase at a faster pace than at lower latitudes (O'Brien et al. 2003; Prowse et al. 2006). As water temperatures rise, the costs of freshwater residence will be altered and ectotherm biology will be affected (Crozier et al. 2008; Jonsson and Jonsson 2009). There are many freshwater animals in coastal zones that use both marine and freshwater environments to complete their life history, with water temperatures generally much warmer in freshwater. Migrants must negotiate the two environments and allocate energy such that their rate of energy depletion does not exceed physiological limits or energetic reserves (Hodgson and Quinn 2002; Burnett et al. 2014). As temperatures increase, the physiology and behaviour of freshwater animals is expected to reflect higher energetic costs of residence (Crozier and Hutchings 2014). 
Energetics models provide tools for ecologists to investigate energy allocation of animals; energy acquisition must be balanced against depletion, which depends on the individual's size, activity, and the water temperature (Brett 1971; Fry 1971; Kingsolver and Huey 2008). Individuals must allocate energy during the migration efficiently with a goal of successfully participating in spawning and other life history events, which yields considerable diversity in physiological and behavioural phenotypes to promote survival (Glebe and Leggett 1981; Jonsson et al. 1997; Standen et al. 2002).

Atlantic salmon have a Holarctic distribution and rely on freshwater for spawning and nursery grounds. Adults return from the sea to spawn at various sizes, often with an earlier timed river entry associated with southern latitudes (Heggberget 1988; Klemetsen et al. 2003; Thorstad et al. 2011). Freshwater residence is also briefer for many adult salmon at the northern edge of their range, although some individuals enter more than a year before reproducing. Timing of entry is known to depend upon river characteristics as well as individual size (Jonsson et al. 1991a) and salmon can exhibit a refuging behaviour during the migration as a maintenance strategy (Richard et al. 2014; Frechette et al. In Press). When salmon enter freshwater they cease feeding, such that stored energy must then suffice for migration, completion of sexual maturation, and spawning (Moore 1997). Consequently, an iteroparous migrant, like the Atlantic salmon, must also preserve enough energy after spawning for its return to the ocean where it can begin the reconditioning process for subsequent migration and reproduction (Jonsson et al. 1991b, 1997; Halttunen et al. 2013). The Arctic is an area of relatively sparse human habitation and impact; therefore, climate change may present one of the most salient threats to salmon in the north. The phenotypic plasticity of salmon means that they may adjust 
either their body size through changes in maturation schedules or their behaviour by shifting run timing to adapt to changing demands associated with climate change (Clark et al. 2012; Otero et al. 2014; Dempson et al. 2017). Models predicting the energetic costs of size, activity, and water temperature therefore will yield a better understanding of Atlantic salmon migration and potential responses to climate change.

Animal size, activity, and temperature contribute simultaneously to the metabolic rate and the energy demands upon the individual. Warming temperatures portend bioenergetic failure of some organisms (Farrell et al. 2008; Rummer et al. 2014) and the temperature-size rule posits that smaller organisms should be favoured in warmer temperatures (Kingsolver and Huey 2008). Given that thermal ecology of adult Atlantic salmon during their freshwater migration is poorly understood (Bardonnet and Baglinière 2000), I designed a study to investigate the contributions of water temperature and size, along with swimming activity, to energetic depletion of this anadromous fish on its spawning migration in freshwater. I hypothesized that all three variables (size, swimming activity, temperature) would influence energy demands on individuals, which would imply that changes due to climate warming will the rate of accelerate energy depletion of freshwater fish during their migration.

7.3 Methods

\subsubsection{Study Area}


I studied a population of Atlantic salmon in the Lakselva River in Finnmark, Norway. Atlantic salmon enter the river from May-September (E. Liberg, Personal Communication), but based on quantitative catch records the majority begin their freshwater migration in July and August (www.scanatura.no). The Lakselva River flows through two lakes, Øvrevatnet and Nedrevatnet (Figure 7.1). River discharge is measured at Skoganvarre ( $\left.69^{\circ} 50^{\prime} 13.2^{\prime \prime} \mathrm{N} 25^{\circ} 05^{\prime} 07.5^{\prime \prime} \mathrm{E}\right)$, encompassing $61 \%$ of the watershed, which can be extrapolated to estimate total discharge (T. Havn, unpublished). Estimated average yearly discharge from 2000-2016 was $24 \pm 2.2 \mathrm{~m}^{3} \mathrm{~s}^{-1}\left(\mathrm{range}=21-33 \mathrm{~m}^{3} \mathrm{~s}^{-1}\right)$. The river also has one major tributary, which flows into Lake Nedrevatnet. Most fish hold in in the reach of the river below the lakes (Chapter 3) until spawning begins in October (E. Liberg, Personal Communication). After spawning, surviving Atlantic salmon may overwinter in the river as kelts and exit the following spring to recondition at sea. Lakselva has a catchment area of $1,536 \mathrm{~km}^{2}$ and the mainstem of the river has $45 \mathrm{~km}$ available to salmon for spawning habitat. Lakselva River drains into the Porsangerfjord within the administrative district of the municipality of Lakselv $\left(70^{\circ} 03^{\prime} 55.2^{\prime \prime} \mathrm{N}\right.$ $24^{\circ} 55^{\prime} 43.8^{\prime \prime}$ E). To monitor ambient river water temperature, I deployed four HOBO temperature loggers (HOBO Pendant Temperature/ Light Data Logger 64K-UA-002-64, Onset, Massachusetts, USA) in the river from 17 July to 24 October 2014. One river temperature data logger was stationed in the lower section of the river, one in Lake Nedrevatnet, and one in the upper section of the river; all were placed approximately one meter below the surface (Figure 7.1). The river monitoring stations recorded water temperature every 10 min. Previous monitoring by the Lakselva Landowners Association 
observed little variability of the surface water temperatures among sites in the lower reach of the river (E. Liberg, personal communication).

\subsubsection{Sampling}

I cooperated with local anglers and captured Atlantic salmon for the experiment from July 7 - August 29, 2014. Cooperation with local anglers encouraged engagement of locals and other stakeholders in the work and was important for ensuring that logging tags from recaptured salmon were returned. A 500 NOK reward for returning tags was offered to anglers that captured tagged salmon. Twenty-One Atlantic salmon (mean $=90$ $\pm 16 \mathrm{~cm}$ SD TL, range: $62-121 \mathrm{~cm}$ ) were double-tagged with radio-transmitting tags in the frequency range 142.114 - 142.213 (model F2120, Advanced Telemetry Systems [ATS], Minnesota USA) and archival temperature loggers (iButton Thermochron C Temperature Data Loggers DS1921Z-F5, Maxim Integrated, San Jose, California, USA). The tagging methods used sterile hypodermic needles and steel wire to secure the tag through the dorsal musculature at the base of the dorsal fin (described in Chapter 3). Opposite the radio tag, an iButton archival temperature logger, set to record temperature at 90 min intervals, was attached instead of the usual plastic backplate (Figure 7.2). All participants were experienced salmon anglers and I did not tag any salmon that was in poor condition because of angling (i.e. critical hooking, extreme bleeding; Chapter 3). Calibration of the archival temperature loggers is described in the Supplementary Material. All handling and tagging was conducted in accordance with the Carleton University Animal Care and Use Committee. 


\subsubsection{Archival Temperature Logger Validation}

The accuracy and precision of iButton archival temperature loggers and HOBO temperature loggers were verified by comparing water temperature measurements against a reference Star-Oddi DST CT salinity and temperature logger (reported accuracy of \pm $0.1{ }^{\circ} \mathrm{C}$, Star-Oddi, Garðabær, Iceland). The calibration followed van Marken Lichtenbelt et al. (2006). The temperature loggers were placed in meshed bags $(1.5 \mathrm{~cm}$ mesh diameter) in the middle of a $120 \mathrm{~L}$ water tank filled with heated water. The water tank cooled over a period of $10.5 \mathrm{~h}$ from 24.5 to $8.3^{\circ} \mathrm{C}$, a range that covered the water temperatures experienced by tagged Atlantic salmon in Lakselva $\left(11.5^{\circ} \mathrm{C}\right.$ to $\left.18.0^{\circ} \mathrm{C}\right)$ during the study period. All loggers were set to sample temperature simultaneously ( \pm 3 s) once every minute to ensure that the measurements were comparable. Nineteen iButtons and $31 \mathrm{HOBO}$ loggers were tested, with 629 water temperature observations recorded per logger. An aquarium air pump (AM-Top professional CR-30, AM-Top) was placed in the tank to provide water circulation and the meshed bags allowed for water to flow over the loggers. Linear regressions were used to assess temperature deviation between each thermal logger and the reference logger (Donaldson et al. 2009). For each iButton and HOBO logger, accuracy was calculated as the mean of the differences between the temperature of the logger and that of the reference DST logger, and the standard deviation of these differences yielded the precision. All linear regressions between the experimental loggers and the reference DST logger were highly significant with Pearson correlation coefficients $>0.99$. For the iButtons, mean accuracy was $-0.39 \pm$ 
$0.13{ }^{\circ} \mathrm{C}$ (range -0.59 to -0.19 ), and mean precision was $0.04 \pm 0.003{ }^{\circ} \mathrm{C}$ (range 0.04 0.05). For the $\mathrm{HOBO}$ loggers, mean accuracy was $0.23 \pm 0.06^{\circ} \mathrm{C}$ (range $0.12-0.36$ ) and mean precision was $0.04 \pm 0.003{ }^{\circ} \mathrm{C}$ (range $\left.0.04-0.05\right)$. The accuracy calculated in this experiment is better than what is reported by the manufactures of the iButtons $\left( \pm 1^{\circ} \mathrm{C}\right)$ and the HOBO loggers $\left( \pm 0.53{ }^{\circ} \mathrm{C}\right)$. Because of the differences in accuracy (or bias) between iButtons and HOBO loggers I adjusted both instruments' values when modelling the data in this manuscript. The correctional value was calculated by increasing logged values from iButtons by $0.39^{\circ} \mathrm{C}$ to compensate for the measured accuracy and by subtracting $0.23{ }^{\circ} \mathrm{C}$ from the $\mathrm{HOBO}$ logger in the river to compensate for the calculated accuracy.

\subsubsection{Data Analysis}

Archival temperature loggers were recovered from 10 of the 21 salmon that were tagged (Table 7.1). Five were recovered from salmon that were removed from the river by harpoon on 25 September and the other five loggers were removed from salmon that were recaptured and harvested by anglers (one was recaptured as a kelt the following summer, June 20, 2015). As a result, the sampling intervals differed among individuals, with some temperature records spanning several days whereas others covered much longer periods. Modelling was implemented to determine the relationship between fish habitat and river temperatures using linear regression in $\mathrm{R}$ ( $\mathrm{R}$ Core Team 2017). In consideration of possible differences among fish attributable to differences in fish size, fish position in the river, or other factors, I generated a mixed effects linear model (lme 
function in R package nlme; Pinheiro et al. 2014) with fish ID as a random intercept. To determine whether the mixed effects model fit better than the fixed effects model, the mixed effects model was compared to a generalized least squares regression ( $g l s$ function in R package nlme) with restricted maximum likelihood estimation using Akaike Information Criterion. Model predictions were compared to actual values measured by the tags placed on the fish using linear regression.

\subsubsection{Bioenergetics Modelling}

To determine the rates of oxygen uptake of fish swum at different speeds and temperatures, hatchery-raised adult Atlantic salmon (body mass: $2.6 \pm 0.4 \mathrm{~kg}$; fork length: $60.6 \pm 3.9 \mathrm{~cm} \mathrm{SE}$ ) were held in outdoor $4000 \mathrm{~L}$ circular fiberglass tanks under ambient seawater conditions $\left(7-11^{\circ} \mathrm{C}\right.$, dissolved oxygen $>90 \%$ saturation $)$ and seasonal photoperiod at the Centre for Aquaculture and Environmental Research (West Vancouver, BC, Canada). Food was withheld for $24 \mathrm{~h}$ before experiments. A subset of fish $(\mathrm{N}=22)$ was instrumented to measure cardiovascular parameters (data not shown here) while other fish were not instrumented $(\mathrm{N}=14)$. Surgical protocols followed those detailed in Eliason et al. (2013a). The fish were anesthetized in buffered tricaine methane-sulfonate $\left(0.1 \mathrm{~g} \mathrm{~L}^{-1} \mathrm{MS}-222\right.$ and $0.1 \mathrm{~g} \mathrm{~L}^{-1} \mathrm{NaHCO}_{3}$, Sigma-Aldrich, Oakville, Ontario, Canada), weighed and transferred to a surgical table where they were maintained under a lower dose of buffered anesthetic $\left(0.075 \mathrm{~g} \mathrm{~L}^{-1} \mathrm{MS}-222\right.$ and $\left.0.05 \mathrm{~g} \mathrm{~L}^{-1} \mathrm{NaHCO}_{3}\right)$. A $3 \mathrm{~mm}$ SB flow probe (Transonic Systems, Ithaca, NY, USA) was placed around the ventral aorta, a PE-50 cannula was inserted into the dorsal aorta, and a PE-50 cannula or 
an oxygen probe (custom-designed, Ocean Optics, Dunedin, FL, USA) was placed in the sinus venosus (Eliason et al. 2013a). The flow probe and cannulae/oxygen probe leads were sutured along the dorsal ridge of the fish's body using 2-0 silk sutures. Fish were placed in a Brett-type swim tunnel (220 L or $400 \mathrm{~L}$; described in Steinhausen et al. 2008) and allowed to recover overnight at ambient water temperatures at low water velocity (0.3-0.4 body lengths per second $\left(\mathrm{bl} \mathrm{s}^{-1)}\right)$. This water velocity was sufficient to orient the fish but did not induce swimming. Similar surgeries did not impair swimming metabolism of Pacific salmon compared to controls (Eliason et al. 2013b). The next day, resting oxygen uptake $\left(\mathrm{MO}_{2}\right)$ was measured at the ambient water temperature (ranged from $7-12^{\circ} \mathrm{C}$ over the study) and then the fish underwent a standard ramp $\mathrm{U}_{\text {crit }}$ critical swimming challenge (Eliason et al. 2013a). Water velocity was increased every $5 \mathrm{~min}$ until $\sim 50 \%$ of the critical swimming speed $\left(\mathrm{U}_{\text {critit }} \sim 1 \mathrm{bl} \mathrm{s}^{-1}\right)$ was attained. Thereafter, the water velocity was increased in smaller velocity increments $\left(\sim 0.15 \mathrm{bl} \mathrm{s}^{-1}\right)$ every $20 \mathrm{~min}$ until fatigue was induced (defined as the fish resting at the back of the swim tunnel for > $30 \mathrm{~s}) . \mathrm{MO}_{2}$ was measured during the second half of each 20 min interval. When the fish became fatigued, the water velocity was immediately reduced back to the resting velocity $\left(\sim 0.3 \mathrm{bl} \mathrm{s}^{-1}\right)$ and the fish could recover overnight. The next day, the water temperature was acutely increased by $2{ }^{\circ} \mathrm{C} \mathrm{h}^{-1}$ to the warm test temperature $\left(10-22^{\circ} \mathrm{C}\right)$. Resting $\mathrm{MO}_{2}$ was assessed and then the fish underwent the same $\mathrm{U}_{\text {crit }}$ protocol described above.

To account for the allometric scaling of standard metabolic rate (Brett and Glass 1973), I standardized the resting oxygen uptake for three fish sizes in the river, small (total length $=63.5 \mathrm{~cm}$, mass $=3.03 \mathrm{~kg}$ ), medium (total length $=89.0 \mathrm{~cm}$, mass $=8.34$ $\mathrm{kg}$ ), and large (total length $=119.0 \mathrm{~cm}$, mass $=20.18 \mathrm{~kg}$ ); these lengths approximately 
spanned the minimum, average, and maximum lengths encountered in Lakselva. Corresponding weights were derived from an empirical table of length-to-weight conversions for fish from the study site (www.lakselva.no; the table is based on fork lengths which required total lengths be converted to fork length by dividing by 1.046). The measured resting values of $\mathrm{MO}_{2}$ were scaled using an equation from Steffensen et al.

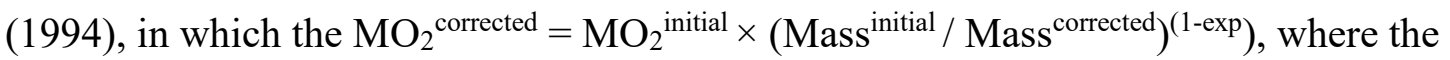
$\mathrm{MO}_{2}{ }^{\text {initial }}$ is the oxygen uptake of fish of Mass ${ }^{\text {initial }}$, corrected by dividing that fish's mass by the mass of the fish of the desired size ( $\mathrm{cm}$; in this case I used the three values above) and the exp is the scaling exponent 0.80 (Winberg 1956; Steffensen et al. 1994; Clarke and Johnston 1999; Rosewarne et al. 2016). The oxygen uptake data at temperatures between 7 and $22{ }^{\circ} \mathrm{C}$ (above) were fit with an exponential curve for resting data and a second order polynomial relationship for fish swimming at $1.0 \mathrm{bl} \mathrm{s}^{-1}$. Although oxygen uptake was not measured at an intermediate swim speed, I estimated oxygen uptake at 0.5 and $0.7 \mathrm{bl} \mathrm{s}^{-1}$ by interpolating from the resting and $1.0 \mathrm{bl} \mathrm{s} \mathrm{s}^{-1}$ data and fit exponential curves through the data to evaluate the internal sensitivity of the oxygen consumption equations. For these curves, values were derived using only fish at temperatures measured for both resting and swimming velocities.

I estimated daily oxygen uptake for fish in the river between July 13 and December 16 based on the calculated daily average temperatures derived from the HOBO river temperature logger. The HOBO river temperature logger was active in the river July 19 - August 19; beyond these dates the water temperatures were estimated from the iButton archival temperature loggers by back calculation using the regression equation (see Results). By fitting the regression equations to the water temperature data, daily 
oxygen uptake ( $\mathrm{mg} \mathrm{O}_{2} \mathrm{~kg}^{-1} \mathrm{~min}^{-1}$ ) was estimated for each day in the study period for three size classes of fish and at the four swimming speeds. Daily energy consumption was then derived by multiplying by 1440 (minutes in a day) and by the total mass of the fish converted from the three lengths selected $(2.67 \mathrm{~kg}, 7.00 \mathrm{~kg}, 17.69 \mathrm{~kg})$ to calculate the $\mathrm{mg}$ $\mathrm{O}_{2} \mathrm{~d}^{-1}$ consumed per fish of the three sizes. Values in $\mathrm{mg} \mathrm{O}_{2} \mathrm{~kg}^{-1} \mathrm{~min}^{-1}$ were multiplied by 60 to get $\mathrm{mg} \mathrm{O}_{2} \mathrm{~kg}^{-1} \mathrm{~h}^{-1}$ and then multiplied by 0.00325 to convert to $\mathrm{kCal} \mathrm{kg}^{-1} \mathrm{~h}^{-1}$ based on the caloric conversion for Pacific salmon (Brett 1995). Daily kilocalories for fish in each size class were then calculated by multiplying by the weight ( $\mathrm{kg}$ ) and by $24(\mathrm{~h})$. Energetic scope of migrants was calculated based on equations in Jonsson et al. (1997). Energy available for migration is a function of individual length $\left(L_{\mathrm{TOTAL}}\right)$; the initial energy in kilojoules is described by the equation: $\mathrm{E}=\exp \left(0.044 \times L_{\mathrm{TOTAL}}+6.99\right)$ and the post-spawn energy described by the equation: $\mathrm{E}=\exp \left(0.035 \times L_{\mathrm{TOTAL}}+6.51\right)$, and then converted from $\mathrm{kJ}$ to $\mathrm{kCal}$ by multiplying by 0.239 . Projected energy depletion was calculated based on the initial energy available with a lower limit (i.e. threshold for life) considered to be the post-spawn energy. Models of global temperature increase are available to project the rate of warming, but vary based on latitude and have uncertainty associated with the emissions scenario, along with concomitant changes in radiative forcing, precipitation, cloud cover, albedo, ecosystem structure, etc. (Joos et al. 2001). Instead of using specific projections, I calculated the expected energetic use for the study period at the present water temperature and for warming scenarios of 1,2 , and $4{ }^{\circ} \mathrm{C}$.

\section{$\underline{7.4 \text { Results }}$}


Of the 21 salmon that were tagged, one salmon left the river prior to the spawning season and one salmon died immediately after release (see Chapter 3). Of the remaining 19 tagged salmon, archival temperature loggers were recovered from 10 salmon (Table 7.1). These salmon were mostly tagged in the lower reaches of the river and none of them transited the lakes to access upper reaches of the river or the tributary Vuolajohka. Therefore, no tagged salmon was recorded by the fixed receiver stations and given that all tagged fish remained in this river section $(\mathrm{N}=39$; Chapter 3), only temperature readings from the lower section of the river were used for modeling purposes (Figure 7.1).

I recorded a seasonal decline as well as daily oscillations in water temperature (range in daily variation $=0.48-4.21^{\circ} \mathrm{C}$ ). Between July 16 and August 19, salmon were recorded at temperatures between $11.5^{\circ} \mathrm{C}$ and $18.0^{\circ} \mathrm{C}$ (average: $14.5 \pm 1.2^{\circ} \mathrm{C}$ ). By comparison, average daily water temperatures during the same period ranged between $11.5^{\circ}$ and $18.5^{\circ} \mathrm{C}$ (average: $14.8 \pm 1.4^{\circ} \mathrm{C}$ ). One salmon, which was caught by an angler in the river in the spring after its release (fish ID 142.123-75; Table 7.1), provided a continuous 126-day temperature log through to December 16, 2014 (Figure 7.3). This fish had experienced temperatures as low as $-0.1^{\circ} \mathrm{C}$ in winter.

Comparison of the mixed effects and fixed effects models suggested a better fit of the mixed effects model rather than the generalized least squares model $(\triangle \mathrm{AIC}=708)$. There was a significant relationship between river temperature and fish habitat temperature $(t=260.82, p<0.01 ;$ Figure 7.4). Model-predicted values of fish habitat temperature had a strong (model adjusted R2 $=0.94$ ) positive relationship to actual values. Predictions of fish habitat temperature could therefore be accurately generated 
using river surface temperature data using a regression equation: $\mathrm{t}_{\mathrm{FISH}}=3.24+$ $0.76\left(t_{\text {RIVER }}\right)$.

Swim tunnel respirometry of hatchery Atlantic salmon was used to derive oxygen uptake equations as a function of water temperature (Table 7.2; Figure 7.5). Based on published equations for estimating energy content of Atlantic salmon, initial energy content of the wild salmon in Lakselva were estimated based on their length to be 48,762 , 13,026 , and 4,242 $\mathrm{kCal}$ for salmon measuring $119.0,89.0$, and $63.5 \mathrm{~cm}$, respectively, with an expected depletion of 52,39 , and $21 \%$ of somatic energy at present temperatures (Figure 7.6). During the 150-d modelled period (July 16 to Dec 16), large fish $(119.0 \mathrm{~cm})$ were projected to deplete the most gross energy, between 10,212 (at rest) and 47,610 $\mathrm{kCal}$ (swimming at $1.0 \mathrm{bl} \mathrm{s}^{-1}$; Figure 7.7). Small salmon had the most extreme relative energy depletion; at rest, I estimated 52\% energy depletion for small salmon but only $21 \%$ for large salmon at ambient present temperatures (Figure 7.8). Projected increases in temperature to $4{ }^{\circ} \mathrm{C}$ increased gross energy consumption to $65 \%$ and $26 \%$ for small and large salmon, respectively. Faster swimming speeds depleted energy more rapidly than slower speeds, demanding $169 \%$ of the somatic energy of small salmon compared to $98 \%$ from large salmon at $1.0 \mathrm{bl} \mathrm{s}^{-1}$ (present temperature regime). Warmer temperature $\left(+4{ }^{\circ} \mathrm{C}\right)$ increased caloric consumption for fish swimming at $1.0 \mathrm{bl} \mathrm{s}^{-1}$ by $9 \%$ for small individuals and 5\% for large individuals (Figure 7.7), with less drastic effects at slower swimming speeds. Overall, this modelling revealed that an individual's activity accelerates energy depletion more drastically than warming does, and the ability to moderate swimming can effectively conserve energy across climate scenarios. Estimates also suggest that large 
fish will be more resilient to temperature increases than small fish provided they can hold using a slow swimming speed during the migration. 
$\underline{7.5 \text { Tables }}$

Table 7.1 Summary of fish from which iButton archival temperature loggers were recovered. The table details the size of the salmon as well as the number of days the tags recorded data.

\begin{tabular}{lrrr}
\hline Fish ID & Tagging Date & Sampling Interval (days) & \multicolumn{2}{c}{ Total Length (cm) } \\
\hline $142.144-8$ & July 13 & 73 & 93 \\
$142.123-14$ & July 14 & 18 & 98 \\
$142.213-14$ & July 15 & 4 & 91 \\
$142.203-12$ & July 16 & 12 & 90 \\
$142.123-9$ & July 16 & 70 & 80 \\
$142.144-11$ & July 17 & 11 & 95 \\
$142.213-9$ & July 19 & 67 & 111 \\
$142.114-8$ & July 30 & 30 & 94 \\
$142.123-75$ & August 12 & 126 & 66 \\
$142.144-112$ & August 28 & 27 & \\
\hline
\end{tabular}




\subsection{Figures}
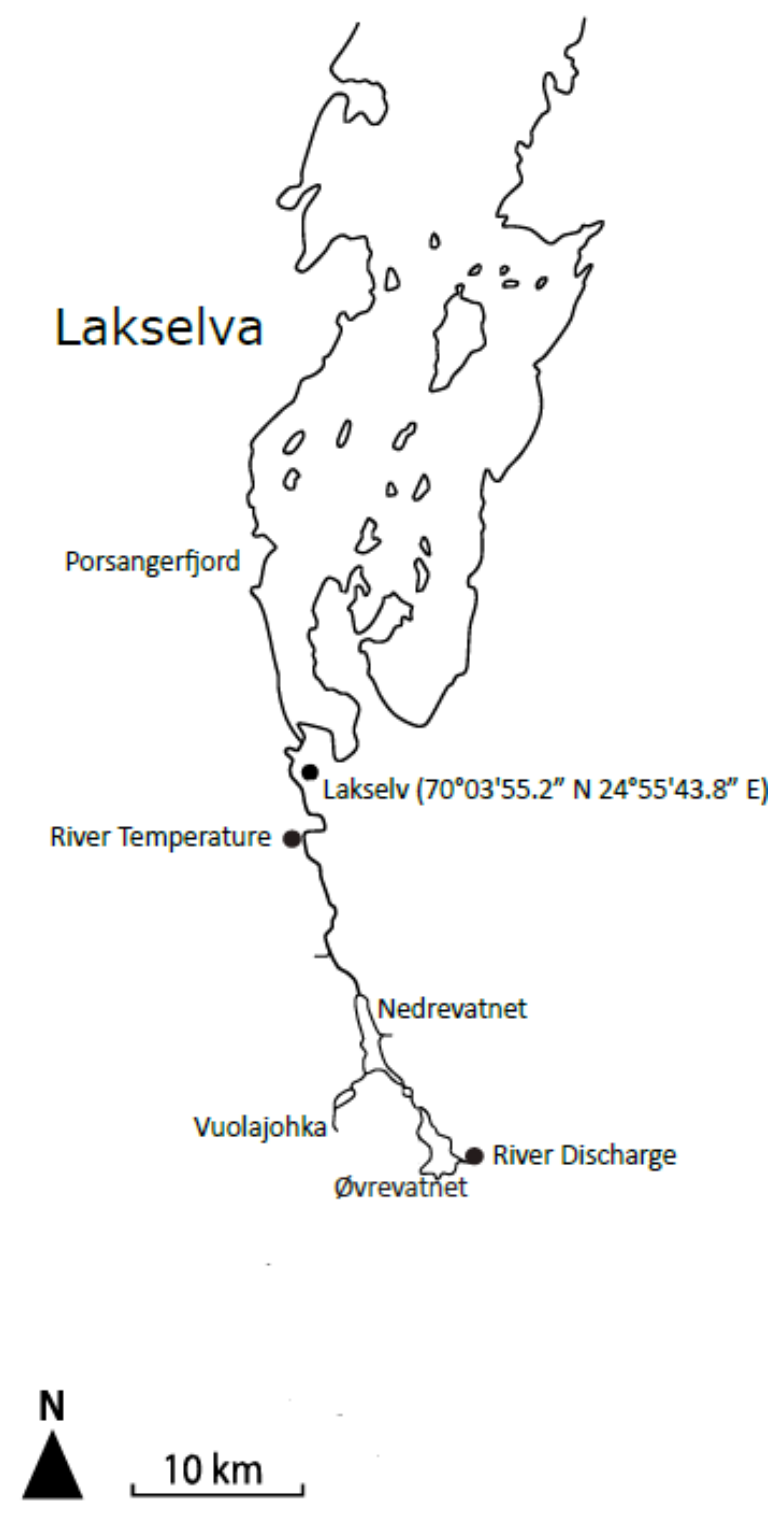

Figure 7.1 Lakselva in Porsanger, Finnmark, Norway. The watershed incorporates two major lakes, Øvrevatnet and Nedrevatnet. Atlantic salmon return to Lakselva from the ocean via Porsangerfjord throughout the summer and migrate upriver to spawning grounds. The location of the river temperature logger is located on the map. For this study, all tagged salmon remained in Lakselva below the lakes throughout their migration. 


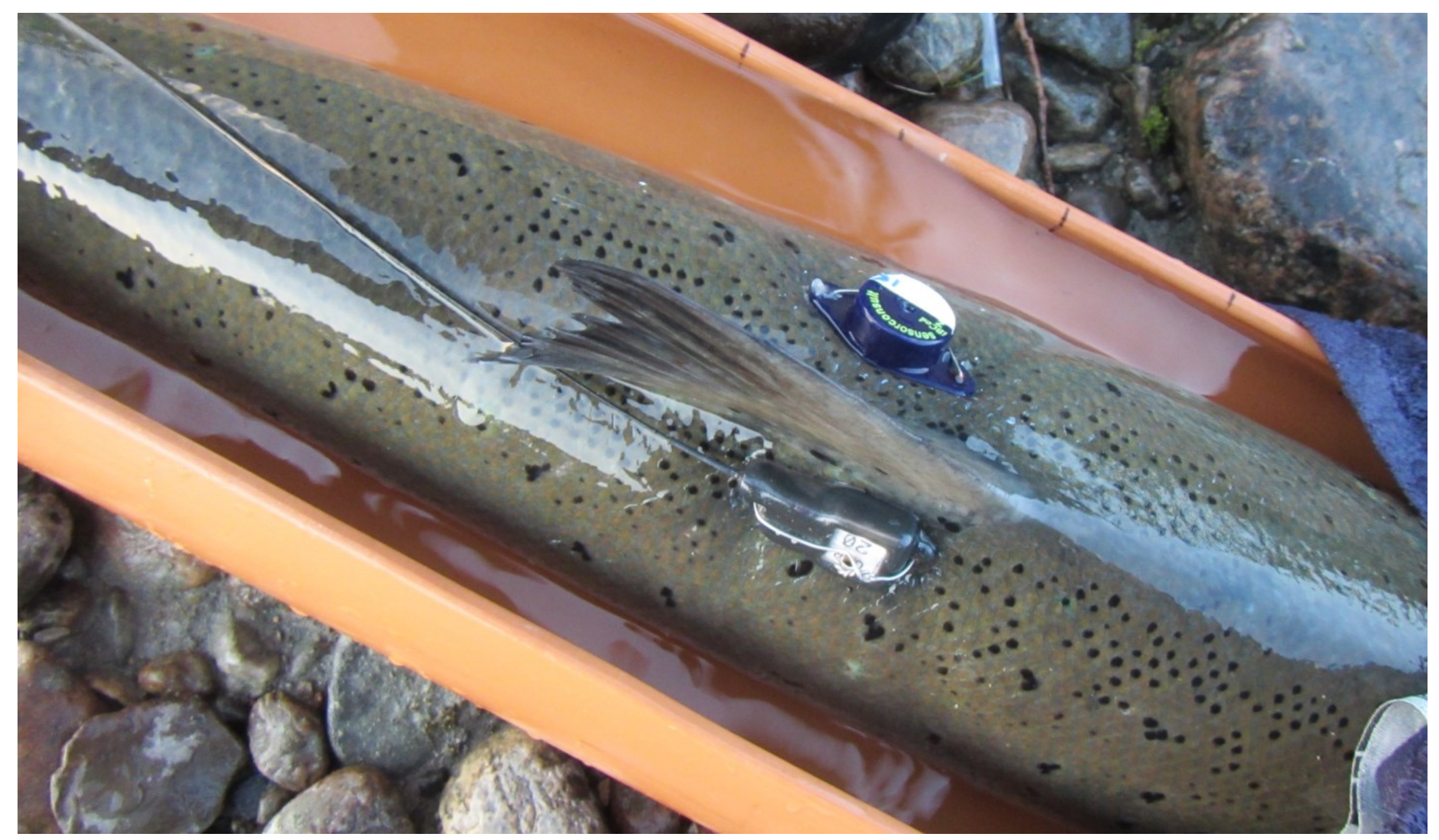

Figure 7.2 Double-tagging Atlantic salmon (Salmo salar) with coded radio transmitting tags (bottom) and archival temperature loggers (top). Salmon were maintained submerged in water in a PVC tube during tagging and externally tagged prior to release. 


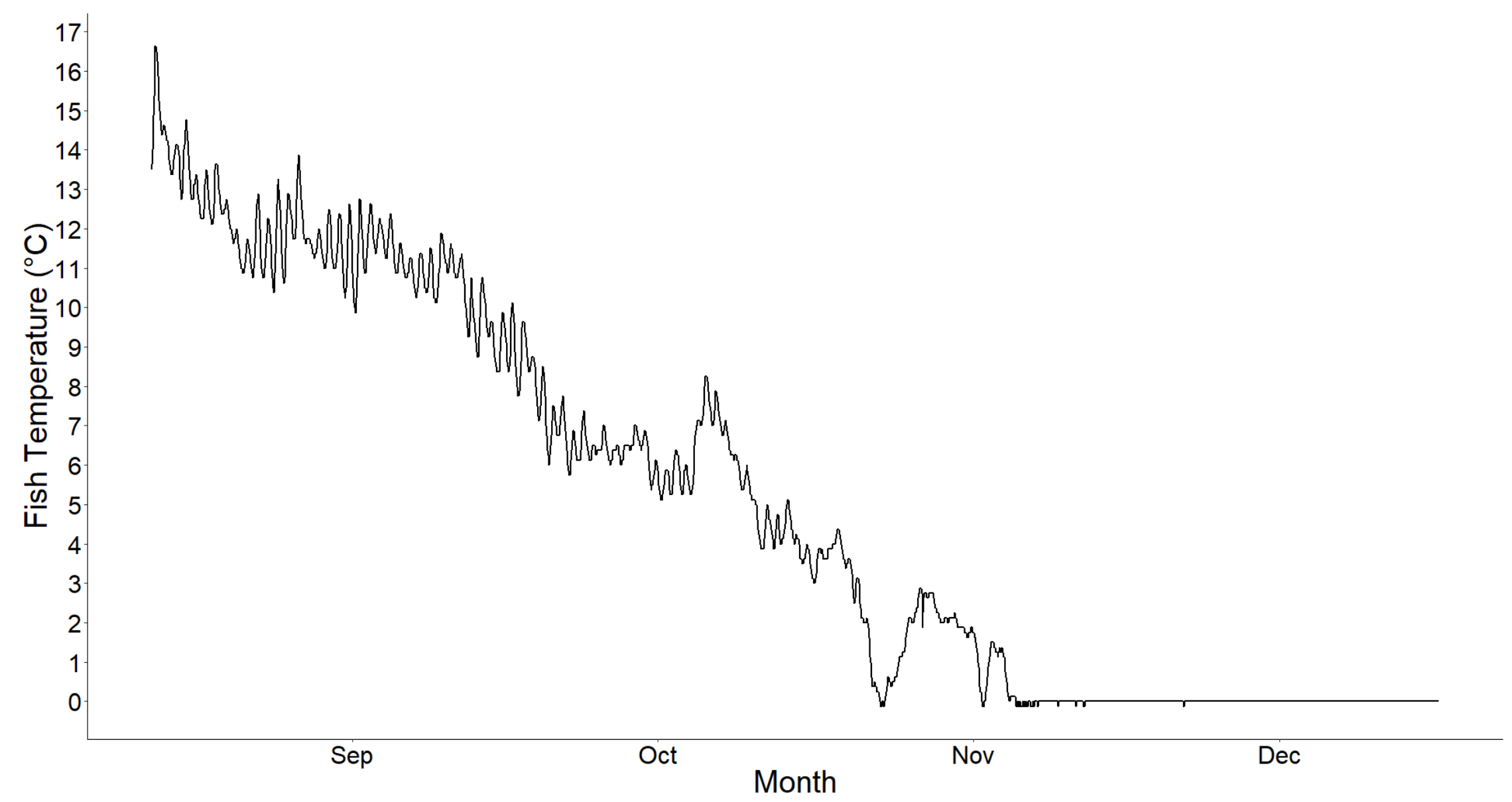

Figure 7.3 Fish thermal experience logged in Lakselva by salmon 142.123-75, whose logger remained active until December 16, 2014 (note that the values have been adjusted based on the regression analysis; see Supplementary Material). 


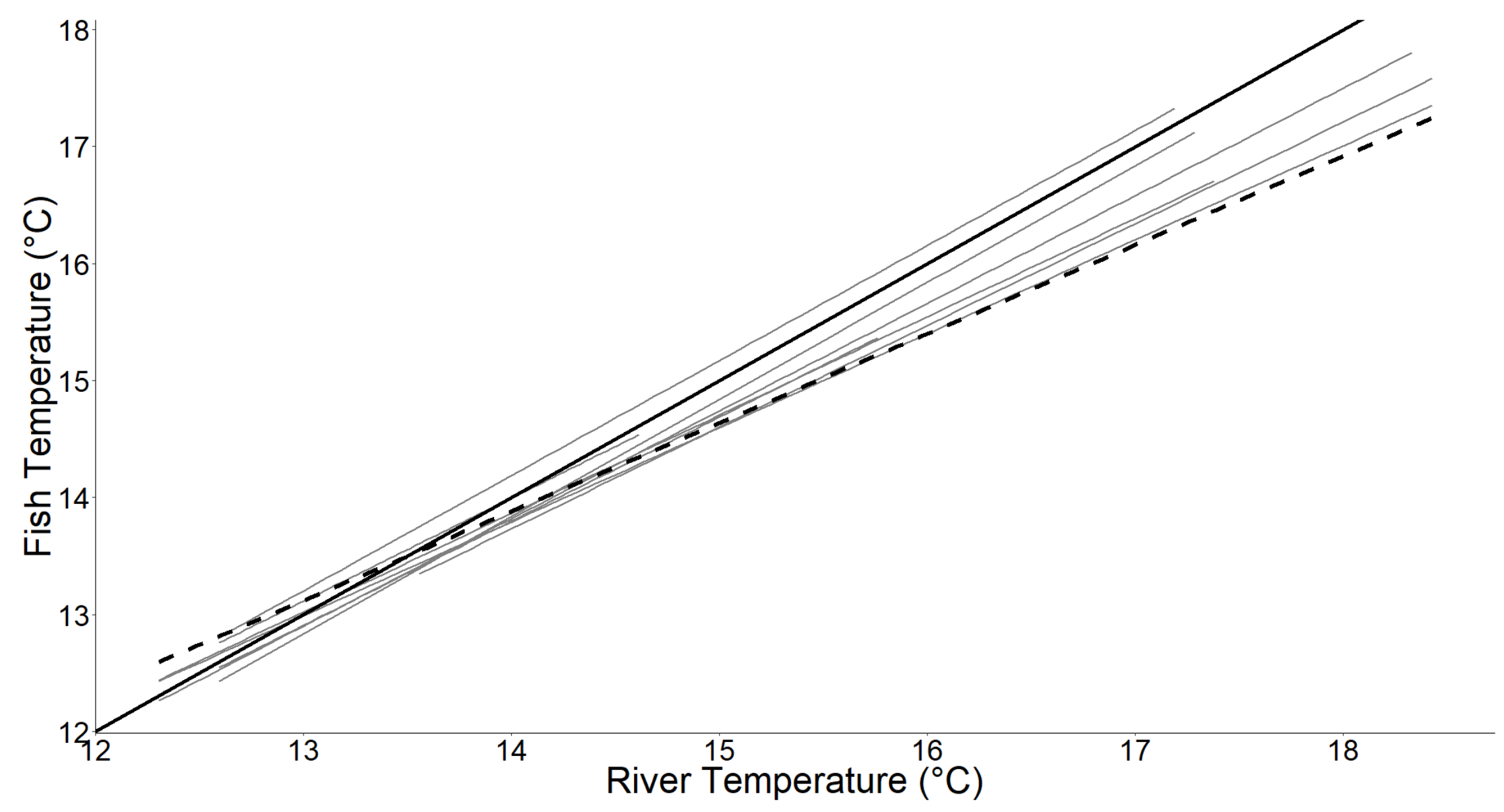

Figure 7.4 The relationship between fish temperature and the river temperature in Lakselva. Each grey line represents values from a temperature logger of an individual salmon in the river. The solid black line is the line of identity at $\mathrm{y}=\mathrm{x}$. Linear mixed effects modelling 
supported a linear relationship between river temperature and habitat temperature of salmon during this period and the line of prediction is illustrated by the broken black line (note that the value is adjusted based on the regression analysis; see Supplementary Material). 


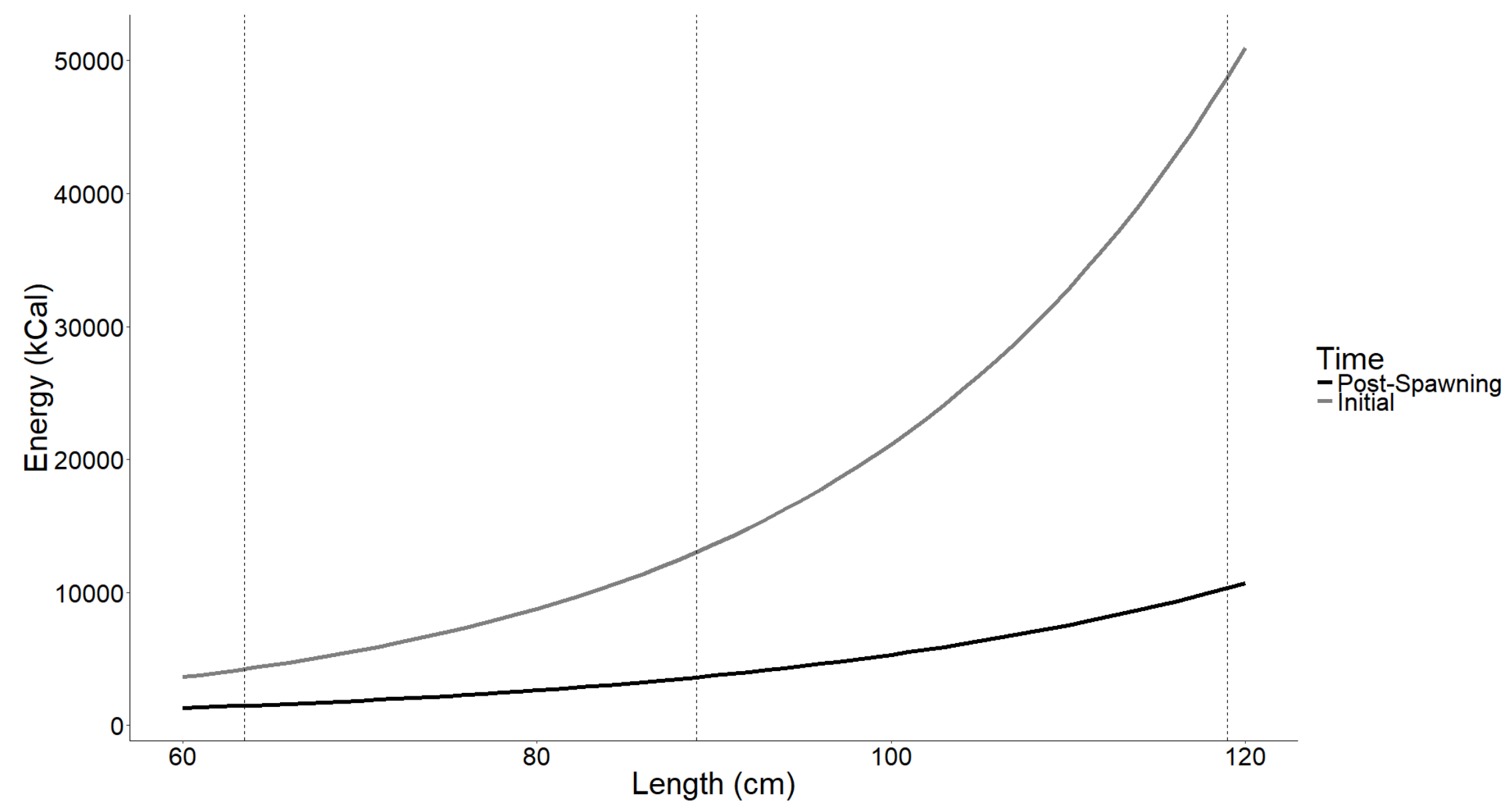

Figure 7.5 Predicted somatic energy density of Atlantic salmon (Salmo salar) based on equations derived by Jonsson et al. (1997) in the River Drammen, Norway. Both curves follow polynomial equations and represent measurements made in $\operatorname{July}\left(\mathrm{E}_{\text {initial }}=\exp (0.044 \times\right.$ 
$\left.\mathrm{L}_{\text {TOTAL }}+6.99\right)$ and November, following spawning $\left(\mathrm{E}_{\text {post-spawn }}=\exp \left(0.035 \times \mathrm{L}_{\text {TOTAL }}+6.51\right)\right.$. Broken vertical lines represent the lengths I selected for the bioenergetics modelling in this study, showing the energetic scope during the freshwater migration. 

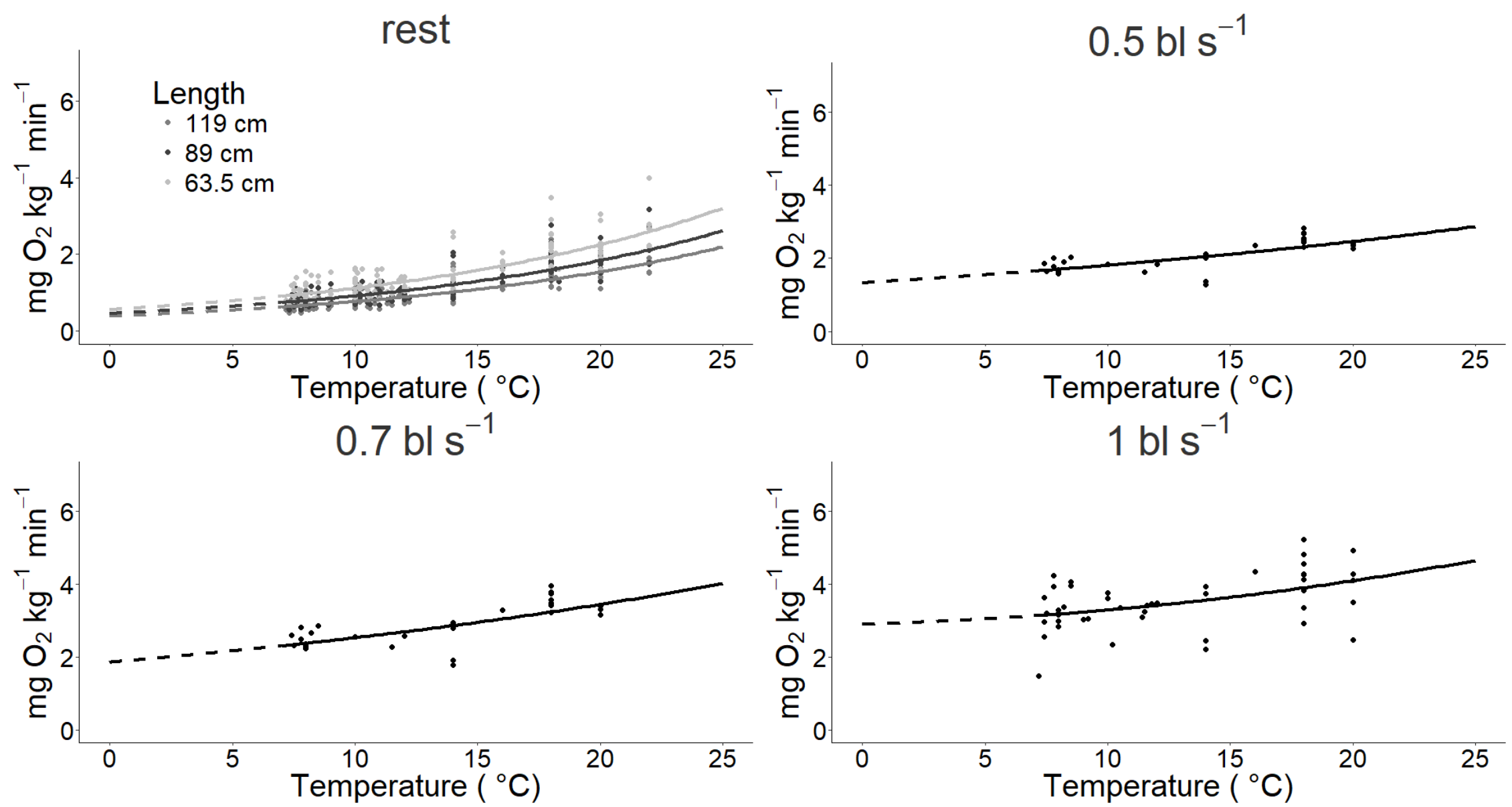

Figure 7.6 Atlantic salmon oxygen metabolism between 7 and $22{ }^{\circ} \mathrm{C}$ at four swimming speeds. Values for the resting fish were masscorrected for three sizes using a scaling exponent of 0.80 (see Clarke and Johnston 1999). Curves are presented for three body lengths, 
near the minimum, mean, and maximum values encountered in Lakselva. Values for resting and $1.0 \mathrm{bl} \mathrm{s}^{-1}$ were derived from swim tunnel respirometry (see Table 2). Values for 0.5 and $0.7 \mathrm{bl} \mathrm{s}^{-1}$ were interpolated from these data by averaging the oxygen uptake values. Regression curves were fit to the plots using a polynomial (second order) equation fit to the $1.0 \mathrm{bl} \mathrm{s}^{-1}$ data and exponential curves fit at other swimming speeds. Dashed portions of the curves are extrapolations made by the regression equations beyond the temperature ranges at which oxygen uptake were measured (i.e. $0-7^{\circ} \mathrm{C}$ ). 


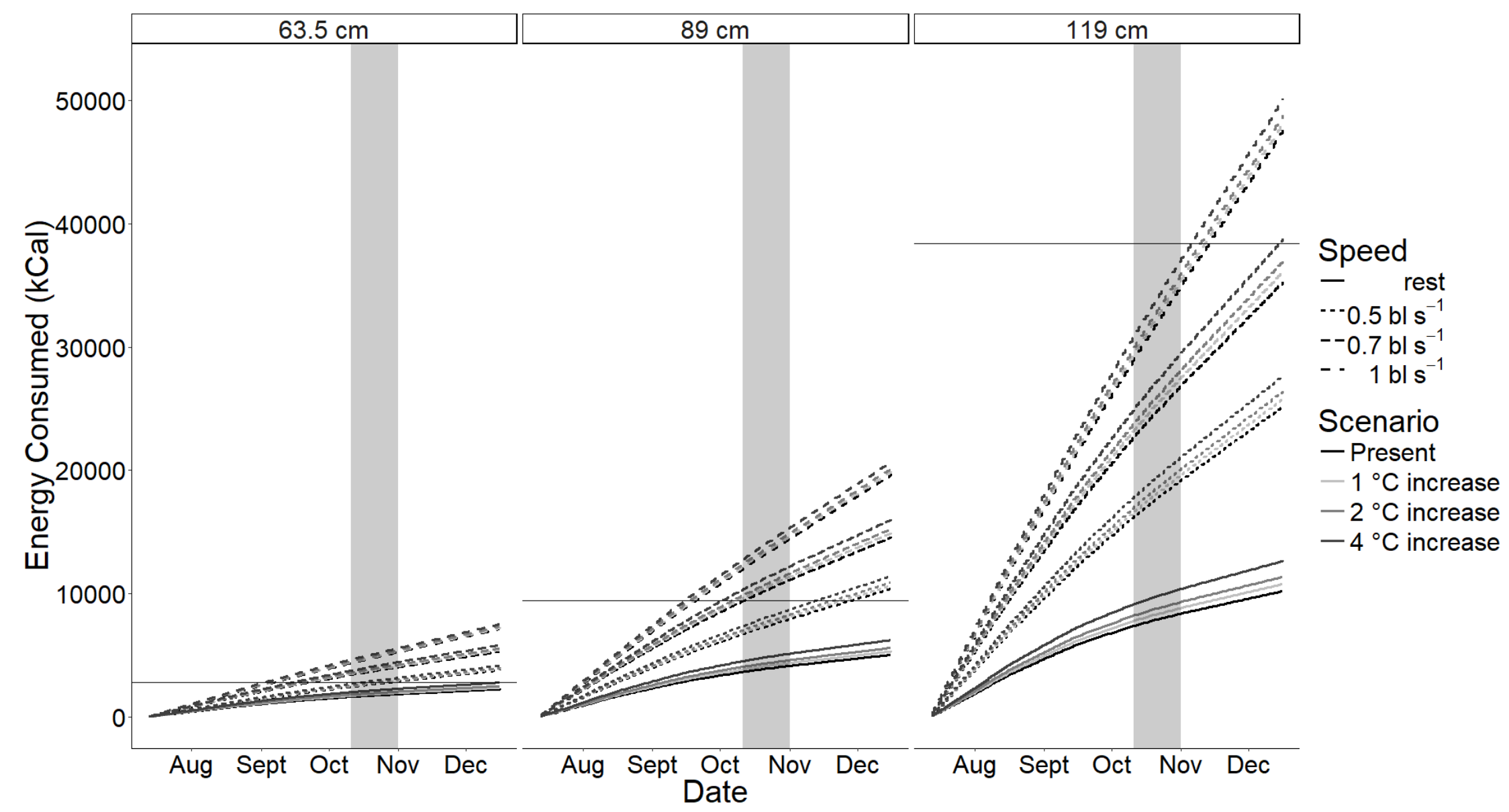

Figure 7.7 Predicted cumulative energetic expenditure (kCal) of Atlantic salmon measuring either 63.5, 89.0, or 119.0 cm, either resting or swimming at $0.5,0.7$, and $1.0 \mathrm{bl} \mathrm{s}^{-1}$ from July 13 - December 16 . Monthly ticks are the first day of the noted month. Daily temperatures experienced were converted from measured river values with the regression equation: $t_{\text {FISH }}=3.24+\left(0.76 \times \mathrm{t}_{\mathrm{RIVER}}\right)$ at present river 
temperatures or given increases of 1,2 , or $4{ }^{\circ} \mathrm{C}$. The horizontal line indicates the scope for depletion (i.e. initial energy minus postspawn energy) for each size class based on regression equations in Jonsson et al. (1997). The shaded area signifies the approximate spawning period in Lakselva, October 10-31. Energy depletion increased at higher temperatures, faster rates of movement, and larger body size. 


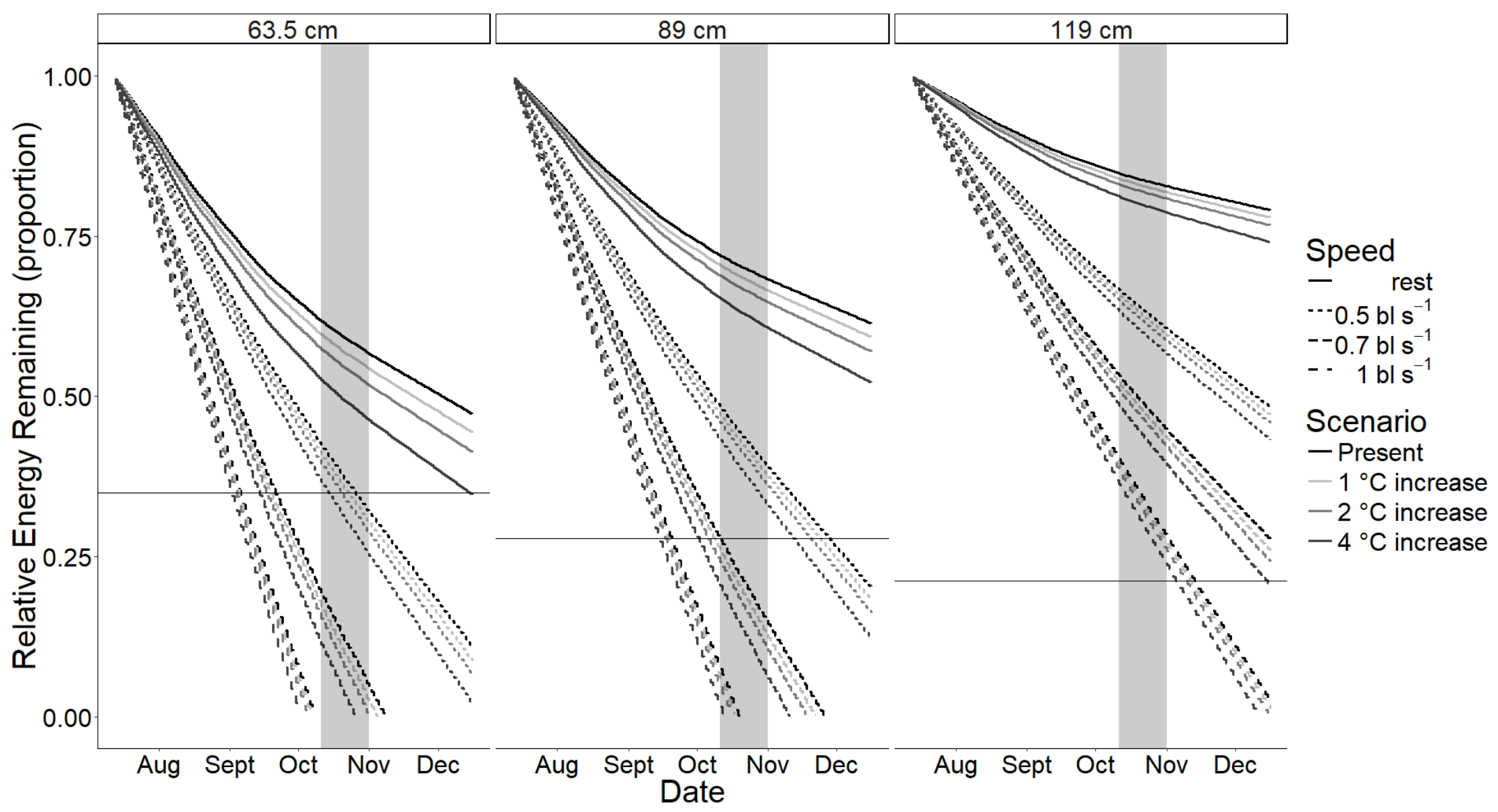

Figure 7.8 Predicted proportion of energy remaining to Atlantic salmon measuring either 63.5, 89.0, or $119.0 \mathrm{~cm}$, either resting or swimming at $0.5,0.7$, and $1.0 \mathrm{bl} \mathrm{s}^{-1}$ from July 13 - December 16 . Monthly ticks are the first day of the noted month. Fish habitat temperatures were calculated from the regression equation: $\mathrm{t}_{\mathrm{FISH}}=1.62+0.88\left(\mathrm{t}_{\mathrm{RIVER}}\right)$ at present river temperatures or given increases 
of 1,2 , or $4{ }^{\circ} \mathrm{C}$. The horizontal line represents the expected proportion of energy remaining in a post-spawn salmon of each size based on a regression equation in Jonsson et al. (1997). The shaded area signifies the approximate spawning period in Lakselva, October 1031. Relative energetic depletion increased at higher temperatures and for faster rates of movement but decreased with body size. 


\section{$\underline{7.5 \text { Discussion }}$}

I derived a linear relationship between water temperature and fish habitat temperature for an anadromous ectotherm during its spawning migration in freshwater. The ability to predict the experienced temperature allowed us to estimate energetic expenditure in situ. In doing so, I also provided the first equations approximating the relationship between water temperature and oxygen uptake of Atlantic salmon at various swimming speeds, and the first estimates of the energy metabolism of Atlantic salmon modelled to wild fish. Climate change is an ongoing threat to all freshwater ecosystems including in the Arctic. Understanding how key parameters, temperature, locomotion, and body size, contribute to energy depletion is relevant across species, particularly as oncoming changes to the global climate will require physiological and behavioural adaptations to cope. The finding that activity is the most substantial contributor to energy depletion suggests that animals will need to adapt their migration activity and behaviours to adjust to the increased metabolic demands associated with warmer river temperatures.

Compared to values published for pink (Oncorhynchus gorbuscha Salmonidae) and sockeye (Oncorhynchus nerka Salmonidae) salmon, Atlantic salmon appear to have slower metabolism (MacNutt et al. 2006; Eliason et al. 2011). Regression validated that ambient water temperatures could predict fish habitat temperature in this river within the summer water temperatures range of $11.5-18.5^{\circ} \mathrm{C}$, which is within the reported range of optimal temperatures of this species (Mills 1989; Booth 1998; Anttila et al. 2014;

Frechette et al. In Press). While ongoing increases in summer temperature may portend an increasingly energetically demanding freshwater migration, I found that the varying 
effects of body size and swimming speeds will play a crucial role in energy management for the response of anadromous fish to warming. Migrants that have stopped feeding necessarily economize energy during the migration to ration their energy reserves for successfully spawning (Bernatchez and Dodson 1987). This is true for today's thermal regime and in future years when rivers are projected to be warmer. Fleming (1998) provided a range of 52-65\% energy depletion for Atlantic salmon during the spawning migration, like that of migratory Arctic charr (Salvelinus alpinus) in Canada (52\%; Dutil 1986). Jonsson et al. (1997). However, they suggested a more extreme energy depletion of $72 \%$ for salmon in the Norwegian River Drammen, like that of anadromous American shad (70-80\%; Glebe and Leggett 1981) but less than long-distance migrating Pacific salmon (males: 82\%, females: 92\%; Bowerman et al. 2017). The disparity within Atlantic salmon is likely related in part to body size; applying the regression equation to the ambient temperatures in the river provided a minimal (i.e. at rest) $20 \%$ depletion of somatic energy for large salmon (119.0 cm length) and 51\% for small salmon $(63.5 \mathrm{~cm}$ length).

Our estimates of energy depletion do not account for a heterogeneity in swim speeds that would include increased activity during active migration, Bowerman et al. (2017) suggested would contribute to most of the energy depletion for Pacific salmon. However, Pacific salmon have a much more extensive spawning migration distance (920 $\mathrm{km}$ ) compared to the much short distance traveled by Lakselva salmon. Correspondingly, a large proportion of the time in freshwater is spent holding because most Atlantic salmon enter rivers weeks or months in advance of spawning (Økland et al. 2001). The precise costs of swimming activity are presently not known because there are no long- 
term studies of migrating Atlantic salmon energetics; therefore, I generated the model at several speeds. Speed is known to be closely linked to the life history of fishes (Glebe and Leggett 1981; Eliason and Farrell 2016). Bernatchez and Dodson (1987) calculated the average swimming speed of Atlantic salmon (river mouth to spawning grounds) to be $0.1 \mathrm{bl} \mathrm{s}^{-1}$ (using data from Belding 1934), which is consistent with observations from telemetry that Atlantic salmon hold for long periods in slow-moving pools prior to spawning (Økland et al. 2001; Richard et al. 2014; Chapter 3). Although fish activity has been suggested to benefit energetically from burst-and-glide over steady-state swimming (Weihs 1976; Hinch and Rand 2000), limitations in data availability require simulations such as ours that assume continuous swimming (see McElroy et al. 2012). The model revealed energy depletion was sensitive to changes in the rate of continuous swimming; individuals at slow swimming speeds will conserve energy across water temperature scenarios. Higher resolution data of swimming behaviour during the migration and throughout the migration (i.e. over the winter) will contribute to more complete models of the energy budget by identifying actual movement rates during all phases of a spawning migration including movement within pools.

Individual size was shown to be very important to depletion of energy stores, with larger individuals depleting less energy and hence being more resilient than small to temperature increases and activity demands. Large size conferred considerably greater scope for activity, likely because of their higher energy reserves, whereas smaller individuals migrate with less stored energy and are likely to have greater sensitivity to temperature increases that accelerate energy depletion. Based on this, large salmon may be more resilient to climate warming and have higher fitness; however, I did not account 
for larger fish having a lower optimum temperature (Morita et al. 2010). Body size in Atlantic salmon is genetically and phenotypically linked to environmental factors such as the difficulty of migration and the flow regime of the natal river (Jonsson et al. 1991a). Larger salmon also have higher fecundity and fitness (Fleming 1996; de Gaudemar et al. 2000). Warming of environmental temperature towards a species' optimum temperature accelerates growth and maturation, generally resulting in smaller body size at the time of maturation (i.e. the temperature-size rule; Kingsolver and Huey 2008; Jonsson et al. 2014), which has been shown experimentally for semelparous salmon (Clark et al. 2012) and reef fishes (Messmer et al. 2017). The temperature-size rule has received attention in the context of climate change (e.g. Daufresne et al. 2009; Sheridan and Bickford 2011; Cheung et al. 2013), although the validity of the underlying physiological mechanisms requires further validation (Lefevre et al. 2017). The data suggest that migratory fish such as salmon could compensate for climate change with a larger size, but there are competing selective pressures. Warm ocean temperatures favour earlier maturation and smaller body size of salmon (Jonsson et al. 2004). Indeed, Atlantic salmon from warmer rivers at southern latitudes tend to mature at smaller body size (Jonsson et al. 2004; Jonsson and Jonsson 2009).

As a relatively cold river, warming of the Lakselva River will increase the cost of freshwater residence by Atlantic salmon, with possible effects on life history such as reducing pre-spawn and post-spawn survival (such impacts have been observed in other species, e.g. American shad Alosa sapidissima Clupeidae; Glebe and Leggett 1981; Castro-Santos and Letcher, 2010). River temperatures and discharge are key factors moulding the life history of Atlantic salmon populations including smolt ages, run timing, 
body sizes, and iteroparity (Power 1981; Jonsson et al. 1991a). Rivers with less annual water discharge are generally characterized by spawning runs of younger and smaller salmon (Jonsson et al. 1991a). Sea trout populations at high latitudes have less frequent iteroparity than do southern populations (Jonsson and L'Abée-Lund 1993), a trend that may also be true of the congeneric Atlantic salmon. Phenological changes such as shifts to later run timing could also buffer energetic costs of warming water, as has been observed for populations in Newfoundland and Labrador, Canada (Dempson et al. 2017). Entering rivers later may decrease the accumulated thermal units during migration and offset energetic costs of higher water temperatures (Katinic et al. 2015) and entering earlier and swimming upriver to holding sites before temperatures become elevated will avoid a collapse in aerobic scope (Farrell et al. 2008). Late entry is generally associated with smaller Atlantic salmon with less somatic energy than larger individuals, and perhaps the relationship can be explained by energy demands of migration (Shearer et al. 1990; Niemelä et al. 2006a). According to Power (1981), increased water temperature promoted the evolution of a bimodal run timing distribution in Atlantic salmon to avoid movement in midsummer at high temperature (i.e. an early run and a late run establish within the same river).

Physiological acclimation to warming thermal regimes is possible when fish rear in those conditions. Anttila et al. (2014) identified significant thermal plasticity of Atlantic salmon originating from the nearby Alta River (69 58'06.3” N 2322'29.5” E) reared in warmer water, suggesting that fish from these northern populations could adjust, to some extent, to warming conditions in freshwater depending on early life experience. In the absence of species adaptation, the estimates of energy depletion suggest that pre- 
spawn mortality of Atlantic salmon is liable to increase in a warming world. For survivors of a first reproduction, it will probably result in decreased survival and reduced iteroparity (Jonsson et al. 1991b; Halttunen et al. 2013). The relationship among temperature, size, activity, and energy use are evidently complex and require further investigation.

\subsubsection{Limitations}

Although bioenergetics modelling is well established as a field of ecological inquiry, field metabolic data for fish including adult Atlantic salmon are scarce (Cooke et al. 2004). I used hatchery Atlantic salmon for the bioenergetic equations, an approach that may be somewhat limited; hatchery and wild salmon (and likely wild salmon of different origin) may have somewhat different conversion of energy to locomotion and future research may address this. Nonetheless, the use of surrogates is relatively common to physiological studies and surrogates of the same species should provide the most reliable information (Cooke et al. 2017). Jonsson et al. (1997) modeled somatic energy density of Atlantic salmon in the Drammen River (Jonsson et al. 1997), which are generally smaller than those in Lakselva. Thus, the energy calculation for the largest sized salmon lies beyond the data range derived for that population. Drammen is also warmer and so the salmon there spawn several weeks later than salmon in Lakselva (Heggberget 1988). The estimates would be improved by using oxygen uptake rates from wild Atlantic salmon that have entered fresh water at temperatures ranging lower than ours $\left(\min =7^{\circ} \mathrm{C}\right)$ instead of relying on extrapolations from hatchery fish oxygen uptake. 
Finer scale data on the cost of swimming and the logged data on swimming effort would also improve the models (Johnstone et al. 1992; Lucas et al. 1993; Hendry and Beall, 2004), but would still contain inaccuracies because it is logistically difficult to perfectly estimate field metabolic rates based on swim tunnel values. Such work would have to include the oxygen debt due to anaerobic exercise (e.g. Lee et al. 2003a, b), especially because burst-and coast swimming behaviours are likely to defer the immediate oxygen cost of swimming.

Like Jonsson et al. (1997), I cannot predict the energy loss through the winter months. Owing to the cold temperatures, the energy demands during this period are predicted to be small $\left(17.53 \mathrm{kCal} \mathrm{d}^{-1}\right.$ at $0{ }^{\circ} \mathrm{C}$ at rest $)$ compared to during the summer (48.73 $\mathrm{kCal} \mathrm{d}^{-1}$ at $14.5^{\circ} \mathrm{C}$ at rest), as calculated for an average sized salmon $(89.0 \mathrm{~cm})$ for this site. Nevertheless, salmon kelts clearly have exceedingly lower energetic reserves prior to outmigration (Moore 1997), warranting the term 'spent'. Consequently, warmer winter river temperatures will accelerate energy depletion and could perhaps trigger an earlier outmigration, possibly resulting in a mismatch of outmigration and peak ocean productivity that is believed to facilitate reconditioning of spent Atlantic salmon, as it does for out-migrating smolts (Otero et al. 2014).

Intersexual differences were set aside from the analysis, yet Jonsson et al. (1991b) found somatic energy loss to be much greater for males than females (this is different from Pacific salmon; Bowerman et al. 2017). Correspondingly, more females survive spawning whereas males are more prone to die (Hawkins and Smith 1986; Jonsson et al. 1991b). The minimum energy density at which salmon can live and still spawning (i.e. threshold for life), has been calculated for semelparous sockeye and pink 
salmons and ranged between $693 \mathrm{kCal} \mathrm{kg}^{-1}$ (Hendry and Berg 1999) to $956 \mathrm{kCal} \mathrm{kg}^{-1}$ (Crossin et al. 2003, 2004). Bowerman et al. (2017) calculated an energy density of 860 (female) and 980 (male) $\mathrm{kCal} \mathrm{kg}^{-1}$ in post-spawned chinook salmon. Jonsson et al. (1997) provided an equation for estimating the somatic energy of a post-spawn salmon based on length (see Methods), although their work did not identify an explicit threshold for life. As expected, energy depletion was accelerated at higher temperatures and under scenarios of higher activity. However, activity had a more profound impact on the rate of energy depletion than did increases in temperature within the modeled range. This disparity was more evident among smaller salmon than for larger individuals given that larger individuals possess greater energetic storage. Body size of Atlantic salmon is closely linked to reproductive success (Fleming 1996; de Gaudemar et al. 2000) and salmon exhibit considerable variation in life history phenotypes across body sizes (Shearer et al. 1990; Niemelä et al. 2006a). The models should inspire research into how physiological plasticity and behavioural adaptations, especially run timing, could compensate for warming. Ultimately, a better understanding of the behavioural and physiological mechanisms that facilitate successful migration, associated life history events (i.e. run timing, spawning), and physiological processes (i.e. cardiophysiology, biochemistry, and biomechanics; Anttila et al. 2014) is necessary to understand and manage fish in a warming Arctic and advance efforts to focus conservation initiatives on sensitive populations. 


\section{Chapter 8 Synthesis and Future Research Directions}

This thesis investigated mechanisms of success and failure related to migration, which is a taxonomically diverse and ecologically sensitive behaviour threatened by environmental and anthropogenic stressors (Wilcove and Wikelski 2008; Robinson et al. 2009). Atlantic salmon was an ideal focal species because the spawning migration is logistically easy to observe after they enter rivers and is well studied, facilitating interpretations of potential fitness costs related to migration success and failure (e.g. Thorstad et al. 2008). In this thesis, I evaluated success using various tools including interception (counting at fish fence [Chapter 2], visual observations by snorkelling [Chapter 3]), mark-and-recapture with anchor tags (Chapter 5), biotelemetry (Chapter 2, $3,4,5,6)$, and biologging (Chapter 2, 7). Although the Atlantic salmon migration begins at sea, the non-feeding period during which salmon are undergoing maturation occurs during the freshwater migration (Kadri et al. 1995). Exposure to stressors during the marine migration is also more limited with greater potential for avoidance of marine nets or temperature isotherms, albeit increasing threats from aquaculture encroachment (Mahlum et al. In Press).

The freshwater migration of Atlantic salmon is characterized by intense potential for exploitation in fisheries (Erkinaro et al. 1999) but importantly the proportion of salmon released alive is increasing (Lennox et al. 2016b [Appendix B]). I found that stressors may interrupt the salmon migration by delaying the upriver movement phase (Chapter 2) and potentially shortening the migration such that salmon spawn lower in the river than they would have had they not been captured (Chapter 3). No impacts on the 
holding phase of migration were found given that the post-release movements were similar to the expected movement during the spawning period (Chapter 4). Indeed, most salmon survive (Chapter 2-6), continue the migration, and may be captured again by anglers (Chapter 5). However, climate change represents an additional stressor and high water temperatures may affect energy processing, recovery from stress (Chapter 6), energy depletion, and migratory phenotypes of Atlantic salmon (Chapter 7).

The behaviour-physiology interface

Behaviour is applied in this thesis as a relevant endpoint with which to investigate the impacts of stressors on the whole animal with a link to lifetime fitness potential. It is difficult to interpret behaviour without consideration of the underlying physiological mechanisms (Cooke et al. 2013a), which is why I also incorporated biologging tools that provided fine-scale details about animals to add context to observations. Bioenergetics are particularly relevant to the understanding of behaviour and the two are inextricable, which is why biologging was incorporated into investigations in Chapters 2 and 7. In Chapter 2, I used accelerometers to measure body action and tailbeat frequencies, which I consider to fall along the interface between physiology and behaviour because locomotion and holding station by tail beating is autonomous and not a behaviour per se (Wallén and Williams 1984). Although I did not calibrate the accelerometer tags in a swim tunnel to calculate actual oxygen consumption, this concept is consistent in providing robust linear relationships that can be applied to convert accelerometer-derived movement into energy consumption in bonefish (Albula vulpes) with the same sub- 
carangiform swimming as Atlantic salmon (see Murchie et al. 2011; Brownscombe et al. 2017b). Composite whole-body metrics summarized from the axes of tri-axial accelerometers have been posited to correlate consistently with energy expenditure (Gleiss et al. 2011) and therefore jerk, the metric chosen to describe accelerometerderived activity, could effectively be translated into values of oxygen consumption and somatic energy depletion with the correct coefficients in future applications.

Energetics models have long been used to simulate fish resource demands, predator-prey interactions, and nutrient cycling (Hansen et al. 1993). Questions of energetics have been especially insightful in the migration of Pacific salmon, revealing, for example, energy demands (Hinch and Rand 1998), predation risk (Peterson and Kitchell 2001), and performance at fish passage structures (Burnett et al. 2014). Jonsson et al. (1991a, 1997) provided some measurements of energy depletion of salmon during the migration but there has still been a lack of information about the bioenergetics of Atlantic salmon that can be applied to the study of their upriver migration. Chapter 7 presents the first published model estimating the temperature-specific oxygen consumption of adult Atlantic salmon to develop bioenergetic models that describe the energy depletion during the migration. This approach could be improved upon by using wild Atlantic salmon and deriving oxygen consumption values in freshwater (Maxime et al. 1990); however, the data were useful for the simulations and predicting how salmon populations will be affected by climate change. As the first oxygen consumption models for adult Atlantic salmon, this represents an important contribution to the literature that merits further attention. 
Bioenergetic modelling of Pacific salmon migrations (Hendry and Berg 1999; Crossin et al. 2003, 2004; Eliason et al. 2011; Katinic et al. 2015) has elucidated some of the mechanisms of mortality. Similar potential exists with Atlantic salmon using biologgers to study migration and spawning exertion (Tsuda et al. 2006; Karppinen and Erkinaro 2009). Calibrating accelerometer or heart rate logging tags along with temperature logging tags to estimate oxygen consumption will allow modelling of energy expenditure and depletion for salmon to investigate natural mortality along the migration route and quantify the impact of various stressors and phases of migration. This would facilitate investigations of trade offs for large and small salmon as they compete for access to spawning resources and provide insight into the strategies exhibited by individuals in conserving energy for future reproduction (i.e. iteroparity). Such approaches would also permit investigations into multiple stressors interacting during the migration (e.g. Crain et al. 2008). Further applications of bioenergetics and research expanding on my energy depletion work could include calculating excess post exercise oxygen consumption (Lee et al. 2003a, b; Zhang et al. 2018), comparing energy demands of different phases of migration (e.g. Bowerman et al. 2017), testing for changes in oxygen uptake efficiency at different phases of maturation, or contrasting life history strategies (run timing, spawning activity, overwinter survival).

\section{$\underline{\text { Ultimate outcomes }}$}

Animals must overcome stressors or else their future reproductive fitness potential is nullified (McEwen and Wingfield 2003). Survival may seem conceptually simple to 
measure but survival can be measured at different temporal scales and using various techniques. In fisheries, short-term survival may be quantified in holding experiments (e.g. Booth et al. 1995; Brobbel et al. 1996; Dempson et al. 2002). Holding is stressful for fish, particularly migratory animals, therefore quantifying fitness in free living fish released after application of a stressor may provide more representative values of survival (Gustaveson et al. 1991; Vijayan et al. 1997). Survival rates can be calculated from passive marks using mark-recapture or using direct estimates calculated from electronic tags (Pollock et al. 2004). There are challenges to the interpretation of survival in some contexts, particularly when tagged animals are predated (Gibson et al. 2015). The potential influence of this was discussed briefly in Chapter 6 in terms of seal predation, but it is not expected to have confounded results in this thesis. Data sharing provided an ideal method for developing a model of survival that extends throughout the range of Atlantic salmon and giving consideration to the high heterogeneity (i.e. rivers with different tackle conventions, water temperature regimes, run timing, angler behaviour, and fish sizes).

Incorporation of estimated natural mortality is necessary to determine whether observations of fishing mortality represent compensatory or additive mortality (Allen et al. 1998). Compensatory mortality is a well-developed concept in natural predator-prey systems (Genovart et al. 2010; Krumm et al. 2010); however, mortality imposed by human predators may often be additive (e.g. Sand et al. 2012). In Lennox et al. (2015 [Appendix B]), I tracked the upriver migration of Atlantic salmon in the River Gaula that had been radio tagged in the Trondheimsfjord, Norway following capture in bag nets. None of these salmon were determined to have suffered in-river mortality suggesting that 
delayed mortality following fisheries capture was additive. Except under supraphysiological environmental conditions (e.g. Baisez et al. 2011), natural mortality should be nominal during upriver migration although an invasive freshwater catfish (Silurus glanis) that preys on adult salmon is apparently spreading through Europe (Boulêtreau et al. 2018). Further investigation may be necessary given that larger scale studies of Pacific salmon have observed natural mortality associated with physiological preparedness, which is likely system-specific depending on the difficulty of migration (Cooke et al. 2006). Nonetheless, the data that are available for Atlantic salmon suggest that delayed mortality following catch-and-release is predominantly additive upon individuals that would likely otherwise survive to spawn rather than compensatory. Hard et al. (2008) reviewed cases in which salmonids have been subjected to fisheries-induced evolution because of non-random fisheries mortality and the additive nature of en route mortality during the spawning migration must be considered when managing these fisheries. For example, avoiding female-biased mortality by shifting the open season of recreational fisheries to avoid bias against female (Pérez et al. 2005) or wild (Chapter 4) salmon that tend to enter rivers earlier when angling is most active.

Fitness is the average reproductive contribution of a phenotype to the successive generation (Maynard Smith 1989). Fitness is therefore not an individual metric but one that is only comparable among phenotypes. I have discussed fitness in this thesis as a proximate explanation for the capacity for individual spawning success, with null fitness for individuals that die and impairments to those that do not migrate to the correct location or at the correct time. Indeed, a successful migration is necessary for migratory animals to realize lifetime fitness (Dingle 1980). Some salmon, however, are repeat 
spawners and have already realized some lifetime fitness (Garant et al. 2001; Halttunen et al. 2013); therefore, an unsuccessful subsequent migration would not nullify lifetime fitness but would reduce it. The limitation of not measuring reproductive output is discussed throughout this thesis because it is acknowledged that this quantification is necessary to make higher resolution conclusions about the impact of stressors at the population scale. Physiologically, acute stressors have not been demonstrated to impact the reproductive potential of congeneric brown trout (Pickering et al. 1987). Investigations of egg and fry viability produced by caught-and-released salmon provided evidence that the reproductive condition is not compromised by catch-and-release, even when the stressor is applied late in the season proximate to the time of spawning (Davidson et al. 1994; Booth et al. 1995) as in Chapter 4. Genetic parentage analysis by Richard et al. (2013) corroborate the reproductive viability of salmon released by anglers; in the Escoumins River, Canada, Atlantic salmon released by anglers comprised important parents in the spawning population and offspring numbers have correlated to efforts to release salmon alive (Whoriskey et al. 2000; Thorstad et al. 2003). These studies validate the approach taken in this thesis to identify the drivers of migration success in salmon given that survival and behaviour in response to acute stressors such as angling appears to be the most important determinant of reproductive success given that spawning appears to be unaffected if fish continue migrating to the appropriate time and place of spawning. Nonetheless, further research is warranted to investigate potential impairments to spawning or offspring quality. Most literature on salmonids has focused on the semelparous Pacific species that are resistant to stress during reproduction (Wingfield and Sapolsky 2003; Raby et al. 2013). Environmental (e.g. drought, high 
water temperature; Chapter 7) or anthropogenic stressors (e.g. multiple stressors; Chapter 4) could result in chronic stress of Atlantic salmon that affects reproduction or is transferred to offspring (Boonstra 2013). Intergenerational effects of such stress may be buffered or transferred to offspring but the information must be matched with the environment that the offspring will encounter to ensure that the endowment is adaptive (Boonstra 2013; Sopinka et al. 2014). Experimental approaches in spawning channels (e.g. de Gaudemar and Beall 1998; de Gaudemar et al. 2000) could be used to investigate treatments on spawning competition, activity, and success in situ to provide different lines of evidence for the impact of stressors on migrating Atlantic salmon.

With suitable evidence that the physiological and behavioural capacity of Atlantic salmon to migrate is not greatly substantially compromised by acute stress such as fisheries capture/handling, I focused on the period encompassing only the estuarine/freshwater migration prior to spawning. The movement, searching, and holding phases that comprise migration are behaviours during which migratory animals encounter barriers, exploitation, and climate change effects (Wilcove and Wikelski 2008). For Atlantic salmon, there are many factors influencing spawning success that may be independent of stressors encountered during the migration. Early entry into freshwater and prior residence at spawning sites confers advantages to individuals (Tantelier et al. 2016). Richard et al. (2013) showed that early entry of one-sea winter adults was an important predictor of reproductive output, which is why delays (Chapter 2), erratic movement (Chapter 4), truncations (Chapter 3), and recapture (Chapter 5) may represent legitimate costs to individual fitness potential as fish ascend to spawn. Atlantic salmon freshwater migration is disturbed in time (Chapter 2) and space (Chapter 3, 4) by 
stressors encountered during the migration and that compensation for stressors appears to be minimal; salmon did not exhibit a recovery profile measured by jerk activity in Chapter 2. Collectively, this suggests tolerance to stressors encountered during the migration with adaptations to avoid further disturbance (e.g. learned hook avoidance; Chapter 5).

Spawning in a given year is not the ultimate measure of individual lifetime fitness for Atlantic salmon, an iteroparous species that can spawn multiple times in its life. Although repeat spawners tend to have less fecundity than predicted by their body size (Garant et al. 2001), the contribution of repeat spawning salmon can be significant and the protection of kelts is increasingly recognized as essential to salmon conservation efforts (Saunders and Schom 1985; Reid et al. 2012; Halttunen et al. 2013). There are some data describing the behaviour of salmon following spawning, knowing that poor condition is a predictor of early outmigration to the sea and that smaller individuals and females are more likely to survive for outmigration (Levesque et al. 1985; Halttunen et al. 2013). There is limited understanding of the potential carryover effects of stressors encountered during the upriver migration that may influence the long-term survival and repeat spawning potential of salmon. Carryover effects emerged in medical literature and acknowledged the potential for stressors to increase susceptibility to latent stressors. In ecology, carryover effects have been explored in diverse taxa including fish. Midwood et al. (2015) demonstrated that an autumn stressor increased overwinter mortality of juvenile congeners, the brown trout, preparing to smolt. Such findings suggest that further research is necessary to investigate impacts on overwintering survival of Atlantic salmon that encounter stressors during their spawning migration. Should stressors such as 
fisheries capture, barrier passage, or climate change influence the repeat spawning potential of captured fish, this would represent a cost to fitness potential that has not yet been investigated and inadequately considered. I received one report of an Atlantic salmon tagged in Lakselva in 2016 (Chapter 4) that was recaptured by an angler in the river in 2017 on a subsequent spawning migration, indicating that it had survived overwintering and returned to spawn a second time. Further research is needed to quantify the contributions of repeat spawning salmon to populations and whether stressors such as angling could have carryover effects that affect the probability of repeat spawning. Consecutive repeat spawners have less fecundity than predicted by their body size and their contributions to the effective population should be more accurately quantified and given greater consideration in salmon conservation efforts (Garant et al. 2001).

$\underline{\text { The Future of Migration }}$

Migration is an ancestral behavioural trait of animals given that it occurs throughout the animal kingdom (Alerstam et al. 2003). Species may adopt or abandon the migratory phenotype as the relative fitness potential value shifts (Martin et al. 2018). Animals strive to maximize the ratio of growth/mortality (Werner and Gilliam 1984) and the benefits of migration must outweigh costs. Stressors may alter the benefits of migration to some species; selection against migrants may reduce the fitness of the migratory phenotype or individuals may have plastic responses to their environment. For an example of the latter, some species could cease migrating as climate change improves 
annual growth potential and increases the risk of mortality (Martin et al. 2018). The phenomenon of partial migration permits individuals within populations to decide their fate; whether to migrate or not can depend on condition (Brodersen et al. 2008; Peiman et al. 2017; Martin et al. 2018). However, conspecific density can also affect migration tendencies likely because it determines the extent of resource competition (Lundberg 1988; Grayson and Wilbur 2009). Selection imposed by fisheries may additionally threaten to alter the fitness of migratory behavioural phenotypes (Consuegra et al. 2005; Pérez et al. 2005). Modern harvest and post-release mortality ostensibly select against migration and could increase the fitness of residents, particularly for males that have an alternative phenotype available in precautious maturation and reproduction. However, the fitness of the precautious phenotype depends on the success of sneaking, which declines in the absence of anadromous males; therefore, this evolutionary stable strategy will likely maintain migration as a highly fit phenotype in Atlantic salmon populations despite stressors such as fisheries and climate change (Gross 1984; Hutchings and Myers 1988). There is also intrapopulation variation in the reaction norm for expression migration compared to maturing without migration that is probably conserved within populations (Piché et al. 2008). Ultimately, substantial changes to the migratory tendencies of Atlantic salmon are unlikely but smaller scale changes may occur to salmon life history and phenology such as shifts in run timing (Chapter 7), particularly if there is directional artificial selection (Consuegra et al. 2005; Hard et al. 2008).

Size, age, and phenology of Atlantic salmon are partially genetic and respond to selection and are partly environmental, a source of stabilizing selection that may counterbalance artificial selection by fisheries (Jonsson et al. 1991a). Atlantic salmon 
populations that are overexploited exhibit smaller average body size (and therefore sea age at maturity; Quinn et al. 2006; Turrero et al. 2014b). Similarly, fisheries-induced evolution resulting from harvest selection against trophy-sized Atlantic salmon may have already made any substantial impact on the average size of fish (Turrero et al. 2014b). Indeed, Saura et al. (2010) predicted a reduction in length and weight of each generation of salmon exposed to selection by recreational angling. In Chapter 6, I found no effect of length on probability of post-release mortality, suggesting that live release is unlikely to drive fisheries-induced evolution of salmon. Harvest is therefore likely to be the most important driver (Lennox et al. 2016b [Appendix B]).

Genetic determination of migration timing (Consuegra et al. 2005) means that the open season for angling will influence the temporal vulnerability of salmon to exploitation and therefore has the potential to exert a selective force on salmon fisheries (Garcia de Léaniz et al. 1992; Consuegra et al. 2005; Pérez et al. 2005). Early entry into freshwater extends the period of exposure to stressors including fisheries and climate change (Pérez et al. 2005); late entry into rivers may allow fish to escape fisheries and remain in the cooler marine water longer, with benefits to spawning if pre-spawn mortality is sufficiently buffered (Saura et al. 2010). Large fish tend to enter earlier (Youngson et al. 1994) and Pérez et al. (2005) showed that this difference in timing was resulting in female-biased harvest in Spanish rivers because females initiate migration earlier than males. Advanced maturation and smaller size is a classic symptom of overfishing and management should be very risk averse to potential fisheries-induced evolution of salmon (Law 2007; Hutchings and Fraser 2008; Heino et al. 2015). Large individuals have greater fitness potential and are also more resilient to disturbance 
(Chapter 7) including those that are anticipated from climate change such as drought and temperature increases (Hutchings and Myers 1993; Anderson et al. 2008). Juvescent populations with smaller size at reproduction have more volatile population dynamics that are more prone to crash and more difficult to manage (Anderson et al. 2008). However, it is important to note that selection may be most pronounced in the at-sea interactions of salmon (Hutchings and Jones 1998). Empirical data supporting this include evidence that sea surface temperatures influence salmon age and phenology (Jonsson et al. 2004; Dempson et al. 2017).

Climate change will also alter the expression of migration in Atlantic salmon (see Otero et al. 2014; Dempson et al. 2017). In Chapter 7, I showed that increases to water temperature in an Arctic river could select for larger sized salmon that appear more tolerant of high water temperatures than small salmon based on swimming metabolism. However, salmon may also adjust their behaviour to enter rivers later in the season to avoid prolonged exposure to high temperatures and energetic depletion. Larger salmon already enter rivers earlier than small salmon and this potentially provided a mechanism to explain this phenomenon because small fish have less somatic energy stored to survive prolonged starvation during migration (Niemelä et al. 2006 a, b). River warming could increase the disparity between the run timing of large and small salmon and males and females such that females would have even greater vulnerability to angling than males because of their availability (Consuegra et al. 2005; Pérez et al. 2005).

\section{$\underline{\text { Applied Perspectives }}$}


This thesis has provided some novel fundamental perspectives about the migration biology of Atlantic salmon and the behavioural response to stressors encountered during the freshwater phase of migration. However, much of the content also has substantial potential for informing management of Atlantic salmon throughout its range. Recreational Atlantic salmon fisheries stand to benefit from scientific research in multiple ways. Some fisheries are threatened by the conservation concerns associated with fishing for this species at risk and data are needed to understand impacts and make informed decisions about the future of these fisheries including regulations to ensure sustainability. Ensuring that these fisheries are sustainable also maintains high quality angling opportunities for stakeholders including anglers, guides, and other industry professionals that may depend on angling tourists as part of their income (Stensland and Baardsen 2012). Governing agencies may be obligated to provide information to anglers so that they catch and handle fish responsibly as stewards of the resource (Pomeroy and Berkes 1997; Brownscombe et al. 2017a).

Collectively, this thesis reveals several details about the biology of Atlantic salmon exposed to recreational angling. Importantly, I present what I believe to be the most robust and reliable estimate of Atlantic salmon mortality in recreational fisheries in (Chapter 6) as well as estimates that extend into the fall (Chapter 4). I have discussed the evolutionary implications of this in the previous section, but from a management perspective this provides important evidence that salmon released by anglers can be expected to survive. Survival in these recreational fisheries remains one of the most contentious issues related to the management of the fishery and the results of Chapter 6 inspired a popular media article in the Atlantic Salmon Journal (Vol. 66 No. 4; Lennox 
2018 [Appendix A]) communicating the findings to stakeholders. Indeed, debate about survival is the reason so much effort has been expended researching this specific topic and inspired me to collaborate on a model that could explain factors associated with mortality throughout the range (Chapter 6). The finding that seven percent of salmon released with electronic tags were concluded to have died following catch-and-release provides a reliable estimate of delayed mortality that should be supplemented with local estimates of immediate mortality that are easy to obtain from anglers. Although there was some selection bias associated with removing fish deemed to be moribund (consistent with local regulations in Norway), I found that hooking in critical locations and bleeding were not significant predictors of post-release mortality and that anglers should use their judgement when they retrieve a salmon in such condition and not assume that the fish is destined to die. The finding that water temperature was a significant predictor of postrelease mortality was consistent with other literature on Atlantic salmon (Dempson et al. 2002; Havn et al. 2015) and can be applied by managers to develop estimates of delayed mortality based on the temperature regime in their local river. My effort to quantify mortality also extended to late-season angling in the Norwegian surveillance fishery (Chapter 4). Surveillance fishing is a relatively inexpensive and low impact method of maintaining records on the extent of farmed salmon intrusion in Norwegian rivers. In addition to providing applications to the management of recreational fisheries, this thesis has also provided an answer to a relevant question about the use of surveillance fishing as a monitoring tool, demonstrating that high survival of released salmon corroborates its implementation (Chapter 4). 
Sublethal effects of stressors are now widely contemplated in fisheries (Wilson et al. 2014). Stressors can impart fitness, life history, or population effects such as diminished fecundity, delayed phenology (as observed here; Chapter 2, 3), or reduced abundance. I explored sublethal effects and discussed how these affect individual fitness potential. From the perspective of fisheries management, it is relevant to understand that, despite high survival, angling and other exploitative activities do have costs that must be reconciled and mitigated (to the extent that it is possible) to achieve sustainability. One way to do so is through regulations that limit fishing effort. A large proportion of the migratory run can be captured by anglers (Erkinaro et al. 1999; Twardek et al. 2018) and if sublethal effects of angling result in population-level impacts, rivers with small populations or high availability of salmon may consider implementing regulations to limit the vulnerability of salmon to angling.

One area I did not explore in depth was recapture of salmon in the recreational fisheries. However, an important finding was that released salmon go on to be captured multiple times by anglers, in some ways increasing the population of fish available to anglers and improving the fishing experience for participants (Chapter 5). Of course, increased abundance owing to high survival of released salmon (Chapter 6) would suggest that catches should be greater when salmon are released. In Chapter 3, 18\% of the tagged salmon were recaptured by anglers (one of which was recaptured twice). In a more spatially and temporally broad sample (multiple rivers in two years), $14 \%$ were recaptured (Chapter 5). Apparently, a released salmon is more likely to be recaptured than to suffer delayed mortality. Of course, there are unknown costs to salmon being captured multiple times and it is uncertain whether such repeated stressors could have 
multiplicative impacts on physiology or induce a more protracted stress response. Based on the analysis in Chapter 5, recapture is facilitated using multiple gear types given that salmon appear to avoid recapture by familiar gear types and management could use this information to manipulate vulnerability, which is an individual phenotype incorporating cognitive, physiological, behavioural, and environmental variables (Lennox et al. 2017b [Appendix D]). Fisheries management that capitalizes on understanding variable vulnerability of fish can improve sustainability by altering catches by changing angler behaviour. In Lennox et al. (2016b [Appendix B]), I worked with data from Norway investigating the impact of different regulation types on the harvest rates of salmon in the fisheries. The distinction between harvest and release was beyond the scope of this thesis. However, it does provide relevant context to the contributions of my work to management of the fishery.

A final note on the applied perspectives offered by this thesis must consider the social dynamics associated with fisheries management and regulation. In recent years, this has been an exciting and accelerating topic of research to understand stakeholder perspectives in fisheries. Having provided relatively thorough evidence that survival from catch-and-release is high and that angler utility can be augmented by the recapture of released fish (Chapter 5), it is tempting to conclude that incorporating catch-and-release should be logical for conservation. However, this would discount perspectives of human dimensions and the utility anglers derive from different aspects of the fishing experience. Olaussen and Liu (2011) found that the utility of Atlantic salmon to anglers in Norway depends on their origin, with wild stocks significantly more valuable than those that have been invaded by escaped farmed fish. Subsequently, Olaussen (2016) observed that up to 
$80 \%$ of the utility of Atlantic salmon fishing may be lost to Norwegian anglers in rivers where catch-and-release is mandatory. This is a fascinating contribution that was beyond the scope of my own thesis but provides essential context to managers considering the biological results of my work. As complex sociobiological systems, recreational fisheries must reconcile the biological and economic sustainability to persist. Declines in willingness to pay for fishing in rivers where harvest is eliminated may reduce the many benefits that recreational fisheries are believed to have for wild salmon and other species at risk that may become vulnerable to poaching should recreational fishing disappear (Cooke et al. 2014).

Crossin et al. (2017) recently reviewed the contributions of telemetry to fisheries management. One of the most relevant contributions that telemetry can make is assisting in the calculation of key demographic parameters such as natural and fishing mortality that are necessary to evidence-based fisheries management (e.g. Beamesderfer and North 1995). However, Young et al. (2017) discussed challenges to mobilizing knowledge from biotelemetry studies into policy and management. In their third case study, they discussed how knowledge of catch-and-release mortality of migratory salmonids in the Fraser River, Canada was disfavoured compared to the "socially robust" and smaller proportion of mortality already in place. Uncertainty about findings in biotelemetry studies is apparently a barrier to operationalizing research such as mine into management. Crossin et al. (2017) advocated for co-creation of research with relevant stakeholders, which I pursued by having a close collaboration with the river manager in Lakselva, where data for Chapters 3-7 were entirely or in part collected. This was a beneficial model because the river manager represents the interests of landowners who are the primary stakeholders 
in the fishery. Working directly with visiting anglers to collect data for these chapters provided opportunities to discuss the project provided access to secondary stakeholders, an important opportunity for ensuring the project was reaching different users of the resource.

\section{Thesis Conclusions}

According to Forseth et al. (2017), exploitation represents a stable and relatively small threat to Atlantic salmon compared to other challenges, especially related to the expanding aquaculture industry. Yet, there are still relatively prominent voices that explicitly fault recreational angling as the cause of salmon declines, for example a recent perspective in the Newfoundland and Labrador newspaper The Telegram by Memorial University Chair of Aquaculture Programs Cyr Couturier (Couturier 2017). My thesis, however, provides empirical evidence against long-term negative impacts of recreational angling, especially where catch-and-release is implemented (see Lennox 2018 [Appendix A]). In rivers where harvest is permitted, accurate demographic data and risk-averse models can be implemented to ensure that appropriate regulations are in place to minimize impacts. More poorly understood threats (according to Forseth et al. 2017) such as hazardous substances, predation, introduced species, and infections could be explored using similar approaches as applied in this thesis, at least in the fresh water phase of the migration to evaluate whether they affect migration success or lead to failure. This thesis therefore provides a flexible framework with which to investigate the impacts of stressors that could be generalized to other stressors on Atlantic salmon. Indeed, the format could 
also be applied to other taxa or conservation threats to make determinations. My approach to use metrics such as activity (measured by jerk, Chapter 2), migration timing (Chapter 2), migration distance (Chapter 3), survival (Chapter 4, 6), and recapture (Chapter 5) as well as bioenergetic modelling of energy depletion (Chapter 7) provides a generalizable format for investigating the impacts of any stressor on migratory animals using biotelemetry and biologging that could be extended to many other aquatic or even terrestrial animals. Just as I concluded frequent survival but delayed and truncated migrations attributable to recreational angling and energy depletion associated with warming, so could the effect of other putative stressors such as infection be tested to determine impacts on migration success and the ability to progress through migratory corridors to breeding habitat of other migratory animals confronting anthropogenic stressors. This model may also be applied to extend beyond the spawning migration to evaluate impacts and develop robust frameworks for understanding and managing sensitive animals globally. 


\section{Appendix A. Atlantic Salmon Journal Article on Atlantic salmon catch-and-release science}

Few topics in recreational fisheries remain as controversial as catch-and-release, a term that means many things to different people, from animal ethics to obeying local laws or regulations. To scientists and managers, catch-and-release simply refers to any component of the recreational catch that is not retained. There is catch-and-release in all recreational fisheries, whether it is releasing fish that could be legally harvested for conservation reasons, releasing large ones outside of a legal slot size, or releasing nontarget species. All these scenarios apply to recreational Atlantic salmon fisheries where there may be quotas, slot limits, or other fisheries (e.g. anadromous brown trout in Europe) that result in some salmon being released even by anglers intending to harvest some fish.

The scientific motivation to study catch-and-release arises from the need for informed management of salmon. Estimating the number of salmon migrating up a river, the number that are captured by anglers, the proportion of the captured fish that are harvested, and knowing the rate at which released salmon die because of stress or injury from the capture event is critical to management. It is the job of scientists and managers to work with anglers to generate these numbers to ensure that the salmon population can withstand angling pressure in the current season so that enough reproduction occurs so that angling, both angling for harvest and angling with the intention of releasing, can continue in the future. 
Atlantic salmon are among the most important recreational fish species; however, the productivity of recreational fisheries in many countries have declined. It is important to be clear that Atlantic salmon are at risk independent of the recreational fishery; stressors including commercial fishing, invasive species (e.g. Gyrodactylus salaris parasite), and habitat alteration (e.g. increasing temperature and acidity, damming or channelization of rivers, siltation) have all contributed to declines in Atlantic salmon populations.

Recreational harvest is rarely the cause of imperilment of Atlantic salmon populations. Nonetheless, the recreational fishing sector in most rivers is the final stressor that Atlantic salmon encounter prior to spawning. The fish that reach the rivers have survived the downstream migration, occasionally through dams, evaded predators and fisheries in the ocean, and are months away from reaching spawning sites to reproduce. As a result, the recreational fishery has the potential to substantially alter the proportion of salmon that spawn successfully in rivers relative to the count of salmon that enter the river.

Estimates of the number of salmon captured by anglers in recreational fisheries are variable Gudjonsson et al. (1996) estimated that up to $70 \%$ of grilse and $85 \%$ of multi sea winter salmon could be captured by anglers in the Icelandic River Nupsa. Whoriskey et al. (2000) estimated that $10.4-19 \%$ of Atlantic salmon entering the Russian Ponoi River were captured by anglers. This suggests that recreational anglers can have significant impacts on the Atlantic salmon spawning population at such high exploitation levels, particularly considering that it does not include salmon that are hooked and not landed (anglers will acknowledge that there are many such fish that never make it to the 
hand!). Figures such as these suggest that studying catch-and-release is essential to the study of Atlantic salmon and the management of their populations in rivers.

Interest in Atlantic salmon catch-and-release has endured since the 1800s when Richard Nettle discussed the importance of returning captured salmon to the water. Lee Wulff suggested that these gamefish are too important to be captured only one time, and there is good evidence that many salmon that are released may be recaptured by anglers, literally living to fight another day. Although marking salmon that are released with small plastic tags is effective for demonstrating that salmon may survive catch-and-release, it does not provide any accurate information about the incidence of survival of salmon captured by anglers because many will survive but not be recaptured.

The question of Atlantic salmon survivorship in recreational fisheries has been studied throughout the range of salmon since the 1990s using a variety of techniques, beginning with simulations of angling and subsequent holding in submerged cages underwater (100\% in Booth et al. 1995; 88\% in Brobbel et al. 1996; 88\% in Dempson et al. 2002). However, study designs that hold fish can stress them, increasing the mortality, or may protect them from predators such as seals or birds that may take advantage of a weakened salmon, decreasing the validity of such predictions. Electronic tagging studies were therefore undertaken to track the migration of salmon after release by anglers. Electronic tags transmit radio signals or acoustic beacons to receivers that detect the tag and the unique ID code associated with the fish.

Electronic tagging is effective for studying post-release survival of fish in recreational fisheries because the fish are free swimming, although the additional stress caused by the tagging procedure may increase mortality. Tagged salmon that are released 
are then tracked in the river with receivers and the positions can be plotted to analyze the movement patterns exhibited by the released salmon. Salmon that die following release generally are tracked downstream of the release location and do not move throughout the season. Tags that move within the river can confidently be considered to represent fish that have survived catch-and-release. Any uncertainties about the survivors can be solved by tracking the tag to a point in the river and snorkelling to visually confirm whether the tag is still attached to a live salmon; I have found this technique to be highly effective to ensure that there are accurate estimates of catch-and-release survival.

Electronic tagging studies have been carried out in rivers around the world to determine how many released Atlantic salmon survive. These studies rely on collaboration and cooperation with local anglers that volunteer to release fish with electronic tags, meaning that many of the fish tagged and followed in these studies are captured and handled by normal anglers that hook, fight, handle, and photograph their catch in a natural setting (although it must be acknowledged that they may modify their behaviour to some extent knowing that they are being watched by scientists). Across studies that have used electronic tags to follow Atlantic salmon released by recreational anglers, most Atlantic salmon survive but there is some mortality of released salmon, generally less than $10 \%$. This provides compelling evidence that Atlantic salmon are resilient to catch-and-release in recreational fisheries. Further evidence of the hardiness of Atlantic salmon to this stressor has been provided by Davidson et al. (1994) and Booth et al. (1995), which appraised the quality of eggs and fry produced by Atlantic salmon exposed to simulated recreational fishing compared to a group of salmon not exposed to recreational angling, finding no difference. Richard et al. (2013) used genetic markers in 
fry in the Escoumins River to demonstrate that captured Atlantic salmon produced similar numbers of progeny to uncaptured salmon.

The story on catch-and-release of Atlantic salmon is remarkably consistent for recreational fisheries. However, I perceived a need for information that anglers could use to inform their fishing and handling practices when preparing to release Atlantic salmon and managers could use to provide evidence-based advice to anglers. I assembled a team of scientists to compile the catch-and-release data from Atlantic salmon tagging studies around the world to analyze the data to understand what the key risk factors were that most frequently contributed to mortality of Atlantic salmon; my rationale being that if I could identify factors that significantly contributed to post-release mortality in the recreational fishery, the information could be communicated to anglers, guides, and managers to ensure that anglers were aware of the potential hazards in capturing or handling Atlantic salmon in recreational fisheries.

Our team included scientists from the Norwegian Institute for Nature Research, the Quebec Ministry of Forests, Fauna, and Parks (Ministère des forêts, de la faune, et des parcs), River Dee Trust, Belfast Agrifood and Biosciences Institute, and Inland Fisheries Ireland to share data from studies in which Atlantic salmon were captured by angling, tagged with electronic transmitters, released, and tracked within the river. I collected the metadata associated with the fishing, including the time of year, water temperature, fish size, playing time, hook location, bleeding, and fishing gear type (flies, lures, or bait) to determine whether any of these factors contribute to the mortality of Atlantic salmon. In my sample, I had 512 Atlantic salmon captured and tracked in 12 rivers throughout their range ranging in size from 44 to $122 \mathrm{~cm}$ total length. Among these 
tracked fish, only 34 died, a survival of $93 \%$. I developed a statistical model to evaluate whether the time of year (date), hook location (shallow or deep hooked), gear type (fly, lure, or bait), play time, or water temperature at capture was a predictor of mortality. Using these studies in combination allowed us to have a large sample size for a more effective model, an advantage over any of the previous studies on Atlantic salmon catchand-release mortality in which sample size was too low individually to identify significant predictors.

I found that there was no effect of the time of year, size, playing time, or hooking location on mortality but that water temperature was a significant predictor of mortality, suggesting that when water temperatures become elevated the mortality of Atlantic salmon increased. I also found that salmon captured with bait (worms or shrimp) were more likely to die after release than those captured by lures or flies. Although most of these fish were lifted out of the water following capture, I did not have consistent numbers on the duration of air exposure so I could not include it in my models. What is known is that all fish are sensitive to air exposure to some extent and that prolonged air exposure will result in mortality, however, the threshold is highly species specific and is greatly affected by water temperature. Underwater photographs of Atlantic salmon are a precautious approach to handling salmon and improving the chances of survival. Antoine Richard included air exposure in a study of Atlantic salmon catch-and-release and found that air exposure had a large potential impact on the reproductive output of salmon (Richard et al. 2013).

In general, recreational fisheries that cannot sustain any post-release mortality would be considered unsustainable and such rivers would be highly vulnerable to any 
fishing activities, whether they are harvest or catch-and-release. In rivers with small populations that could not likely sustain harvest from recreational angling. Fisheries managers must have accurate data in order to effectively govern salmon stocks, including evidence of salmon survival in recreational fisheries. Understanding the likelihood of mortality of salmon that are released can be used to estimate the total spawning stock and is particularly useful in rivers with accurate estimates of the number of fish that enter the river, from which the harvested salmon can be subtracted along with the proportion of fish estimated to die from catch-and-release.

The research on this topic has been remarkably consistent across rivers, nations, years, and size classes of Atlantic salmon, suggesting that most salmon released by anglers can be expected to survive and also reproduce. The impacts of catch-and-release on Atlantic salmon, however, depends greatly on the context including the population structure of salmon in the river and the number of individuals that are harvested. The opinion of individuals may also differ, some perhaps believing that any post-release mortality of salmon is unacceptable on ethical grounds; these opinions are legitimate and an important component of a civil, balanced, and fair discussion of management. However, there must be no misinformation about the facts as it pertains to the survival of Atlantic salmon released by recreational anglers given proper handling (i.e. seasonal water temperatures, not bleeding from gills, brief air exposure prior to release) because it is overwhelmingly clear that salmon do survive.

How these data are used moving forward is a topic for further discussion, one that requires engagement with many different stakeholders with an interest in the fishery. Generally, however, the findings about Atlantic salmon suggest that catch-and-release 
has great potential to be an effective component of an Atlantic salmon management plans in rivers with healthy stocks throughout their native range. 


\section{Appendix B. Abstracts of relevant Atlantic salmon publications}

Lennox, R. J., Thorstad, E. B., Diserud, O.H., Økland, F., Cooke, S. J., Aasestad, I., and Forseth, T. (In Press). Internal and external determinants of speed and behaviour of adult Atlantic salmon transiting waterfalls. River Research and Applications, 00, 00-00.

The spawning migration of Atlantic salmon has been characterized by tracking salmon carrying electronic tags as they ascend rivers but still little is known about how natural obstacles such as waterfalls influence migratory behaviour and how such behaviours are mediated by various biotic (e.g. fish size) and abiotic (e.g. discharge, water temperature, barometric pressure) factors. The Norwegian river Numedalslågen is interrupted by natural waterfalls ranging in height from 2 to $6 \mathrm{~m}$. We tagged 113 Atlantic salmon with radio transmitters in the estuary and used stationary radio telemetry stations to track fish. Ninetyone salmon were recorded in Numedalslågen, 39 of which remained in the river for spawning. Large salmon moved farther and faster upriver but also delayed longer and had lower daily probability to pass the second waterfall. Delay below and passage probability at the final, largest waterfall was affected by water discharge, wherein passage occurred when discharge was declining. Barometric pressure also influenced daily probability of ascent, albeit in opposite directions for each waterfall. Importantly, we also found that salmon with surgically implanted radio transmitters moved farther upriver on average and delayed less time below one of the waterfalls than those with externally attached transmitters. Although there is variance in timing arising from individual decision making, 
we showed that natural waterfalls delay progress of Atlantic salmon on their spawning migration and that both biotic (i.e. size) and abiotic (i.e. barometric pressure, discharge) factors influenced the salmon's decisions to pass waterfalls that they encounter.

Lennox, R. J., Falkegård, M., Vøllestad, L. A., Cooke, S. J., and Thorstad, E. B. (2016). Influence of harvest restrictions on angler release behaviour and size selection in a recreational fishery. Journal of Environmental Management, 176, 139-148.

Fishing regulations such as harvest restrictions are implemented to limit the exploitation of many fish stocks and ensure the sustainability of fisheries. In Norway, inland recreational fisheries are co-managed by the government and by local riparian rights holders, meaning that Atlantic salmon Salmo salar harvest restrictions differ somewhat among rivers. Data from Norwegian rivers from 2009 to 2013 were used to test for variation in the proportion of salmon released by anglers and the relative size of salmon harvested and released by anglers in rivers that had varying harvest restrictions in terms of quotas, size restrictions, and/or female harvest restrictions. The proportion of the catch released by anglers was higher in rivers where there were harvest restrictions (proportion released $=0.09-0.24$ ) than in rivers with no such restrictions (proportion released $=0.01$ ). On average, salmon released in rivers with size restrictions larger (average mass difference between harvested and released salmon $=-1.25 \mathrm{~kg}$ ) than those released in rivers without harvest restrictions (difference $=0.60 \mathrm{~kg}$ ). The proportion of the catch released was larger in rivers with seasonal quotas $(0.29)$ than in rivers with daily $(0.07)$ or collective (i.e. total catch for the river; 0.06) quotas. Rivers with low daily (one salmon per angler per day) or seasonal ( $<5$ 
salmon per angler per year) quotas had a larger proportion of salmon released $(0.23,0.38$, respectively) than rivers with moderate $(0.10,0.21)$ or high $(0.07,0.16)$ quotas. High seasonal quotas resulted in larger individuals harvested than released (difference $=1.16$ $\mathrm{kg})$, on average, compared to moderate $(1.22 \mathrm{~kg})$ and high seasonal quotas $(-0.30 \mathrm{~kg})$. We conclude that harvest restrictions influenced the extent to which fish were released and thus the stock composition (i.e. size distribution) escaping the recreational fishery with the potential to spawn.

Lennox, R. J., Uglem, I., Cooke, S. J., Næsje, T. F., Whoriskey, F. G., Havn, T. B., Ulvan, E. M., Solem, Ø., and Thorstad, E. B. (2015). Does catch-and-release angling alter the behaviour and fate of adult Atlantic salmon during upriver migration? Transactions of the American Fisheries Society, 144(2), 400-409.

To reproduce, Atlantic Salmon Salmo salar return to freshwater rivers and migrate upriver to spawning areas. This migration is the basis for recreational fisheries, which for conservation reasons are increasingly characterized by catch-and-release angling. The effectiveness of catch and release for Atlantic Salmon conservation is contingent on the ability of individuals to recover from angling, resume migration, and reach spawning grounds at appropriate times. We monitored 27 caught and released Atlantic Salmon in River Gaula in 2013, a prominent and relatively pristine Norwegian river, by affixing external radio transmitters to them. Those fish were compared with a control group of 33 individuals caught and radio-tagged at sea in bag nets before river entry. Whereas none of the control fish died during the study period, there were three mortalities among the caught- 
and-released fish (11\%; significant difference). All mortalities were qualitatively associated with poor angler care, emphasizing the responsibility of anglers in practicing effective catch and release of Atlantic Salmon. Both control and caught and released Atlantic Salmon spent similar time resting below and in transiting a large natural barrier to migration, an 80-m gorge. The angled and released Atlantic Salmon were distributed in similar locations throughout the river during the spawning season compared with control fish, but those caught and released later in the season appeared to migrate shorter total distances than control fish. Among the caught and released Atlantic Salmon, 17\% were recaptured by anglers, which was similar to the rate of recapture of the control fish $(21 \%)$. Ultimately, individual and population fitness was not likely to be significantly compromised as a result of catch and release because individuals were recorded in spawning areas at appropriate times. Catch and release can therefore be considered a tenable strategy for balancing the costs and benefits associated with the recreational fishery. 


\section{Appendix C. Abstracts of non-thesis publications from graduate courses}

Lennox, R. J., Chapman, J. M., Souliere, C. M., Tudorache, C., Wikelski, M., Metcalfe, J. D., and Cooke, S. J. (2016). Conservation physiology of animal migration. Conservation Physiology, 4(1), cov072.

Migration is a widespread phenomenon among many taxa. This complex behaviour enables animals to exploit many temporally productive and spatially discrete habitats to accrue various fitness benefits (e.g. growth, reproduction, predator avoidance). Human activities and global environmental change represent potential threats to migrating animals (from individuals to species) and research is underway to understand mechanisms that control migration and how migration responds to modern challenges. Focusing on behavioural and physiological aspects of migration can help to better understand, manage, and conserve migratory populations. Here we highlight different physiological, behavioural, and biomechanical aspects of animal migration that will help us to understand how migratory animals interact with current and future anthropogenic threats. We are in the early stages of a changing planet and our understanding of how physiology is linked to the persistence of migratory animals is still developing. Therefore, we regard the following questions as being central to the conservation physiology of animal migrations: Will climate change influence the energetic costs of migration? Will shifting temperatures change the annual clocks of migrating animals? Will anthropogenic influences have an effect on orientation during migration? Will increased anthropogenic alteration of migration stopover sites/migration corridors affect the stress physiology of migrating animals? Can 
physiological knowledge be used to identify strategies for facilitating the movement of animals? Our synthesis reveals that given the inherent challenges of migration, additional stressors derived from altered environments (e.g. climate change, physical habitat alteration, light pollution) or interaction with human infrastructure (e.g. wind or hydrokinetic turbines, dams) or activities (e.g. fisheries) could lead to long-term changes to migratory phenotypes. However, uncertainty remains given the complexity of biological systems, the inherent dynamic nature of the environment, and the scale at which many migrations occur and associated threats operate, necessitating improved integration of physiological approaches to the conservation of migratory animals.

Lennox, R. J., Blouin-Demers, G., Rous, A. M., and Cooke, S. J. (2016). Tracking invasive animals with electronic tags to assess risks and develop management strategies. Biological Invasions, 18(5), 1219-1233.

Invasive species alter ecosystem structure and function when they establish in new habitats. Although preventing or managing invasions is extremely important for maintaining biodiversity, doing so is difficult and requires efficient intervention. Remote monitoring of free-living animals with electronic tags (i.e. tags that transmit data remotely or log them for future retrieval) can contribute important knowledge about invasive animal biology. A quantitative literature review identified instances in which electronic tagging has contributed to studying invasions. Electronic tags were generally used for one of four purposes: (1) characterize spatial ecology; (2) identify interactions; (3) assess risk 
potential; or (4) evaluate management options. Overall, electronic tags have considerable potential for developing, refining, and evaluating invasion management strategies that contribute to conservation efforts. We explore the role of electronic tags as a component of integrated control program design and implementation for invasive animals.

Lennox, R. J., Choi, K., Harrison, P. M., Paterson, J. E., Peat, T. B., Ward, T. D., and Cooke, S. J. (2015). Improving science-based invasive species management with physiological knowledge, concepts, and tools. Biological Invasions, 17(8), 22132227.

Biological invasions are a prominent factor contributing to global biodiversity loss. As a result, managing invasive species is a priority for many conservation scientists and natural resource managers. Invasive species management requires a multidisciplinary approach and there is increasing recognition that physiology can be used to inform conservation efforts because physiological processes underlie an individual's response to its environment. For example, physiological concepts and tools can be used to assess the impacts of invasive animals on their new ecosystems, to predict which animal species are likely to become invasive, to prevent the introduction of nonnative animals, and to control incipient or established invasions. To evaluate whether physiology is integrated within invasion science, the journal Biological Invasions was surveyed for a quantitative literature review. To determine how physiology is used to inform invasion science and which subdisciplines of physiology are particularly relevant to invasive animal management, the broader invasion literature was also reviewed to identify examples where physiology has 
contributed to studying and managing invasive animals. Only $6 \%$ of articles published in Biological Invasions incorporated physiological knowledge or tools, mostly for the purposes of identifying traits associated with species invasiveness (i.e. prediction). However, the broader literature indicated that successful invasive species research and management can be supported by fundamental and applied physiological research for assessing, predicting, preventing, and controlling invasive animals. Development of new techniques and increased availability of equipment for remote or rapid monitoring of physiology in the field will increase opportunities for integrating physiology within invasion science.

Chapman, J. M., Algera, D., Dick, M., Hawkins, E. E., Lawrence, M. J., Lennox, R. J., Rous, A. M., Souliere, C. M., Stemberger, H. J. L., Struthers, D. P., Vu, M., Ward, T. D., Zolderdo, A. J., and Cooke, S. J. (2015). Being relevant: practical guidance for early career researchers interested in solving conservation problems. Global Ecology and Conservation, 4, 334-348.

In a human-altered world where biodiversity is in decline and conservation problems abound, there is a dire need to ensure that the next generation of conservation scientists have the knowledge, skills, and training to address these problems. So called "early career researchers" (ECRs) in conservation science have many challenges before them and it is clear that the status quo must change to bridge the knowledge-action divide. Here we identify thirteen practical strategies that ECRs can employ to become more relevant. In this context, "relevance" refers to the ability to contribute to solving conservation problems 
through engagement with practitioners, policy makers, and stakeholders. Conservation and career strategies outlined in this article include the following: thinking 'big picture' during conservation projects; embracing various forms of knowledge; maintaining positive relationships with locals familiar with the conservation issue; accepting failure as a viable (and potentially valuable) outcome; daring to be creative; embracing citizen science; incorporating interdisciplinarity; promoting and practicing pro-environmental behaviours; understanding financial aspects of conservation; forming collaboration from the onset of a project; accepting the limits of technology; ongoing and effective networking; and finally, maintaining a positive outlook by focusing on and sharing conservation success stories. These strategies move beyond the generic and highlight the importance of continuing to have an open mind throughout the entire conservation process, from establishing one's self as an asset to embracing collaboration and interdisciplinary work, and striving to push for professional and personal connections that strengthen personal career objectives. 


\section{Appendix D. Abstracts of non-thesis publications}

Lennox, R. J., Økland, F. Mitamura, H., Cooke, S. J., and Thorstad, E. B. (In Press). European eel Anguilla anguilla compromise speed for safety in the early marine spawning migration. ICES Journal of Marine Science, 00, 00-00.

There are substantial benefits to potential fitness conferred to animals that undertake migrations. However, animals must make compromises to maximize survival and compensate for the risks associated with long-distance movement. European eel (Anguilla anguilla), a migratory catadromous fish, has undergone population declines owing to changes in marine and freshwater habitat and interactions with human infrastructure, instigating research to investigate the mechanisms controlling their migration. Yellowphase European eels from the local River Opo and silver-phase European eels transplanted from River Imsa, Norway were implanted with acoustic transmitters and released within a network of receiver stations in the Hardangerfjord, Norway. Silver-phase eels exhibited more movement within the array than yellow-phase eels, signifying the onset of migration. Silver-phase eels moved through the fjord nocturnally, arriving at gates predominantly at night. Eels had slower rates of migration than expected based on models predicting continuous movement, suggesting that movement ceased during daylight hours. Reduced net rates of travel supported the hypothesis that eels compromise speed for safety during the early marine migration by avoiding predators and not actively migrating during daylight. The silver eels were capable of directed movement towards the ocean and were not recorded by receivers in bays or dead ends. European eels must successfully transit this 
coastal zone, where their residence is prolonged because of the relatively slow speeds. These results suggest that the early marine phase of the European eel spawning migration be a focal period for European eel conservation efforts.

Lennox, R. J., Gallagher, A. J., Ritchie, E. G., and Cooke, S. J. (In Press). Evaluating the efficacy of predator removal in a conflict-prone world. Biological Conservation, 00, 00-00.

Predators shape ecosystem structure and function through their direct and indirect effects on prey, which permeate through ecological communities. Predators are often perceived as competitors or threats to human values or well-being. This conflict has persisted for centuries, often resulting in predator removal (i.e. killing) via targeted culling, trapping, poisoning, and/or public hunts. Predator removal persists as a management strategy but requires scientific evaluation to assess the impacts of these actions, and to develop a way forward in a world where human-predator conflict may intensify due to predator reintroduction and rewilding, along with an expanding human population. We reviewed literature regarding predator removal and focused on identifying instances of successes and failures. We found that predator removal was generally intended to protect domestic animals from depredation, to preserve prey species, or to mitigate risks of direct human conflict, corresponding to being conducted in farmland, wild land, or urban areas. Because of the many different motivations for predator removal, there was no consistent definition of what success entailed so we developed one with which to assess studies we reviewed. Research tended to be retrospective and correlative and there were few controlled 
experimental approaches that evaluated whether predator removal achieved its stated objectives, making formal meta-analysis impossible. Predator removal appeared to only be effective for the short-term, failing in the absence of sustained predator suppression. This means predator removal was typically an ineffective and costly approach to conflicts between humans and predators. Improved incorporation of ecosystem perspectives that consider the role of the predator in the ecosystem and how removal might affect prey species and mesopredators after predator removal, species-specific approaches to management that recognise demographic processes, use of experimental studies/simulation modelling prior to implementation, and consideration/adoption of possible alternative actions, all offer potential benefits for pathways towards more effective and long-term resolution of human-predator conflict.

Lennox, R. J., Brownscombe, J. W., Cooke, S. J., and Danylchuk, A. J. (In Press). Postrelease behaviour and survival of recreationally-angled arapaima (Arapaima $c f$. arapaima) assessed with accelerometer biologgers. Fisheries Research, 00, 00-00.

Recreational fisheries are increasingly important sectors of tourism-based economies. In the last decade, new recreational fisheries have emerged that target species of varying conservation status including vulnerable, endangered, and unassessed species. In Guyana, catch-and-release angling tourism has begun to target arapaima, a genus of giant obligatory air-breathing fishes. Given the uncertain conservation status of this species and that no information is available to evaluate the sustainability of this activity, we sought to describe the responses of arapaima to recreational angling. We harnessed tri-axial accelerometer 
biologgers around the trunk of fish that had been captured and released by recreational anglers, allowing us to monitor post-release survival and behaviour, including surfacing, which is essential for this air-breathing fish to recover from exhaustion. Twenty-seven individuals were instrumented $(162 \pm 25 \mathrm{~cm}), 24$ of which were considered survivors (89\%) during the $47 \pm 35$ (SD) min monitoring period. Fish that died were observed to drown soon after release (i.e. within minutes), not surfacing to breathe air. Supervised machine learning classification of behaviours using a random forest algorithm identified surfacing events with $80 \%$ accuracy (i.e. out-of-bag error rate $=20 \%$ ), which we applied to unobserved data to estimate breathing frequency after release, along with overall dynamic body acceleration (ODBA) as a proxy for activity. Neither mean breathing frequency nor ODBA were related to body size (total length), handling time (which incorporated facilitated recovery of individuals), nor time of capture (early or late in the dry season spanning water temperatures of 29.3 to $34.1^{\circ} \mathrm{C}$ ). The precise angling-related factors that led to arapaima mortality were unclear, but the frequency of mortality aligns with the mortality documented in other recreational fisheries. This mortality source can be incorporated into conservation plans and provide context to the impacts of recreational angling relative to the costs of legal or illegal harvest.

Lennox, R. J., Twardek, W., and Cooke, S. J. (In Press). Observations of Mudpuppy bycatch in a recreational ice fishery in northern Ontario. Canadian Field Naturalist, 00, 00-00. 
Bycatch in fisheries is a well-explored topic. Although bycatch in recreational fisheries is relatively rare and poorly addressed, we encountered frequent bycatch of mudpuppy Mudpuppy (Necturus maculosus), a neotenic aquatic salamander that is active in wintertime, while targeting teleost fishes with passively baited ice fishing gear. We noted the anatomical hook location of mudpuppies captured by two different hook types, J-hooks and circle hooks. Our prediction was that circle hooks would reduce the frequency of deep hooking of mudpuppies, which is often cited as an important predictor of post-release mortality in fisheries. We found no difference in the frequency of deep hooking for mudpuppies captured by circle or J-hooks, although a subset of mudpuppies, $\mathrm{N}=13$, held for $24 \mathrm{~h}$ after captured revealed one mortality (8\%). Further research may be necessary to determine whether deeply hooked mudpuppies can pass or shed hooks and survive beyond the $24 \mathrm{~h}$ period we monitored for, but our findings suggest that anglers and managers should seriously consider refinements to the handling practices of mudpuppies captured as bycatch because they are likely to survive if handled cautiously. These results are among the first describing non-fish bycatch in recreational fisheries and call attention to managers and anglers that encounter mudpuppies during recreational fishing to seek more information and educational opportunities to improve the fate of mudpuppies, an important component of temperate freshwater ecosystems and an ecological indicator species, that are incidentally captured by ice angling. 
Lennox, R. J., Engler-Palma, C., Kowarski, K., Filous, A., Whitlock, R., Cooke, S. J., and Auger-Méthé, M. (In Press). Optimizing marine spatial plans with animal tracking data. Canadian Journal of Fisheries and Aquatic Sciences, 00, 00-00.

Marine user-environment conflicts can have consequences for ecosystems that negatively affect humans. Strategies and tools are required to identify, predict, and mitigate such conflicts between marine anthropogenic activities and marine wildlife. Estimating individual, population, and species-scale distributions of marine animals has historically been challenging, but electronic tagging and tracking technologies (i.e. biotelemetry and biologging) and analytical tools are emerging that can assist marine spatial planning (MSP) efforts by documenting animal interactions with marine infrastructure (e.g. tidal turbines, oil rigs), identifying critical habitat for animals (e.g. migratory corridors, foraging hotspots, reproductive or nursery zones), or delineating distributions for fisheries exploitation. MSP that excludes consideration of animals is suboptimal, and animal space-use estimates can contribute to efficient and responsible exploitation of marine resources that harmonize economic and ecological objectives of MSP. This review considers the application of animal tracking to MSP objectives, presents case studies of successful integration, and provides a look forward to the ways in which MSP will benefit from further integration of animal tracking data. 
Lennox, R. J., Suski, C. D., and Cooke, S. J. (2018). A macrophysiology approach to watershed science and management. The Science of the Total Environment, 626, 434-440.

Freshwaters are among the most imperiled ecosystems on the planet such that much effort is expended on environmental monitoring to support the management of these systems. Many traditional monitoring efforts focus on abiotic characterization of water quantity or quality and/or indices of biotic integrity that focus on higher scale population or community level metrics such as abundance or diversity. However, these indicators may take time to manifest in degraded systems and delay the identification and restoration of these systems. Physiological indicators manifest rapidly and portend oncoming changes in populations that can hasten restoration and facilitate preventative medicine for degraded habitats. Therefore, assessing freshwater ecosystem integrity using physiological indicators of health is a promising tool to improve freshwater monitoring and restoration. Here, we discuss the value of using comparative, longitudinal physiological data collected at a broad spatial (i.e. watershed) scale (i.e. macrophysiology) as a tool for monitoring aquatic ecosystem health within and among local watersheds to develop timely and effective management plans. There are emerging tools and techniques available for rapid, costeffective, and non-lethal physiological sampling and we discuss how these can be integrated into management using fish as sentinel indicators in freshwater. Although many examples of this approach are relatively recent, we foresee increasing use of macrophysiology in monitoring, and advocate for the development of more standard tools for consistent and reliable assessment. 
Lennox, R. J., Alós, J., Arlinghaus, R., Horodysky, A., Klefoth, T., Monk, C. T., and

Cooke, S. J. (2017). What makes fish vulnerable to capture by hooks? A conceptual framework and a review of key determinants. Fish and Fisheries, 18(5), 986-1010.

Considerable time and money are expended in the pursuit of catching fish with hooks (e.g. handlining, angling, longlining, trolling, drumlining) across the recreational, commercial and subsistence fishing sectors. The fish and other aquatic organisms (e.g. squid) that are captured are not a random sample of the population because external (e.g. turbidity) and underlying internal variables (e.g. morphology) contribute to variation in vulnerability to hooks. Vulnerability is the probability of capture for any given fish in a given location at a given time and mechanistically explains the population level catchability coefficient, which is a fundamental and usually time-varying (i.e. dynamic) variable in fisheries science and stock assessment. The mechanistic drivers of individual vulnerability to capture are thus of interest to fishers by affecting catch rates, but are also of considerable importance to fisheries managers whenever hook and-line-generated data contribute to stock assessments. In this paper, individual vulnerability to hooks is conceptualized as a dynamic state, in which individual fish switch between vulnerable and invulnerable states as a function of three interdependent key processes: an individual fish's internal state, its encounter with the gear, and the characteristics of the encountered gear. We develop a new conceptual framework of "vulnerability," summarize the major drivers of fish vulnerability, and conclude that fish vulnerability involves complex processes. To understand vulnerability, a shift to interdisciplinary research and the integration of 
ecophysiology, fish ecology, fisheries ecology and human movement ecology, facilitated by new technological developments, is required.

Lennox, R. J., Aarestrup, K., Cooke, S. J., Cowley, P. D., Deng, Z. D., Fisk, A. T., Harcourt, R. G., Heupel, M., Hinch, S. G., Holland, K. N., Hussey, N. E., Iverson, S. J., Kessel, S. T., Kocik, J. F., Lucas, M. C., Flemming, J. M., Nguyen, V. M., Stokesbury, M. J. W., Vagle, S., VanderZwaag, D. L., Whoriskey, F. G., Young, N. (2017). Envisioning the future of aquatic animal tracking: technology, science, and application. BioScience, 67(10), 884-896.

Electronic tags are significantly improving our understanding of aquatic animal behavior and are emerging as key sources of information for conservation and management practices. Future aquatic integrative biology and ecology studies will increasingly rely on data from electronic tagging. Continued advances in tracking hardware and software are needed to provide the knowledge required by managers and policymakers to address the challenges posed by the world's changing aquatic ecosystems. We foresee multiplatform tracking systems for simultaneously monitoring the position, activity, and physiology of animals and the environment through which they are moving. Improved data collection will be accompanied by greater data accessibility and analytical tools for processing data, enabled by new infrastructure and cyberinfrastructure. To operationalize advances and facilitate integration into policy, there must be parallel developments in the accessibility of education and training, as well as solutions to key governance and legal issues. 
Lennox, R. J., Filous, A., Clark Danylchuk, S., Cooke, S. J., Brownscombe, J. W., Friedlander, A. M., and Danylchuk, A. J. (2017). Factors influencing postrelease predation for a catch-and-release tropical flats fishery with high predator burden. North American Journal of Fisheries Management, 37(5), 1045-1053.

Post-release predation (PRP) of fishes released by anglers is a potentially significant contributor to overall mortality in recreational fisheries. We quantified PRP and examined the impacts of handling and release practices on Albula glossodonta, a species of shallowwater Pacific Bonefish that supports a recreational fishery throughout its range and is emerging as recreationally important to the small economy in Anaa Atoll, French Polynesia. We caught, released, and monitored the post-release movements of Bonefish on the shallow flats of Anaa using recreational angling gear and small floats attached to the Bonefish. Observations of PRP allowed us to test how handling practices (air exposure) and release strategies (retained for a short period compared to immediate release) influenced the probability of PRP using Cox Proportional Hazards regression, a semiparametric survival analysis. There was some evidence that air exposure increased susceptibility to PRP. However, retention in a recovery bag for $30 \mathrm{~min}$ did not reduce PRP. Actually, retention in the recovery bag increased the number of sharks in the release area after 30 min suggesting that Bonefish should be released quickly to avoid aggregating sharks. In both the handling and release practices components of the study, the number of sharks encountered proximate to the release site was the strongest predictor of PRP. Anglers and guides fishing in areas of high predator density such as at Anaa Atoll should release Bonefish quickly to minimize aggregation of sharks that depredate released 
Bonefish. Avoiding fishing flats with high predator densities and frequently rotating fishing flats may be necessary to quell PRP. Acknowledging risks and accounting for PRP and its contribution to overall post-release mortality is essential for maintaining sustainable recreational fisheries for this species.

Lennox, R. J., Mayer, I., Havn, T. B., Johansen, M. R., Whoriskey, K., Cooke, S. J., Thorstad, E. B., and Uglem, I. (2016). Effects of recreational angling and air exposure on the physiological status and reflex impairment of European grayling (Thymallus thymallus). Boreal Environment Research, 21, 461-470.

European grayling (Thymallus thymallus) is a popular recreational fish that may be lifted out of the water to facilitate hook removal or for admiration. To evaluate the effects of air exposure and angling-induced exhaustive exercise on released grayling condition, we assessed blood physiology and reflexes of grayling after angling and air exposure in the subarctic River Lakselva (Norway) at midsummer temperatures (i.e. $17-18{ }^{\circ} \mathrm{C}$ ). Blood samples were drawn 30 min after angling and analyzed for lactate anions, glucose, sodium ions, and $\mathrm{pH}$. Reflex impairment was determined with orientation and tail grab reflex action assessments immediately after landing, after air exposure, and after $30 \mathrm{~min}$ holding. Blood physiology did not indicate an exacerbating effect of air exposure relative to just anglinginduced exercise, but significant and prolonged reflex impairment was associated with the $120 \mathrm{~s}$ air exposure interval. Anglers must take care to minimize air exposure to adhere to best handling practices. 
Lennox, R. J., Brownscombe, J. W., Cooke, S. J., Danylchuk, A. J., Moro, P. S., Sanches, E. A., and Garrone-Neto, D. (2015). Evaluation of catch-and-release angling practices for the fat snook Centropomus parallelus in a Brazilian estuary. Ocean and Coastal Management, 113, 1-7.

Recreational fisheries are developing for many iconic marine and estuarine fish species and are generating important social and economic returns in Brazil. Fat snook is the primary target species in southeastern Brazil and it supports a vibrant fisheries sector, including fishing tournaments. To evaluate the impacts of recreational angling practices, we examined external hooking injuries, secondary physiological stress responses (i.e. blood glucose and lactate concentrations; $\mathrm{N}=24)$, reflex impairment $(\mathrm{N}=39)$, and overnight survival $(\mathrm{N}=39)$ of fat snook angled with and without air exposure. We also examined physiological stress and reflex impairment of fat snook captured in a fishing tournament $(\mathrm{N}=43)$ immediately post weigh-in and $1 \mathrm{hr}$ post weigh-in. Values were compared to baseline reflexes $(\mathrm{N}=10)$ and physiology $(\mathrm{N}=8)$ collected from minimally stressed fat snook. Fish captured by anglers infrequently had hooking injury but all angling and tournament treatments resulted in significantly elevated blood glucose and lactate, indicating a considerable physiological response to angling. Angling with air exposure and tournament weigh-in (in a dry container) resulted in the highest blood lactate values. The body flex reflex was occasionally impaired after angling or tournament practices, but this was consistent with baseline reflex actions, and the body flex reflex was therefore not a valuable indicator of fisheries stress or mortality in fat snook. Although angling and tournament practices caused a marked physiological stress response, low mortality of 
snook indicated that the species is resilient to brief bouts of angling at moderate water temperatures. However, high lactate values associated with air exposure suggest that handling practices be refined, particularly during tournament weigh-in. We recommend that anglers reduce air exposure intervals when handling snook prior to release and that recreational tournaments adopt wet weigh-in procedures to maximize the utility of catchand-release in this fishery.

Lennox, R. J., and Cooke, S. J. (2014). State of the interface between conservation and physiology: a bibliometric analysis. Conservation Physiology, 2(1), cou003.

Contemporary conservation science benefits from the perspectives of a variety of different disciplines, including a recent synergy with physiology, an interface known as 'conservation physiology'. To evaluate the degree of interaction between conservation and animal/plant physiology, we conducted three bibliometric analyses. We first pursued the use of the term 'conservation physiology' since its first definition in 2006 to determine how frequently it has been used and in which publications. Secondly, we evaluated the occurrence of conservation terms in animal and plant physiology journals, physiological terms in conservation journals, and a combination of terms in ecology journals. Thirdly, we explored trends in a subset of conservation physiology articles published between 2006 and 2012. We identified a surge in the use of the term 'conservation physiology' in 2012, after only a slow increase in usage between 2006 and 2011. Conservation journals tend to have been significantly more active in publishing conservation physiology than animal physiology, plant physiology or ecology journals. However, we found evidence that 
ecology and animal physiology journals began to incorporate more conservation physiology after 2006, while conservation- and plant physiology-themed journals did not. Among 299 conservation physiology articles that we identified, vertebrate taxa have been over-represented in conservation physiology compared with their relative taxonomic abundance, invertebrate taxa have been under-represented, and plants have been represented in proportion to their relative taxonomic abundance; however, those findings are reasonably consistent with publication trends in conservation biology. Diffuse distribution of conservation physiology papers throughout the literature may have been a barrier to the growth of the subdiscipline when the interface was emerging. The introduction of the focused journal Conservation Physiology in 2013 may address that deficiency. Moreover, development of a unifying framework could help to aggregate knowledge and attract potential contributors by highlighting and facilitating access to and application of conservation physiology.

Bliss, S. M., Lennox, R. J., Midwood, J. D., and Cooke, S. J. (2017). Temporally stable and distinct fish assemblages between stream and earthen stormwater drain reaches in an urban watershed. Urban Ecosystems, 20(5), 1045-1055.

Streams and rivers have essential roles in landscape connectivity; however, urban watersheds are frequently modified to drain stormwater from urban areas. To determine whether an earthen stormwater drain in an urban landscape provides fish habitat temporally, we compared the fish assemblage among three reaches of a contiguous urbanized watershed in Kanata, Ontario, Canada. Watts Creek is connected to an earthen 
municipal surface stormwater drain (herein Kizell Drain), before discharging into the Ottawa River. We delineated transects in three reaches of the system, in Watts, in the Drain, and below their confluence (Main) and assessed the fish community using single-pass electrofishing repeated across eight months covering all seasons. Fish community composition was compared among reaches using non-metric multidimensional scaling (NMDS) and permutated multivariate analyses of variance (perMANOVA). Sign association tests identified indicator species driving assemblage patterns among reaches. Redundancy analysis (RDA) was used to assess the influence of physical characteristics of the transects on fish assemblage structure. Finally, fish assemblage measures were separated by month and temporal comparisons of fish assemblage were performed with NMDS and perMANOVA. Over the year, fish assemblages were distinct among the three reaches, and appear to be significantly influenced by temperature, undercut banks, and riparian vegetation type. Biotic homogenization in the Drain can be attributed to degraded physical features associated with channel modification in stormwater drains. Despite management and jurisdictional differences between streams and stormwater drains, evidence that earthen stormwater drains can maintain fish assemblages temporally demonstrates their biological potential and need to be considered as interconnected fish habitat elements within the overall watershed.

Bower, S. D., Lennox, R. J., and Cooke, S. J. (2015). Is there a role for freshwater protected areas in the conservation of migratory fish? Inland Waters, 5(1), 1-6. 
Migratory fish have been declining in number as a result of numerous processes including hydropower development, pollution, invasive species, and climate change. Migratory fish are important ecosystem components, and yet there are many gaps in our knowledge of migratory fish life history and their relationship with hydrological processes. Consequently, few mechanisms are available to promote their conservation. An emergent tool is the Freshwater Protected Area (FPA), a zone of restricted use and access within freshwater systems analogous to terrestrial or marine protected areas that aim to conserve constituent resources. These protected areas are often criticized for their inability to control pollution inputs and their tendency to be implemented only as components of terrestrial parks, meaning that they traditionally do not reflect the importance of aquatic systems or promote connectivity. This paper reassesses FPAs in the context of migratory fish conservation and addresses a variety of obstacles inhibiting FPAs from being suitable for protecting migratory fishes. Developing FPAs that encompass critical life-stage habitat for migratory species, such as spawning and nursery areas, migratory corridors, and feeding zones, is essential for ensuring ample interconnected habitat for migratory fishes to thrive and ecological and evolutionary processes to occur.

Brownscombe, J. W., Lennox, R. J., Danylchuk, A. J., and Cooke, S. J. (2018). The influence of sampling frequency on estimates of fish swimming metrics and metabolic rates using tri-axial accelerometers. Journal of Fish Biology, 00, 00-00.

Accelerometer loggers and transmitters are useful tools for remotely measuring the behaviour, metabolic rates, and bioenergetics of diverse animal species in both captivity 
and the wild. These devices offer a range of sampling frequencies, where higher frequencies provide greater temporal resolution but limit tag longevity and present greater analytical challenges. It is therefore of interest to identify optimal sampling frequencies that will capture relevant metrics and maximize tag life. Here, we examine the influence of sampling frequency $(1-25 \mathrm{~Hz})$ with tri-axial accelerometer biologgers on estimates of overall dynamic body acceleration (ODBA), tail beat frequency, swimming speed, and metabolic rate of bonefish (Albula vulpes) in a swim tunnel respirometer and free swimming in a wetland mesocosm. In the swim tunnel, a $1 \mathrm{~Hz}$ sampling frequency was sufficient to establish strong relationships between ODBA, swimming speed, and metabolic rate, but linear mixed effects model coefficients were more variable below 10 Hz. As a result, ODBA-based predictions of swimming speed and metabolic rate in free swimming bonefish in the mesocosm were less reliable below $10 \mathrm{~Hz}$. While optimal sampling frequency likely varies between species due to body size and swimming style, this study may serve as a basis with a medium body-sized sub-carangiform teleost fish.

Cook, K. V., Lennox, R. J., Hinch, S. G., and Cooke, S. J. (2015). Fish out of water: how much air is too much? Fisheries, 40(9), 452-461.

Exposing fish to air following capture influences postrelease survival and behavior. Air exposure causes acute hypoxia and physical damage to the gill lamellae, resulting in physiological stress and physical damage that increases with air exposure duration. Air exposure duration is a relevant and easily quantified metric for both fishers and managers and can therefore provide a definitive benchmark for improving postrelease survival. Yet, 
fishers are rarely provided with specific recommendations other than simply to "minimize" air exposure. This is a subjective recommendation, potentially causing confusion and noncompliance. Here we discuss and summarize the literature regarding air exposure thresholds in both commercial and recreational fisheries, the factors influencing these thresholds, and identify knowledge gaps limiting our understanding of tolerance to air exposure in captured fish.

Cooke, S. J., Twardek, W. M., Lennox, R. J., Zolderdo, A. J., Bower, S. D., Gutowsky, L. F., Danylchuk, A. J., Arlinghaus, R., and Beard, D. (2018). The nexus of fun and nutrition: Recreational fishing is also about food. Fish and Fisheries, 00, 00-00.

Recreational fishing is a popular activity in aquatic ecosystems around the globe using a variety of gears including rod and line and to a lesser extent handlines, spears, bow and arrow, traps and nets. Similar to the propensity to engage in voluntary catch-and-release, the propensity to harvest fishes strongly varies among cultures, locations, species and fisheries. There is a misconception that because recreational fishing happens during nonwork (i.e. leisure) time, the nutritional motivation is negligible; therefore, the role of recreational fishing in supporting nutrition (and thus food security) at regional, national or global scales is underappreciated. We consider the factors that influence whether fish will be harvested or released by examining the motives that underlie recreational fishing. Next, we provide an overview of the magnitude and role of recreational fishing harvest in supporting nutrition using regional case-studies. Then, we address issues such as contaminants and parasites that constrain the ability of fish harvested by recreational 
fishers to be consumed. Although recreational fishing is foremost a leisure activity, the harvest of fish for personal consumption by recreational fishers has contributed and will continue to contribute to human nutrition by providing an accessible, affordable and generally highly sustainable food source, notwithstanding concerns about food safety and possibly overfishing. Attempts to better quantify the role of fish harvested by recreational fishers and the relative contribution to overall food security and personal nutrition will provide resource managers and policymakers the information needed to guide management activities and policy development.

Cooke, S. J., Lennox, R. J., Bower, S. D., Horodysky, A. Z., Treml, M. K., Stoddard, E., Donaldson, L. A., and Danylchuk, A. J. (2017). Fishing in the dark: the science and management of recreational fisheries at night. Bulletin of Marine Science, 93(2), 519-538.

Recreational fishing is a popular activity around the globe, generating billions of dollars in economic benefit based on fisheries in marine and inland waters. In most developed countries, recreational fisheries are managed to achieve diverse objectives and ensure that such fisheries are sustainable. While many anglers fish during daylight hours, some target fish species during the night. Indeed, sensory physiology of some species makes them vulnerable to capture at night, while being more difficult to capture during the day. However, night creates a number of challenges for recreational fisheries assessment and management. In some jurisdictions, fishing is prohibited at night (through both effort and harvest controls) or there are specific restrictions placed on night fisheries (e.g. no use of 
artificial lights). Here, we summarize the science and management of recreational fisheries at night covering both inland and marine realms. In doing so, we also provide a review of different angling regulations specific to night fisheries across the globe, as well as the basis for those regulations. We discuss the extent to which there is both need and opportunity to actively manage anglers who are targeting fish at night and how this differs from fisheries that occur during lighted periods. We provide two case studies, one for white sturgeon (Acipenser transmontanus Richardson, 1836) and one for walleye [Sander vitreus (Mitchill, 1818)], for which nighttime closures have been used as a fisheries management tool to control effort and harvest (illegal harvest in the case of the sturgeon case study). Based on the synthesis, we conclude that natural resource management agencies should decide if and how they need to manage recreational fisheries at night, recognizing the practical challenges (e.g. compliance monitoring, stock assessment) with doing so in the dark.

Cooke, S. J., Wilson, A. D., Elvidge, C. K., Lennox, R. J., Jepsen, N., Colotelo, A. H., and Brown, R. S. (2016). Ten practical realities for institutional animal care and use committees when evaluating protocols dealing with fish in the field. Reviews in Fish Biology and Fisheries, 26(1), 123-133.

Institutional Animal Care and Use Committee's (IACUCs) serve an important role in ensuring that ethical practices are used by researchers working with vertebrate taxa including fish. With a growing number of researchers working on fish in the field and expanding mandates of IACUCs to regulate field work, there is potential for interactions 
between aquatic biologists and IACUCs to result in unexpected challenges and misunderstandings. Here we raise a number of issues often encountered by researchers and suggest that they should be taken into consideration by IACUCs when dealing with projects that entail the examination of fish in their natural environment or other field settings. We present these perspectives as ten practical realities along with their implications for establishing IACUC protocols. The ten realities are: (1) fish are diverse; (2) scientific collection permit regulations may conflict with IACUC policies; (3) stakeholder credibility and engagement may constrain what is possible; (4) more (sample size) is sometimes better; (5) anesthesia is not always needed or possible; (6) drugs such as analgesics and antibiotics should be prescribed with care; (7) field work is inherently dynamic; (8) wild fish are wild; (9) individuals are different, and (10) fish capture, handling, and retention are often constrained by logistics. These realities do not imply ignorance on the part of IACUCs, but simply different training and experiences that make it difficult for one to understand what happens outside of the lab where fish are captured and not ordered/purchased/reared, where there are engaged stakeholders, and where there is immense diversity (in size, morphology, behaviour, life-history, physiological tolerances) such that development of rigid protocols or extrapolation from one species (or life-stage, sex, size class, etc.) to another is difficult. We recognize that underlying these issues is a need for greater collaboration between IACUC members (including veterinary professionals) and field researchers which would provide more reasoned, rational and useful guidance to improve or maintain the welfare status of fishes used in field research while enabling researchers to pursue fundamental and applied questions related to the 
biology of fish in the field. As such, we hope that these considerations will be widely shared with the IACUCs of concerned researchers.

Crawford, C., Midwood, J. D., Lennox, R. J., Bliss, S. M., Belanger, C. B., and Cooke, S. J. (2016). Experimental displacement of longnose dace, Rhinichthys cataractae (Actinopterygii, Cyprinidae), reveals rapid fish avoidance of a stormwater drain in an urban watershed. Hydrobiologia, 767(1), 197-206.

Land-use change associated with human development can alter aquatic habitat and imperil aquatic species. Fish are challenged when urban streams are altered, for example for stormwater conveyance, but little is known about how such activities influence the space use of individual fish. Electronic tagging and experimental displacement of fish can be used to explore site fidelity and homing behaviour of fish and can therefore be useful for testing hypotheses about space use and habitat selection. In this study, we used experimental displacement to determine how longnose dace (LND, Rhinichthys cataractae) utilize reaches within a watershed that have varying degrees of degradation. LND were tagged using passive integrated transponders (PIT tags), transported upstream, and released either into the natural stream reach, impaired stormwater drain reach, or at their confluence. Fixed PIT antennas were used to monitor movement of the PIT-tagged fish among the three reaches for a period of 3 weeks. LND exhibited dramatic and rapid selection against the stormwater drain. No LND moved into the drain and $97 \%$ of fish transported to the drain left within $24 \mathrm{~h}$. LND were actively avoiding the stormwater drain, 
emphasizing the need for enhancement work to improve the biological connectivity of the system.

Kerr, S. M., Ward, T. D., Lennox, R. J., Brownscombe, J. W., Chapman, J. M., Gutowsky, L. F., Logan, J. M., Twardek, W. M., Elvidge, C. K., Danylchuk, A. J., and Cooke, S. J. (2017). Influence of hook type and live bait on the hooking performance of inline spinners in the context of catch-and-release brook trout Salvelinus fontinalis fishing in lakes. Fisheries Research, 186, 642-647.

The objective of catch-and-release angling is for the fish to survive with minimal fitness consequences. However, fish survival can be compromised by a number of factors, especially anatomical hooking location. To evaluate whether hook type or bait influence hooking outcomes, we tested different combinations of hook (treble or single siwash hooks) and bait (hook tipped with worm or no worm) while angling for brook trout (Salvelinus fontinalis) with inline spinner-style fishing lures. The study was conducted at spring water temperatures $\left(\sim 20^{\circ} \mathrm{C}\right)$ in small lakes stocked with trout in southwestern Quebec, Canada. Incidences of hooking in the interior of the mouth (i.e. internal hooking) were uncommon (19\%), did not differ significantly between hook types or bait treatments, and occurred independently of fish size. Reflex impairments after hook removal were not related to hook or bait treatment. Short-term mortality was quantified with $24 \mathrm{~h}$ holding in net pens and was determined to be infrequent for all treatment groups (treble/worm: 6\%; treble/no worm: 5\%; single/worm: $2 \%$; single/no worm: $0 \%$ ). Although no fish were hooked in the gills, esophagus, stomach, odds of mortality increased by 14.21 when fish 
were hooked internally, which is consistent with the position that hook placement is an important predictor of the fate of fish released by anglers. However, our finding that neither hook nor bait type significantly increased the odds of internal hooking, bleeding, reflex impairment, or mortality in this study suggests that restrictions imposed on the use of baited lures or certain hook types attached to lures when fishing may have little influence on shortterm catch-and-release mortality of brook trout at these temperatures.

Lizée, T. W., Lennox, R. J., Ward, T. D., Brownscombe, J. W., Chapman, J. M., Danylchuk, A. J., Nowell, L. B., and Cooke, S. J. (2017). Influence of landing net mesh type on handling time and tissue damage of angled brook trout. North American Journal of Fisheries Management, 00, 00-00.

Recreational catch-and-release angling is a popular activity. Anglers often use landing nets to shorten fight times, reduce stress on the line and rod, restrict fish movement to facilitate dehooking of the fish, and protect fish from undue harm caused by handling or dropping. Landing nets are constructed using a variety of netting materials that could have varied consequences when coming in contact with fish. Salmonids are among the most targeted fishes in the world, but little is known about how landing nets contribute to postcapture tissue damage. We compared handling time and instances of fin fraying, scale loss, and mucus loss sustained by Brook Trout Salvelinus fontinalis landed by four net mesh types (i.e. large, knotless rubber mesh; knotless nylon micromesh; large, knotted polypropylene mesh; and small, knotless rubber-coated nylon mesh) or by using bare wet hands in a recreational fishery. The knotted polypropylene mesh resulted in the greatest extent of fin 
fraying, whereas the bare wet hands method, knotless nylon micromesh, and rubber-coated nylon mesh resulted in the most scale loss. Interestingly, extended handling times were noted for several mesh types (i.e. knotless nylon micromesh and rubber-coated nylon mesh) relative to bare wet hands because of hook entanglement in the netting material. However, using bare wet hands to land Brook Trout resulted in higher odds of the fish being dropped into the bottom of the boat. We concluded that the large, knotless rubber mesh was the least damaging to Brook Trout. Changes to angler practices, such as using appropriate landing tools, can benefit fish welfare in catch-and-release fisheries.

Nguyen, V. M., Brooks, J. L., Young, N., Lennox, R. J., Haddaway, N., Whoriskey, F. G., Harcourt, R., and Cooke, S. J. (2017). To share or not to share in the emerging era of big data: perspectives from fish telemetry researchers on data sharing. Canadian Journal of Fisheries and Aquatic Sciences, 74(8), 1260-1274.

The potential for telemetry data to answer complex questions about aquatic animals and their interactions with the environment is limited by the capacity to store, manage, and access data across the research community. Large telemetry networks and databases exist, but are limited by the actions of researchers to share their telemetry data. Promoting data sharing and understanding researchers' views on open practices is a major step toward enhancing the role of big data in ecology and resources management. We surveyed 307 fish telemetry researchers to understand their perspectives and experiences on data sharing. A logistic regression revealed that data sharing was positively related to researchers with collaborative tendencies, who belong to a telemetry network, who are prolific publishers, 
and who express altruistic motives for their research. Researchers were less likely to have shared telemetry data if they engage in radio and (or) acoustic telemetry, work for regional government, and value the time it takes to complete a research project. We identify and provide examples of both benefits and concerns that respondents have about sharing telemetry data.

Patterson, D. A., Robinson, K. A., Lennox, R. J., Nettles, T. L., Donaldson, L. A., Eliason, E. J., Raby, G. D., Chapman, J. M., Cook, K. V., Donaldson, M. R., Bass, A. L., Drenner, S. M., Reid, A. J., Cooke, S. J., Hinch, S. G. (2017). Review and evaluation of fishing-related incidental mortality of Pacific salmon. Canadian Science Advisory Secretariat Report 2017/010. 164 pp.

The number of fish that encounter fishing gear is greater than the number of fish retained as catch. The proportion of this difference that die from the encounter is defined as fishingrelated incidental mortality (FRIM). FRIM estimates are required for improved stock assessments, but they are difficult to attain and vary across fisheries. To cope with this challenge we review and evaluate the scientific knowledge on FRIM. First, we review the different mortality components of FRIM (i.e. avoidance, escape, depredation, drop-out, onboard, short-term release, and delayed mortality) in relation to how a fish responds to different aspects of a fishery encounter (e.g. handling). To better understand how fish respond to a fishing encounter, different fishing factors (e.g. gear type) that act in consort with extrinsic (e.g. water temperature) and intrinsic (e.g. fish size) factors elicit different fish responses that can lead to the different types of mortality (e.g. acute) were examined. 
A fish response to a stressor (i.e. factor) is a combination of the magnitude and duration of the stressor itself. The initial fish response includes acute physiological stress and injury, followed by behaviour changes, chronic stress, and increased risk of infection. Next, a review was done to provide an up-to-date accounting of the mortality rate information available on estimates of FRIM for Pacific salmon (Oncorhynchus spp.). We created an interactive and searchable catalogue of evidence from predominantly primary literature using standardized systematic mapping protocols, with a focus on coding information to determine study reliability and relevance. Next, we synthesize the factor and mortality information to provide recommendations on the use of five major mortality risk factors that are linked to FRIM. Each factor (capture, handling, injury, water temperature, and predators) is scaled to a mortality risk to provide guidance on evaluating FRIM estimates. The recommendations from this work are focussed on addressing the current knowledge gaps and examining FRIM in broader physiological and ecological context. Ideas for future work include researching cumulative impacts, sub-lethal effects, drop-off mortality, and predation. We have chosen a fish-centric hybrid approach that focusses first on understanding factors that drive mortality, and then on mortality estimates. As such, this paper is not meant as the definitive guide on FRIM but a transparent, defensible, and rigorous evaluation of the primary evidence base for making future decisions about FRIM. Further guidance on how to use the information herein is part of an accompanying CSAS research document. 
Redfern, J. C., Cooke, S. J., Lennox, R. J., Nannini, M. A., Wahl, D. H., and Gilmour, K. M. (2017). Effects of maternal cortisol treatment on offspring size, responses to stress, and anxiety-related behavior in wild largemouth bass (Micropterus salmoides). Physiology and behavior, 180, 15-24.

Cortisol, the main glucocorticoid stress hormone in teleost fish, is of interest as a mediator of maternal stress on offspring characteristics because it plays an organizational role during early development. The present study tested the hypothesis that maternal exposure to cortisol treatment prior to spawn affects offspring phenotype using wild largemouth bass (Micropterus salmoides). Baseline and stress-induced cortisol concentrations, body size (i.e. length and mass), and behavior (i.e. anxiety, exploration, boldness, and aggression) were assessed at different offspring life-stages and compared between offspring of control and cortisol-treated females. Cortisol administration did not affect spawning success or timing, nor were whole-body cortisol concentrations different between embryos from cortisol-treated and control females. However, maternal cortisol treatment had significant effects on offspring stress responsiveness, mass, and behavior. Compared to offspring of control females, offspring of cortisol-treated females exhibited larger mass right after hatch, and young-of-the-year mounted an attenuated cortisol response to an acute stressor, and exhibited less thigmotaxic anxiety, exploratory behavior, boldness and aggression. Thus, offspring phenotype was affected by elevated maternal cortisol levels despite the absence of a significant increase in embryo cortisol concentrations, suggesting that a mechanism other than the direct deposition of cortisol into eggs mediates effects on offspring. The results of the present raise questions about the mechanisms through which 
maternal stress influences offspring behavior and physiology, as well as the impacts of such phenotypic changes on offspring fitness.

Struthers, D. P., Bower, S. D., Lennox, R. J., Gilroy, C., MacDonald, C., Cooke, S. J., and Litvak, M. (2018). Short-term physiological disruption and reflex impairment in shortnose sturgeon Acipenser brevirostrum exposed to catch-and-release angling. North American Journal of Fisheries Management, 00, 00-00.

Sturgeons (Acipenseridae) are the most imperilled group of fishes globally. Yet, many species remain important targets of recreational anglers. In the Saint John River, New Brunswick, Canada, Shortnose Sturgeon Acipenser brevirostrum is a popular species targeted by recreational anglers, while the International Union for the Conservation of Nature has placed Shortnose Sturgeon on the Red List as "Vulnerable" and afforded protection from harvest in Canada by the federal Species at Risk Act. Here, we evaluated physiological stress using two principal components axes, $\mathrm{RC} 1$ and $\mathrm{RC} 2$, generated from blood lactate, glucose and $\mathrm{pH}$, hematocrit and reflex impairment of Sturgeon exposed to exhaustive chase experiments at a hatchery and angled Sturgeon that were captured during an annual fall competitive angling event. Physiological indicators of stress increased with holding time for Sturgeon transferred into a tank and for Sturgeon exposed to a chase trial. Circulating metabolite concentrations were not associated with reflex impairment. Odds of reflex impairment increased as a function of air exposure, with a 1 min increase in air exposure increasing odds of impairment by 1.78. All Sturgeon survived hatchery experiments. Most of the wild Sturgeon captured in the derby (71\%) exhibited reflex 
impairment and 38\% had superficial injuries such as cuts or wounds. None of these factors were associated with physiological disturbance, although ordinated stress physiology axes were elevated both 1 and $2 \mathrm{~h}$ after initial sampling, which was predictive by holding time prior to weigh-in and fish size. All fish were hooked in the mouth and each was released alive from the derby. Taken together the evidence suggests that Sturgeon are resilient to recreational angling interactions, yet managers could use this information to improve best practices of catch-and-release angling.

Twardek, W. M., Lennox, R. J., Lawrence, M. J., Logan, J. M., Szekeres, P., Tremblay, K., Morgan, G. E., Danylchuk, A. J., and Cooke, S. J. In Press. The post-release survival of Walleye Sander vitreus following ice angling on Lake Nipissing, Ontario. North American Journal of Fisheries Management, 00, 00-00.

Natural resource agencies have developed catch-and-release regulations for Walleye (Sander vitreus) of prohibited size and number to reduce mortality in many recreational fisheries. The efficacy of such regulations is contingent upon the released fish surviving, but survival data on Walleye captured by ice angling are lacking. We estimated the survival of Lake Nipissing, Ontario, Canada, Walleye captured by both active and passive ice angling methods using a variety of hook types and lures baited with Emerald Shiner (Notropis atherinoides). We also assessed the role of de-hooking methods on the survival of deeply-hooked Walleye. Following the angling event, Walleye $(n=260)$ were held for $24 \mathrm{~h}$ in a submerged holding pen to estimate post-release survival. Average mortality following the $24 \mathrm{~h}$ holding period was $6.9 \%$. Fewer Walleye captured by active angling 
were deeply-hooked (9.3\%) than passively caught fish (50.4\%) and deeply-hooked Walleye were observed to have more frequent post-release mortality (14.8\%) than shallowhooked Walleye (3.0\%). There was no significant difference in Walleye mortality rates caught by passive $(9.8 \%)$ or active angling $(2.8 \%)$ nor between circle $(6.1 \%)$, J-hook (8.2\%), and treble hooks (5.6\%). Neither air temperature nor the presence of barotrauma had a significant effect on mortality of captured Walleye. There was also no significant difference in survival for deeply-hooked fish that had the line cut (11.1\%) or hook removed (22.6\%). Results from this study suggest relatively high incidence of Walleye survival following catch-and-release angling through the ice. 


\section{References}

Aas, Ø., Policansky, D., Einum, S., and Skurdal, J. (2011). Salmon ecological research and conservation. In: Aas, Ø., Einum, S., Klemetsen, A. and Skudal, J. (eds), Atlantic Salmon Ecology. Oxford: Wiley-Blackwell, pp. 445-456.

Able, K. P. (1980). Mechanisms of orientation, navigation and homing. In: Gauthreaux, S. (ed), Animal Migration, Orientation and Navigation. Academic Press, New York, pp. 283-373.

Adams, L. (1965). Progress in ecological biotelemetry. BioScience, 15, 83-86.

Agafonkin, V., and Thieurmel, B. (2017). suncalc: Compute Sun Position, Sunlight Phases, Moon Position and Lunar Phase. R package version 0.3. https://CRAN.Rproject.org/package $=$ suncalc.

Alabaster, J. S. (1990). The temperature requirements of adult Atlantic salmon, Salmo salar L., during their upstream migration in the River Dee. Journal of Fish Biology, 37(4), 659-661.

Alerstam, T., Hedenström, A., and Åkesson, S. (2003). Long-distance migration: evolution and determinants. Oikos, 103(2), 247-260.

Allen, A. M., and Singh, N. J. (2016). Linking movement ecology with wildlife management and conservation. Frontiers in Ecology and Evolution, 3, 155.

Allen, M. S., Miranda, L. E., and Brock, R. E. (1998). Implications of compensatory and additive mortality to the management of selected sportfish populations. Lakes and Reservoirs: Research and Management, 3(1), 67-79. 
Altizer, S., Bartel, R., and Han, B. A. (2011). Animal migration and infectious disease risk. Science, 331(6015), 296-302.

Anderson, C. N., Hsieh, C. H., Sandin, S. A., Hewitt, R., Hollowed, A., Beddington, J., May, R. M., and Sugihara, G. (2008). Why fishing magnifies fluctuations in fish abundance. Nature, 452(7189), 835.

Anon. (2016a). Status for Norwegian salmon populations in 2016. Report from the Scientific Board for Salmon Management, 9, 1-190

Anon. (2016b). Classification of 104 salmon populations according to the quality norm for wild salmon. Themed Report, 4, 1-85.

Anttila, K., Couturier, C. S., Øverli, Ø., Johnsen, A., Marthinsen, G., Nilsson, G. E., and Farrell, A. P. (2014). Atlantic salmon show capability for cardiac acclimation to warm temperatures. Nature Communications, 5, 4252.

Arlinghaus, R., and Cooke, S.J. (2009). Recreational fisheries: socioeconomic importance, conservation issues and management challenges. In: Dickson, B., Hutton, J., and Adams, W. A. (eds), Recreational Hunting, Conservation and Rural Livelihoods: Science and Practice. Blackwell Publishing, Oxford, pp. 3958.

Arlinghaus, R., Cooke, S. J., and Potts, W. (2013). Towards resilient recreational fisheries on a global scale through improved understanding of fish and fisher behaviour. Fisheries Management and Ecology, 20(2-3), 91-98.

Arlinghaus, R., Cooke, S. J., Lyman, J., Policansky, D., Schwab, A., Suski, C., Sutton, S. G., and Thorstad, E. B. (2007). Understanding the complexity of catch-andrelease in recreational fishing: an integrative synthesis of global knowledge from 
historical, ethical, social, and biological perspectives. Reviews in Fisheries Science, 15(1-2), 75-167.

Armstrong, J. D., Kemp, P. S., Kennedy, G. J. A., Ladle, M., and Milner, N. J. (2003). Habitat requirements of Atlantic salmon and brown trout in rivers and streams. Fisheries Research, 62(2), 143-170.

Arreguín-Sánchez, F. (1996). Catchability: a key parameter for fish stock assessment. Reviews in Fish Biology and Fisheries, 6(2), 221-242.

Askey, P. J., Richards, S. A., Post, J. R., and Parkinson, E. A. (2006). Linking angling catch rates and fish learning under catch-and-release regulations. North American Journal of Fisheries Management, 26(4), 1020-1029.

Auguie, B. (2017). gridExtra: Miscellaneous Functions for "Grid" Graphics. R package version 2.3. https://CRAN.R-project.org/package=gridExtra

Baisez, A., Bach, J. M., Leon, C., Parouty, T., Terrade, R., Hoffmann, M., and Laffaille, P. (2011). Migration delays and mortality of adult Atlantic salmon Salmo salar en route to spawning grounds on the River Allier, France. Endangered Species Research, 15(3), 265-270.

Bardonnet, A., and Baglinière, J. L. (2000). Freshwater habitat of Atlantic salmon (Salmo salar). Canadian Journal of Fisheries and Aquatic Sciences, 57(2), 497-506.

Barnett, A., Abrantes, K. G., Baker, R., Diedrich, A. S., Farr, M., Kuilboer, A., Mahony, T., McLeod, I., Moscardo, G., Prideaux, P., Stoeckl, N., van Luyn, A., and Sheaves, M. (2016). Sportfisheries, conservation and sustainable livelihoods: a multidisciplinary guide to developing best practice. Fish and Fisheries, 17(3), 696-713. 
Barnhart, R. A. (1989). Symposium review: catch-and-release fishing, a decade of experience. North American Journal of Fisheries Management, 9, 74-80.

Bartholomew, A., and Bohnsack, J. A. (2005). A review of catch-and-release angling mortality with implications for no-take reserves. Reviews in Fish Biology and Fisheries, 15(1-2), 129-154.

Barton, B. A. (2002). Stress in Fishes: A diversity of responses with particular reference to changes in circulating corticosteroids. Integrative and Comparative Biology, $42(3), 517-525$.

Barton, B. A., and Iwama, G. K. (1991). Physiological changes in fish from stress in aquaculture with emphasis on the response and effects of corticosteroids. Annual Review of Fish Diseases, 1, 3-26.

Bates, D., Maechler, M., Bolker, B., and Walker, S. (2015). Fitting linear mixed-effects models using lme4. Journal of Statistical Software, 67, 1-48.

Beamesderfer, R. C., and North, J. A. (1995). Growth, natural mortality, and predicted response to fishing for largemouth bass and smallmouth bass populations in North America. North American Journal of Fisheries Management, 15(3), 688-704.

Behrisch, H. W. (1969). Temperature and the regulation of enzyme activity in poikilotherms. Fructose diphosphatase from migrating salmon. Biochemical Journal, 115(4), 687-696.

Belding, D. L. (1934). The cause of the high mortality in the Atlantic salmon after spawning. Transactions of the American Fisheries Society, 64(1), 219-224. 
Bernatchez, L., and Dodson, J. J. (1987). Relationship between bioenergetics and behavior in anadromous fish migrations. Canadian Journal of Fisheries and Aquatic Sciences, 44(2), 399-407.

Berntsen, H. H., and Bech, C. (2016). Incubation temperature influences survival in a small passerine bird. Journal of Avian Biology, 47(2), 141-145.

Berthold, P. (1999). A comprehensive theory for the evolution, control and adaptability of avian migration. Ostrich, 70(1), 1-11.

Beukema, J. J. (1970). Acquired hook-avoidance in the pike Esox lucius L. fished with artificial and natural baits. Journal of Fish Biology, 2(2), 155-160.

Beukema, J. J. and Vos, G. J. (1974). Experimental tests of a basic assumption of the capture-recapture method in pond populations of carp Cyprinus carpio L. Journal of Fish Biology, 6, 317-329.

Bielak A. T. (1996). A discussion document on the implications of catch-and-release angling for Atlantic salmon, with particular reference to water temperature-related river closures. Department of Fisheries and Oceans, Atlantic Fisheries Research Document 96/117, 17 pp.

Bivand, R., and Lewin-Koh, N. (2015). maptools: Tools for reading and handling spatial objects. R package version 0.8-34. http://CRAN.R-project.org/package=maptools Bjerselius, R., Li, W., Teeter, J. H., Seelye, J. G., Johnsen, P. B., Maniak, P. J., Grant, G. C., Polkinghorne, C. N., and Sorensen, P. W. (2000). Direct behavioral evidence that unique bile acids released by larval sea lamprey (Petromyzon marinus) function as a migratory pheromone. Canadian Journal of Fisheries and Aquatic Sciences, 57(3), 557-569. 
Bolstad, G. H., Hindar, K., Robertsen, G., Jonsson, B., Sægrov, H., Diserud, O. H., Fiske, P., Jensen, A. J., Urdal, K., Næsje, T., Barlaup, B. T., Florø-Larsen, B., Lo, H., Niemelä, E., and Karlsson, S. (2017). Gene flow from domesticated escapes alters the life history of wild Atlantic salmon. Nature Ecology and Evolution, 1(5), 0124.

Boonstra, R. (2013). Reality as the leading cause of stress: rethinking the impact of chronic stress in nature. Functional Ecology, 27(1), 11-23.

Booth, R. K. (1998) Swimming performance of anadromous Atlantic salmon, Salmo salar L., during their spawning migration in the Exploits River, Newfoundland, Canada. Doctor of Philosophy thesis, University of Waterloo, Ontario

Booth, R. K., Kieffer, J. D., Tufts, B. L., Davidson, K., and Bielak, A. T. (1995). Effects of late-season catch and release angling on anaerobic metabolism, acid-base status, survival, and gamete viability in wild Atlantic salmon (Salmo salar). Canadian Journal of Fisheries and Aquatic Sciences, 52(2), 283-290.

Booth, R. K., McKinley, R. S., Økland, F., and Sisak, M. M. (1997). In situ measurement of swimming performance of wild Atlantic salmon (Salmo salar) using radio transmitted electromyogram signals. Aquatic Living Resources, 10(4), 213-219.

Bottrill, M. C., Joseph, L. N., Carwardine, J., Bode, M., Cook, C., Game, E. T., Grantham, H., Kark, S., Linke, S., McDonald-Madden, E., Pressey, R. L., Walker, S., Wilson, K. A., and Possingham, H. P. (2008). Is conservation triage just smart decision making? Trends in Ecology and Evolution, 23(12), 649-654. 
Boulêtreau, S., Gaillagot, A., Carry, L., Tétard, S., De Oliveira, E., and Santoul, F. (2018). Adult Atlantic salmon have a new freshwater predator. PloS One, 13(4), e0196046.

Bowerman, T. E., Pinson-Dumm, A., Peery, C. A., and Caudill, C. C. (2017). Reproductive energy expenditure and changes in body morphology for a population of Chinook salmon Oncorhynchus tshawytscha with a long distance migration. Journal of Fish Biology, 90(5), 1960-1979.

Bowlin, M. S., Bisson, I. A., Shamoun-Baranes, J., Reichard, J. D., Sapir, N., Marra, P. P., Kunz, T. H., Wilcove, D. S., Hedenström, A., Guglielmo, C. G., Åkesson, S., Ramenofsky, M., and Wikelski, M. (2010). Grand challenges in migration biology. Integrative and Comparative Biology, 50(3), 261-279.

Bradshaw, W. E., and Holzapfel, C. M. (2008). Genetic response to rapid climate change: it's seasonal timing that matters. Molecular Ecology, 17(1), 157-166.

Brett, J. R. (1971). Energetic responses of salmon to temperature. A study of some thermal relations in the physiology and freshwater ecology of sockeye salmon (Oncorhynchus nerka). American Zoologist, 11(1), 99-113.

Brett, J. R. (1995). Energetics. In: Groot, C., Margolis, L., and Clarke, W.C. (eds), Physiological Ecology of Pacific Salmon. University of British Columbia Press, Vancouver, BC, pp. 3-68.

Brett, J. R., and Glass, N. R. (1973). Metabolic rates and critical swimming speeds of sockeye salmon (Oncorhynchus nerka) in relation to size and temperature. Journal of the Fisheries Board of Canada, 30(3), 379-387. 
Brobbel, M. A., Wilkie, M. P., Davidson, K., Kieffer, J. D., Bielak, A. T., and Tufts, B. L. (1996). Physiological effects of catch and release angling in Atlantic salmon (Salmo salar) at different stages of freshwater migration. Canadian Journal of Fisheries and Aquatic Sciences, 53(9), 2036-2043.

Brodersen, J., Nilsson, P. A., Hansson, L. A., Skov, C., and Brönmark, C. (2008). Condition-dependent individual decision-making determines cyprinid partial migration. Ecology, 89(5), 1195-1200.

Broell, F., Taylor, A. D., Litvak, M. K., Bezanson, A., and Taggart, C. T. (2016). Posttagging behaviour and habitat use in shortnose sturgeon measured with highfrequency accelerometer and PSATs. Animal Biotelemetry, 4(1), 11.

Brown, C., Laland, K.N., and Krause, J. (2011). Fish Cognition and Behaviour. WileyBlackwell Scientific, Oxford.

Brown, D. D., Kays, R., Wikelski, M., Wilson, R., and Klimley, A. P. (2013). Observing the unwatchable through acceleration logging of animal behavior. Animal Biotelemetry, 1(1), 20.

Brown, J. H., Gillooly, J. F., Allen, A. P., Savage, V. M., and West, G. B. (2004). Toward a metabolic theory of ecology. Ecology, 85(7), 1771-1789.

Brown, W. (1862). The Natural History of the Salmon, as Ascertained by the Recent Experiments in the Artificial Spawning and Hatching of the Ova and Rearing of the Fry at Stormontfield, on the Tay. Thomas Murray and Son, Glasgow.

Brownscombe, J. W., Bower, S. D., Bowden, W., Nowell, L., Midwood, J. D., Johnson, N., and Cooke, S. J. (2014). Canadian recreational fisheries: 35 years of social, 
biological, and economic dynamics from a national survey. Fisheries, 39(6), 251260.

Brownscombe, J. W., Cooke, S. J., and Danylchuk, A. J. (2017b). Spatiotemporal drivers of energy expenditure in a coastal marine fish. Oecologia, 183(3), 689-699.

Brownscombe, J. W., Danylchuk, A. J., Chapman, J. M., Gutowsky, L. F., and Cooke, S. J. (2017a). Best practices for catch-and-release recreational fisheries-Angling tools and tactics. Fisheries Research, 186, 693-705.

Brownscombe, J. W., Thiem, J. D., Hatry, C., Cull, F., Haak, C. R., Danylchuk, A. J., and Cooke, S. J. (2013). Recovery bags reduce post-release impairments in locomotory activity and behavior of bonefish (Albula spp.) following exposure to angling-related stressors. Journal of Experimental Marine Biology and Ecology, 440, 207-215.

Buchholz, R. (2007). Behavioural biology: an effective and relevant conservation tool. Trends in Ecology and Evolution, 22(8), 401-407.

Byers, T., and Dickson, D. L. (2001). Spring migration and subsistence hunting of king and common eiders at Holman, Northwest Territories, 1996-98. Arctic, 54, 122134.

Caissie, D. (2006). The thermal regime of rivers: a review. Freshwater Biology, 51(8), 1389-1406.

Calenge, C. (2006) The package adehabitat for the R software: a tool for the analysis of space and habitat use by animals. Ecological Modelling, 197, 516-519.

Campbell, P. M., Pottinger, T. G., and Sumpter, J. P. (1992). Stress reduces the quality of gametes produced by rainbow trout. Biology of Reproduction, 47(6), 1140-1150. 
Casillas, C. E., and Kammen, D. M. (2010). The energy-poverty-climate nexus. Science, 330(6008), 1181-1182.

Castro-Santos, T., and Letcher, B. H. (2010). Modeling migratory energetics of Connecticut River American shad (Alosa sapidissima): implications for the conservation of an iteroparous anadromous fish. Canadian Journal of Fisheries and Aquatic Sciences, 67(5), 806-830.

Chapman, J. W., Klaassen, R. H., Drake, V. A., Fossette, S., Hays, G. C., Metcalfe, J. D., Reynolds, A. M., Reynolds, D. R., and Alerstam, T. (2011). Animal orientation strategies for movement in flows. Current Biology, 21(20), R861-R870.

Charnov, E. L. (1976). Optimal foraging: The marginal value theorem. Theoretical Population Biology, 9, 129-136.

Cheung, W. W., Sarmiento, J. L., Dunne, J., Frölicher, T. L., Lam, V. W., Palomares, M. D., Watson, R., and Pauly, D. (2013). Shrinking of fishes exacerbates impacts of global ocean changes on marine ecosystems. Nature Climate Change, 3(3), 254258.

Childress, E. S., Allan, J. D., and McIntyre, P. B. (2014). Nutrient subsidies from iteroparous fish migrations can enhance stream productivity. Ecosystems, 17(3), $522-534$.

Chopin, F. S., and Arimoto, T. (1995). The condition of fish escaping from fishing gears-a review. Fisheries Research, 21, 315-327.

Chuenpagdee, R., Morgan, L. E., Maxwell, S. M., Norse, E. A., and Pauly, D. (2003). Shifting gears: assessing collateral impacts of fishing methods in US waters. Frontiers in Ecology and the Environment, 1(10), 517-524. 
Clark, T. D., Donaldson, M. R., Pieperhoff, S., Drenner, S. M., Lotto, A., Cooke, S. J., Hinch, S.G., Patterson, D. A., and Farrell, A. P. (2012). Physiological benefits of being small in a changing world: responses of coho salmon (Oncorhynchus kisutch) to an acute thermal challenge and a simulated capture event. PLoS One, 7(6), e39079.

Clarke, A., and Johnston, N. M. (1999). Scaling of metabolic rate with body mass and temperature in teleost fish. Journal of Animal Ecology, 68(5), 893-905.

Clemmons, J. R., and Buchholz, R. (1997). Behavioral approaches to conservation in the wild. Cambridge University Press.

Clifford, S. L., McGinnity, P., and Ferguson, A. (1998). Genetic changes in Atlantic salmon (Salmo salar) populations of northwest Irish rivers resulting from escapes of adult farm salmon. Canadian Journal of Fisheries and Aquatic Sciences, 55(2), $358-363$.

Coggins, L. G., Catalano, M. J., Allen, M. S., Pine, W. E., and Walters, C. J. (2007). Effects of cryptic mortality and the hidden costs of using length limits in fishery management. Fish and Fisheries, 8(3), 196-210.

Cohen, J. E. (2003). Human population: the next half century. Science, 302(5648), 11721175.

Consuegra, S., Leániz, D., García, C., Serdio, A., and Verspoor, E. (2005). Selective exploitation of early running fish may induce genetic and phenotypic changes in Atlantic salmon. Journal of Fish Biology, 67(s1), 129-145.

Conway, F., and Opsommer, L. (2007). Communicating and interacting with Oregon's coastal marine recreational fishing community. Fisheries, 32(4), 182-188. 
Cooke, S. J., and Cowx, I. G. (2004). The role of recreational fishing in global fish crises. AIBS Bulletin, 54(9), 857-859.

Cooke, S. J., and Schramm, H. L. (2007). Catch-and-release science and its application to conservation and management of recreational fisheries. Fisheries Management and Ecology, 14(2), 73-79.

Cooke, S. J., and Suski, C. D. (2005). Do we need species-specific guidelines for catchand-release recreational angling to effectively conserve diverse fishery resources? Biodiversity and Conservation, 14(5), 1195-1209.

Cooke, S. J., Birnie-Gauvin, K., Lennox, R. J., Taylor, J. J., Rytwinski, T., Rummer, J. L., Franklin, C. E., Bennett, J. R., and Haddaway, N. R. (2017). How experimental biology and ecology can support evidence-based decision-making in conservation: avoiding pitfalls and enabling application. Conservation Physiology, 5(1), cox043.

Cooke, S. J., Blumstein, D. T., Buchholz, R., Caro, T., Fernández-Juricic, E., Franklin, C. E., Metcalfe, J., O'Connor, C., St. Clair, C. C., Sutherland, W. J., and Wikelski, M. (2013a). Physiology, behavior, and conservation. Physiological and Biochemical Zoology, 87(1), 1-14.

Cooke, S. J., Brownscombe, J. W., Raby, G. D., Broell, F., Hinch, S. G., Clark, T. D., and Semmens, J. M. (2016). Remote bioenergetics measurements in wild fish: opportunities and challenges. Comparative Biochemistry and Physiology Part A: Molecular and Integrative Physiology, 202, 23-37.

Cooke, S. J., Donaldson, M. R., O'Connor, C. M., Raby, G. D., Arlinghaus, R., Danylchuk, A. J., Hanson, K. C., Hinch, S. G., Clark, T. D., Patterson, D. A., and 
Suski, C. D. (2013a). The physiological consequences of catch-and-release angling: perspectives on experimental design, interpretation, extrapolation and relevance to stakeholders. Fisheries Management and Ecology, 20(2-3), 268-287. Cooke, S. J., Hinch, S. G., Crossin, G. T., Patterson, D. A., English, K. K., Healey, M. C., Shrimpton, J. M., van der Kraak, G., and Farrell, A. P. (2006). Mechanistic basis of individual mortality in Pacific salmon during spawning migrations. Ecology, 87(6), 1575-1586.

Cooke, S. J., Schreer, J. F., Dunmall, K. M., and Philipp, D. P. (2002). Strategies for quantifying sub-lethal effects of marine catch-and-release angling: insights from novel freshwater applications. American Fisheries Society Symposium, 30, 121134

Cooke, S. J., Suski, C. D., Ostrand, K. G., Wahl, D. H., and Philipp, D. P. (2007). Physiological and behavioral consequences of long-term artificial selection for vulnerability to recreational angling in a teleost fish. Physiological and Biochemical Zoology, 80(5), 480-490.

Cooke, S. J., Thorstad, E. B., and Hinch, S. G. (2004). Activity and energetics of freeswimming fish: insights from electromyogram telemetry. Fish and Fisheries, 5(1), $21-52$.

Costanza, R., d'Arge, R., De Groot, R., Farber, S., Grasso, M., Hannon, B., Limburg, K., Naeem, S., O’Neill, R. V., Paruelo, J., Raskin, R. G., Sutton, P., and van den Belt, M. (1997). The value of the world's ecosystem services and natural capital. Nature, 387(6630), 253. 
Couturier, C. (2017). Letter: Pink salmon in N.L. nothing new. The Telegram. March 20, 2018.

Cowx, I. G., Arlinghaus, R., and Cooke, S. J. (2010). Harmonizing recreational fisheries and conservation objectives for aquatic biodiversity in inland waters. Journal of Fish Biology, 76(9), 2194-2215.

Cox, S. P., and Walters, C. (2002). Modeling exploitation in recreational fisheries and implications for effort management on British Columbia rainbow trout lakes. North American Journal of Fisheries Management, 22(1), 21-34.

Crain, C. M., Kroeker, K., and Halpern, B. S. (2008). Interactive and cumulative effects of multiple human stressors in marine systems. Ecology Letters, 11(12), 13041315.

Cross, T. F., and Challanain, D. N. (1991). Genetic characterisation of Atlantic salmon (Salmo salar) lines farmed in Ireland. Aquaculture, 98(1-3), 209-216.

Crossin, G. T., Heupel, M. R., Holbrook, C. M., Hussey, N. E., Lowerre-Barbieri, S. K., Nguyen, V. M., Raby, G. D., and Cooke, S. J. (2017). Acoustic telemetry and fisheries management. Ecological Applications, 27(4), 1031-1049.

Crossin, G. T., Hinch, S. G., Farrell, A. P., Higgs, D. A., Lotto, A. G., Oakes, J. D., and Healey, M. C. (2004). Energetics and morphology of sockeye salmon: effects of upriver migratory distance and elevation. Journal of Fish Biology, 65(3), 788-810.

Crossin, G. T., Hinch, S. G., Farrell, A. P., Whelly, M. P., and Healey, M. C. (2003). Pink salmon (Oncorhynchus gorbuscha) migratory energetics: response to migratory difficulty and comparisons with sockeye salmon (Oncorhynchus nerka). Canadian Journal of Zoology, 81(12), 1986-1995. 
Croze, O. (2008) The impact of the channeled part of the Auline River (France) on the upstream migration of returning adult Atlantic salmon as determined by radiotracking. American Fisheries Society Symposium, 65, 23-37.

Crozier, L. G., and Hutchings, J. A. (2014). Plastic and evolutionary responses to climate change in fish. Evolutionary Applications, 7(1), 68-87.

Crozier, L. G., Hendry, A. P., Lawson, P. W., Quinn, T. P., Mantua, N. J., Battin, J., Shaw, R. G., and Huey, R. B. (2008). Potential responses to climate change in organisms with complex life histories: evolution and plasticity in Pacific salmon. Evolutionary Applications, 1(2), 252-270.

Crozier, W. W. (1993). Evidence of genetic interaction between escaped farmed salmon and wild Atlantic salmon (Salmo salar L.) in a Northern Irish river. Aquaculture, 113(1-2), 19-29.

Dall, S. R., Giraldeau, L. A., Olsson, O., McNamara, J. M., and Stephens, D. W. (2005). Information and its use by animals in evolutionary ecology. Trends in Ecology and Evolution, 20(4), 187-193.

Daufresne, M., Lengfellner, K., and Sommer, U. (2009). Global warming benefits the small in aquatic ecosystems. Proceedings of the National Academy of Sciences, 106(31), 12788-12793.

Davidson, K., Hayward, J., Hambrook, M., Bielak, A. T., and Sheasgreen, J. (1994). The effects of late-season angling on gamete viability and early fry survival in Atlantic salmon. Canadian Technical Report of Fisheries and Aquatic Sciences, 1982, 112. 
Davies, N. B., Krebs, J. R., and West, S. A. (2012) An Introduction to Behavioural Ecology, $4^{\text {th }}$ edition. Wiley-Blackwell, Oxford.

Davis, M. W. (2010). Fish stress and mortality can be predicted using reflex impairment. Fish and Fisheries, 11(1), 1-11.

Dayton, P. K., Thrush, S. F., Agardy, M. T., and Hofman, R. J. (1995). Environmental effects of marine fishing. Aquatic Conservation: Marine and Freshwater Ecosystems, 5(3), 205-232.

de Gaudemar, B. D., and Beall, E. (1998). Effects of overripening on spawning behaviour and reproductive success of Atlantic salmon females spawning in a controlled flow channel. Journal of Fish Biology, 53(2), 434-446.

de Gaudemar, B.., Bonzom, J. M., and Beall, E. (2000). Effects of courtship and relative mate size on sexual motivation in Atlantic salmon. Journal of Fish Biology, 57(2), 502-515.

Dee River Trust. (2010). Monitoring of the River Dee fishery season extension 2008 2010. Available from: http://www.riverdee.org.uk/

Dell, M. B. (1968). A new fish tag and rapid, cartridge-fed applicator. Transactions of the American Fisheries Society, 97, 57-59.

Dempson, B., Schwarz, C. J., Bradbury, I. R., Robertson, M. J., Veinott, G., Poole, R., and Colbourne, E. (2017). Influence of climate and abundance on migration timing of adult Atlantic salmon (Salmo salar) among rivers in Newfoundland and Labrador. Ecology of Freshwater Fish, 26(2), 247-259. 
Dempson, J. B., Furey, G., and Bloom, M. (2002). Effects of catch and release angling on Atlantic salmon, Salmo salar L., of the Conne River, Newfoundland. Fisheries Management and Ecology, 9(3), 139-147.

Dempson, J. B., O'Connell, M. F., and Cochrane, N. M. (2001). Potential impact of climate warming on recreational fishing opportunities for Atlantic salmon, Salmo salar L., in Newfoundland, Canada. Fisheries Management and Ecology, 8(1), 6982.

Dempson, J. B., O'Connell, M. F., and Schwarz, C. J. (2004). Spatial and temporal trends in abundance of Atlantic salmon, Salmo salar, in Newfoundland with emphasis on impacts of the 1992 closure of the commercial fishery. Fisheries Management and Ecology, 11(6), 387-402.

Dickerson, B. R., Brinck, K. W., Willson, M. F., Bentzen, P., and Quinn, T. P. (2005). Relative importance of salmon body size and arrival time at breeding grounds to reproductive success. Ecology, 86(2), 347-352.

Dickinson, M. H., Farley, C. T., Full, R. J., Koehl, M. A. R., Kram, R., and Lehman, S. (2000). How animals move: an integrative view. Science, 288(5463), 100-106.

Dill, L. M. (1983). Adaptive flexibility in the foraging behavior of fishes. Canadian Journal of Fisheries and Aquatic Sciences, 40(4), 398-408.

Dingle, H. (1980). Ecology and evolution of migration. In: Cauthreaux, A. (ed), Animal Migration, Orientation, and Navigation. Academic Press, New York, pp 1-101.

Dingle, H., and Drake, V. A. (2007). What is migration? Bioscience, 57(2), 113-121.

Dodson, J. J. (1988). The nature and role of learning in the orientation and migratory behavior of fishes. Environmental Biology of Fishes, 23(3), 161-182. 
Donaldson, M. R., Arlinghaus, R., Hanson, K. C., and Cooke, S. J. (2008). Enhancing catch-and-release science with biotelemetry. Fish and Fisheries, 9(1), 79-105.

Donaldson, M. R., Cooke, S. J., Patterson, D. A., Hinch, S. G., Robichaud, D., Hanson, K. C., Olsson, I., Crossin, G. T., English, K. K., and Farrell, A. P. (2009). Limited behavioural thermoregulation by adult upriver-migrating sockeye salmon (Oncorhynchus nerka) in the Lower Fraser River, British Columbia. Canadian Journal of Zoology, 87(6), 480-490.

Downton, P. R., Reddin, D. G., and Johnson, R. W. (2001). Status of Atlantic salmon (Salmo salar L.) in Campbellton River, Notre Dame Bay (SFA 4), Newfoundland in 2000. Canadian Science Advisory Secretariat. Research Document, 2001/031.

Ducharme, L. J. A. (1969). Atlantic salmon returning for their fifth and sixth consecutive spawning trips. Journal of the Fisheries Board of Canada, 26(6), 1661-1664.

Dutil, J. D. (1986). Energetic constraints and spawning interval in the anadromous Arctic charr (Salvelinus alpinus). Copeia, 1986(4), 945-955.

Einum, S., and Nislow, K. H. (2005). Local-scale density-dependent survival of mobile organisms in continuous habitats: an experimental test using Atlantic salmon. Oecologia, 143(2), 203-210.

Einum, S., Sundt-Hansen, L., and H Nislow, K. (2006). The partitioning of densitydependent dispersal, growth and survival throughout ontogeny in a highly fecund organism. Oikos, 113(3), 489-496.

Eliason, E. J., and Farrell, A. P. (2016). Oxygen uptake in Pacific salmon Oncorhynchus spp.: when ecology and physiology meet. Journal of Fish Biology, 88(1), 359388. 
Eliason, E. J., Clark, T. D., Hague, M. J., Hanson, L. M., Gallagher, Z. S., Jeffries, K. M., Gale, M. K., Patterson, D. A., Hinch, S. G., and Farrell, A. P. (2011). Differences in thermal tolerance among sockeye salmon populations. Science, 332(6025), 109-112.

Eliason, E. J., Clark, T. D., Hinch, S. G., and Farrell, A. P. (2013b). Cardiorespiratory performance and blood chemistry during swimming and recovery in three populations of elite swimmers: adult sockeye salmon. Comparative Biochemistry and Physiology Part A: Molecular and Integrative Physiology, 166(2), 385-397.

Eliason, E. J., Clark, T. D., Hinch, S. G., and Farrell, A. P. (2013a). Cardiorespiratory collapse at high temperature in swimming adult sockeye salmon. Conservation Physiology, 1(1).

Elmer, L. K., Kelly, L. A., Rivest, S., Steell, S. C., Twardek, W. M., Danylchuk, A. J., Arlinghaus, R., Bennett, J. R., and Cooke, S. J. (2017). Angling into the future: Ten commandments for recreational fisheries science, management, and stewardship in a good Anthropocene. Environmental Management, 60(2), 165175.

Erkinaro, J., Økland, F., Moen, K., and Niemelä, E. (1999). Return migration of the Atlantic salmon in the Tana River: distribution and exploitation of radiotagged multi-sea-winter salmon. Boreal Environment Research, 4, 115-124.

ESRI. (2011). ArcGIS Desktop: Release 10. Redlands, CA: Environmental Systems Research Institute 
Farrell, A. P., Eliason, E. J., Sandblom, E., and Clark, T. D. (2009). Fish cardiorespiratory physiology in an era of climate change. Canadian Journal of Zoology, 87(10), 835-851.

Farrell, A. P., Hinch, S. G., Cooke, S. J., Patterson, D. A., Crossin, G. T., Lapointe, M., and Mathes, M. T. (2008). Pacific salmon in hot water: applying aerobic scope models and biotelemetry to predict the success of spawning migrations. Physiological and Biochemical Zoology, 81(6), 697-708.

Ferguson, A., Fleming, I., Hindar, K., Skaala, Ø., McGinnity, P., Cross, T. F., and Prodöhl, P. (2007). Farm escapes. In: Verspoor, E., Stradmeyer, L., and Nielsen, J. L. (eds), The Atlantic Salmon: Genetics, Conservation and Management. Wiley-Blackwell, Oxford, pp. 357-398

Ferguson, R. A., Kieffer, J. D., and Tufts, B. L. (1993). The effects of body size on the acid-base and metabolite status in the white muscle of rainbow trout before and after exhaustive exercise. Journal of Experimental Biology, 180(1), 195-207.

Ferter, K., Weltersbach, M. S., Strehlow, H. V., Vølstad, J. H., Alós, J., Arlinghaus, R., Armstrong, M., Dorow, M., de Graaf, M., van der Hammen, T., Hyder, K., Levrel, H., Paulrud, A., Radtke, K., Rocklin, D., Sparrevohn, C. R., and Veiga, P. (2013). Unexpectedly high catch-and-release rates in European marine recreational fisheries: implications for science and management. ICES Journal of Marine Science, 70(7), 1319-1329.

Filous, A., Friedlander, A., Wolfe, B., Stamoulis, K., Scherrer, S., Wong, A., Stone, K., and Sparks, R. (2017). Movement patterns of reef predators in a small isolated 
marine protected area with implications for resource management. Marine Biology, 164(1), 2.

Fiske, P., Lund, R. A., and Hansen, L. P. (2005). Identifying fish farm escapees. In: Cadrin, S. X., Friedland, K. D., and Waldman, J. D. (eds), Stock Identification Methods. Elsevier Academic Press, Amsterdam, pp. 659-680.

Fleming, I. A. (1996). Reproductive strategies of Atlantic salmon: Ecology and evolution. Reviews in Fish Biology and Fisheries, 6(4), 379-416.

Fleming, I. A. (1998). Pattern and variability in the breeding system of Atlantic salmon (Salmo salar), with comparisons to other salmonids. Canadian Journal of Fisheries and Aquatic Sciences, 55(S1), 59-76.

Fleming, I. A., Hindar, K., Mjølnerød, I. B., Jonsson, B., Balstad, T., and Lamberg, A. (2000). Lifetime success and interactions of farm salmon invading a native population. Proceedings of the Royal Society of London B: Biological Sciences, 267(1452), 1517-1523.

Flik, G., Klaren, P. H., Van den Burg, E. H., Metz, J. R., and Huising, M. O. (2006). CRF and stress in fish. General and Comparative Endocrinology, 146(1), 36-44.

Fobert, E., Meining, P., Colotelo, A., O'Connor, C., and Cooke, S. J. (2009). Cut the line or remove the hook? An evaluation of sublethal and lethal endpoints for deeply hooked bluegill. Fisheries Research, 99(1), 38-46.

Foley, J. A., DeFries, R., Asner, G. P., Barford, C., Bonan, G., Carpenter, S. R., Chapin, F. S., Coe, M. T., Daily, G. C., Gibbs, H. K., Helkowski, J. H., Holloway, T., Howard, E. A., Kucharik, C. J., Monfreda, C., Patz, J. A., Prentice, I. C., 
Ramankutty, N., and Snyder, P. K. (2005). Global consequences of land use. Science, 309(5734), 570-574.

Folmar, L. C., and Dickhoff, W. W. (1980). The parr-smolt transformation (smoltification) and seawater adaptation in salmonids: A review of selected literature. Aquaculture, 21(1), 1-37.

Fonteneau, A., and Hallier, J. P. (2015). Fifty years of dart tag recoveries for tropical tuna: a global comparison of results for the western Pacific, eastern Pacific, Atlantic, and Indian Oceans. Fisheries Research, 163, 7-22.

Forseth, T., Barlaup, B. T., Finstad, B., Fiske, P., Gjøsæter, H., Falkegård, M., Hindar, A., Mo, T. A., Rikardsen, A. H., Thorstad, E. B., Vøllestad, L. A., and Wennevik, V. (2017). The major threats to Atlantic salmon in Norway. ICES Journal of Marine Science, 74(6), 1496-1513.

Frank, H. J., Mather, M. E., Smith, J. M., Muth, R. M., Finn, J. T., and McCormick, S. D. (2009). What is "fallback"?: metrics needed to assess telemetry tag effects on anadromous fish behavior. Hydrobiologia, 635(1), 237-249.

Frechette, D. M., Dugdale, S. J., Dodson, J. J., and Bergeron, N. E. (In Press). Understanding summertime thermal refuge use by adult Atlantic salmon using remote sensing, river temperature monitoring and acoustic telemetry. Canadian Journal of Fisheries and Aquatic Sciences, 00, 00-00.

Fretwell, S. D., and Lucas, H. L. (1969). On territorial behavior and other factors influencing habitat distribution in birds. Acta Biotheoretica, 19(1), 16-36. 
Fry F. E. J. (1971) The effect of environmental factors on the physiology of fish. In: Hoar, W. S., and Randall, D. J. (eds), Fish Physiology: Environmental Relations and Behavior. Academic Press, New York, pp. 1-98.

Gale, M. K., Hinch, S. G., and Donaldson, M. R. (2013). The role of temperature in the capture and release of fish. Fish and fisheries, 14(1), 1-33.

Garant, D., Dodson, J. J., and Bernatchez, L. (2000). Ecological determinants and temporal stability of the within-river population structure in Atlantic salmon (Salmo salar L.). Molecular Ecology, 9(5), 615-628.

Garant, D., Dodson, J. J., and Bernatchez, L. (2001). A genetic evaluation of mating system and determinants of individual reproductive success in Atlantic salmon (Salmo salar L.). Journal of Heredity, 92(2), 137-145.

García de Leániz, C., Caballero, P., Valero, E., Martinez, J. J., and Hawkins, A. D. (1992). Historical changes in some Spanish rod and line salmon, Salmo salar L. fisheries: why are large multi-sea winter fish becoming scarcer. Journal of Fish Biology, 41, 179.

Gargan, P. G., Stafford, T., Økland, F., and Thorstad, E. B. (2015). Survival of wild Atlantic salmon (Salmo salar) after catch and release angling in three Irish rivers. Fisheries Research, 161, 252-260.

Garrett, G. P. (2002). Behavioral modification of angling vulnerability in largemouth bass through selective breeding. American Fisheries Society Symposium, 31, 387392.

Gende, S. M., Edwards, R. T., Willson, M. F., and Wipfli, M. S. (2002). Pacific salmon in aquatic and terrestrial ecosystems. BioScience, 52(10), 917-928. 
Genovart, M., Negre, N., Tavecchia, G., Bistuer, A., Parpal, L., and Oro, D. (2010). The young, the weak and the sick: evidence of natural selection by predation. PLoS One, 5, e9774.

Gibson, A. J. F., Halfyard, E. A., Bradford, R. G., Stokesbury, M. J., and Redden, A. M. (2015). Effects of predation on telemetry-based survival estimates: insights from a study on endangered Atlantic salmon smolts. Canadian Journal of Fisheries and Aquatic Sciences, 72(5), 728-741.

Gingerich, A. J., Cooke, S. J., Hanson, K. C., Donaldson, M. R., Hasler, C. T., Suski, C. D., and Arlinghaus, R. (2007). Evaluation of the interactive effects of air exposure duration and water temperature on the condition and survival of angled and released fish. Fisheries Research, 86(2-3), 169-178.

Glebe, B. D., and Leggett, W. C. (1981). Latitudinal differences in energy allocation and use during the freshwater migrations of American shad (Alosa sapidissima) and their life history consequences. Canadian Journal of Fisheries and Aquatic Sciences, 38(7), 806-820.

Gleiss, A. C., Wilson, R. P., and Shepard, E. L. (2011). Making overall dynamic body acceleration work: on the theory of acceleration as a proxy for energy expenditure. Methods in Ecology and Evolution, 2(1), 23-33.

Glover, K. A., Pertoldi, C., Besnier, F., Wennevik, V., Kent, M., and Skaala, Ø. (2013). Atlantic salmon populations invaded by farmed escapees: quantifying genetic introgression with a Bayesian approach and SNPs. BMC Genetics, 14(1), 74.

Glover, K. A., Quintela, M., Wennevik, V., Besnier, F., Sørvik, A. G., and Skaala, Ø. (2012). Three decades of farmed escapees in the wild: a spatio-temporal analysis 
of Atlantic salmon population genetic structure throughout Norway. PloS One, $7(8)$, e43129.

Glover, K. A., Solberg, M. F., McGinnity, P., Hindar, K., Verspoor, E., Coulson, M. W., Hansen, M. M., Araki, H., Skaala, Ø., and Svåsand, T. (2017). Half a century of genetic interaction between farmed and wild Atlantic salmon: Status of knowledge and unanswered questions. Fish and Fisheries, 18(5), 890-927.

Gowans, A. R. D., Armstrong, J. D., and Priede, I. G. (1999). Movements of adult Atlantic salmon in relation to a hydroelectric dam and fish ladder. Journal of Fish Biology, 54(4), 713-726.

Grayson, K. L., and Wilbur, H. M. (2009). Sex-and context-dependent migration in a pond-breeding amphibian. Ecology, 90(2), 306-312.

Greenwood, P. J. (1980). Mating systems, philopatry and dispersal in birds and mammals. Animal Behaviour, 28(4), 1140-1162.

Grilli, G., Landgraf, G., Curtis, J., and Hynes, S. (In Press). A travel cost evaluation of the benefits of two destination salmon rivers in Ireland. Journal of Outdoor Recreation and Tourism, 00, 00-00.

Gross, M. R. (1984). Sunfish, salmon, and the evolution of alternative reproductive strategies and tactics in fishes. In: Potts, G., and Wootton, R. J. (eds), Fish Reproduction: Strategies and Tactics. Academic Press, London, pp. 55-75.

Gross, M. R. (1998). One species with two biologies: Atlantic salmon (Salmo salar) in the wild and in aquaculture. Canadian Journal of Fisheries and Aquatic Sciences, 55(S1), 131-144. 
Gubili, C., Johnson, R., Gennari, E., Oosthuizen, W. H., Kotze, D., Meÿer, M., Sims, D. W., Jones, C. S., and Noble, L. R. (2009). Concordance of genetic and fin photo identification in the great white shark, Carcharodon carcharias, off Mossel Bay, South Africa. Marine Biology, 156(10), 2199-2207.

Gudjonsson, S., Antonsson, T., and Tomasson, T. (1996). Exploitation ratio of salmon in relation to salmon run in three Icelandic rivers. ICES CM, 1000, 8.

Gustaveson, A. W., Wydoski, R. S., and Wedemeyer, G. A. (1991). Physiological response of largemouth bass to angling stress. Transactions of the American Fisheries Society, 120(5), 629-636.

Gutowsky, L. F. G., Stoot, L. J., Cairns, N. A., Thiem, J. D., Brownscombe, J. W., Danylchuk, A. J., Blouin-Demers, G. and Cooke, S. J. (2017). Biologgers reveal post-release behavioural impairments of freshwater turtles following interactions with fishing nets. Animal Conservation, 20(4), 350-359.

Halttunen, E., Gjelland, K. Ø., Glover, K. A., Johnsen, I. A., Serra-Llinares, R. M., Skaala, Ø., Nilsen, R., Bjørn, P.-A., Karlsson, Ø., Finstad, B. and Skilbrei, O. T. (2018). Migration of Atlantic salmon post-smolts in a fjord with high infestation pressure of salmon lice. Marine Ecology Progress Series, 592, 243-256.

Halttunen, E., Jensen, J. L. A., Næsje, T. F., Davidsen, J. G., Thorstad, E. B., Chittenden, C. M., Hamel, S., Primicerio, R., Havard, A., and Rikardsen, A. H. (2013). Statedependent migratory timing of postspawned Atlantic salmon (Salmo salar). Canadian Journal of Fisheries and Aquatic Sciences, 70(7), 1063-1071. 
Hansen, L. P., and Jacobsen, J. A. (2003). Origin and migration of wild and escaped farmed Atlantic salmon, Salmo salar L., in oceanic areas north of the Faroe Islands. ICES Journal of Marine Science, 60(1), 110-119.

Hansen, L. P., and Quinn, T. P. (1998). The marine phase of the Atlantic salmon (Salmo salar) life cycle, with comparisons to Pacific salmon. Canadian Journal of Fisheries and Aquatic Sciences, 55(S1), 104-118.

Hansen, M. J., Boisclair, D., Brandt, S. B., Hewett, S. W., Kitchell, J. F., Lucas, M. C., and Ney, J. J. (1993). Applications of bioenergetics models to fish ecology and management: where do we go from here? Transactions of the American Fisheries Society, 122(5), 1019-1030.

Hanson, K. C., Cooke, S. J., Suski, C. D., Niezgoda, G., Phelan, F. J. S., Tinline, R., and Philipp, D. P. (2007). Assessment of largemouth bass (Micropterus salmoides) behaviour and activity at multiple spatial and temporal scales utilizing a wholelake telemetry array. Hydrobiologia, 582(1), 243-256.

Hard, J. J., Gross, M. R., Heino, M., Hilborn, R., Kope, R. G., Law, R., and Reynolds, J. D. (2008). Evolutionary consequences of fishing and their implications for salmon. Evolutionary Applications, 1(2), 388-408.

Harrell, F. E. (2014). Hmisc: Harrell Miscellaneous. R package version3.14-6. http://CRAN.R-project.org/package=Hmisc

Harrell, F. E. (2015a). Regression Modeling Strategies: With Applications to Linear Models, Logistic Regression, and Survival Analysis. Springer, New York, NY. Harrell, F. E. (2015b). rms: Regression Modeling Strategies. R package version 4.5-0. https://CRAN.R-project.org/package=rms. 
Harrell, F. E., Lee, K. L., and Mark, D. B. (1996). Multivariable prognostic models: issues in developing models, evaluating assumptions and adequacy, and measuring and reducing errors. Statistics in Medicine, 15(4), 361-387.

Harrison, P. M., Gutowsky, L. F. G., Martins, E. G., Patterson, D. A., Cooke, S. J., and Power, M. (2014). Personality-dependent spatial ecology occurs independently from dispersal in wild burbot (Lota lota). Behavioral Ecology, 26(2), 483-492.

Harvell, C. D., Mitchell, C. E., Ward, J. R., Altizer, S., Dobson, A. P., Ostfeld, R. S., and Samuel, M. D. (2002). Climate warming and disease risks for terrestrial and marine biota. Science, 296(5576), 2158-2162.

Havn, T. B., Thorstad, E. B., Teichert, M. A., Sæther, S. A., Heermann, L., Hedger, R. D., Tambets, M., Diserud, O. H., Borcherding, J., and Økland, F. (2018). Hydropower-related mortality and behaviour of Atlantic salmon smolts in the River Sieg, a German tributary to the Rhine. Hydrobiologia, 805(1), 273-290. Havn, T. B., Uglem, I., Solem, Ø., Cooke, S. J., Whoriskey, F. G., and Thorstad, E. B. (2015). The effect of catch-and-release angling at high water temperatures on behaviour and survival of Atlantic salmon Salmo salar during spawning migration. Journal of Fish Biology, 87(2), 342-359.

Hawkins, A. D. and Smith, G. W. (1986). Radio-tracking observations on Atlantic salmon ascending the Aberdeenshire Dee. Scottish Fisheries Research Report 36, 24pp. Scottish Office, Edinburgh.

Heggberget, T. G. (1988). Timing of spawning in Norwegian Atlantic salmon (Salmo salar). Canadian Journal of Fisheries and Aquatic Sciences, 45(5), 845-849. 
Heggberget, T. G., Lund, R. A., Ryman, N., and Ståhl, G. (1986). Growth and genetic variation of Atlantic salmon (Salmo salar) from different sections of the River Alta, North Norway. Canadian Journal of Fisheries and Aquatic Sciences, 43(10), 1828-1835.

Heino, M., Pauli, B. D., and Dieckmann, U. (2015). Fisheries-induced evolution. Annual Review of Ecology, Evolution, and Systematics, 46, 461-480.

Hendry, A. P., and Beall, E. (2004). Energy use in spawning Atlantic salmon. Ecology of Freshwater Fish, 13(3), 185-196.

Hendry, A. P., and Berg, O. K. (1999). Secondary sexual characters, energy use, senescence, and the cost of reproduction in sockeye salmon. Canadian Journal of Zoology, 77, 1663-1675.

Hendry, A. P., Castric, V., Kinnison, M. T., Quinn, T. P., Hendry, A., and Stearns, S. (2004). The evolution of philopatry and dispersal. In: Hendry, A. P., and Stearns, S. (eds), Evolution Illuminated: Salmon and their Relatives. Oxford University Press, Oxford, pp. 52-91.

Heupel, M. R., Semmens, J. M., and Hobday, A. J. (2006). Automated acoustic tracking of aquatic animals: scales, design and deployment of listening station arrays. Marine and Freshwater Research, 57(1), 1-13.

Hewson, C. M., Thorup, K., Pearce-Higgins, J. W., and Atkinson, P. W. (2016). Population decline is linked to migration route in the Common Cuckoo. Nature Communications, 7, 12296.

Hinch, S. G., and Rand, P. S. (1998). Swim speeds and energy use of upriver-migrating sockeye salmon (Oncorhynchus nerka): role of local environment and fish 
characteristics. Canadian Journal of Fisheries and Aquatic Sciences, 55(8), 18211831.

Hinch, S. G., and Rand, P. S. (2000). Optimal swimming speeds and forward-assisted propulsion: energy-conserving behaviours of upriver-migrating adult salmon. Canadian Journal of Fisheries and Aquatic Sciences, 57(12), 2470-2478.

Hindar, K., C. García de Leániz, M. L. Koljonen, J. Tufto, and A. F. Youngson. (2007). Fisheries exploitation. In: Verspoor, E., Stradmeyer, L., and Nielsen, J. (eds), The Atlantic Salmon: Genetics, Conservation and Management. Wiley-Blackwell, Oxford, pp. 299-324.

Hindar, K., J. A. Hutchings, O. H. Diserud, and P. Fiske. (2010). Stock, recruitment and exploitation. In: Aas, Ø., Klemetsen, A., Einum, S., and Skurdal, J. (eds), Atlantic Salmon Ecology. Wiley-Blackwell Publishers, pp. 299-325.

Hodgson, S., and Quinn, T. P. (2002). The timing of adult sockeye salmon migration into fresh water: adaptations by populations to prevailing thermal regimes. Canadian Journal of Zoology, 80(3), 542-555.

Holmlund, C. M., and Hammer, M. (1999). Ecosystem services generated by fish populations. Ecological Economics, 29(2), 253-268.

Hosmer, D. W., Hosmer, T., Le Cessie, S., and Lemeshow, S. (1997). A comparison of goodness-of-fit tests for the logistic regression model. Statistics in medicine, 16(9), 965-980.

Hühn, D. and R. Arlinghaus. (2011). Determinants of hooking mortality in freshwater recreational fisheries: a quantitative meta-analysis. American Fisheries Society Symposium, 75, 141-170. 
Hulthén, K., Chapman, B. B., Nilsson, P. A., Vinterstare, J., Hansson, L. A., Skov, C., Brodersen, J., Baktoft, H., and Brönmark, C. (2015). Escaping peril: perceived predation risk affects migratory propensity. Biology Letters, 11(8), 20150466.

Huntingford, F.A. and Wright, P.J. (1989). How sticklebacks learn to avoid dangerous feeding patches. Behavioural Processes, 19, 181-189.

Hussey, N. E., Kessel, S. T., Aarestrup, K., Cooke, S. J., Cowley, P. D., Fisk, A. T., Harcourt, R. G., Holland, K. N., Iverson, S. J., Kocik, J. F., Mills Flemming, J. E., Whoriskey, F. G. (2015). Aquatic animal telemetry: a panoramic window into the underwater world. Science, 348(6240), 1255642.

Hutchings, J. A., and Fraser, D. J. (2008). The nature of fisheries-and farming-induced evolution. Molecular Ecology, 17(1), 294-313.

Hutchings, J. A., and Jones, M. E. (1998). Life history variation and growth rate thresholds for maturity in Atlantic salmon, Salmo salar. Canadian Journal of Fisheries and Aquatic Sciences, 55(S1), 22-47.

Hutchings, J. A., and Myers, R. A. (1988). Mating success of alternative maturation phenotypes in male Atlantic salmon, Salmo salar. Oecologia, 75(2), 169-174.

Hutchings, J. A., and Myers, R. A. (1993). Effect of age on the seasonality of maturation and spawning of Atlantic cod, Gadus morhua, in the Northwest Atlantic. Canadian Journal of Fisheries and Aquatic Sciences, 50(11), 2468-2474.

Hutchings, J. A., and Myers, R. A. (1994). The evolution of alternative mating strategies in variable environments. Evolutionary Ecology, 8(3), 256-268.

ICES. (2013). Report of the Working Group on North Atlantic Salmon, Copenhagen, Denmark, pp. 1-380. 
Järvi, T. (1990). The effects of male dominance, secondary sexual characteristics and female mate choice on the mating success of male Atlantic salmon Salmo salar. Ethology, 84(2), 123-132.

Jepsen, N., Thorstad, E. B., Havn, T., and Lucas, M. C. (2015). The use of external electronic tags on fish: an evaluation of tag retention and tagging effects. Animal Biotelemetry, 3(1), 49.

Johansen, M. (2001). Evidence of freshwater feeding by adult salmon in the Tana River, northern Norway. Journal of Fish Biology, 59(5), 1405-1407.

Johnstone, A. D. F., Lucas, M. C., Boylan, P., and Carter, T. J. (1992). Telemetry of tail beat frequency in Atlantic salmon, Salmo salar L., during spawning. In: Priede, L. M., and Swift, S. W. (eds), Wildlife Telemetry. Ellis Horwood, New York, pp. 456-465.

Jones, T., and Cresswell, W. (2010). The phenology mismatch hypothesis: are declines of migrant birds linked to uneven global climate change? Journal of Animal Ecology, 79(1), 98-108.

Jonsen, I. D., Flemming, J. M., and Myers, R. A. (2005). Robust state-space modeling of animal movement data. Ecology, 86(11), 2874-2880.

Jonsson, B., and Jonsson, N. (2009). A review of the likely effects of climate change on anadromous Atlantic salmon Salmo salar and brown trout Salmo trutta, with particular reference to water temperature and flow. Journal of Fish Biology, 75(10), 2381-2447.

Jonsson, B., and L'Abée-Lund, J. H. (1993). Latitudinal clines in life-history variables of anadromous brown trout in Europe. Journal of Fish Biology, 43(sA), 1-16. 
Jonsson, B., Jonsson, N., and Finstad, A. G. (2013). Effects of temperature and food quality on age and size at maturity in ectotherms: an experimental test with Atlantic salmon. Journal of Animal Ecology, 82(1), 201-210.

Jonsson, B., Jonsson, N., and Hansen, L. P. (2003). Atlantic salmon straying from the River Imsa. Journal of Fish Biology, 62(3), 641-657.

Jonsson, N., and Jonsson, B. (2004). Size and age of maturity of Atlantic salmon correlate with the North Atlantic Oscillation Index (NAOI). Journal of Fish Biology, 64(1), 241-247.

Jonsson, N., Hansen, L. P., and Jonsson, B. (1991a). Variation in age, size and repeat spawning of adult Atlantic salmon in relation to river discharge. The Journal of Animal Ecology, 60, 937-947.

Jonsson, N., Jonsson, B., and Hansen, L. P. (1991b). Energetic cost of spawning in male and female Atlantic salmon (Salmo salar L.). Journal of Fish Biology, 39(5), 739744.

Jonsson, N., Jonsson, B., and Hansen, L. P. (1997). Changes in proximate composition and estimates of energetic costs during upstream migration and spawning in Atlantic salmon Salmo salar. Journal of Animal Ecology, 425-436.

Joos, F., Prentice, I. C., Sitch, S., Meyer, R., Hooss, G., Plattner, G. K., Gerber, S. and Hasselmann, K. (2001). Global warming feedbacks on terrestrial carbon uptake under the Intergovernmental Panel on Climate Change (IPCC) emission scenarios. Global Biogeochemical Cycles, 15(4), 891-907.

Jordan, W. C., Youngson, A. F., Hay, D. W., and Ferguson, A. (1992). Genetic protein variation in natural populations of Atlantic salmon (Salmo salar) in Scotland: 
temporal and spatial variation. Canadian Journal of Fisheries and Aquatic Sciences, 49(9), 1863-1872.

Kadri, S., Metcalfe, N. B., Huntingford, F. A., and Thorpe, J. E. (1997). Daily feeding rhythms in Atlantic salmon II: size-related variation in feeding patterns of postsmolts under constant environmental conditions. Journal of Fish Biology, 50(92), 273-279.

Kadri, S., Metcalfe, N. B., Huntingford, F. A., and Thorpe, J. E. (1995). What controls the onset of anorexia in maturing adult female Atlantic salmon? Functional Ecology, 9, 790-797.

Karlsson, S., Diserud, O. H., Fiske, P., and Hindar, K. (2016). Widespread genetic introgression of escaped farmed Atlantic salmon in wild salmon populations. ICES Journal of Marine Science, 73(10), 2488-2498.

Karlsson, S., Moen, T., Lien, S., Glover, K. A., and Hindar, K. (2011). Generic genetic differences between farmed and wild Atlantic salmon identified from a 7K SNPchip. Molecular Ecology Resources, 11(s1), 247-253.

Karppinen, P., and Erkinaro, J. (2009). Using motion-sensitive radio tags to record the activity and behavioural patterns of spawning Atlantic salmon. Ecology of freshwater fish, 18(2), 177-182.

Karppinen, P., Erkinaro, J., Niemelä, E., Moen, K., and Økland, F. (2004). Return migration of one-sea-winter Atlantic salmon in the River Tana. Journal of Fish Biology, 64(5), 1179-1192. 
Kassahn, K. S., Crozier, R. H., Pörtner, H. O., and Caley, M. J. (2009). Animal performance and stress: responses and tolerance limits at different levels of biological organisation. Biological Reviews, 84(2), 277-292.

Katinic, P. J., Patterson, D. A., and Ydenberg, R. C. (2015). Thermal regime, predation danger and the early marine exit of sockeye salmon Oncorhynchus nerka. Journal of Fish Biology, 86(1), 276-287.

Kennedy, J. S. (1985). Migration: Behavioral and ecological. In: Rankin, M. A. (ed), Migration: Mechanisms and Adaptive Significance: Contributions in Marine Science, 27. Marine Science Institute, University of Texas, Austin, pp. 5-26.

Kieffer, J. D. (2000). Limits to exhaustive exercise in fish. Comparative Biochemistry and Physiology Part A: Molecular and Integrative Physiology, 126(2), 161-179.

Kiers, E. T., Leakey, R. R., Izac, A. M., Heinemann, J. A., Rosenthal, E., Nathan, D., and Jiggins, J. (2008). Agriculture at a crossroads. Science, 320(5874), 320.

King, G. D., Chapman, J. M., Cooke, S. J., and Suski, C. D. (2016). Stress in the neighborhood: tissue glucocorticoids relative to stream quality for five species of fish. Science of The Total Environment, 547, 87-94.

Kingsolver, J. G., and Huey, R. B. (2008). Size, temperature, and fitness: three rules. Evolutionary Ecology Research, 10(2), 251-268.

Klefoth, T., Pieterek, T., and Arlinghaus, R. (2013). Impacts of domestication on angling vulnerability of common carp, Cyprinus carpio: the role of learning, foraging behaviour and food preferences. Fisheries Management and Ecology, 20(2-3), 174-186. 
Klemetsen, A., Amundsen, P. A., Dempson, J. B., Jonsson, B., Jonsson, N., O'Connell, M. F., and Mortensen, E. (2003). Atlantic salmon Salmo salar L., brown trout Salmo trutta L. and Arctic charr Salvelinus alpinus (L.): a review of aspects of their life histories. Ecology of Freshwater Fish, 12(1), 1-59.

Kowalczyk, S., and Shankar, K. (2011). Data sharing in the sciences. Annual Review of Information Science and Technology, 45(1), 247-294.

Kristinsson, K. Ó., Gudbergsson, G., and Gislason, G. M. (2015). Variable migration and delay in two stock components of an Atlantic salmon population. Environmental Biology of Fishes, 98(6), 1513-1523.

Krumm, C. E., Conner, M. M., Hobbs, N. T., Hunter, D. O., and Miller, M. W. (2010). Mountain lions prey selectively on prion-infected mule deer. Biology Letters, 6(2), 209-211.

Kuparinen, A., Klefoth, T., and Arlinghaus, R. (2010). Abiotic and fishing-related correlates of angling catch rates in pike (Esox lucius). Fisheries Research, 105(2), 111-117.

Large, S. I., Fay, G., Friedland, K. D., and Link, J. S. (2015). Critical points in ecosystem responses to fishing and environmental pressures. Marine Ecology Progress Series, 521, 1-17.

Larsen, T. A., Hoffmann, S., Lüthi, C., Truffer, B., and Maurer, M. (2016). Emerging solutions to the water challenges of an urbanizing world. Science, 352(6288), 928-933.

Law, R. (2007). Fisheries-induced evolution: present status and future directions. Marine Ecology Progress Series, 335, 271-277. 
Le Cren, E. D. (1965). A note on the history of mark-recapture population estimates. Journal of Animal Ecology, 34, 453-454.

Lee, C. G., Devlin, R. H., and Farrell, A. P. (2003a). Swimming performance, oxygen consumption and excess post-exercise oxygen consumption in adult transgenic and ocean-ranched coho salmon. Journal of Fish Biology, 62(4), 753-766.

Lee, C. G., Farrell, A. P., Lotto, A., Hinch, S. G., and Healey, M. C. (2003b). Excess post-exercise oxygen consumption in adult sockeye (Oncorhynchus nerka) and coho (O. kisutch) salmon following critical speed swimming. Journal of Experimental Biology, 206(18), 3253-3260.

Lefevre, S., McKenzie, D. J., and Nilsson, G. E. (2017). Models projecting the fate of fish populations under climate change need to be based on valid physiological mechanisms. Global Change Biology, 23(9), 3449-3459.

Lennox, R. J. Engler-Palma, C., Kowarski, K., Filous, A., Whitlock, R., Cooke, S. J., and Auger-Méthé, M. (In Press, a). Optimizing marine spatial plans with animal tracking data. Canadian Journal of Fisheries and Aquatic Sciences, 00, 00-00.

Lennox, R. J., Aarestrup, K., Cooke, S. J., Cowley, P. D., Deng, Z. D., Fisk, A. T., Harcourt, R. G., Heupel, M., Hinch, S. G., Holland, K. N., Hussey, N. E., Iverson, S. J., Kessel, S. T., Kocik, J. F., Lucas, M. C., Mills Flemming, J., Nguyen, V. M., Stokesbury, M. J. W., Vagle, S., VanderSwaag, D. L., Whoriskey, F. G., and Young, N. (2017a). Envisioning the future of aquatic animal tracking: technology, science, and application. Bioscience, 67(10), 884-896.

Lennox, R. J., Alós, J., Arlinghaus, R., Horodysky, A., Klefoth, T., Monk, C. T., and Cooke, S. J. (2017b). What makes fish vulnerable to capture by hooks? A 
conceptual framework and a review of key determinants. Fish and Fisheries, 18(5), 986-1010.

Lennox, R. J., Brownscombe, J. W., Cooke, S. J., and Danylchuk, A. J. (In Press, b). Post-release behaviour and survival of recreationally-angled arapaima (Arapaima cf. arapaima) assessed with accelerometer biologgers. Fisheries Research, 00, 0000.

Lennox, R. J., Chapman, J. M., Souliere, C. M., Tudorache, C., Wikelski, M., Metcalfe, J. D., and Cooke, S. J. (2016a). Conservation physiology of animal migration. Conservation Physiology, 4(1), cov072.

Lennox, R. J., Falkegård, M., Vøllestad, L. A., Cooke, S. J., and Thorstad, E. B. (2016b). Influence of harvest restrictions on angler release behaviour and size selection in a recreational fishery. Journal of Environmental Management, 176, 139-148.

Lennox, R. J., Uglem, I., Cooke, S. J., Næsje, T. F., Whoriskey, F. G., Havn, T. B., Solem, Ø., Ulvan, M., and Thorstad, E. B. (2015). Does catch-and-release angling alter the behaviour and fate of adult Atlantic salmon during upriver migration? Transactions of the American Fisheries Society, 144(2), 400-409.

Lewis, W. M., and Flickinger, S. (1967). Home range tendency of the largemouth bass (Micropterus salmoides). Ecology, 48(6), 1020-1023.

Lima, S. L., and Dill, L. M. (1990). Behavioral decisions made under the risk of predation: a review and prospectus. Canadian journal of zoology, 68(4), 619-640.

Lorenz, K. Z. (1958). The evolution of behavior. Scientific American, 199(6), 67-82.

Lorenz, K. Z. (1981). The Foundations of Ethology. Springer, Vienna. 
Lucas, M. C., Johnstone, A. D., and Priede, I. G. (1993). Use of physiological telemetry as a method of estimating metabolism of fish in the natural environment. Transactions of the American Fisheries Society, 122(5), 822-833.

Lüdecke, D. (2016). sjstats: Statistical functions for regression Models. R package version 0.6.0, https://CRAN.R-project.org/package=sjstats.

Lund, R. A., and Hansel, L. P. (1991). Identification of wild and reared Atlantic salmon, Salmo salar L., using scale characters. Aquaculture Research, 22(4), 499-508. Lundberg, P. (1988). The evolution of partial migration in birds. Trends in Ecology and Evolution, 3(7), 172-175.

MacCrimmon, H. R., and Gots, B. L. (1979). World distribution of Atlantic salmon, Salmo salar. Journal of the Fisheries Board of Canada, 36(4), 422-457.

MacNutt, M. J., Hinch, S. G., Lee, C. G., Phibbs, J. R., Lotto, A. G., Healey, M. C., and Farrell, A. P. (2006). Temperature effects on swimming performance, energetics, and aerobic capacities of mature adult pink salmon (Oncorhynchus gorbuscha) compared with those of sockeye salmon (Oncorhynchus nerka). Canadian Journal of Zoology, 84(1), 88-97.

Mahlum, S. K., Vollset, K. W., Barlaup, B. T., Velle, G., and Wiers, T. (In Press). Where the salmon roam: fjord habitat use of adult Atlantic salmon. ICES Journal of Marine Science, 00, 00-00.

Mäkinen, T. S., Niemelä, E., Moen, K., and Lindström, R. (2000). Behaviour of gill-net and rod-captured Atlantic salmon (Salmo salar L.) during upstream migration and following radio tagging. Fisheries Research, 45(2), 117-127. 
Marten, G. G. (1970). A regression method for mark-recapture estimation of population size with unequal catchability. Ecology, 51(2), 291-295.

Martin, J., Tolon, V., Morellet, N., Santin-Janin, H., Licoppe, A., Fischer, C., Bombois, J., Patthey, P., Pesenti, E., Chenesseau, D., and Saïd, S. (2018). Common drivers of seasonal movements on the migration-residency behavior continuum in a large herbivore. Scientific Reports, 8(1), 7631.

Maxime, V., Peyraud-Waitzenergger, M., Claireaux, G., and Peyraud, C. (1990). Effects of rapid transfer from sea water to fresh water on respiratory variables, blood acid-base status and O 2 affinity of haemoglobin in Atlantic salmon (Salmo salar L.). Journal of Comparative Physiology B, 160(1), 31-39.

Maynard Smith, J. (1989). Evolutionary Genetics. Oxford University Press, New York. McCormick, S. D., Hansen, L. P., Quinn, T. P., and Saunders, R. L. (1998). Movement, migration, and smolting of Atlantic salmon (Salmo salar). Canadian Journal of Fisheries and Aquatic Sciences, 55(S1), 77-92.

McDowall, R. M. (2001). Anadromy and homing: two life-history traits with adaptive synergies in salmonid fishes? Fish and Fisheries, 2(1), 78-85.

McElroy, B., DeLonay, A., and Jacobson, R. (2012). Optimum swimming pathways of fish spawning migrations in rivers. Ecology, 93(1), 29-34.

McEwen, B. S., and Wingfield, J. C. (2003). The concept of allostasis in biology and biomedicine. Hormones and Behavior, 43(1), 2-15.

McEwen, B. S., and Wingfield, J. C. (2010). What's in a name? Integrating homeostasis, allostasis and stress. Hormones and Behavior, 57(2), 105. 
McGinnity, P., Prodöhl, P., Ferguson, A., Hynes, R., ó Maoiléidigh, N., Baker, N., Cotter, D., O’Hea, B., Cooke, D., Rogan, G., Taggart, J., and Cross, T. (2003). Fitness reduction and potential extinction of wild populations of Atlantic salmon, Salmo salar, as a result of interactions with escaped farm salmon. Proceedings of the Royal Society of London B: Biological Sciences, 270(1532), 2443-2450.

McGinnity, P., Stone, C., Taggart, J. B., Cooke, D., Cotter, D., Hynes, R., McCamley, C., Cross, T., and Ferguson, A. (1997). Genetic impact of escaped farmed Atlantic salmon (Salmo salar L.) on native populations: use of DNA profiling to assess freshwater performance of wild, farmed, and hybrid progeny in a natural river environment. ICES Journal of Marine Science, 54(6), 998-1008.

McLean, I. G. (1997). Conservation and the ontogeny of behaviour. In: Clemmons, J. R., and Buchholz, R. (eds), Behavioural Approaches to Conservation in the Wild. Cambridge University Press, Cambridge, pp. 132-156.

McNamara, J. M., and Houston, A. I. (1986). The common currency for behavioral decisions. The American Naturalist, 127(3), 358-378.

Meka, J. M. (2004). The influence of hook type, angler experience, and fish size on injury rates and the duration of capture in an Alaskan catch-and-release rainbow trout fishery. North American Journal of Fisheries Management, 24(4), 13091321.

Meka, J. M., and McCormick, S. D. (2005). Physiological response of wild rainbow trout to angling: impact of angling duration, fish size, body condition, and temperature. Fisheries Research, 72(2-3), 311-322. 
Messmer, V., Pratchett, M. S., Hoey, A. S., Tobin, A. J., Coker, D. J., Cooke, S. J., and Clark, T. D. (2017). Global warming may disproportionately affect larger adults in a predatory coral reef fish. Global Change Biology, 23(6), 2230-2240.

Millard, M. J., Welsh, S. A., Fletcher, J. W., Mohler, J., Kahnle, A., and Hattala, K. (2003). Mortality associated with catch and release of striped bass in the Hudson River. Fisheries Management and Ecology, 10(5), 295-300.

Milligan, C. L. (1996). Metabolic recovery from exhaustive exercise in rainbow trout. Comparative Biochemistry and Physiology Part A: Physiology, 113(1), 51-60.

Mills, D. (1989). Ecology and Management of Atlantic Salmon. Chapman and Hall, London.

Moe, K., Næsje, T. F., Haugen, T. O., Ulvan, E. M., Aronsen, T., Sandnes, T., and Thorstad, E. B. (2016). Area use and movement patterns of wild and escaped farmed Atlantic salmon before and during spawning in a large Norwegian river. Aquaculture Environment Interactions, 8, 77-88.

Moore, J. P. (1997). Energetics of spring and autumn run Atlantic salmon from the Ponoi River, Russia. M.Sc. Thesis, University of New Brunswick.

Moore, J. W., and Schindler, D. E. (2008). Biotic disturbance and benthic community dynamics in salmon-bearing streams. Journal of Animal Ecology, 77(2), 275-284.

Morales, J. M., and Ellner, S. P. (2002). Scaling up animal movements in heterogeneous landscapes: the importance of behavior. Ecology, 83(8), 2240-2247.

Morbey, Y. E., Brassil, C. E., and Hendry, A. P. (2005). Rapid senescence in Pacific salmon. The American Naturalist, 166(5), 556-568. 
Morita, K., Fukuwaka, M. A., Tanimata, N., and Yamamura, O. (2010). Size-dependent thermal preferences in a pelagic fish. Oikos, 119(8), 1265-1272.

Mote, P. W., Parson, E. A., Hamlet, A. F., Keeton, W. S., Lettenmaier, D., Mantua, N., Miles, E. L., Peterson, D. W., Peterson, D. L., and Snover, A. K. (2003). Preparing for climatic change: the water, salmon, and forests of the Pacific Northwest. Climatic Change, 61(1), 45-88.

Muoneke, M. I., and Childress, W. M. (1994). Hooking mortality: a review for recreational fisheries. Reviews in Fisheries Science, 2(2), 123-156.

Murchie, K. J., Cooke, S. J., Danylchuk, A. J., and Suski, C. D. (2011). Estimates of field activity and metabolic rates of bonefish (Albula vulpes) in coastal marine habitats using acoustic tri-axial accelerometer transmitters and intermittent-flow respirometry. Journal of Experimental Marine Biology and Ecology, 396(2), 147155.

Murray, D. L. (2006). On improving telemetry-based survival estimation. The Journal of Wildlife Management, 70(6), 1530-1543.

Nathan, R., Getz, W. M., Revilla, E., Holyoak, M., Kadmon, R., Saltz, D., and Smouse, P. E. (2008). A movement ecology paradigm for unifying organismal movement research. Proceedings of the National Academy of Sciences, 105(49), 1905219059.

Nettle, R. (1857). The Salmon Fisheries of the St. Lawrence and its Tributaries. Printed by J. Lovell, pp. 144.

Newbold, T., Hudson, L. N., Arnell, A. P., Contu, S., De Palma, A., Ferrier, S., Hill, S. L. L., Hoskins, A. J., Lysenko, I., Phillips, H. R. P., Burton, V. J., Chng, C. W. T., 
Emerson, S., Gao, D., Pask-Hale, G., Hutton, J., Jung, M., Sanchez-Ortiz, K., Simmons, B. I., Whitmee, S., Zhang, H., Scharlemann, J. P. W., and Purvis, A. (2016). Has land use pushed terrestrial biodiversity beyond the planetary boundary? A global assessment. Science, 353(6296), 288-291.

Nguyen, V. M., Rudd, M. A., Hinch, S. G., and Cooke, S. J. (2012). Differences in information use and preferences among recreational salmon anglers: implications for management initiatives to promote responsible fishing. Human Dimensions of Wildlife, 17(4), 248-256.

Nicola, G. G., Elvira, B., Jonsson, B., Ayllón, D., and Almodóvar, A. (2018). Local and global climatic drivers of Atlantic salmon decline in southern Europe. Fisheries Research, 198, 78-85.

Niemelä, E., Erkinaro, J., Julkunen, M., Hassinen, E., Länsman, M., and Brørs, S. (2006a). Temporal variation in abundance, return rate and life histories of previously spawned Atlantic salmon in a large subarctic river. Journal of Fish Biology, 68(4), 1222-1240.

Niemelä, E., Orell, P., Erkinaro, J., Dempson, J. B., Brørs, S., Svenning, M. A., and Hassinen, E. (2006b). Previously spawned Atlantic salmon ascend a large subarctic river earlier than their maiden counterparts. Journal of Fish Biology, 69(4), 1151-1163.

Nosil, P., Vines, T. H., and Funk, D. J. (2005). Reproductive isolation caused by natural selection against immigrants from divergent habitats. Evolution, 59(4), 705-719. 
O'Brien, K., Sygna, L., and Haugen, J. E. (2004). Vulnerable or resilient? A multi-scale assessment of climate impacts and vulnerability in Norway. Climatic Change, 64(1-2), 193-225.

Økland, F., Erkinaro, J., Moen, K., Niemelä, E., Fiske, P., McKinley, R. S., and Thorstad, E. B. (2001). Return migration of Atlantic salmon in the River Tana: phases of migratory behaviour. Journal of Fish Biology, 59(4), 862-874.

Økland, F., Heggberget, T. G., and Jonsson, B. (1995). Migratory behaviour of wild and farmed Atlantic salmon (Salmo salar) during spawning. Journal of Fish Biology, 46(1), 1-7.

Olaussen, J. O. (2016). Catch-and-release and angler utility: evidence from an Atlantic salmon recreational fishery. Fisheries Management and Ecology, 23(3-4), 253263.

Olaussen, J. O., and Liu, Y. (2011). On the willingness-to-pay for recreational fishingEscaped farmed versus wild Atlantic Salmon. Aquaculture Economics and Management, 15(4), 245-261.

Olaussen, J. O., and Skonhoft, A. (2008). A bioeconomic analysis of a wild Atlantic salmon (Salmo salar) recreational fishery. Marine Resource Economics, 23(3), 273-293.

Orell, P., and Erkinaro, J. (2007). Snorkelling as a method for assessing spawning stock of Atlantic salmon, Salmo salar. Fisheries Management and Ecology, 14(3), 199208.

Otero, J., L’Abee-Lund, J. H., Castro-Santos, T., Leonardsson, K., Storvik, G. O., Jonsson, B., Dempson, B., Russell, I. C., Jensen, A. J., Bagliniere, J. L., Dionne, 
M., Armstrong, J. D., Romakkaniemi, A., Letcher, B. H., Kocik, J. F., Erkinaro, J., Poole, R., Rogan, G., Lundqvist, H., MacLean, J. C., Jokikokko, E., Arnekleiv, J. V., Kennedy, R. J., Niemelä, E., Caballero, P., Music, P. A., Antonsson, T., Gudjonsson, S., Veselov, A. E., Lamberg, A., Groom, S., Taylor, B. H., Taberner, M., Dillane, M., Arnason, F., Horton, G., Hvidsten, N.A., Jonsson, I.R., Jonsson, N., McKelvey, S., Næsje, T. F., Skaala, O., Smith, G. W., Saegrov, H., Stenseth, N. C., Vøllestad, L. A (2014) Basin-scale phenology and effects of climate variability on global timing of initial seaward migration of Atlantic salmon (Salmo salar). Global Change Biology 20(1), 61-75.

Ovidio, M., Philippart, J. C., and Baras, É. (2001). Methodological bias in home range and mobility estimates when locating radio-tagged trout, Salmo trutta, at different time intervals. Aquatic Living Resources, 13(6), 449-454.

Owen-Smith, N., Fryxell, J. M., and Merrill, E. H. (2010). Foraging theory upscaled: the behavioural ecology of herbivore movement. Philosophical Transactions of the Royal Society of London B: Biological Sciences, 365(1550), 2267-2278.

Pankhurst, N. W. (2011). The endocrinology of stress in fish: an environmental perspective. General and comparative endocrinology, 170(2), 265-275.

Papastamatiou, Y. P., Lowe, C. G., Caselle, J. E., and Friedlander, A. M. (2009). Scaledependent effects of habitat on movements and path structure of reef sharks at a predator-dominated atoll. Ecology, 90(4), 996-1008.

Parr, C. S., and Cummings, M. P. (2005). Data sharing in ecology and evolution. Trends in Ecology and Evolution, 20(7), 362-363. 
Parrish, D. L., Behnke, R. J., Gephard, S. R., McCormick, S. D., and Reeves, G. H. (1998). Why aren't there more Atlantic salmon (Salmo salar)? Canadian Journal of Fisheries and Aquatic Sciences, 55(S1), 281-287.

Payne, N. L., Taylor, M. D., Watanabe, Y. Y., and Semmens, J. M. (2014). From physiology to physics: are we recognizing the flexibility of biologging tools? Journal of Experimental Biology, 217(3), 317-322.

Peiman, K. S., Birnie-Gauvin, K., Midwood, J. D., Larsen, M. H., Wilson, A. D., Aarestrup, K., and Cooke, S. J. (2017). If and when: intrinsic differences and environmental stressors influence migration in brown trout (Salmo trutta). Oecologia, 184(2), 375-384.

Pérez, J., J. I. Izquierdo, J. de la Hoz, and E. Garcia-Vazquez. 2005. Female biased angling harvests of Atlantic salmon in Spain. Fisheries Research 74:127-133.

Perrier, C., Normandeau, É., Dionne, M., Richard, A., and Bernatchez, L. (2014). Alternative reproductive tactics increase effective population size and decrease inbreeding in wild Atlantic salmon. Evolutionary Applications, 7(9), 1094-1106.

Persson, P., Sundell, K., Björnsson, B. T., and Lundqvist, H. (1998). Calcium metabolism and osmoregulation during sexual maturation of river running Atlantic salmon. Journal of Fish Biology, 52(2), 334-349.

Petersen, J. H., and Kitchell, J. F. (2001). Climate regimes and water temperature changes in the Columbia River: bioenergetic implications for predators of juvenile salmon. Canadian Journal of Fisheries and Aquatic Sciences, 58(9), 1831-1841. 
Philipp, D. P., Cooke, S. J., Claussen, J. E., Koppelman, J. B., Suski, C. D., and Burkett, D. P. (2009). Selection for vulnerability to angling in largemouth bass. Transactions of the American Fisheries Society, 138(1), 189-199.

Piché, J., Hutchings, J. A., and Blanchard, W. (2008). Genetic variation in threshold reaction norms for alternative reproductive tactics in male Atlantic salmon, Salmo salar. Proceedings of the Royal Society of London B: Biological Sciences, 275(1642), 1571-1575.

Pickering, A. D., Pottinger, T. G., and Christie, P. (1982). Recovery of the brown trout, Salmo trutta L., from acute handling stress: a time-course study. Journal of Fish Biology, 20(2), 229-244.

Pickering, A. D., Pottinger, T. G., Carragher, J., and Sumpter, J. P. (1987). The effects of acute and chronic stress on the levels of reproductive hormones in the plasma of mature male brown trout, Salmo trutta L. General and Comparative Endocrinology, 68(2), 249-259.

Pinheiro, J., Bates, D., DebRoy, S., Sarkar, D., and R Core Team. (2014). nlme: Linear and Nonlinear Mixed Effects Models_. R package version 3.1-128, <URL: http://CRAN.R-project.org/package=nlme>.

Pinheiro, J., Bates, D., DebRoy, S., Sarkar, D., and R Core Team. (2017). nlme: Linear and Nonlinear Mixed Effects Models_. R package version 3.1-128, <URL: http://CRAN.R-project.org/package=nlme> .

Policansky, D. (2002). Catch-and-release recreation fishing: a historical perspective. In: Recreational Fisheries: Ecological, Economic and Social Evaluation. (eds T.J. Pitcher and C. Hollingworth). Blackwell Science, Oxford, pp. 74-94. 
Pollock, K. H., Hoenig, J. M., Hearn, W. S., and Calingaert, B. (2001). Tag reporting rate estimation: 1. An evaluation of the high-reward tagging method. North American Journal of Fisheries Management, 21(3), 521-532.

Pollock, K. H., Jiang, H., and Hightower, J. E. (2004). Combining telemetry and fisheries tagging models to estimate fishing and natural mortality rates. Transactions of the American Fisheries Society, 133(3), 639-648.

Pomeroy, R. S., and Berkes, F. (1997). Two to tango: the role of government in fisheries co-management. Marine Policy, 21(5), 465-480.

Pörtner, H. O. (2002). Climate variations and the physiological basis of temperature dependent biogeography: systemic to molecular hierarchy of thermal tolerance in animals. Comparative Biochemistry and Physiology Part A: Molecular and Integrative Physiology, 132(4), 739-761.

Pörtner, H. O., and Knust, R. (2007). Climate change affects marine fishes through the oxygen limitation of thermal tolerance. Science, 315(5808), 95-97.

Power, G. (1981). Stock characteristics and catches of Atlantic salmon (Salmo salar) in Quebec, and Newfoundland and Labrador in relation to environmental variables. Canadian Journal of Fisheries and Aquatic Sciences, 38(12), 1601-1611.

Priede, I. G. (1977). Natural selection for energetic efficiency and the relationship between activity level and mortality. Nature, 267, 610-611.

Prowse, T. D., Wrona, F. J., Reist, J. D., Gibson, J. J., Hobbie, J. E., Lévesque, L. M., and Vincent, W. F. (2006). Climate change effects on hydroecology of Arctic freshwater ecosystems. AMBIO: A Journal of the Human Environment, 35(7), 347-358. 
Putman, N. F., Jenkins, E. S., Michielsens, C. G., and Noakes, D. L. (2014). Geomagnetic imprinting predicts spatio-temporal variation in homing migration of pink and sockeye salmon. Journal of The Royal Society Interface, 11(99), 20140542.

Pyke, G. H., Pulliam, H. R., and Charnov, E. L. (1977). Optimal foraging: a selective review of theory and tests. The Quarterly Review of Biology, 52(2), 137-154.

Quinn, T. P., McGinnity, P., and Cross, T. F. (2006). Long-term declines in body size and shifts in run timing of Atlantic salmon in Ireland. Journal of Fish Biology, 68(6), $1713-1730$.

Quinn, T. P., McGinnity, P., and Reed, T. E. (2015). The paradox of "premature migration" by adult anadromous salmonid fishes: patterns and hypotheses. Canadian Journal of Fisheries and Aquatic Sciences, 73(7), 1015-1030.

R Core Team (2014). R: A language and environment for statistical computing. $R$ Foundation for Statistical Computing, Vienna, Austria. URL https://www.Rproject.org/.

R Core Team (2016). R: A language and environment for statistical computing. $R$ Foundation for Statistical Computing, Vienna, Austria. URL https://www.Rproject.org/.

R Core Team (2017). R: A language and environment for statistical computing. $R$ Foundation for Statistical Computing, Vienna, Austria. URL https://www.Rproject.org/.

Raat, A. J. P. (1985). Analysis of angling vulnerability of common carp, Cyprinus carpio L., in catch-and-release angling in ponds. Aquaculture Research, 16(2), 171-187. 
Raby, G. D., Clark, T. D., Farrell, A. P., Patterson, D. A., Bett, N. N., Wilson, S. M., Willmore, W. G., Suski, C. D., Hinch, S. G., and Cooke, S. J. (2015). Facing the river gauntlet: understanding the effects of fisheries capture and water temperature on the physiology of coho salmon. PLoS One, 10(4), e0124023.

Raby, G. D., Cooke, S. J., Cook, K. V., McConnachie, S. H., Donaldson, M. R., Hinch, S. G., Drenner, M., Patterson, D. A., Clark, T. D., and Farrell, A. P. (2013). Resilience of pink salmon and chum salmon to simulated fisheries capture stress incurred upon arrival at spawning grounds. Transactions of the American Fisheries Society, 142(2), 524-539.

Raby, G. D., Packer, J. R., Danylchuk, A. J., and Cooke, S. J. (2014). The understudied and underappreciated role of predation in the mortality of fish released from fishing gears. Fish and Fisheries, 15(3), 489-505.

Radomski, P. J., Grant, G. C., Jacobson, P. C., and Cook, M. F. (2001). Visions for recreational fishing regulations. Fisheries, 26(5), 7-18.

Railsback, S. F., Lamberson, R. H., Harvey, B. C., and Duffy, W. E. (1999). Movement rules for individual-based models of stream fish. Ecological Modelling, 123(2-3), $73-89$.

Rand, P. S., Hinch, S. G., Morrison, J., Foreman, M. G. G., MacNutt, M. J., Macdonald, J. S., Healey, M. C., Farrell, A. P., and Higgs, D. A. (2006). Effects of river discharge, temperature, and future climates on energetics and mortality of adult migrating Fraser River sockeye salmon. Transactions of the American Fisheries Society, 135(3), 655-667. 
Real, L. A. (1992). Information processing and the evolutionary ecology of cognitive architecture. The American Naturalist, 140, S108-S145.

Reed, J. M., and Dobson, A. P. (1993). Behavioural constraints and conservation biology: conspecific attraction and recruitment. Trends in Ecology and Evolution, 8(7), 253-256.

Reid, J. E., and Chaput, G. (2012). Spawning history influence on fecundity, egg size, and egg survival of Atlantic salmon (Salmo salar) from the Miramichi River, New Brunswick, Canada. ICES Journal of Marine Science, 69(9), 1678-1685.

Richard, A., Bernatchez, L., Valiquette, E., and Dionne, M. (2014). Telemetry reveals how catch and release affects prespawning migration in Atlantic salmon (Salmo salar). Canadian Journal of Fisheries and Aquatic Sciences, 71(11), 1730-1739.

Richard, A., Dionne, M., Wang, J., and Bernatchez, L. (2013). Does catch and release affect the mating system and individual reproductive success of wild Atlantic salmon (Salmo salar L.)? Molecular Ecology, 22(1), 187-200.

Robinson, R. A., Crick, H. Q., Learmonth, J. A., Maclean, I., Thomas, C. D., Bairlein, F., Forchhammer, M. C., Francis, C. M., Gill, J. A., Godley, B. J., Harwood, J., Hays, G. C., Huntley, B., Hutson, A. M., Pierce, G. J., Rehfisch, M. M., Sims, D. W., Santos, M. B., Sparks, T. H., Stroud, D. A., and Visser, M. E. (2009). Travelling through a warming world: climate change and migratory species. Endangered Species Research, 7(2), 87-99.

Rockström, J., Steffen, W., Noone, K., Persson, Å., Chapin III, F. S., Lambin, E. F., Lenton, T. M., Scheffer, M., Folke, K., Schellnhuber, H. J., Nykvist, B., de Wit, C. A., Hughes, T., van der Leeuw, S., Rodhe, H., Sörlin, S., Snyder, P. K., 
Costanza, R., Svedin, U., Falkenmark, M., Karlberg, L., Corell, R. W., Fabry, V. J., Hansen, J., Walker, B., Liverman, D., Richardson, K., Crutzen, P., and Foley, J. A. (2009). A safe operating space for humanity. Nature, 461(7263), 472.

Romero, L. M. (2004). Physiological stress in ecology: lessons from biomedical research. Trends in Ecology and Evolution, 19(5), 249-255.

Rosewarne, P. J., Wilson, J. M., and Svendsen, J. C. (2016). Measuring maximum and standard metabolic rates using intermittent-flow respirometry: a student laboratory investigation of aerobic metabolic scope and environmental hypoxia in aquatic breathers. Journal of Fish Biology, 88(1), 265-283.

Rummer, J. L., Couturier, C. S., Stecyk, J. A., Gardiner, N. M., Kinch, J. P., Nilsson, G. E., and Munday, P. L. (2014). Life on the edge: thermal optima for aerobic scope of equatorial reef fishes are close to current day temperatures. Global Change Biology, 20(4), 1055-1066.

Sand, H., Wikenros, C., Ahlqvist, P., Strømseth, T. H., and Wabakken, P. (2012). Comparing body condition of moose (Alces alces) selected by wolves (Canis lupus) and human hunters: consequences for the extent of compensatory mortality. Canadian Journal of Zoology, 90(3), 403-412.

Santos, G. A., Schrama, J. W., Mamauag, R. E. P., Rombout, J. H. W. M., and Verreth, J. A. J. (2010). Chronic stress impairs performance, energy metabolism and welfare indicators in European seabass (Dicentrarchus labrax): the combined effects of fish crowding and water quality deterioration. Aquaculture, 299(1-4), 73-80. 
Sapolsky, R. M., Romero, L. M., and Munck, A. U. (2000). How do glucocorticoids influence stress responses? Integrating permissive, suppressive, stimulatory, and preparative actions. Endocrine Reviews, 21(1), 55-89.

Satterfield, D. A., Maerz, J. C., and Altizer, S. (2015). Loss of migratory behaviour increases infection risk for a butterfly host. Proceedings of the Royal Society of London B: Biological Sciences, 282(1801), 20141734.

Saunders, R. L., and Schom, C. B. (1985). Importance of the variation in life history parameters of Atlantic salmon (Salmo salar). Canadian Journal of Fisheries and Aquatic Sciences, 42(3), 615-618.

Saura, M., Moran, P., Brotherstone, S., Caballero, A., Alvarez, J., and Villanueva, B. (2010). Predictions of response to selection caused by angling in a wild population of Atlantic salmon (Salmo salar). Freshwater Biology, 55(4), 923-930.

Scarabello, M., Heigenhauser, G. J. F., and Wood, C. M. (1991). The oxygen debt hypothesis in juvenile rainbow trout after exhaustive exercise. Respiration Physiology, 84(2), 245-259.

Schick, R. S., Loarie, S. R., Colchero, F., Best, B. D., Boustany, A., Conde, D. A., Halpin, P. N., Joppa, L. N., McClellan, C. M., and Clark, J. S. (2008). Understanding movement data and movement processes: current and emerging directions. Ecology Letters, 11(12), 1338-1350.

Schreck, C. B. (1990). Physiological, behavioral, and performance indicators of stress. American Fisheries Society Symposium, 8, 29-37.

Schreck, C. B., Olla, B. L. and Davis, M. W. (1997). Behavioral responses to stress. In: Iwama, G. K., Pickering, A. G., Sumpter, J. P., and Schreck, C. B. (eds), Fish 
Stress and Health in Aquaculture (Society for Experimental Biology Seminar Series), vol. 62. Cambridge: Cambridge University Press, pp. 145-170.

Shearer, W. M. (1990). The Atlantic salmon (Salmo salar L.) of the North Esk with particular reference to the relationship between both river and sea age and time of return to home waters. Fisheries Research, 10(1-2), 93-123.

Sheridan, J. A., and Bickford, D. (2011). Shrinking body size as an ecological response to climate change. Nature Climate Change, 1(8), 401.

Simon, M., Johnson, M., and Madsen, P. T. (2012). Keeping momentum with a mouthful of water: behavior and kinematics of humpback whale lunge feeding. Journal of Experimental Biology, 215(21), 3786-3798.

Sims, D. W., Wearmouth, V. J., Genner, M. J., Southward, A. J., and Hawkins, S. J. (2004). Low-temperature-driven early spawning migration of a temperate marine fish. Journal of Animal Ecology, 73(2), 333-341.

Skaala, Ø., Glover, K. A., Barlaup, B. T., Svåsand, T., Besnier, F., Hansen, M. M., and Borgstrøm, R. (2012). Performance of farmed, hybrid, and wild Atlantic salmon (Salmo salar) families in a natural river environment. Canadian Journal of Fisheries and Aquatic Sciences, 69(12), 1994-2006.

Slater, L. E. (1963). Bio-telemetry: The Use of Telemetry in Animal Behavior and Physiology in Relation to Ecological Problems. Pergamon Press, Oxford.

Smith, G. W., Campbell, R. N. B., and MacLaine, J. S. (1998). Regurgitation rates of intragastric transmitters by adult Atlantic salmon (Salmo salar L.) during riverine migration. Hydrobiologia, 371, 117-121. 
Sopinka, N. M., Donaldson, M. R., O’Connor, C. M., Suski, C. D., and Cooke, S. J. (2016). Stress indicators in fish. In: Schreck, C. B., Tort, L., Farrell, A. P., and Brauner, C. J. (eds), Fish Physiology, Vol. 35, Biology of Stress in Fish. Academic Press, Amsterdam, pp. 405-462

Sopinka, N. M., Hinch, S. G., Middleton, C. T., Hills, J. A., and Patterson, D. A. (2014). Mother knows best, even when stressed? Effects of maternal exposure to a stressor on offspring performance at different life stages in a wild semelparous fish. Oecologia, 175(2), 493-500.

Soulé, M. E. (1985). What is conservation biology? BioScience, 35(11), 727-734. Spitler, R. J. (1998). Animal rights essay--The animal rights movement and fisheries: They're heeeeere!. Fisheries-Bulletin of the American Fisheries Society, 23(1), 21-22.

Standen, E. M., Hinch, S. G., Healey, M. C., and Farrell, A. P. (2002). Energetic costs of migration through the Fraser River Canyon, British Columbia, in adult pink (Oncorhynchus gorbuscha) and sockeye (Oncorhynchus nerka) salmon as assessed by EMG telemetry. Canadian Journal of Fisheries and Aquatic Sciences, 59(11), 1809-1818.

Steffensen, J. F., Bushnell, P. G., and Schurmann, H. (1994). Oxygen consumption in four species of teleosts from Greenland: no evidence of metabolic cold adaptation. Polar Biology, 14(1), 49-54.

Steinhausen, M. F., Sandblom, E., Eliason, E. J., Verhille, C., and Farrell, A. P. (2008). The effect of acute temperature increases on the cardiorespiratory performance of 
resting and swimming sockeye salmon (Oncorhynchus nerka). Journal of Experimental Biology, 211(24), 3915-3926.

Stensland, S., Aas, Ø., and Mehmetoglu, M. (2013). The influence of norms and consequences on voluntary catch and release angling behavior. Human dimensions of wildlife, 18(5), 373-385.

Stensland, S., and Baardsen, S. (2012). The effects of property and landowner characteristics on profit efficiency in salmon angling tourism in Norway. Journal of Sustainable Tourism, 20(4), 627-644.

Stewart, A. M., Keith, D., and Scottie, J. (2004). Caribou crossings and cultural meanings: Placing traditional knowledge and archaeology in context in an Inuit landscape. Journal of Archaeological Method and Theory, 11(2), 183-211.

Steyerberg, E. W., Vickers, A. J., Cook, N. R., Gerds, T., Gonen, M., Obuchowski, N., Pencina, M. J., and Kattan, M. W. (2010). Assessing the performance of prediction models: a framework for some traditional and novel measures. Epidemiology (Cambridge, Mass.), 21(1), 128.

Strøm, J. F., Thorstad, E. B., Chafe, G., Sørbye, S. H., Righton, D., Rikardsen, A. H., and Carr, J. (2017). Ocean migration of pop-up satellite archival tagged Atlantic salmon from the Miramichi River in Canada. ICES Journal of Marine Science, 74(5), 1356-1370.

Strøm, J. F., Thorstad, E. B., Hedger, R. D., and Rikardsen, A. H. (2018). Revealing the full ocean migration of individual Atlantic salmon. Animal Biotelemetry, 6(1), 2.

Sutherland, W. J. (1998). The importance of behavioural studies in conservation biology. Animal Behaviour, 56(4), 801-809. 
Sutherland, W. J., Pullin, A. S., Dolman, P. M., and Knight, T. M. (2004). The need for evidence-based conservation. Trends in Ecology and Evolution, 19(6), 305-308.

Svenning, M. A., Lamberg, A., Dempson, B., Strand, R., Hanssen, Ø. K., and Fauchald, P. (2017). Incidence and timing of wild and escaped farmed Atlantic salmon (Salmo salar) in Norwegian rivers inferred from video surveillance monitoring. Ecology of Freshwater Fish, 26(3), 360-370.

Taggart, J. B., McLaren, I. S., Hay, D. W., Webb, J. H., and Youngson, A. F. (2001). Spawning success in Atlantic salmon (Salmo salar L.): a long-term DNA profiling-based study conducted in a natural stream. Molecular Ecology, 10(4), 1047-1060.

Teichert, M. A., Foldvik, A., Forseth, T., Ugedal, O., Einum, S., Finstad, A. G., Hedger, R. D., and Bellier, E. (2010). Effects of spawning distribution on juvenile Atlantic salmon (Salmo salar) density and growth. Canadian Journal of Fisheries and Aquatic Sciences, 68(1), 43-50.

Tenopir, C., Allard, S., Douglass, K., Aydinoglu, A. U., Wu, L., Read, E., Manoff, M., and Frame, M. (2011). Data sharing by scientists: practices and perceptions. PloS One, 6(6), e21101.

Tentelier, C., Larranaga, N., Lepais, O., Manicki, A., Rives, J., and Lange, F. (2016). Space use and its effects on reproductive success of anadromous Atlantic salmon. Canadian Journal of Fisheries and Aquatic Sciences, 73(10), 1461-1471.

Thiem, J. D., Hatry, C., Brownscombe, J. W., Cull, F., Shultz, A. D., Danylchuk, A. J., and Cooke, S. J. (2013). Evaluation of radio telemetry to study the spatial ecology 
of checkered puffers (Sphoeroides testudineus) in shallow tropical marine systems. Bulletin of Marine Science, 89(2), 559-569.

Thorley, J. L., Youngson, A. F., and Laughton, R. (2007). Seasonal variation in rod recapture rates indicates differential exploitation of Atlantic salmon, Salmo salar, stock components. Fisheries Management and Ecology, 14(3), 191-198.

Thorpe, J. E., Mangel, M., Metcalfe, N. B., and Huntingford, F. A. (1998). Modelling the proximate basis of salmonid life-history variation, with application to Atlantic salmon, Salmo salar L. Evolutionary Ecology, 12(5), 581-599.

Thorstad, E. B., Forseth, T., Aasestad, I., Økland, F., and Johnsen, B. O. (2005). In situ avoidance response of adult Atlantic salmon to waste from the wood pulp industry. Water, Air, and Soil Pollution, 165(1-4), 187-194.

Thorstad, E. B., Heggberget, T. G., and Økland, F. (1998). Migratory behaviour of adult wild and escaped farmed Atlantic salmon, Salmo salar L., before, during and after spawning in a Norwegian river. Aquaculture Research, 29(6), 419-428.

Thorstad, E. B., Næsje, T. F., and Leinan, I. (2007). Long-term effects of catch-andrelease angling on ascending Atlantic salmon during different stages of spawning migration. Fisheries Research, 85(3), 316-320.

Thorstad, E. B., Økland, F., Aarestrup, K., and Heggberget, T. G. (2008). Factors affecting the within-river spawning migration of Atlantic salmon, with emphasis on human impacts. Reviews in Fish Biology and Fisheries, 18(4), 345-371.

Thorstad, E. B., Økland, F., and Finstad, B. (2000). Effects of telemetry transmitters on swimming performance of adult Atlantic salmon. Journal of Fish Biology, 57(2), $531-535$. 
Thorstad, E. B., Rikardsen, A. H., Alp, A., and Økland, F. (2013). The use of electronic tags in fish research—an overview of fish telemetry methods. Turkish Journal of Fisheries and Aquatic Sciences, 13, 881-896.

Thorstad, E.B., Whoriskey, F.G., Rikardsen, A.H. and Aarestrup, K. (2011). Aquatic nomads: the life and migrations of the Atlantic salmon. In: Aas, Ø., Einum, S., Klemetsen, A. and Skurdal, J. (eds), Atlantic Salmon Ecology. Wiley-Blackwell, Oxford, pp. 1-32.

Tinbergen, N. (1963). On aims and methods of ethology. Zeitschrift für Tierpsychologie, $20,410-433$.

Trefethen, P. S. (1956). Sonic equipment for tracking individual fish. US Department of the Interior, Fish and Wildlife Service, 179, $11 \mathrm{pp.}$

Tsuboi, J. I., and Morita, K. (2004). Selectivity effects on wild white-spotted charr (Salvelinus leucomaenis) during a catch and release fishery. Fisheries Research, 69, 229-238.

Tsuda, Y., Kawabe, R., Tanaka, H., Mitsunaga, Y., Hiraishi, T., Yamamoto, K., and Nashimoto, K. (2006). Monitoring the spawning behaviour of chum salmon with an acceleration data logger. Ecology of Freshwater Fish, 15(3), 264-274.

Tufts, B. L., Davidson, K., and Bielak, A. T. (2000). Biological implications of "catchand-release" angling of Atlantic salmon. In: Whoriskey, F. G., and Whelan, K. B. Managing Wild Atlantic Salmon - New Challenges, New Techniques. Atlantic Salmon Federation, St. Andrews, New Brunswick, pp. 100-138.

Tufts, B. L., Holden, J., and DeMille, M. (2015). Benefits arising from sustainable use of North America's fishery resources: economic and conservation impacts of 
recreational angling. International Journal of Environmental Studies, 72(5), 850868.

Tufts, B. L., Tang, Y., Tufts, K., and Boutilier, R. G. (1991). Exhaustive exercise in "wild" Atlantic salmon (Salmo salar): Acid-base regulation and blood gas transport. Canadian Journal of Fisheries and Aquatic Sciences, 48(5), 868-874.

Tuomainen, U., and Candolin, U. (2011). Behavioural responses to human-induced environmental change. Biological Reviews, 86(3), 640-657.

Turchin, P. (1991). Translating foraging movements in heterogeneous environments into the spatial distribution of foragers. Ecology, 72(4), 1253-1266.

Turrero, P., Ardura, A., and García-Vázquez, E. (2014a). Paleolithic vs. epipaleolithic fisheries in northern Iberia. Quaternary Research 82:51-55.

Turrero, P., García-Vázquez, E., and de Leaniz, C. G. (2014b). Shrinking fish: comparisons of prehistoric and contemporary salmonids indicate decreasing size at age across millennia. Open Science, 1(2), 140026.

Twardek, W. M., Gagne, T. O., Elmer, L. K., Cooke, S. J., Beere, M. C., and Danylchuk, A. J. (2018). Consequences of catch-and-release angling on the physiology, behaviour and survival of wild steelhead in the Bulkley River, British Columbia. Fisheries Research, 206, 235-246.

Ulvan, E. M., Foldvik, A., Jensen, A. J., Finstad, B., Thorstad, E. B., Rikardsen, A. H., and Næsje, T. F. (2017). Return migration of adult Atlantic salmon (Salmo salar L.) to northern Norway. ICES Journal of Marine Science, 75(2), 653-661. 
Vähä, J. P., Erkinaro, J., Niemelä, E., and Primmer, C. R. (2007). Life-history and habitat features influence the within-river genetic structure of Atlantic salmon. Molecular Ecology, 16(13), 2638-2654.

Vähä, J. P., Erkinaro, J., Niemelä, E., Primmer, C. R., Saloniemi, I., Johansen, M., Svenning, M., and Brørs, S. (2011) Temporally stable population-specific differences in run timing of one-sea-winter Atlantic salmon returning to a large river system. Evolutionary Applications, 4, 39-53.

van der Boon, J., Van Den Thillart, G. E., and Addink, A. D. (1991). The effects of cortisol administration on intermediary metabolism in teleost fish. Comparative Biochemistry and Physiology Part A: Physiology, 100(1), 47-53.

van Marken Lichtenbelt, W. D., Daanen, H. A., Wouters, L., Fronczek, R., Raymann, R. J., Severens, N. M., and Van Someren, E. J. (2006). Evaluation of wireless determination of skin temperature using iButtons. Physiology and Behavior, 88(4), 489-497.

Veinott, G. I., Robertson, M. J., Bradbury, I., Dempson, J. B., Grant, C., Kelly, N., Whalen, J., and Poole, R. (2018b). Status of Atlantic salmon (Salmo salar L.) stocks within the Newfoundland and Labrador region (Salmon Fishing Areas 114B), 2016. Canadian Science Advisory Secretariat 2018/08, 43 pp.

Veinott, G., Pike, L., and Variyath, A. M. (2018a). Response of anglers to less-restrictive harvest controls in a recreational Atlantic salmon fishery. North American Journal of Fisheries Management, 38(1), 210-222.

Verspoor, E., Beardmore, J. A., Consuegra, S., García de Leániz, C., Hindar, K., Jordan, W. C., Koljonen, M.-L., Mahkrov, A. A., Paaver, T., Sánchez, J. A., Skaala, Ø., 
Titov, S., Cross, and T. F. (2005). Population structure in the Atlantic salmon: insights from 40 years of research into genetic protein variation. Journal of Fish Biology, 67(s1), 3-54.

Verspoor, E., Fraser, N. H. C., and Youngson, A. F. (1991). Protein polymorphism in Atlantic salmon within a Scottish river: evidence for selection and estimates of gene flow between tributaries. Aquaculture, 98(1-3), 217-230.

Verspoor, E., Stradmeyer, L. and Nielsen, J. L. (2008). The Atlantic Salmon: Genetics, Conservation, and Management. Blackwell Publishing, Oxford.

Vijayan, M. M., Pereira, C., Grau, E. G., and Iwama, G. K. (1997). Metabolic responses associated with confinement stress in tilapia: the role of cortisol. Comparative Biochemistry and Physiology Part C: Pharmacology, Toxicology and Endocrinology, 116(1), 89-95.

Wallén, P., and Williams, T. L. (1984). Fictive locomotion in the lamprey spinal cord in vitro compared with swimming in the intact and spinal animal. The Journal of Physiology, 347(1), 225-239.

Walther, G. R., Post, E., Convey, P., Menzel, A., Parmesan, C., Beebee, T. J., Fromentin, J.-M., Hoegh-Guldberg, O., and Bairlein, F. (2002). Ecological responses to recent climate change. Nature, 416(6879), 389.

Walton, I. (1653) The Compleat Angler. Charles Lamb Publisher, London.

Warner, K. (1979). Mortality of landlocked Atlantic salmon hooked on four types of fishing gear at the hatchery. The Progressive Fish-Culturist, 41(2), 99-102. 
Warner, K., and Johnson, P. R. (1978). Mortality of landlocked Atlantic salmon (Salmo salar) hooked on flies and worms in a river nursery area. Transactions of the American Fisheries Society, 107(6), 772-775.

Webb, B. W. (1996). Trends in stream and river temperature. Hydrological Processes, $10(2), 205-226$.

Webb, J. H. (1998). Catch and release: the survival and behaviour of Atlantic salmon angled and returned to the Aberdeenshire Dee, in spring and early summer. Scottish Fisheries Research Report, 62, 1-15.

Webb, J. H., Hay, D. W., Cunningham, P. D., and Youngson, A. F. (1991). The spawning behaviour of escaped farmed and wild adult Atlantic salmon (Salmo salar L.) in a northern Scottish river. Aquaculture, 98(1-3), 97-110.

Wedemeyer, G. A., and Wydoski, R. S. (2008). Physiological response of some economically important freshwater salmonids to catch-and-release fishing. North American Journal of Fisheries Management, 28(5), 1587-1596.

Weihs, D. (1974). Energetic advantages of burst swimming of fish. Journal of Theoretical Biology, 48(1), 215-229.

Weiner, G. S., Schreck, C. B., and Li, H. W. (1986). Effects of low pH on reproduction of rainbow trout. Transactions of the American Fisheries Society, 115(1), 75-82.

Weir, L. K., Hutchings, J. A., Fleming, I. A., and Einum, S. (2004). Dominance relationships and behavioural correlates of individual spawning success in farmed and wild male Atlantic salmon, Salmo salar. Journal of Animal Ecology, 73(6), 1069-1079. 
Wendelaar Bonga, S. E. (1997). The stress response in fish. Physiological Reviews, 77(3), 591-625.

Werner, E. E., and Anholt, B. R. (1993). Ecological consequences of the trade-off between growth and mortality rates mediated by foraging activity. The American Naturalist, 142(2), 242-272.

Werner, E. E., and Gilliam, J. F. (1984). The ontogenetic niche and species interactions in size-structured populations. Annual Review of Ecology and Systematics, 15(1), $393-425$.

Whitney, N. M., White, C. F., Gleiss, A. C., Schwieterman, G. D., Anderson, P., Hueter, R. E., and Skomal, G. B. (2016). A novel method for determining post-release mortality, behavior, and recovery period using acceleration data loggers. Fisheries Research, 183, 210-221.

Whoriskey, F. G., Brooking, P., Doucette, G., Tinker, S., and Carr, J. W. (2006). Movements and survival of sonically tagged farmed Atlantic salmon released in Cobscook Bay, Maine, USA. ICES Journal of Marine Science, 63(7), 1218-1223. Whoriskey, F. G., Prusov, S., and Crabbe, S. (2000). Evaluation of the effects of catchand-release angling on the Atlantic salmon (Salmo salar) of the Ponoi River, Kola Peninsula, Russian Federation. Ecology of Freshwater Fish, 9(1-2), 118-125. Whoriskey, K., Auger-Méthé, M., Albertsen, C. M., Whoriskey, F. G., Binder, T. R., Krueger, C. C., and Mills Flemming, J. (2017). A hidden Markov movement model for rapidly identifying behavioral states from animal tracks. Ecology and Evolution, 7(7), 2112-2121.

Wickham, H. (2009). ggplot2: Elegant graphics for data analysis. Springer, New York. 
Wikelski, M., and Cooke, S. J. (2006). Conservation physiology. Trends in Ecology and Evolution, 21(1), 38-46.

Wilcove, D. S., and Wikelski, M. (2008). Going, going, gone: is animal migration disappearing. PLoS Biology, 6(7), e188.

Wilke, C. O. (2017). ggridges: Ridgeline plots in 'ggplot2'. R package version 0.4.1. https://CRAN.R-project.org/package=ggridges.

Wilkie, M. P., Brobbel, M. A., Davidson, K. G., Forsyth, L., and Tufts, B. L. (1997). Influences of temperature upon the postexercise physiology of Atlantic salmon (Salmo salar). Canadian Journal of Fisheries and Aquatic Sciences, 54(3), 503511.

Wilkie, M. P., Davidson, K., Brobbel, M. A., Kieffer, J. D., Booth, R. K., Bielak, A. T., and Tufts, B. L. (1996). Physiology and survival of wild Atlantic salmon following angling in warm summer waters. Transactions of the American Fisheries Society, 125(4), 572-580.

Wilson, A. D., Wikelski, M., Wilson, R. P., and Cooke, S. J. (2015). Utility of biological sensor tags in animal conservation. Conservation Biology, 29(4), 1065-1075.

Wilson, S. M., Raby, G. D., Burnett, N. J., Hinch, S. G., and Cooke, S. J. (2014). Looking beyond the mortality of bycatch: sublethal effects of incidental capture on marine animals. Biological Conservation, 171, 61-72.

Winberg, G. G. (1956). Rate of metabolism and food requirements of fishes. Fisheries Research Board of Canada Series, 194, 202 pp.

Wingfield, J. C. (2013). Ecological processes and the ecology of stress: the impacts of abiotic environmental factors. Functional Ecology, 27(1), 37-44. 
Wingfield, J. C., and Sapolsky, R. M. (2003). Reproduction and resistance to stress: when and how. Journal of Neuroendocrinology, 15(8), 711-724.

Wood, C. M. (1991). Acid-base and ion balance, metabolism, and their interactions, after exhaustive exercise in fish. Journal of Experimental Biology, 160(1), 285-308.

Wood, C. M., Turner, J. D., and Graham, M. S. (1983). Why do fish die after severe exercise? Journal of Fish Biology, 22(2), 189-201.

WWF. (2001). The status of wild Atlantic salmon: A river by river assessment. World Wildlife Fund, Morges, Switzerland.

Wydoski R.S. (1977). Relation of hooking mortality and sublethal hooking stress to quality fishery management. In: Barnhart R. A., and Roelofs, T. D. (eds), Catchand-Release Fishing as a Management Tool. Humbolt State University, Arcata, California, pp. 43-87.

Wydoski, R. S. (1976). Angler responses to special regulations. Proceedings of the Annual Conference Western Association of Game and Fish Commissioners, 56, $154-167$.

Ydesen, K. S., Wisniewska, D. M., Hansen, J. D., Beedholm, K., Johnson, M., and Madsen, P. T. (2014). What a jerk: prey engulfment revealed by high-rate, supercranial accelerometry on a harbour seal (Phoca vitulina). Journal of Experimental Biology, 217(13), 2239-2243.

Youngson, A. F., Jordan, W. C., and Hay, D. W. (1994). Homing of Atlantic salmon (Salmo salar L.) to a tributary spawning stream in a major river catchment. Aquaculture, 121(1-3), 259-267. 
Zhang, Y., Claireaux, G., Takle, H., Jørgensen, S. M., and Farrell, A. P. (2018). A threephase excess post-exercise oxygen consumption in Atlantic salmon Salmo salar and its response to exercise training. Journal of Fish Biology, 92(5), 1385-1403.

Zuur, A. F., Ieno, E. N., Walker, N. J., Saveliev, A. A., and Smith, G. M. (2009). In: Gail, M., Krickeberg, K., Samet, J. M., Tsiatis, A., and Wong, W. (eds), Mixed effects models and extensions in ecology with R. Spring Science and Business Media, New York. 